\title{
Designing Photosystem II: \\ Molecular Engineering of Photo-Catalytic Proteins
}

\author{
Brendon Francis Conlan
}

A thesis submitted for the degree of Doctor of Philosophy of

The Australian National University

March 2009 


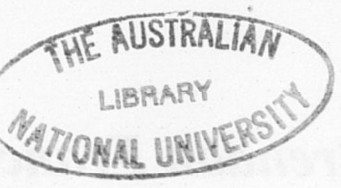

ii 
This thesis represents research undertaken in the Photobioenergetics group, Research School of Biological Sciences, The Australian National University, Canberra. This work was completed between March 2005 and March 2009

Except where otherwise acknowledged, the work presented in this thesis is my own, and was performed under the supervision of Professor Tom Wydrzynski.

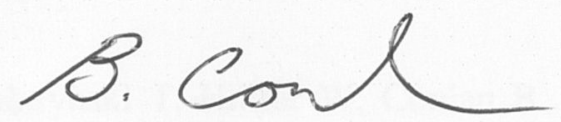

Brendon Francis Conlan, 


\section{Publications}

Conlan B, Cox N, Su J, Hillier W, Messinger J, Lubitz W, Dutton PL, Wydrzynski T. Photo-catalytic oxidation of a di-manganese centre in an engineered bacterioferritin 'reaction centre'. (Manuscript accepted to BBA Bioenergetics Mar 2009).

Conlan B. Designing Photosystem II: Molecular Engineering of Photo-catalytic Proteins. Photosynthesis Research 2008 Oct 98: 687-700.

Wydrzynski T, Hillier W, Conlan B. Engineering model proteins for Photosystem II function. Photosynthesis Research 2007 Nov-Dec; 94 (2-3): 225-33

Conlan B, Wydrzynski T, Hillier W. Designing artificial photosynthesis: Engineering bacterioferritin for light-activated electron transfer. Chapter 3: 1261-1265 Photosynthesis. Energy from the Sun. 14th International Congress on Photosynthesis. 



\section{Oral Presentations}

Conlan B. Designing Photosynthesis: Molecular engineering of photo-catalytic proteins. Presented at Bio21 Melbourne University, Melbourne, Australia 2009.

Conlan B. Designing Photosynthesis: Molecular engineering of photo-catalytic proteins. Presented at the Research School of Biological Science, Australian National University, Canberra, Australia 2009.

Conlan B. Designing Photosynthesis: Molecular engineering of photo-catalytic proteins. Presented at the 17th International Conference on Photochemical Conversion and Storage of Solar Energy 2008, Sydney, Australia.

Conlan B. Designing Photosynthesis: Molecular engineering of photo-catalytic proteins. Presented at the $1^{\text {st }}$ Australian Bioconjugate Chemistry Workshop 2008, University of New South Wales, Sydney, Australia.

Conlan B. Designing artificial photosynthesis: Engineering bacterioferritin for lightactivated electron transfer. Presented at Arizona State University, Department of Chemistry and Biochemistry, Tempe, USA 2007.

Conlan B. Designing artificial photosynthesis: Engineering bacterioferritin for lightactivated electron transfer. Presented at the International Congress on Photosynthesis 2007, Glasgow, UK.

Conlan B. Engineering a light activated metal binding protein. Presented at The Max Planck Institute for Bioinorganic Chemistry. Mülheim, Germany 2006.

Conlan B. Engineering a light activated metal binding protein. Presented at the Department of Biochemistry and Biophysics, Gothenburg University, Gothenburg, Sweden 2006. 
Minds are like parachutes. They only function when they are open.

\section{Sir James Dewar}

(1877-1925) 



\section{Table of Contents}

DESIGNING PHOTOSYSTEM II:

PUBLICATIONS V

ORAL PRESENTATIONS......................................................................................................................................... VII

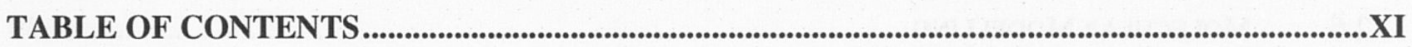

ACKNOWLEDGEMENTS.......................................................................................................................... XV

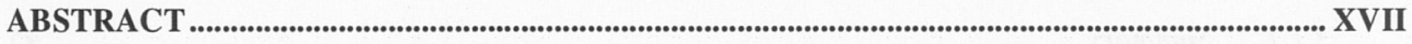

LIST OF TABLES

LIST OF FIGURES ….............................................................................................................................XXI

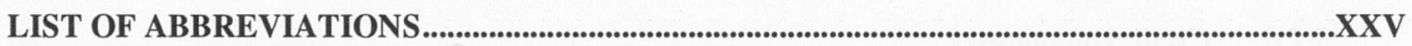

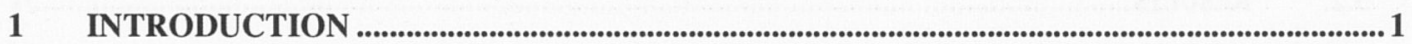

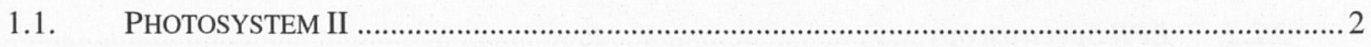

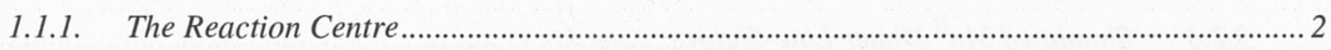

1.1.2. The Oxygen Evolving Complex: Models and Mechanisms............................................. 3

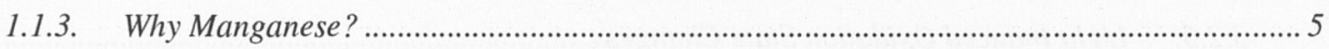

1.2. DESIGN OF PHOTO-CATALYTIC PROTEINS …………..........................................................

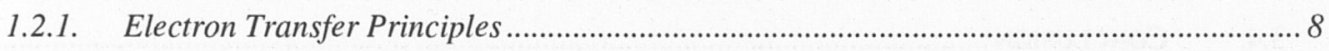

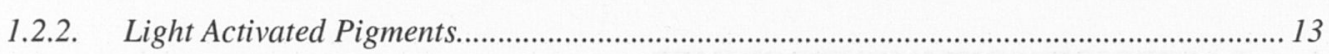

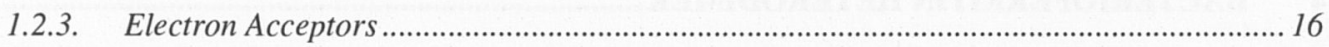

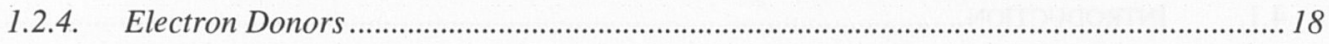

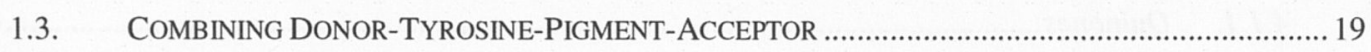

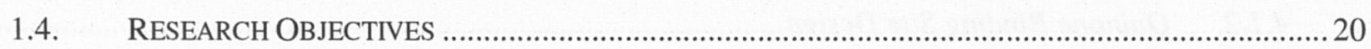

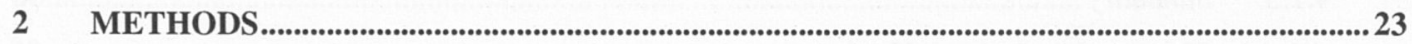

2.1. CLONING AND MUTAGENESIS OF BACTERIOFERRITIN HOMODIMER ……….............................2

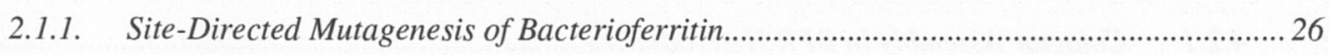

2.2. PRODUCTION OF THE BFR HETERODIMER CONSTRUCT ….................................................... 27

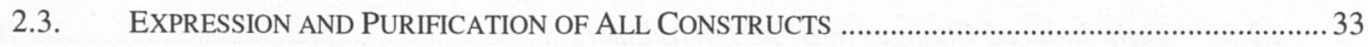

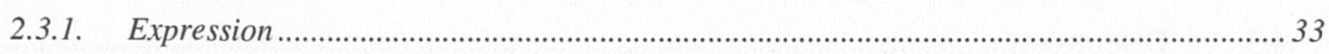

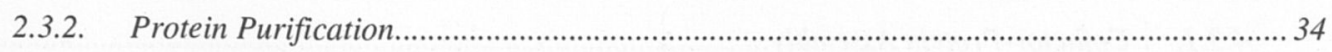




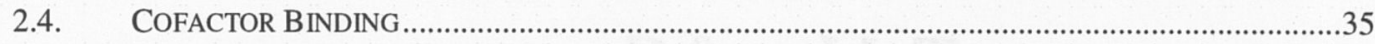

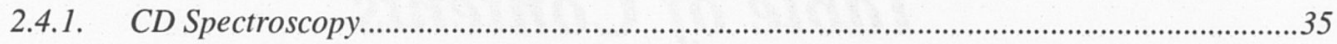

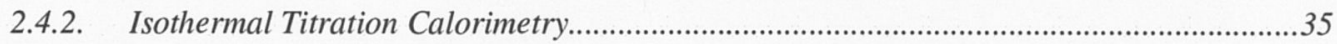

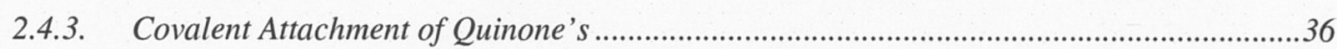

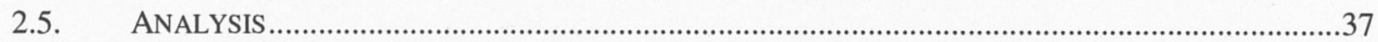

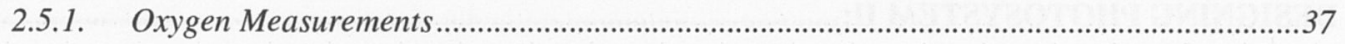

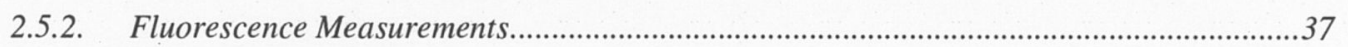

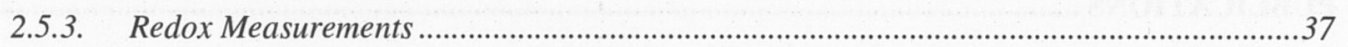

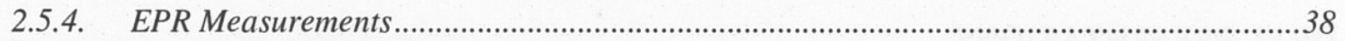

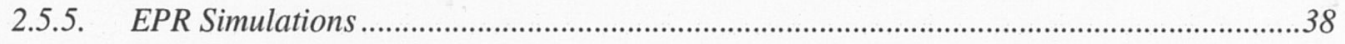

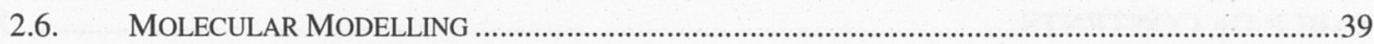

3 BACTERIOFERRITIN AS A 'REACTION CENTRE' ..........................................................41

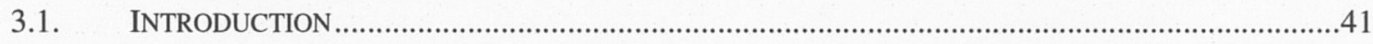

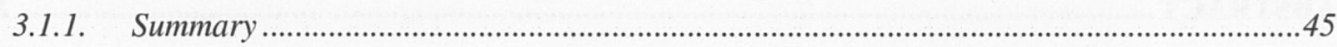

3.1.2. Techniques Used to Analyse the BFR Complex............................................................4

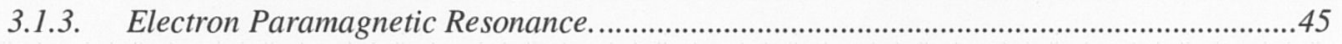

3.1.4. Circular Dichroism Spectroscopy....................................................................................4

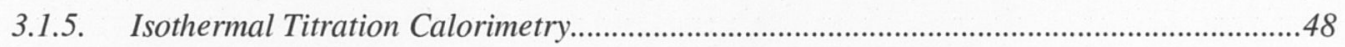

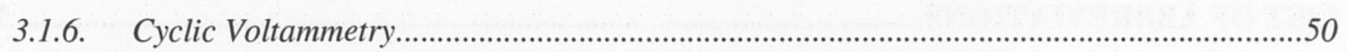

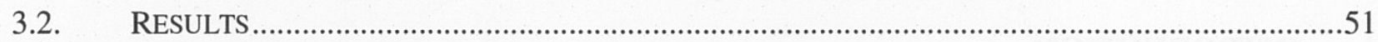

3.2.1. Cofactor Assembly in Bacterioferritin ........................................................................

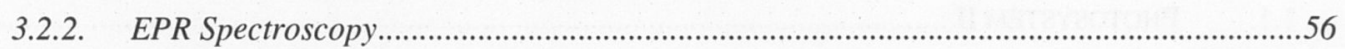

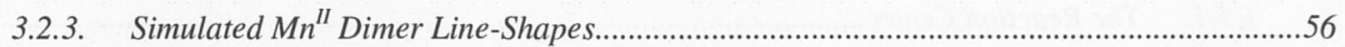

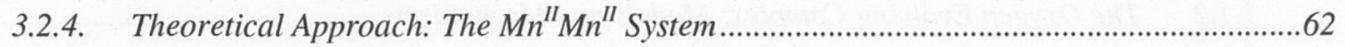

3.2.5. Light Induced Oxidation State Changes ……………......................................................65

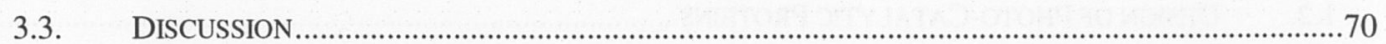

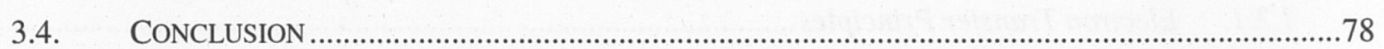

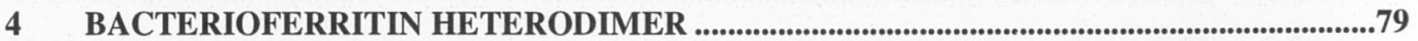

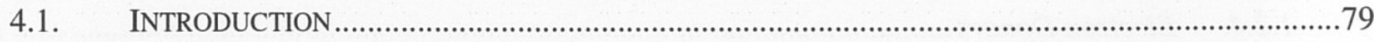

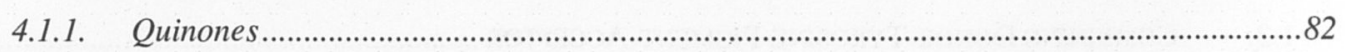

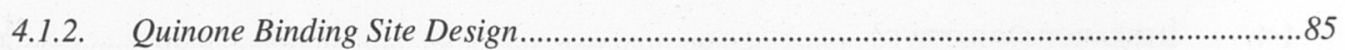

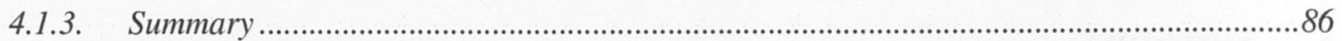

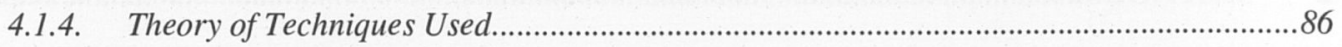

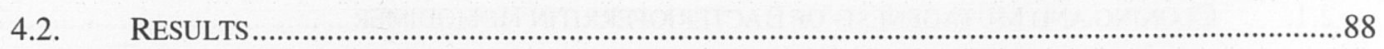

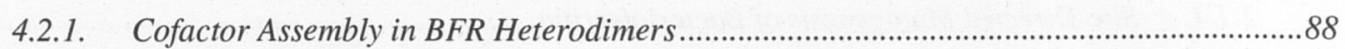

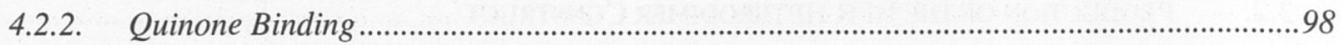

4.2.3. Light Induced Changes in BFR Heterodimers ............................................................. 101

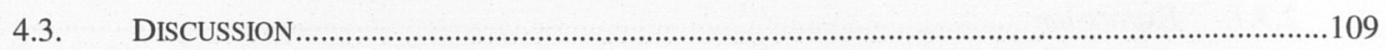

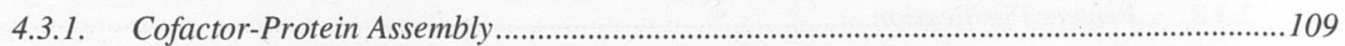




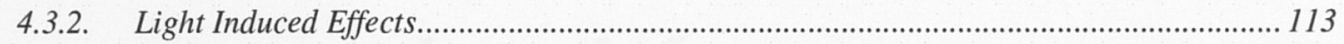

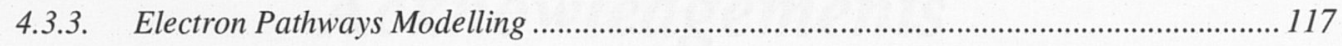

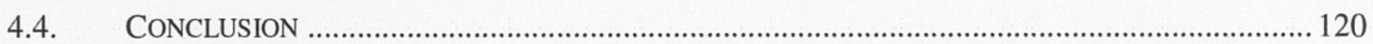

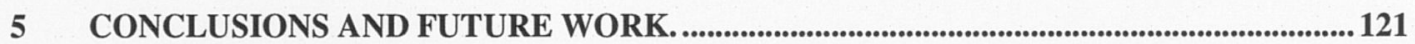

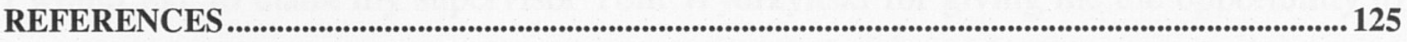





\section{Acknowledgements}

I would like to thank my supervisor Tom Wydrzynski for giving me the opportunity to do this project, and for his help throughout it. Nick Cox for his help with all things EPR related. Spencer Whitney for RSBS happy hour, which keeps a student sane, and also his help as the molecular biology guru. Warwick Hillier for reading manuscripts and general discussions. The Photobioenergetics group for generally being a good group of people to share a lab with. Thanks also to my fellow students Adele Williamson and Iain McConnell for a student's point of view. Particular thanks go to my parents and family for always supporting my scientific adventures. Finally I would like to thank my lovely wife Carly for giving me a reason to just drop it all and come home at the end of the day. 


\section{Abstract}

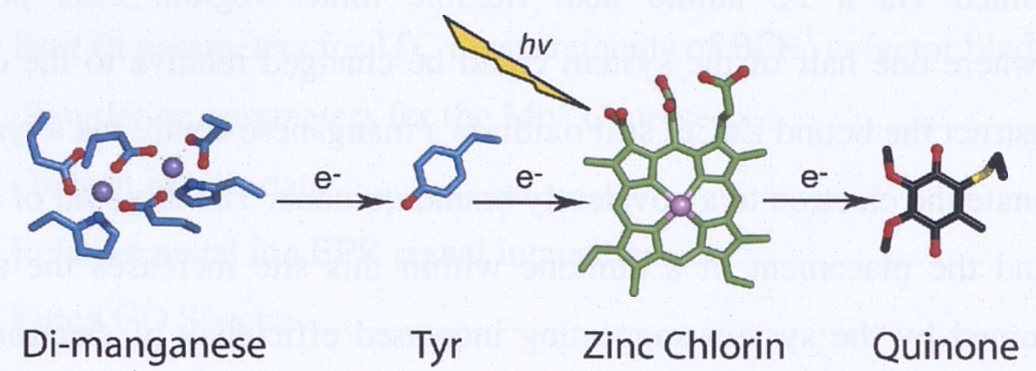

Photosynthesis involves the conversion of light into chemical energy through a series of electron transfer reactions within membrane-bound pigment/protein complexes. The unique Photosystem II (PSII) complex in plants, catalyses the oxidation of water to molecular oxygen. The complexity of PSII has thus far limited attempts to chemically mimic this enzyme. Here I have used a reverse engineering approach to attempt to build several simple light driven manganese oxidising catalysts based on PSII structure and function. I have used bacterioferritin (BFR) (cytochrome $b 1$ ) from $E$. coli as a protein scaffold to make an in vitro model of the PSII reaction centre. BFR has several design features, which can be utilized to engineer light-driven electron transport - a di-iron binding site, a potentially redox active tyrosine residue, and the ability to dimerise and form an inter-protein heme binding pocket. The heme could be replaced with a photoactive zinc-chlorin $\mathrm{e}_{6}\left(\mathrm{ZnCe}_{6}\right)$ molecule and the di-iron metal binding site with two manganese ions.

Two protein systems were made, firstly a homodimeric BFR and secondly a heterodimeric form of BFR which enabled the addition of a quinone electron acceptor within the protein matrix. In the first system I was able to demonstrate that BFR binds two magnetically interacting $\mathrm{Mn}$ ions as a weakly coupled $\mathrm{Mn}_{2}{ }^{\mathrm{IIII}}$ centre, and that $\mathrm{ZnCe}_{6}$ is bound stoichiometrically to the dimeric BFR complex. The bound $\mathrm{ZnCe}_{6}$ species initiates electron transfer upon illumination, which oxidizes a tyrosine and causes oxidation of the Mn centre in a light and oxygen dependent reaction. The light 
dependent loss of $\mathrm{Mn}^{\mathrm{II}}$ signals and the formation of low field parallel mode $\mathrm{Mn}$ signals in the EPR spectra are attributed to the formation of $\mathrm{Mn}^{\mathrm{III}}$ species.

The second system was produced by engineering a protein containing two BFR monomers joined via a 22 amino acid flexible linker region. This produced a heterodimer where one half of the system could be changed relative to the other half. With this construct the bound $\mathrm{ZnCe}_{6}$ still oxidises a manganese centre via a tyrosine and appears to donate the electron to a covalently bound quinone. The removal of one of the metal sites and the placement of a quinone within this site increases the amount of oxygen consumed by the system suggesting increased efficiency of electron transfer. These two models are the first artificial reaction centres developed which carry out photo-catalytic oxidation of a dimetal site within a protein matrix. 


\section{List of Tables}

Table 3.1: Best fit parameters for ITC measurements of $\mathrm{BFR}^{1}$ cofactor binding .55

Table 3.2: Simulation parameters for the $\mathrm{Mn}^{\mathrm{II}}$ dimers 61

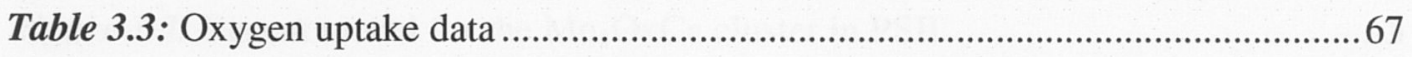

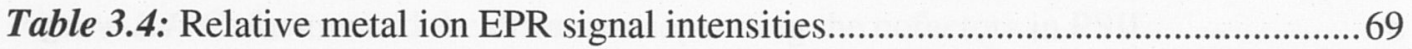

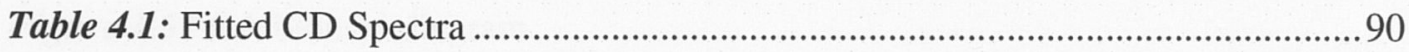

Table 4.2: Best fit parameters for ITC measurements of $\mathrm{Mn}$ and $\mathrm{ZnCe}_{6}$ binding to BFR constructs 95

Table 4.3: Iron oxidation rates as monitored by UV-visible spectroscopy 97

Table 4.4: $\mathrm{ZnCe}_{6}$ absorbance maxima when bound to BFR proteins .......................... 100

Table 4.5: Oxygen uptake data 104 


\section{List of Figures}

Figure 1.1: Schematic of photosystem II showing the major redox active cofactors...... 1

Figure 1.2: PSII energy redox potentials for the essential redox cofactors ..................... 3

Figure 1.3: Recent model for the $\mathrm{Mn}_{4} \mathrm{OxCa}$ cluster in PSII. ...........................................5

Figure 1.4: Cofactors and the distances separating the cofactors in PSII........................ 8

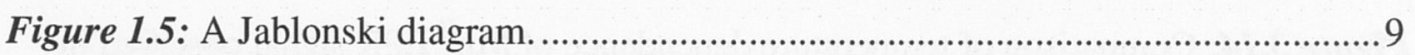

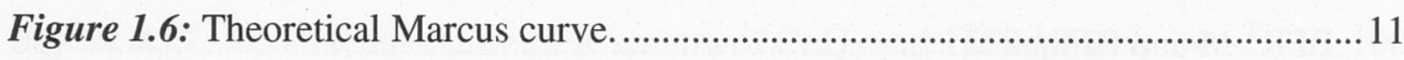

Figure 1.7: Three light active porphyrins; Chlorophyll-a, Zinc chlorin $\mathrm{e}_{6}$ and Zinc

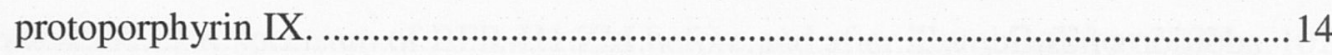

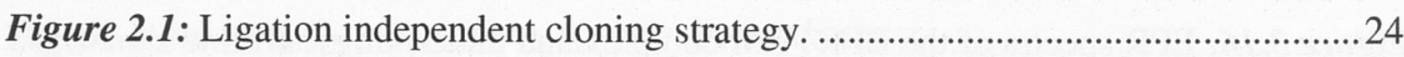

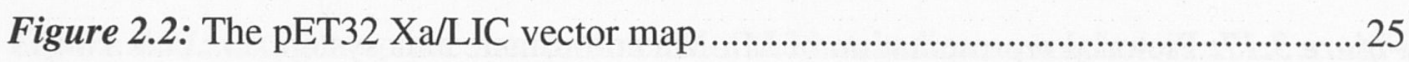

Figure 2.3: The amino acid and DNA sequence for the double mutant, BFR ${ }^{1}$.............26

Figure 2.4: Four gene constructs made with different restriction sites to enable ligation

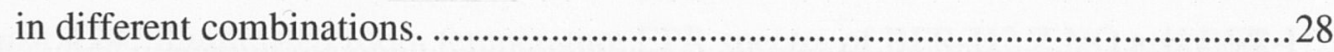

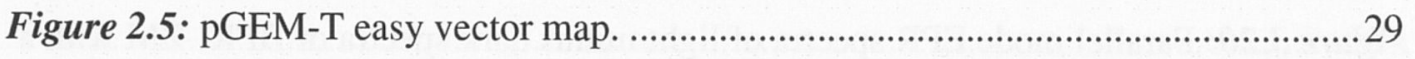

Figure 2.6: The amino acid sequence and DNA sequence of the linker used to join the

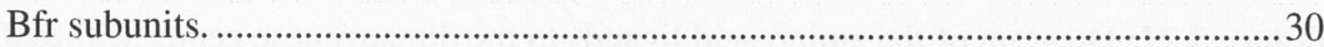

Figure 2.7: The $b f r$ gene construct $\mathrm{BFR}^{1}$-SE-L made with a $b f r$ gene and a linker region.

Figure 2.8: The two heterodimer constructs assembled in the pTE vector.

Figure 2.9: Amino acid sequence and DNA sequence of the linker region after mutation of both histidines to serines.

Figure 2.10: The final two heterodimer gene constructs after site-directed mutagenesis to remove the EcoRV and NdeI restriction sites. 32

Figure 2.11: The Histidine-tagged Ubiquitin Expression vector (pHUE) map.

Figure 3.1: A ribbon diagram of the sphere structure formed by E.coli bacterioferritin.

Figure 3.2: The BFR homodimer showing bound manganese and heme.....................43

Figure 3.3: Distances of cofactors in the BFR complex as compared to PSII...............44

Figure 3.4: $\mathrm{UV}$-visible spectra of $\mathrm{BFR}^{1}$ in its oxidised form and reduced form. ..........51

Figure 3.5: Circular dichroism spectra of BFR and the double mutant $\mathrm{BFR}^{1}$..............52 
Figure 3.6: UV-visible spectra of $\mathrm{ZnCe}_{6}$ free in solution and bound to $\mathrm{BFR}^{1}$. 53

Figure 3.7: Calorimetric titration of $\mathrm{BFR}^{1}$ into a solution of $\mathrm{ZnCe}_{6} \ldots \ldots \ldots \ldots \ldots \ldots \ldots \ldots \ldots . . . .54$

Figure 3.8: Calorimetric titrations of $\mathrm{MnCl}_{2}$ into a solution of $\mathrm{BFR}^{1}$..........................55

Figure 3.9: Cyclic voltammogram of $\mathrm{BFR}^{1}-\mathrm{Mn}$........................................................ 56

Figure 3.10: Temperature dependence of the EPR spectra of $\mathrm{BFR}^{1}-\mathrm{M}$...........................57

Figure 3.11: Simulated EPR spectra and temperature dependence of $\mathrm{BFR}^{1}-\mathrm{M}$.............58

Figure 3.12: Temperature dependence of the EPR line-shape observed in $\mathrm{BFR}^{1}$-ZM.. 59

Figure 3.13: Comparison of $\mathrm{Mn}^{\mathrm{II}} \mathrm{EPR}$ signal observed in $\mathrm{BFR}^{1}-\mathrm{M}$ and $B F{ }^{1}-\mathrm{ZM}$...... 60

Figure 3.14: Comparison of temperature dependence of $\mathrm{Mn}^{\mathrm{II}} \mathrm{EPR}$ signal observed in $\mathrm{BFR}^{1}-\mathrm{M}$ and $\mathrm{BFR}^{1}-\mathrm{ZM}$.

Figure 3.15: Simulated EPR spectra and temperature dependence of $\mathrm{BFR}^{1}-\mathrm{ZM}$ after the addition of $\mathrm{ZnCe}_{6}$.

Figure 3.16: $\mathrm{EPR}$ spectra of the $\mathrm{BFR}^{1}$-ZM complex and underlying multiline signal.. 62

Figure 3.17: Pictorial representation of Mn-Mn co-ordinate axis system.

Figure 3.18: Clarke type oxygen electrode measurements of the $\mathrm{BFR}^{1}$ complex. .66

Figure 3.19: Light induced $E P R$ spectra for $B F R^{1}-Z$ with and without manganese bound

Figure 3.20: Parallel mode EPR spectra of light minus dark spectra of $B F R^{1}-\mathrm{ZM}$ with a five fold excess of Mn.

Figure 3.21: Diagram of the amino acid ligands to the dimanganese center with $\mathrm{ZnCe}_{6}$ bound at the interface of the BFR dimeric complex. .70

Figure 4.1: Bacterioferritin heterodimer (BFR-H2) with one subunit of the dimer changed relative to the other.

Figure 4.2: Diagram showing the relative distance of separation of all of the cofactors bound to the BFR heterodimer protein.

Figure 4.3: Ubiquinone.

Figure 4.4: Covalent attachement of a quinone to the cysteine sulphur of a protein..... 85

Figure 4.5: UV-visible spectra of holo BFR-H2 in its oxidised and reduced form.......88 88

Figure 4.6: CD spectra of BFR-H1 with and without manganese.................................. 89

Figure 4.7: $\mathrm{CD}$ spectra of BFR-H2 with and wihtout manganese ............................... 90

Figure 4.8: Calorimetric titration of $\mathrm{MnCl}_{2}$ into a solution of $\mathrm{BFR}^{2}$.......................... 91

Figure 4.9: Calorimetric titrations of $\mathrm{MnCl}_{2}$ into a solution of $\mathrm{BFR}-\mathrm{H} 1$....................... 92

Figure 4.10: Calorimetric titrations of $\mathrm{MnCl}_{2}$ into a solution of BFR-H2 ................... 93 
Figure 4.11: Calorimetric titrations of BFR-H1 into a solution of $\mathrm{ZnCe}$.

Figure 4.12: EPR spectra of BFR-H2-ZM-CoQ, BFR-H1-ZM and BFR ${ }^{1}-\mathrm{ZM}$ 96

Figure 4.13: Iron oxidation monitored by absorbance at $340 \mathrm{~nm}$. .97

Figure 4.14: Absorbance spectra of $\mathrm{CoQ}_{0}$, glutathione and the $\mathrm{CoQ}_{0}-$ Glutathione complex .98

Figure 4.15: UV-visible absorbance spectra of BFR-H2-CoQ, BFR-H2 and $\mathrm{CoQ}_{0}-$ Glutathione complex. .99

Figure 4.16: Absorbance spectra of $\mathrm{ZnCe}_{6}$ free in solution, and bound to BFR-H2$\mathrm{CoQ}_{0}$. .99

Figure 4.17: Room temperature EPR spectra of $\mathrm{CoQ}_{0}$ and 1,2-naphthoquine. 100

Figure 4.18: Room temperature EPR spectra of $\mathrm{CoQ}_{0}$ and $\mathrm{CoQ}_{0}$ bound to $\mathrm{BFR}^{2} \ldots \ldots .101$

Figure 4.19: EPR spectrum of BFR-H1 ZM before and after illumination at 200K...102

Figure 4.20: EPR spectra of BFR-H1 ZM and BFR-H1 Z. 103

Figure 4.21: Oxygen uptake measurements of the heterodimer complexes. 104

Figure 4.22: Fluorescence spectra of BFR-H2 ZM and BFR-H2 ZM CoQ . 105

Figure 4.23: Fluorescence spectra of reduced BFR heterodimer proteins. 106

Figure 4.24: Illuminated room temperature EPR spectra of BFR-H2 Z NQ and BFR-H2 $\mathrm{Z}$.

Figure 4.25: Illuminated room temperature EPR spectra of BFR-H2 ZM and BFR-H2 ZM NQ. 108

Figure 4.26: A cartoon model of the BFR heterodimer. 109

Figure 4.27: Calculated best pathway for electron transfer within the BFR heterodimer quino-protein. 118

Figure 4.28: Calculated best pathway for electron transfer within the Cyt $b_{562}$ quinoprotein. 



\section{List of Abbreviations}

\begin{tabular}{|c|c|}
\hline A & electron acceptor \\
\hline Amp & ampicillin \\
\hline BFR & bacterioferritin \\
\hline $\mathrm{BFR}^{1}$ & bacterioferritin double mutant $\mathrm{H} 46 \mathrm{R}, \mathrm{H} 112 \mathrm{R}$ without cofactors \\
\hline $\mathrm{BFR}^{1}-\mathrm{M}$ & $\mathrm{BFR}^{1}$ with two manganese ions bound \\
\hline $\mathrm{BFR}^{1}-\mathrm{Z}$ & $\mathrm{BFR}^{1}$ with $\mathrm{ZnCe}_{6}$ bound \\
\hline $\mathrm{BFR}^{1}-\mathrm{ZM}$ & $\mathrm{BFR}^{1}$ with stoichiometric amounts of $\mathrm{ZnCe}_{6}$ and manganese bound \\
\hline $\mathrm{BFR}^{2}$ & BFR triple mutant H46R, H112R, E51C \\
\hline BFR-H1 & $\mathrm{BFR}^{1}$ plus $\mathrm{BFR}^{1}$ heterodimer joined by a linker region \\
\hline BFR-H2 & $\mathrm{BFR}^{1}$ plus $\mathrm{BFR}^{2}$ heterodimer joined by a linker region \\
\hline $\mathrm{BFR}-\mathrm{H} 2 \mathrm{CoQ}_{0}$ & BFR-H2 with co-enzyme $\mathrm{Q}_{0}$ covalently bound \\
\hline BFR-H2 NQ & BFR-H2 with 1,2-naphthoquinone covalently bound \\
\hline $\mathrm{BChl}$ & bacteriochlorophyll \\
\hline $\mathrm{BRC}$ & bacterial reaction centre \\
\hline $\mathrm{CD}$ & circular dichroism \\
\hline Chl & chlorophyll \\
\hline $\mathrm{CoQ}_{0}$ & co-enzyme $\mathrm{Q}_{0}$ (2,3-dimethoxy-5-methyl-1,4-benzoquinone) \\
\hline Cyt & cytochrome \\
\hline $\mathrm{D}$ & electron donor \\
\hline $\mathrm{E}_{\mathrm{m}}$ & midpoint redox potential \\
\hline EPR & electron paramagnetic resonance \\
\hline Heme & $\mathrm{Fe}(2+$ or $3+)$-protoporphyrin-IX \\
\hline IPTG & Isopropyl $\beta$-D-1-thiogalactopyranoside \\
\hline LB & Luria-Bertani Media \\
\hline IC & internal conversion \\
\hline ISC & inter system crossing \\
\hline ITC & isothermal titration calorimetry \\
\hline MEK & methyl ethyl ketone \\
\hline $\mathrm{Mn}_{4} \mathrm{O}_{x} \mathrm{Ca}$ & tetranuclear manganese/calcium cluster \\
\hline Native PAGE & native polyacrylamide gel electrophoresis \\
\hline NQ & 1,2-naphthoquinone \\
\hline
\end{tabular}




$\begin{array}{ll}\text { OEC } & \text { oxygen evolving complex } \\ \text { P } & \text { primary donor } \\ \mathrm{P}^{*} & \text { excited state of primary donor } \\ \text { PCR } & \text { polymerase chain reaction } \\ \text { PSII } & \text { photosystem II } \\ \text { Q } & \text { quinone } \\ \text { T } & \text { temperature } \\ \text { Tyr } & \text { tyrosine } \\ \text { Y } & \text { redox-active tyrosine } \\ \text { ZnCe } & \text { zinc }{ }^{\text {II }} \text { chlorin } \text { e }_{6} \\ \text { ZnPP } & \text { zinc protoporphyrin } \\ \mathrm{Xgal} & \text { 5-bromo-4-chloro-3-indolyl- beta-D-galactopyranoside }\end{array}$




\section{CHAPTER 1}

\section{Introduction}

One of the most devastating transitions in the history of the earth occurred two to three billion years ago; primitive bacteria acquired the ability to split water into $\mathrm{O}_{2}$ using the energy from sunlight. This tumultuous event turned the world upside down since all life previously existed under a purely anaerobic environment. Organisms were then forced to develop ways to prevent oxidative damage or else face extinction. Today multicellular organisms thrive in an oxygenic environment by using aerobic respiration for energy conversion (Blankenship 2002).

At the heart of oxygenic photosynthesis is photosystem II (PSII), the light-driven oxidoreductase that catalyses the oxidation of water into molecular $\mathrm{O}_{2}$ and the reduction of plastoquinone to plastoquinol (Figure 1.1) (Wydrzynski and Satoh 2005). This enzyme utilizes sunlight to catalyse the most energetically demanding reaction in biology - the formation of the O-O bond. PSII is one of the most elaborate nanoscale biological machines which has evolved only once in Nature.

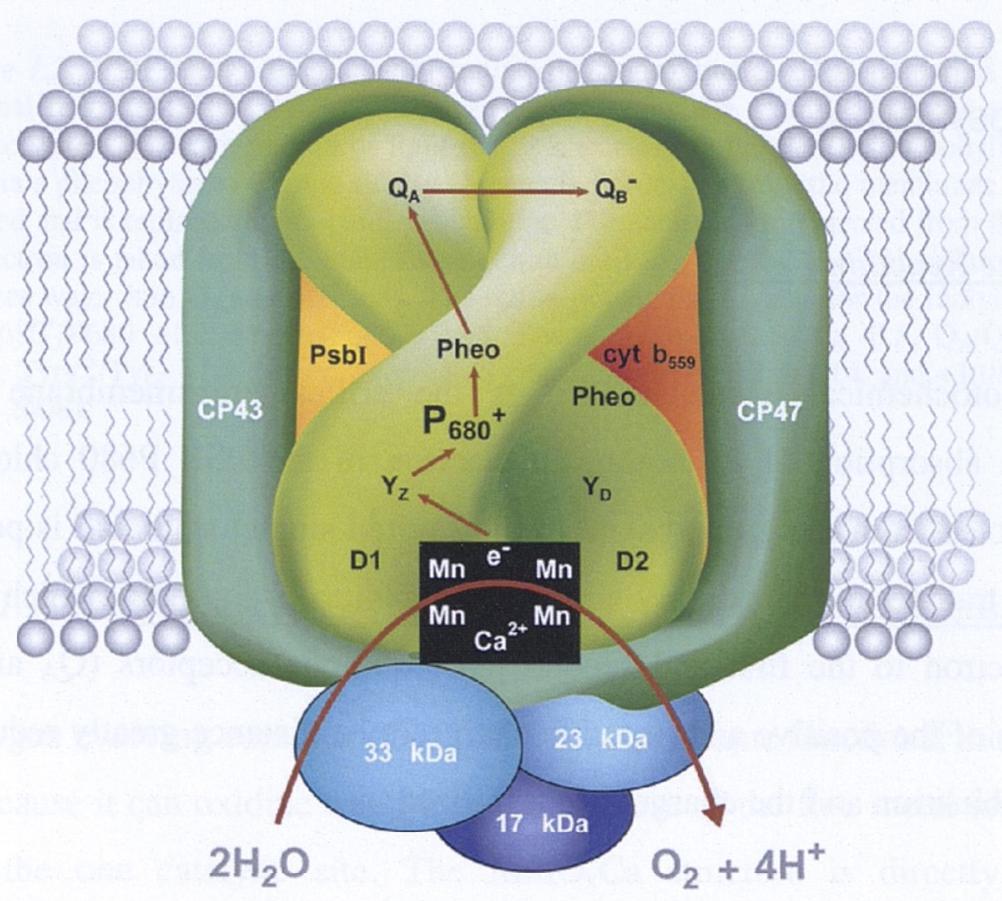

Figure 1.1: Schematic of photosystem II showing the major redox active cofactors necessary for function. 
Over millennia a vast amount of carbon based material was laid down from oxygenic photosynthesis and converted into the fossil fuels we use today - coal, oil and natural gas. The utilization of fossil fuels is becoming a crucial concern as human energy consumption has climbed to such levels that we are now changing our climate patterns due to the $\mathrm{CO}_{2}$ emissions. To prevent further release of greenhouse gases, alternative energy sources need to be used. Understanding oxygenic photosynthesis and being able to exploit its ability to directly convert sunlight and water into clean fuel is now taking on a greater priority in research centres worldwide. The initial charge separation events in PSII have a remarkable efficiency of approximately $90 \%$ making it extremely attractive to mimic this system. Development of equally efficient catalysts would provide for cheap and renewable fuel sources. The production of hydrogen ions that can be converted into hydrogen gas, is now being promoted as the next generation clean fuel for transport and much research is focused on developing such technologies (Kruse et al. 2005; Lewis and Nocera 2006). The first step towards this goal is to replicate PSII function in a well-defined, robust supporting matrix. The following sections outline the photosynthetic capture of energy and describe my reverse engineering approach for developing PSII model proteins.

\subsection{Photosystem II}

\subsubsection{The Reaction Centre}

The primary photochemical event in PSII is the critical transmembrane charge separation. Upon absorption of a photon, an electron in the PSII P680 chlorophyll complex is promoted from the ground state to the excited singlet state and is poised to undergo electron transfer to the primary electron acceptor, a pheophytin, which rapidly transfers this electron to the first and second plastoquinone acceptors $\left(Q_{A}\right.$ and $\left.Q_{B}\right)$. Spatial separation of the positive and negative charges by a distance greatly reduces the chances of recombination and the charges are stabilized.

The $\mathrm{P} 680^{\circ+}$ radical is a strong oxidant $\left(\mathrm{E}_{0} \sim 1.2 \mathrm{~V}\right)$ that is reduced by the proximal tyrosine $\left(\mathrm{Y}_{\mathrm{Z}}\right)$. This is believed to be coupled to a deprotonation reaction generating the 
neutral $\mathrm{Y}_{\mathrm{Z}}^{\bullet}$ radical (Rappaport and Diner 2008), which then oxidizes the $\mathrm{Mn}_{4} \mathrm{O}_{\mathrm{x}} \mathrm{Ca}$ cluster. For each photon-induced charge separation event at $\mathrm{P} 680$, the $\mathrm{Mn}_{4} \mathrm{O}_{\mathrm{x}} \mathrm{Ca}$ cluster advances one oxidation state termed $\mathrm{S}_{0}-\mathrm{S}_{4}$. After four such photo-events $\left(\mathrm{S}_{4}\right)$, molecular oxygen and protons are released and the $\mathrm{Mn}_{4} \mathrm{O}_{\mathrm{x}} \mathrm{Ca}$ cluster reverts to its original oxidation state $\left(\mathrm{S}_{0}\right)$ (Figure 1.2) (Yachandra 2005).

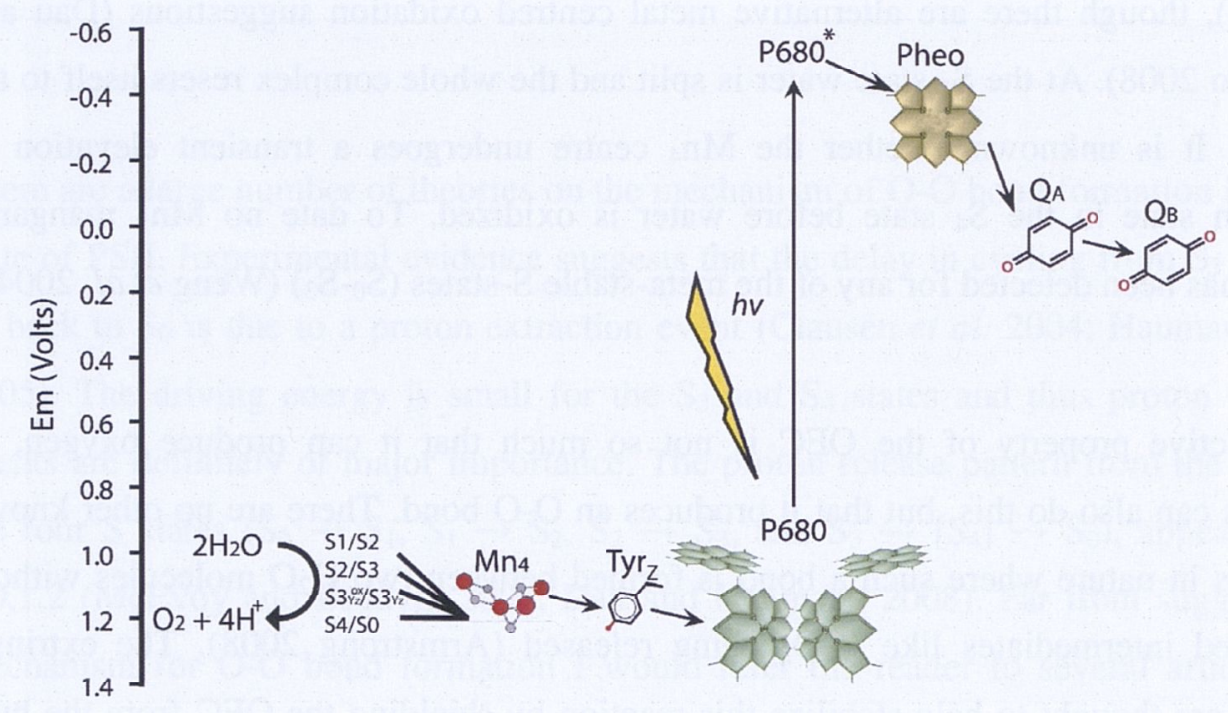

Figure 1.2: PSII energy diagram illustrating the approximate redox potentials in Volts for the essential redox cofactors of PSII involved in producing the charge separated state necessary to oxidize water. For each photon of light that is absorbed by the P680 chlorophylls one electron is sent via a pheophytin to $Q_{A}$ and finally $Q_{B}$ which dissociates from the membrane once it is doubly reduced and is replaced by an oxidized quinone. For each electron ejected from the P680 complex an electron is taken from the manganese centre until the fourth and final electron is taken which oxidizes water into $\mathrm{O}_{2}$ and $4 \mathrm{H}^{+}$ions. The redox potentials in Volts for the individual components are $\mathrm{P} 680^{+} / \mathrm{P} 680+1.2, \mathrm{P} 680+/ \mathrm{P} 60^{*}-0.55, \mathrm{Pheo}_{\mathrm{DI}} / \mathrm{Pheo}_{\mathrm{D} 1}{ }^{-}-0.37$ to $-0.5, \mathrm{Q}_{\mathrm{A}} / \mathrm{Q}_{\mathrm{A}}{ }^{-}-0.03, \mathrm{Q}_{\mathrm{B}} / \mathrm{Q}_{\mathrm{B}}{ }^{-}$ $+0.07, \mathrm{Tyr}_{\mathrm{Z}}{ }^{\mathrm{ox}} / \mathrm{Tyr}_{\mathrm{Z}}+1.2, \mathrm{Mn}_{4}$ cluster $-\mathrm{S}_{1} / \mathrm{S}_{2}, \mathrm{~S}_{2} / \mathrm{S}_{3}, \mathrm{~S}_{3} / \mathrm{S}_{0}+1.12,+1.14$, and +1.08 (Rappaport and Diner 2008).

\subsubsection{The Oxygen Evolving Complex: Models and Mechanisms}

The oxygen evolving complex (OEC) of PSII is a unique functional motif in biology not only because it can oxidize water but also because of the five metal ions that are bound within the one catalytic site. The $\mathrm{Mn}_{4} \mathrm{O}_{\mathrm{x}} \mathrm{Ca}$ structure is directly coordinated by glutamate, aspartate, histidine and alanine residues (Ferreira et al. 2004; Loll et al. 2005; Sproviero et al. 2006; Yano et al. 2006). These metal ions are also complexed 
with bridging $\mu$-oxo bonds. The accumulation of oxidizing potential is assumed to take the form of incremental changes in the formal oxidation states of the Mn ions in the OEC. The 4 electron S-state cycle is predicted to begin in the $\mathrm{S}_{0}$ state as $\mathrm{Mn}^{\text {III }} \mathrm{Mn}^{\text {III }} \mathrm{Mn}^{\text {III }} \mathrm{Mn}^{\text {IV }}$ (Kulik et al. 2007) and progresses to $\mathrm{Mn}^{\text {III }} \mathrm{Mn}^{\text {III }} \mathrm{Mn}^{\text {IV }} \mathrm{Mn}^{\text {IV }}$ in the $\mathrm{S}_{1}$ state (Sauer et al. 2005; Yachandra 2005), finally reaching $\mathrm{Mn}^{\mathrm{III}} \mathrm{Mn}^{\mathrm{IV}} \mathrm{Mn}^{\mathrm{IV}} \mathrm{Mn}^{\mathrm{IV}}$ in the $S_{2}$ state (Kulik et al. 2007). The $S_{3}$ state is also suggested to possibly involve a ligand centred oxidation event with no change in the formal Mn oxidation states (Messinger et al. 2001), though there are alternative metal centred oxidation suggestions (Dau and Haumann 2008). At the $S_{4}$ state water is split and the whole complex resets itself to the $\mathrm{S}_{0}$ state. It is unknown whether the $\mathrm{Mn}_{4}$ centre undergoes a transient elevation of oxidation state in the $\mathrm{S}_{4}$ state before water is oxidized. To date no $\mathrm{Mn}^{\mathrm{V}}$ manganyl species has been detected for any of the meta-stable S-states $\left(\mathrm{S}_{0}-\mathrm{S}_{3}\right)$ (Weng et al. 2004).

A distinctive property of the OEC is not so much that it can produce oxygen, as catalases can also do this, but that it produces an $\mathrm{O}-\mathrm{O}$ bond. There are no other known examples in nature where such a bond is formed between two $\mathrm{H}_{2} \mathrm{O}$ molecules without long lived intermediates like $\mathrm{H}_{2} \mathrm{O}_{2}$ being released (Armstrong 2008). The extrinsic proteins are thought to help stabilize this reaction by shielding the OEC from the bulk solvent water and by providing channels that deliver substrate $\left(\mathrm{H}_{2} \mathrm{O}\right)$ and permit an orderly exit of products $\left(\mathrm{O}_{2}, \mathrm{H}^{+}\right)$. This idea was first promoted by Wydrzynski (Wydrzynski et al. 1996) and since then analysis of the crystal structures has revealed several channels that potentially aid in the transport of $\mathrm{O}_{2}$ and $\mathrm{H}_{2} \mathrm{O}$ (Murray and Barber 2007; Ho and Styring 2008). These channels would undoubtedly be involved in limiting substrate access aiding catalysis and reducing the possibility of damaging side reactions.

The Mn ions themselves are thought to bind the substrate water molecules. Two separate binding sites have been identified from ${ }^{18} \mathrm{O}$ isotope exchange measurements revealing a slow and a fast exchanging site (Messinger et al. 1995). Through the use of specialized EPR techniques it has been shown that a solvent water molecule definitely ligates directly to a $\mathrm{Mn}$ ion at one of the exchange sites

Figure 1.3) (Su et al. 2008). The slow exchanging site is due to ligation of the solvent water molecule to the Ca ion and another Mn ion (Hendry and Wydrzynski 2003). 


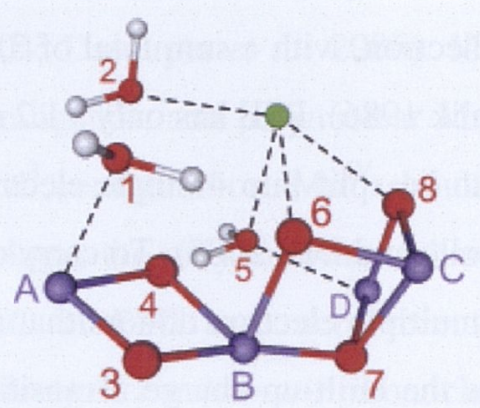

Figure 1.3: Recent model for the $\mathrm{Mn}_{4} \mathrm{OxCa}$ cluster in PSII with suggested substrate "water" binding sites. O-O bond formation has been proposed by different groups to occur in the $\mathrm{S}_{4}$ state between oxygen's 1 and 2, 3 and 4, 4 and 5, 1 and 6 , or 6 and 8 (Su et al 2008). Purple (Mn), red (O), green $(\mathrm{Ca})$, and grey $(\mathrm{H})$.

There are a large number of theories on the mechanism of O-O bond formation in the $\mathrm{S}_{4}$ state of PSII. Experimental evidence suggests that the delay in cycling from $\mathrm{S}_{3}$ through $\mathrm{S}_{4}$ back to $\mathrm{S}_{0}$ is due to a proton extraction event (Clausen et al. 2004; Haumann et al. 2005). The driving energy is small for the $S_{3}$ and $S_{4}$ states and thus proton removal events are definitely of major importance. The proton release pattern from the OEC in the four $S$ states $\left(S_{0} \rightarrow S_{1}, S_{1} \rightarrow S_{2}, S_{2} \rightarrow S_{3}\right.$, and $\left.S_{3} \rightarrow\left[S_{4}\right] \rightarrow S_{0}\right)$, appears to be 1,0,1,2 (McEvoy and Brudvig 2006; Dau and Haumann 2008). Far from suggesting a mechanism for O-O bond formation I would refer the reader to several articles that discuss the different possibilities that could apply given the latest refinements in structure (Hillier and Messinger 2005; McEvoy et al. 2005; Siegbahn 2006; Siegbahn 2008).

\subsubsection{Why Manganese?}

In order to function the OEC can only use manganese and no other metal ions. The calcium ion is not so specific as it can be replaced with strontium, but there are no functional substitutes for Mn (Boussac et al. 2004). One may speculate that plants initially utilized $\mathrm{Mn}$ because of its high availability as the aqua ion $\mathrm{Mn}\left(\mathrm{H}_{2} \mathrm{O}\right)_{6}{ }^{2+}$ in aqueous solution. This $\mathrm{Mn}^{\text {II }}$ cation is very stable, exchanges ligands rapidly and forms soluble salts; this coupled with its high natural abundance and the fact that a cell's requirements for $\mathrm{Mn}$ are very low means that supply usually exceeds demand. Once taken up by an organism, Mn will tend to remain as $\mathrm{Mn}^{\mathrm{II}}$ unless it is captured by ligands that favour its oxidation to $\mathrm{Mn}^{\mathrm{III}}$ and $\mathrm{Mn}^{\text {IV }}$ (Armstrong 2008). 
The energetics of $\mathrm{O}_{2}$ formation from $\mathrm{H}_{2} \mathrm{O}$ are such that at $\mathrm{pH} 7$, formation of free molecular $\mathrm{O}_{2}$ requires an energy input of $0.82 \mathrm{eV}$ per electron, with a sum total of 3.68 $\mathrm{eV}$ for 4 electrons and 4 protons to be removed (Krishtalik 1986). PSII has only $\sim 1.2 \mathrm{eV}$ potential provided by $\mathrm{P} 60^{+}$, and so the reaction has to be split into 4 single electron transfer steps in order for the reaction to proceed (Grabolle and Dau 2005). To carry out such a reaction it is necessary for the OEC to contain multiple electron donors that are able to cycle through different oxidation states to store the built-up charge. Transition metals are the obvious choice for such a catalyst as these ions commonly have multiple stable oxidation states, due to the relative ease of removing unpaired d-electrons (Cowan 1996).

Nature uses many different first-row transition (d-block) elements such as $\mathrm{V}, \mathrm{Mn}, \mathrm{Fe}$, $\mathrm{Co}, \mathrm{Ni}, \mathrm{Cu}$, and $\mathrm{Zn}$. As we move across the $3 \mathrm{~d}$ row, the highest accessible oxidation states as well as the number of accessible oxidation states increases up to $\mathrm{Mn}$ then decreases to $\mathrm{Zn}$ where only the $\mathrm{Zn}^{\mathrm{II}}$ state is observed. This is mainly a product of ionization energies, which increase across the row and for each electron removed. Not only does Mn display a greater range of oxidation states than other $3 \mathrm{~d}$ metals, but all the simple higher states, from $\mathrm{Mn}^{\text {III }}$ upwards, are hydroxo- or oxo-species with reduction potentials in the ranges of O-transformation reactions (Armstrong 2008).

Of all the transition metals iron has the most similar chemistry to that of manganese. Iron II, III and IV oxidation states (?) have been reported in biological systems. A multitude of enzymes utilize Fe $\mathrm{F}^{\mathrm{I} / \mathrm{III}}$ chemistry and enzymes such as iron catalase and peroxidase, employ an $\mathrm{Fe}^{\mathrm{IV}}=\mathrm{O}$ species from heme iron. Like manganese, iron also has preferences for oxygen ligands in higher oxidation states (Hersleth et al. 2006).

Mn can reach a large number of oxidation states with the biologically relevant states being the II, III, and IV states. $\mathrm{Mn}^{\text {II }}$ has a ligand preference for O-donors, although compared with either $\mathrm{Mg}$ or $\mathrm{Ca}$, it does have a greater tendency to bind to $\mathrm{N}$-donors. The intrinsic stability of $\mathrm{Mn}^{\mathrm{II}}$ arises from the electron configuration $3 \mathrm{~d}^{5}$ where the $\mathrm{d}$ shell is half filled. This configuration is favoured due to optimal exchange energy, making it difficult to remove the fifth d-electron, so $\mathrm{Mn}^{\mathrm{III}}$ compounds are particularly oxidizing. The difficulty in stabilizing $\mathrm{Mn}^{\mathrm{III}}$ decreases as ligands with good donor properties are introduced. A good example of this is bicarbonates ability to ligate and 
stabilize Mn lowering the IV/III reduction potential from 1.5 to $0.6 \mathrm{eV}$ (Kozlov et al. 2004; Dasgupta et al. 2006). $\mathrm{Mn}^{\mathrm{IV}}$ complexes regularly contain bridging or terminal oxo-ligands, and polynuclear $\mathrm{Mn}-\mathrm{O}$ clusters of mixed valency are common. Owing to its $\mathrm{d}^{3}$ configuration, $\mathrm{Mn}^{\mathrm{IV}}$ should favour octahedral geometry. $\mathrm{Mn}^{\mathrm{IV}}$ is rarely found in biology, the only enzymes where this high oxidation state is found naturally is in the OEC of PSII and more recently it was found as a mixed $\mathrm{Mn}^{\mathrm{IV}} / \mathrm{Fe}^{\mathrm{III}}$ cofactor in Chlamydia trachomatis ribonucleotide reductase (Jiang et al. 2007).

\subsection{Design of Photo-Catalytic Proteins}

PSII in higher plants is a highly complex, membrane-based enzyme made up of at least 27 protein subunits and 32 cofactors involved in electron transfer and light harvesting (Wydrzynski and Satoh 2005) (Figure 1.4). The large size and complexity of this enzyme makes it difficult to work with and any mimic of this protein must by definition be simpler. Development of a minimalist photo-catalytic structural unit requires that only the essential redox cofactors of PSII are engineered into a simple framework. The essential cofactors for the function of PSII include: a bound plastoquinone electron acceptor; a high potential photo-oxidisable chlorophyll (Chl) complex; a redox-active tyrosine; and a tetra-nuclear manganese/calcium cluster $\left(\mathrm{Mn}_{4} \mathrm{O}_{\mathrm{x}} \mathrm{Ca}\right)$ i.e. quinone $-\mathrm{Chl}$ complex - tyrosine - manganese cluster (Figure 1.2).

The cofactors present in PSII are placed at specific positions in space by the protein framework. The amino acid residues responsible for binding these cofactors function not only as a scaffold but to mediate the redox potentials of the cofactors bound. In the majority of enzymes redox midpoint potentials of bound cofactors are set such that electron transfer is unidirectional (Rabanal et al. 1996; Page et al. 1999). The following section will detail electron transfer principles necessary for engineering a photocatalytic system and previous attempts to introduce light activated pigments, electron acceptors and electron donors within a protein framework in a redox active form. 


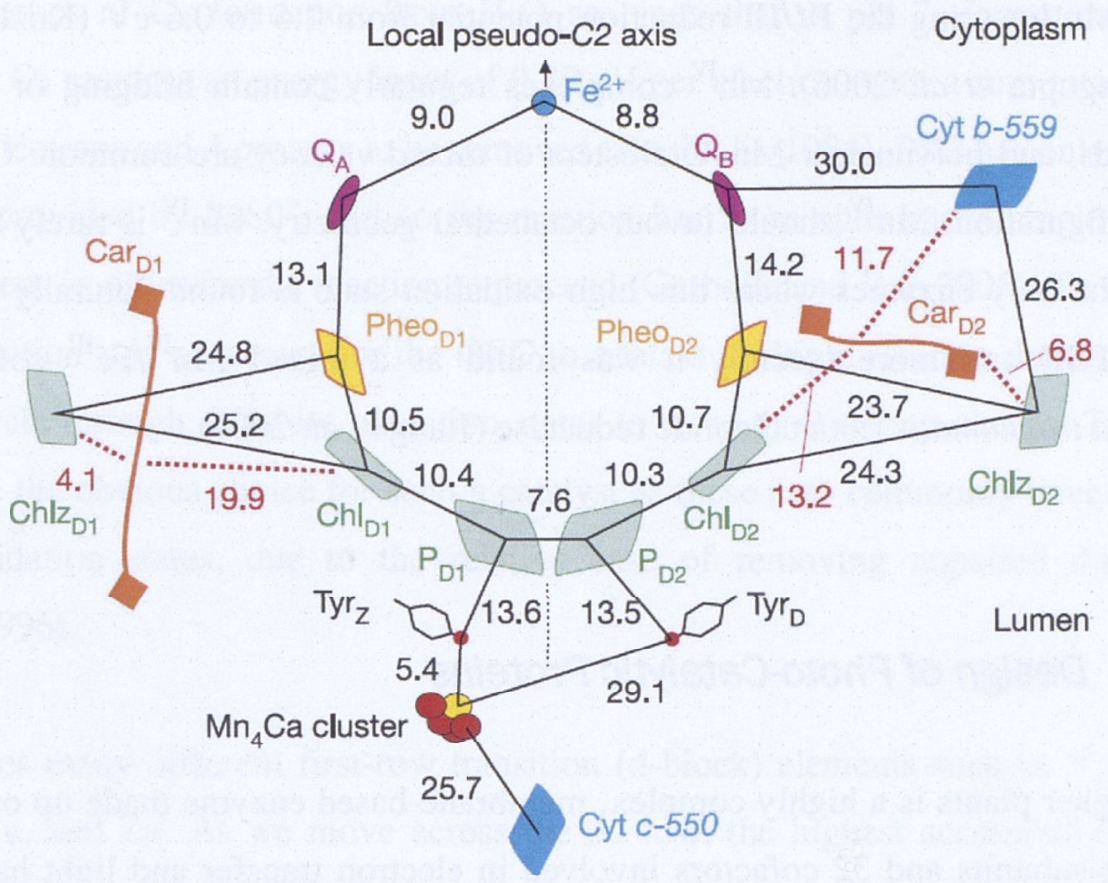

Figure 1.4: Schematic showing the cofactors and the distances separating the cofactors in PSII. Image taken from Loll et al 2005.

\subsubsection{Electron Transfer Principles}

In order for light activated systems to operate a charge separated state must be accomplished through electron transfer between donor (D) and acceptor (A) molecules, at a rate faster than the relaxation of the excited state. Upon absorption of a sufficiently energetic photon a light activated molecule $(\mathrm{P})$, such as Chlorophyll a, is transformed to an electronically excited state $\left(\mathbf{P}^{*}\right)$. This is generally a highly-energetic, unstable and short lived state. $\mathrm{P}^{*}$ is deactivated by either radiative or non-radiative transitions back to the ground state or through electron transfer. Figure 1.5 illustrates the energy levels of the various mechanisms of energy dissipation. In some circumstances the excited state lifetimes are sufficiently long-lived ( $>\sim 1 \mathrm{~ns}$ ) to allow a bimolecular reaction with an acceptor molecule (generally ground state). Deactivation of P* through ET occurs when $\mathrm{P}^{*}$ is returned to the ground state via a radical state ( such as $\mathrm{P}^{\text {ot+ }}$ ). 
An example of this is:

$$
\begin{array}{lll}
\mathrm{P}^{*}+\mathrm{Q} \rightarrow \mathrm{P}^{\bullet+}+\mathrm{Q}^{\bullet-} & \text { Electron transfer } & \text { Equation 1-1 } \\
\mathrm{P}^{\bullet+}+\mathrm{Q}^{\bullet-} \rightarrow \mathrm{P}+\mathrm{Q} & \text { Charge recombination } & \text { Equation 1-2 }
\end{array}
$$

Equation 1.2 is a consequence of the instability of the charge separated state leading to charge recombination also known as the back reaction. In photosynthesis a functional reaction centre minimizes charge recombination by additional electron transfer reactions thereby separating the charges by a greater distance. The charge separated state is energetically unstable due to Coulombic attraction between the cation and anion radicals but this attraction decreases exponentially with distance. In order to prevent charge recombination, either the charges must be further separated or the charges otherwise neutralized.

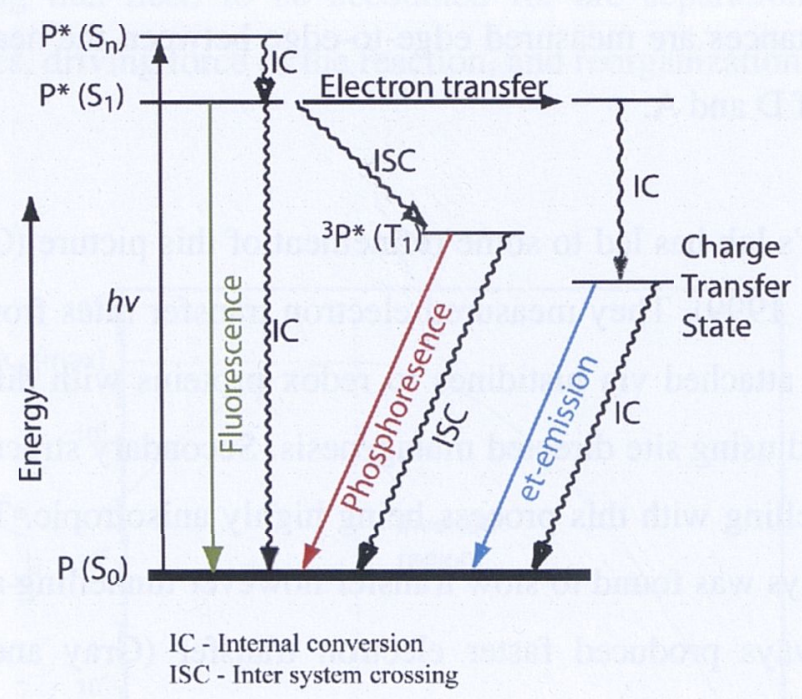

Figure 1.5: A Jablonski diagram illustrating the different energy levels and types of transitions that can occur in e.g. a porphyrin system. $S_{0}$ is the singlet ground state while $S_{n}$ is any excited singlet state and $S_{1}$ is the lowest excited singlet state whilst $T_{1}$ is the lowest excited triplet state. The fluorescence and phosphorescence transitions are radiative, whilst IC and ISC are nonradiative. 
Intraprotein electron transfer is typically rate-limited by tunnelling through the insulating protein medium between the edges of the D and A redox centres. This electron tunnelling is reasonably accurately described by a simple exponential decay with distance (Moser et al. 1992; Page et al. 1999). The intervening protein medium also has some role to play in electron tunnelling rates and a simple use of the packing density $(\rho)$ to equate the tunnelling barrier has been used successfully by Dutton and coworkers. They have produced an empirical equation relating rate to distance:

$\log k_{e t}^{\text {exer }}=13-0.6(R-3.6)-3.1(\Delta G+\lambda) 2 / \lambda$

Equation 1-3

where $\mathrm{k}_{\mathrm{et}}{ }^{\mathrm{exer}}$ is the rate in units of $\mathrm{s}^{-1}, \mathrm{R}$ is the edge-to-edge distance between redox cofactors and 3.6 represents van der Waals contacts in $\AA$. The $\Delta \mathrm{G}$ and $\lambda$ terms are in eV with a typical $\lambda$ value of $0.9 \pm 0.2 \mathrm{eV}$. Because electrons can transfer across conjugated systems virtually instantaneously, electron transfer across the distance spanned by the ring systems does not contribute significantly to the electron transfer time (Moser and Dutton 1992). This is implicit in the treatment summarized in Dutton's equation, and all electron transfer distances are measured edge-to-edge between the nearest atoms in the conjugate systems of $\mathrm{D}$ and $\mathrm{A}$.

Work in Harry Gray's lab has led to some refinement of this picture (Gray and Winkler 1996; Winkler et al. 1999). They measured electron transfer rates from ruthenium and rhenium complexes attached via histidines to redox proteins with different secondary structures, positioned using site directed mutagenesis. Secondary structure was found to affect electron tunnelling with this process being highly anisotropic. Tunnelling across alpha helical pathways was found to slow transfer however tunnelling along more linear B strand like pathways produced faster electron transfer (Gray and Winkler 1996; Winkler and Gray 1997; Winkler et al. 1999; Gray and Winkler 2003)

Much more important than packing density is that of driving force $\left(\Delta G^{\circ}\right)$. This is estimated from the difference in the redox midpoint potentials $\left(\mathrm{E}_{\mathrm{m}}\right)$ between donor and acceptor, assuming that redox centres are not too close. One other major factor that affects tunnelling rates is that of reorganization energy $(\lambda)$. Reorganization energy is defined as the energy required for all structural adjustments in the nuclear geometry of 
reactants and the surrounding solvent molecules, which are needed in order that D and A molecules assume the configuration required for the transfer of the electron. The charge distribution can be quite different in the charge-separated state and must be accommodated through alteration of the local dielectric via structural rearrangements. It can be viewed as an indirect measure of activation energy for the electron transfer reaction. If the exergonic driving force of the reaction matches the reorganization energy for the reactions $(\Delta G=-\lambda)$, then the tunnelling rate will be activation less and as fast as possible. If the driving force is different from this optimal value, either less exergonic (Marcus normal region) or more exergonic (Marcus inverted region), the electron tunnelling rate will decrease in an approximately Gaussian dependence of rate on driving force (see Figure 1.6) (Marcus 1956; Marcus and Sutin 1985). If one or both donor or acceptor complexes is solvent exposed then $\lambda$ can become quite large $(>1 \mathrm{eV})$.

When engineering light-activated enzymes that mimic PSII, in order to produce a functional light activated redox protein, it is necessary to understand and apply the physiological limitations of electron transfer. The main elements of protein based electron tunnelling that need to be accounted for are separation distance of donor acceptor molecules, driving force of the reaction, and reorganization energies.

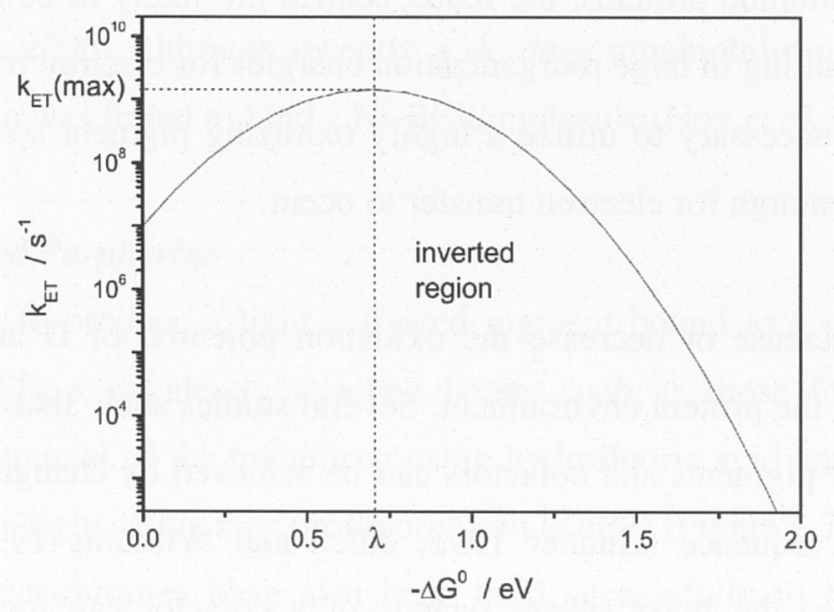

Figure 1.6: A theoretical Marcus curve (derived from Dutton's ruler Equation 1-3) where $\lambda=0.7$ $\mathrm{eV}$ and the cofactor separation $=10 \AA$ (Moser and Dutton 1996). 


\section{Distance:}

Electron transfer rates are mostly affected by the edge-to-edge distances between $\mathrm{D}$ and A redox centres. Natural proteins with productive electron transfer reactions have been found to have cofactors separated by no more than $\sim 14 \AA$ (Page et al. 1999; Page et al. 2003; Noy et al. 2006). Looking more specifically at the electron transport chain in PSII, the average redox cofactor separation distance is $\sim 10 \AA$ for any one component and none are greater than $13.6 \AA$ (Loll et al. 2005). Therefore when engineering a light activated electron transport chain it is wise to place all cofactors within $10-14 \AA$. Another important consideration is that cofactors should not be placed too close to each other so as to prevent energy wasting back reactions.

\section{Driving force:}

For the purposes of engineering photo-active proteins, aside from changing the cofactor distance, altering the driving force is probably the most tangible method of tuning electron transfer reactions in a protein. Driving force is described by a Gaussian curve and as $-\Delta G^{0}$ is increased, $K_{e t}$ becomes maximal and then slows when $-\Delta G^{0}>\lambda$. This is a rather counter-intuitive effect that has been experimentally well documented (Marcus and Sutin 1985). The region where $-\Delta G^{0}>\lambda$ is called the inverted region. The value of $\Delta \mathrm{G}^{0}$ for light-induced electron transfer can be calculated by a method developed by Rehm and Weller (Rehm and Weller 1970). In the majority of engineered proteins, unless they are membrane proteins, the redox centres are likely to be at least partially solvent exposed resulting in large reorganization energies for electron transfer reactions. In such cases it is necessary to utilize a highly oxidizing pigment so that the driving force will be large enough for electron transfer to occur.

It is possible to increase or decrease the oxidation potential of D and A centres in proteins by varying the protein environment. Several studies show that large changes in redox potentials for pigments and cofactors can be achieved by changing single amino acids in a protein sequence (Gunner 1991; Allen and Williams 1995). Introducing hydrogen bonds into the inner sphere ligands of a cofactor can increase the redox midpoint potential substantially and removal of hydrogen bonds acts to decrease this potential. 


\section{Reorganization energies:}

Membrane based proteins are ideal for engineering redox reactions with low reorganization energies due to $\mathrm{D}$ and $\mathrm{A}$ molecules being buried far from the polar solvent, but these proteins are extremely difficult to work with. The majority of light activated proteins engineered so far tend to be small soluble four helix bundle proteins, which are easier to work with but have solvent exposed donor and acceptor groups. This leads to high reorganization energies for electron transfer reactions thus a large driving force is desirable for these types of reaction centres.

\subsubsection{Light Activated Pigments}

\section{Chlorophyll}

Attempts at producing mimics of PSII have centred on the introduction of a pigment into a peptide matrix. At first glance it would appear that a good way to incorporate a photoactive pigment would be to bind $\mathrm{Chl}$ as used in all reaction centres including PSII. Unfortunately it is very difficult to work with Chl due to its long phytyl tail, making the molecule very hydrophobic and not amenable to binding to smaller soluble proteins in solution (Figure 1.7). There are relatively few studies on the incorporation of Chl into non-photosynthetic proteins (Kehoe et al. 1998; Meadows et al. 1998; Eggink and Hoober 2000; Rau et al. 2001; Satoh et al. 2001; Chen et al. 2005; Hughes et al. 2006; Noy and Dutton 2006), although recently a de novo amphiphilic protein containing a lipophilic domain was found to bind a Ni-BChl molecule (Noy et al. 2005).

\section{Metal Substituted Porphyrins}

A sure fire way to produce a light activated pigment bound to a protein matrix is to chemically modify a covalently attached heme, such as those found in the c-type cytochromes. Removal of the heme iron using hydrofluoric acid and replacement with zinc produces the light active zinc protoporphyrin (ZnPP) (Figure 1.7)(Vanderkooi et al. 1976). B-type cytochromes have also been used successfully to bind light-activated pigments. The heme group in these proteins is not covalently linked to the protein which enables the easy removal of the heme $b$ molecule from the binding pocket (Teale 1959) and replacement with light active porphyrins (Petersonkennedy et al. 1984; Simolo et al. 1984; McGourty et al. 1987). 


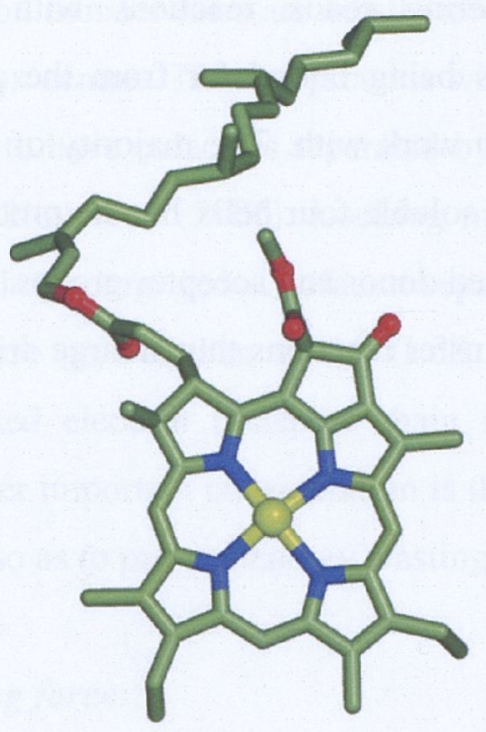

Chlorophyll-a

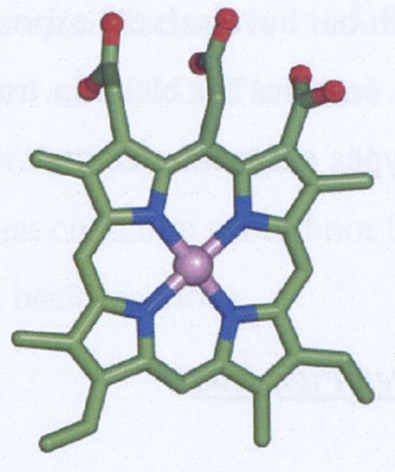

Zinc Chlorin $\mathrm{e}_{6}$

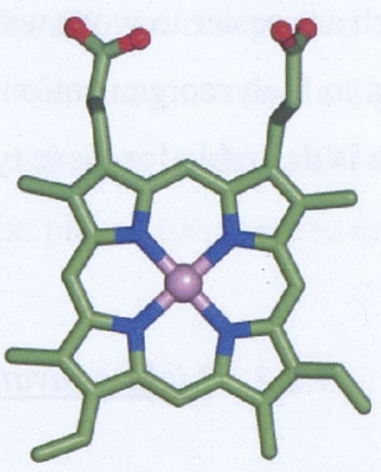

Zinc Protoporphyrin

Figure 1.7: Stick diagrams of three light active porphyrins. Chlorophyll-a is found in higher plants whilst Zinc chlorin $\mathrm{e}_{6}$ is a synthesized pigment. Zinc protoporphyrin IX is just a zinc substituted heme $b$ molecule.

Upon light excitation $\mathrm{ZnPP}$ forms a triplet state with near unity efficiency $(\Phi \mathrm{t}=0.9)$ which is long lived ( $\tau \sim 14 \mathrm{~ms}$ ) (Zemel and Hoffman 1981; Sudha et al. 1984). This has been utilized to study long range electron transfer reactions such as those between proteins. Electronically excited ZnPP (Ho et al. 1985; McLendon et al. 1985) and also the free base porphyrin (Cheung et al. 1986) can act as electron donors. The rate of interprotein electron transfer has been measured in several protein-protein complexes such as between $\mathrm{Zn}$-hemoglobin and Fe $\mathrm{Fe}^{\mathrm{III}}$-cyt $b_{5}$ (Simolo et al. 1984) as well as between Zn-cyt $c$ and cyt $b_{5}$ (McLendon et al. 1985; Qin and Kostic 1994). These electron transfer reactions are quite slow $10^{3}-10^{5} \mathrm{~s}^{-1}$ despite donor/acceptor distances of 8-10 $\mathrm{A}$.

Interprotein electron transfer between $\mathrm{Fe}^{\mathrm{II}}$-cyt $c$ peroxidase and $\mathrm{Fe} \mathrm{e}^{\mathrm{III}}$-cyt $c$ has been utilized to measure physiological electron transfer reactions. This suggested the reorganization energy associated with these interprotein electron transfer reactions was approximately $1 \mathrm{eV}$ (Cheung et al. 1986). The reported oxidative potentials, $\mathrm{E}\left(\mathrm{P} / \mathrm{P}^{*+}\right)$, for zinc substituted cytochromes in horseradish peroxidase, cytochrome c, and myoglobin are $+0.75+0.8$ and $+0.98 \mathrm{eV}$ respectively (Kaneko et al. 1980; Cowan and 
Gray 1989; Magner and McLendon 1989). More recently electron transfer has been reported in other metal substituted proteins such as ZnPP-substituted nitrite reductase (Bellelli et al. 1996) and cyt P450cam (Furukawa et al. 2000). Triplet electron transfer from bound $\mathrm{ZnPP}$ to a quinone in solution has also been demonstrated by several groups (Satoh et al. 1997; Fahnenschmidt et al. 2001).

One major drawback of utilizing $\mathrm{ZnPP}$ is that due to triplet state formation it produces a long lived charge separated state which allows oxygen to readily react under aerobic conditions producing damaging reactive oxygen species. By utilizing $b$-type cytochromes, porphyrins which primarily donate an electron from the singlet state can be bound to the heme pocket. Of particular success has been the use of zinc chlorin $\mathrm{e}_{6}$ $\left(\mathrm{ZnCe}_{6}\right)$ which is very similar to heme $b$ except for changes in the length of the carbon chains terminating in carboxylates and also addition of an extra carboxylic acid (Figure 1.7). This makes the pigment more soluble and easier to handle whilst maintaining a high binding affinity for the heme site. $\mathrm{ZnCe}_{6}$ is utilized as a photoactive pigment due to its strong $\mathrm{Q}_{y}$ absorption band in the red $(\sim 638 \mathrm{~nm})$, and high estimated oxidation potential of $\sim+1.1 \mathrm{eV}$ (Hay et al. 2004). Zinc substituted porphyrins exhibit pentacoordinate geometry and have only one amino acid axial ligand unlike heme $b$ in which the central Fe ion exhibits bis-ligation and has two amino acid axial ligands, usually histidine or methionine.

Razeghifard and Wydrzynski (2003) found that $\mathrm{ZnCe}_{6}$ could be bound in place of heme in a de novo 4-helix bundle protein with two histidine residues acting as axial ligands. Upon replacing one histidine with phenylalanine, only half the amount of $\mathrm{ZnCe}_{6}$ was bound, and upon replacing both histidines with phenylalanine, completely ablated $\mathrm{ZnCe}_{6}$ binding. The bound $\mathrm{ZnCe}_{6}$ could undergo some photochemistry after repetitive light flash illumination in the presence of an external quinone acceptor though with low yield (Razeghifard and Wydrzynski 2003). Light activated electron transfer has also been demonstrated with $\mathrm{ZnCe}_{6}$ bound within a de novo protein to a quinone electron acceptor in solution (Mennenga et al. 2006). 


\section{Flavins}

Flavin molecules can be utilized to carry out photo-initiated electron transfer within proteins. Upon excitation flavin in solution was found to form a semi-quinone species by abstracting an electron from a donor in solution, such as EDTA. The semi-quinone was then capable of reducing cyt $c \mathrm{Fe}^{\mathrm{III}}$-heme through an electron transfer reaction (Ahmad et al. 1981). Flavin derivatives covalently bound to cysteine residues on the surface of cyt $c$, through disulphide bond, were shown to transfer an electron to the heme group within the protein and a reorganization energy of $1.2 \mathrm{eV}$ was determined (Twitchett et al. 1997). Other work demonstrated that a flavin bound within the interior of a de novo designed heme-binding maquette could carry out electron transfer from the photo-generated semi-quinone to the bound heme (Sharp et al. 1998).

\subsubsection{Electron Acceptors}

The use of electron acceptors present in solution have major drawbacks in that they must be present in high concentration and the reorganization energies associated with electron transfer are large and thus produce low yields of electron transfer in artificial systems. In order to optimize electron transfer reactions between cofactors it is ideal to bury the cofactors within the protein matrix to increase efficiency. There are a large number of electron transport chains present in natural systems that allow for transport of electrons across large distances. Within PSII, Chls, pheophytin's, and quinones are utilized. Quinones have been utilized extensively as electron acceptors due to their efficiency in transferring charge in natural systems.

\section{Quinones}

In PSII the first stable quinone electron acceptor is a specially bound plastoquinone molecule, $\mathrm{Q}_{\mathrm{A}}$. This quinone is highly hydrophobic, having a long hydrocarbon side chain for binding purposes and membrane solubility. Engineering a binding site for plastoquinone in a protein is as difficult as engineering a Chl binding site, due to the fact that both have long hydrophobic tails. These natural quinones are not covalently bound to the protein however in artificial reaction centres covalent attachment is a more practical approach due to the inherent difficulties in designing a binding site. A quinone 
will covalently link to a free sulfhydro group (-SH), such as that found in cysteine, through a sulphur addition reaction (Redfearn 1965).

Hay et al (2004) were the first group to make use of this novel addition reaction and by modifying the gene for cytochrome $b_{562}$ were able to place a cysteine residue within the interior of this protein and covalently attach a quinone molecule. The cytochrome $b_{562}$ was chosen as it is a small soluble 4-helix bundle protein $(11.6 \mathrm{kDa})$ which has been extensively characterized both biophysically and structurally (Moore et al. 1985; Hamada et al. 1995; Barker et al. 1996; Robinson et al. 1997; Arnesano et al. 1999; Springs et al. 2002)

Like all b-type cytochromes this protein binds a heme $b$ molecule, therefore a mutation was made which placed a cysteine-bound quinone within $\sim 11 \AA$ edge-to-edge distance of the heme group. The heme could then be removed and replaced with the light active $\mathrm{ZnCe}_{6}$. When the cysteine site was covalently linked to a coenzyme Q $\left(\mathrm{CoQ}_{0}\right)$ molecule that doesn't have the hydrophobic tail, and $\mathrm{ZnCe}_{6}$ was bound in the heme pocket, lightinduced electron transfer from the bound pigment to the bound quinone was achieved with approximately $20 \%$ efficiency compared with pre-reduced bound $\mathrm{CoQ}_{0}$ (Hay et al. 2004).

When other substituted quinones were analysed, the rates of electron transfer differed by less than a factor of two, indicating that the chemical nature of the quinone molecule itself had little effect on the electron transfer efficiency (Hay et al. 2004). The relatively invariant electron transfer rates and the large driving forces that were estimated for the various quinones analysed also indicated that the electron transfer in the modified cyt $b_{562}$ is near the top of the Marcus curve with relatively large reorganization energies. Based on the quinone fluorescence emission properties, the cysteine-quinone binding site appears to be partially solvent exposed, which explains the large reorganization energies (Hay et al. 2004). Other methods for binding quinone's to proteins have been investigated using thiol addition reactions as well as addition-elimination reactions between the cysteine sulphur and thioether quinones (Li et al. 2005). 


\subsubsection{Electron Donors}

\section{Tyrosine radicals}

In order for PSII to function a tyrosine molecule positioned near the P680 complex is oxidized donating an electron to $\mathrm{P} 680^{+}$. The tyrosine radical is then reduced by an electron taken from the $\mathrm{Mn}_{4} \mathrm{O}_{\mathrm{x}} \mathrm{Ca}$ complex. In producing a mimic of PSII it may be advantageous to involve a tyrosine residue to mediate the donation of electrons from the metal centre.

The Gray laboratory, in their work on metal-modified redox proteins, produced a rhenium-based photosensitiser with a $\mathrm{Re}^{\mathrm{II}} / \mathrm{Re}^{\mathrm{I}}$ redox pair reduction potential of $1.85 \mathrm{eV}$ vs. SCE (Connick et al. 1995). At pH 7.0 tyrosine has a redox potential of $0.83 \mathrm{eV}$ relative to NHE (Tommos et al. 1999), therefore the $\operatorname{Re}($ II) should be a powerful enough oxidant to generate tyrosyl radicals at a high driving force. Di Bilio et al (2001) showed that aromatic amino-acid radicals can be generated in rhenium modified proteins. A tyrosine could be selectively oxidized and the radical state trapped at low temperatures by preparing a rhenium-containing azurin sample in which the copper was substituted with zinc and a sacrificial oxidant was added to the medium. The irradiated freezetrapped sample gave rise to an EPR spectrum with a line shape characteristic of that of a neutral tyrosyl radical (Di Bilio et al. 2001).

\section{Metal Centres}

It is quite difficult to engineer a light activated group and an electron donating metal centre within the one protein. When looking for examples of light activated oxidation of a metal centre the vast majority of studies involve the use of ruthenium and rhenium based photosensitiser's covalently attached to the surface of proteins. These photosensitiser's achieve extremely high driving forces, particularly the more recently developed rhenium adducts (Connick et al. 1995; Lin et al. 1996). Utilization of ruthenium enabled demonstration of electron transfer from the heme-Fe in cytochrome $c$ to a light activated $\mathrm{Ru}^{3+}$ complex (Chang et al. 1991). Electron transfer has also been demonstrated from a copper ion bound within a ruthenium modified plastocyanin which is oxidized upon illumination of the ruthenium complex (Di Bilio et al. 1998). Utilizing a rhenium complex attached to $P$. aeruginosa azurin with a sacrificial electron acceptor in solution, oxidation of a bound copper ion has been demonstrated with subsequent 
reduction of the oxidized rhenium complex (Connick et al. 1995; Di Bilio et al. 2001)reviewed in (Miller et al. 2004).

\subsection{Combining Donor-Tyrosine-Pigment-Acceptor}

Utilizing larger, natural enzymes is a good way to introduce multiple cofactors and produce a light activated electron transport chain. The key advantage here is that the proteins selected should already contain features that facilitate the redesign of the protein. An elegant example of this approach is the modification of the bacterial reaction centre (BRC) for PSII function (Kalman et al. 2005). The bacteriochlorophyll dimer (BChl2), P870, in the BRC from the purple bacterium Rhodobacter sphaeroides has a relatively low redox potential $(\sim 0.5 \mathrm{eV})$ compared to P680 in PSII $(\sim 1.25 \mathrm{eV})$. Lin et al (1994) found that the reduction potential of the $\mathrm{BChl} 2$ in the reaction centre is influenced by hydrogen-bonding interactions with surrounding side chains. In wild-type P870, a hydrogen bond is present between a histidine and one of the acetyl groups involved in the conjugated $\pi$-system of the bacteriochlorophyll dimer. Upon removal of this hydrogen bond by mutating the histidine to a phenylalanine, the BChl 2 potential drops from 505 to $410 \mathrm{mV}$. Conversely addition of hydrogen bonds to the conjugated $\pi$ system raises the $\mathrm{E}_{\mathrm{m}}$ and the effects of these single-point mutations are additive. By using various single, double and triple mutants, the BChl2 potential could be tuned within the range of $410-765 \mathrm{mV}$ (Lin et al. 1994). Subsequently a quadruple mutant was engineered in which the number of hydrogen bonds to the conjugated carbonyl groups of the dimer was maximized. The $\mathrm{BChl} 2$ reduction potential for this mutant was elevated to above $800 \mathrm{mV}$ however, this mutation was relatively unstable (Kalman et al. 1999). Hydrogen bonding with histidine tends to have the greatest effect on the midpoint redox potential, but the $\mathrm{E}_{\mathrm{m}}$ is also influenced by charge groups within the vicinity of the porphyrin head (Williams et al. 2001; Johnson and Parson 2002). Therefore, by selectively modifying the interactions with the protein scaffold, P870 could be tuned to a much higher redox potential approaching that for P680 in PSII.

In addition to mutating the four residues, Kalman et al (1999) introduced a tyrosine at positions analogous to the positions of the redox active tyrosine's in PSII ( $Y_{Z}$ and $Y_{D}$ ), which following light excitation was oxidized and a tyrosine radical was observed 
(Kalman et al. 1999). Measurements revealed that the tyrosyl radical was more prominent at higher $\mathrm{pH}$ values and modelling of the tyrosine mutations suggested that a $\mathrm{H}$-bond was formed between the introduced tyrosine and a neighbouring histidine residue (Narvaez et al. 2002). By replacing the histidine with a non $\mathrm{H}$-bonding residue, the $E_{m}$ of the tyrosine increased and the amount of oxidized tyrosine decreased. Therefore the $E_{m}$ and the extent of oxidation of the introduced tyrosine are dependent upon the availability of a proton acceptor group, characteristic of PSII (Diner and Britt 2005).

As well as the above modifications carboxylate residues were introduced by mutagenesis into the highly oxidizing reaction centre at a site homologous to the manganese binding site of PSII (Thielges et al. 2005). This created a monomeric metal binding site that could bind $\mathrm{Mn}$ with a low dissociation constant ( 1uM). Upon illumination the bound $\mathrm{Mn}$ was able to reduce $\mathrm{P} 870^{+}$in a first order reaction. This same site was found to also bind $\mathrm{Fe}^{\mathrm{II}}$ which could be oxidized to $\mathrm{Fe}^{\mathrm{III}}$, upon illumination of P870 (Kalman et al. 2006).

\subsection{Research Objectives}

The work carried out on the BRC is novel and of great interest however I have focused my research on utilizing a minimalist protein scaffold to engineer PSII activity. The large BRC enzyme is almost as complicated as PSII and thus difficult to utilize. Smaller proteins tend to be more robust than the much larger photosystem complexes though there are limits to the number of cofactors which can be bound. De novo designed proteins tend to be limited in that most are single 4 helix bundles that are too small to bind multiple cofactors. The use of existing protein scaffolds enables slightly larger proteins to be chosen which are often better characterized with higher resolution crystal structures. These proteins have an added advantage in that they can be produced in large amounts through bacterial expression systems.

The following chapters detail the work carried out in designing a minimalist PSII mimic from bacterioferritin. This robust protein is easy to handle and though only a four-helix bundle itself, dimerises enabling several redox active cofactors to be bound. Later 
Research Objectives

modification of the protein enabled the formation of a heterodimer which more closely resembles the cofactor arrangement within PSII. Light induced electron transfer was demonstrated with storage of the light energy as higher oxidation states within a dimanganese centre. 


\section{CHAPTER 2}

\section{Methods}

\subsection{Cloning and Mutagenesis of Bacterioferritin Homodimer}

The bacterioferritin gene from E.coli was cloned into a plasmid and the protein expressed using the methods that follow. This protein was used to test the binding of the light active Zinc Chlorin $\mathrm{e}_{6}$ in place of the heme group in the hydrophobic porphyrin binding pocket. The Bfr protein was also used to assess manganese binding at the metal binding site. This protein with the two new cofactors bound was then used to look at light activated oxidation state changes in the manganese centre.

Genomic DNA was extracted from E.coli strain BL21 DE3 (Novagen). A phenolchloroform protocol was used to purify the genomic DNA with a sodium acetate and isopropanol precipitation step ( $\operatorname{Rex} 2000$ ). This procedure was repeated to ensure the purity of the DNA. The gene sequence for the E.coli bacterioferritin gene ( $b f r$ ) was taken from the published sequence of Andrews and co-workers (Andrews et al. 1989). The $b f r$ gene encoding bacterioferritin was amplified from the genomic DNA, using the following PCR primers:

Forward - 5' ATGAAAGGTGATACTAAAGTTATAAATTATCTC 3'

Reverse - 5' TCAACCTTCTTCGCGGAT 3'

The PCR method utilized involved a hot start followed by 30 cycles of $95^{\circ} \mathrm{C}$ for 1 minute, $55^{\circ} \mathrm{C}$ for 1 minute and $72^{\circ} \mathrm{C}$ for 3 minutes. The PCR product was cleaned up using a chloroform/isoamyl alcohol extraction then gel-purified on a $1.5 \%$ agarose gel. The band corresponding to the desired amplification product was cut out of the gel. The excised band was further purified using a QIAquick Spin Gel Extraction kit (Qiagen). 
Ligation independent cloning (LIC) regions were added to each end of the amplified $b f r$ gene product by another round of PCR using the following primers:

\section{Forward - 5' GGTATTGAGGGTCGCATGAAAGGTGATACTAAAGTTATAA 3'}

\section{Reverse - 5' AGAGGAGAGTTAGAGCCTCATCAACCTTCTTCGCGGAT 3'}

LIC regions in each primer (underlined) facilitated cloning into the pET32 Xa/LIC expression vector (Novagen) (Figure 2.1). The same PCR method used to amplify the $b f r$ gene was also used to add the LIC ends to the $b f r$ gene. The new amplified DNA with the LIC ends was T4 treated to remove overhanging nucleotides. The $b f r$ gene was then ligated into pET-32 Xa/LIC (Novagen) (Figure 2.2) as per standard Novagen protocols for the LIC system.

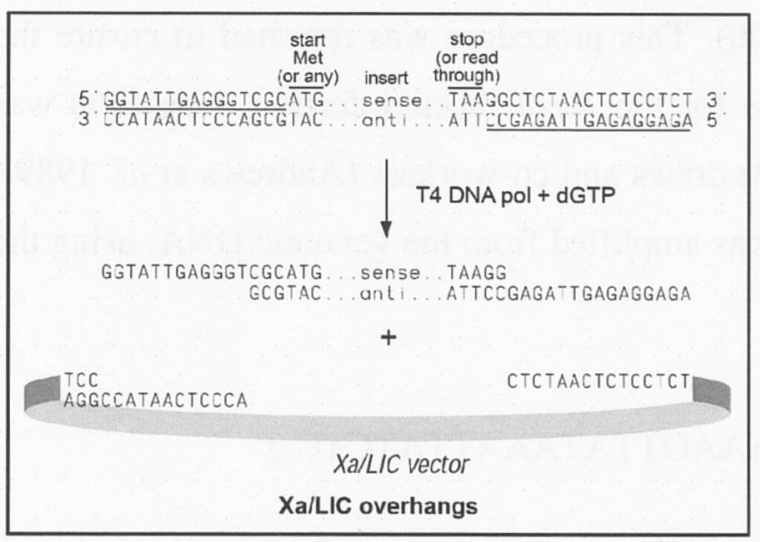

Figure 2.1: Ligation independent cloning strategy. LIC sequences are added onto the gene by PCR amplification with specific primers. Then overhangs are created from the LIC sequences by treatment with $\mathrm{T} 4$ DNA polymerase. LIC sequences in the linearised pET32 Xa/LIC plasmid. The overhangs on the gene and the plasmid are complementary allowing the gene to anneal and create a circularized plasmid without the need for ligase (figure adapted from Novagen).

The annealed pET32 Xa/LIC vector with $b f r$ gene was then transformed into NovaBlue cells (Novagen) using a standard heat shock protocol $\left(42^{\circ} \mathrm{C}\right.$ for 30 seconds). Transformed cells were grown in liquid culture then plated onto LB plates containing 50 $\mu \mathrm{g} / \mathrm{ml}$ ampicillin to select for the plasmid. 


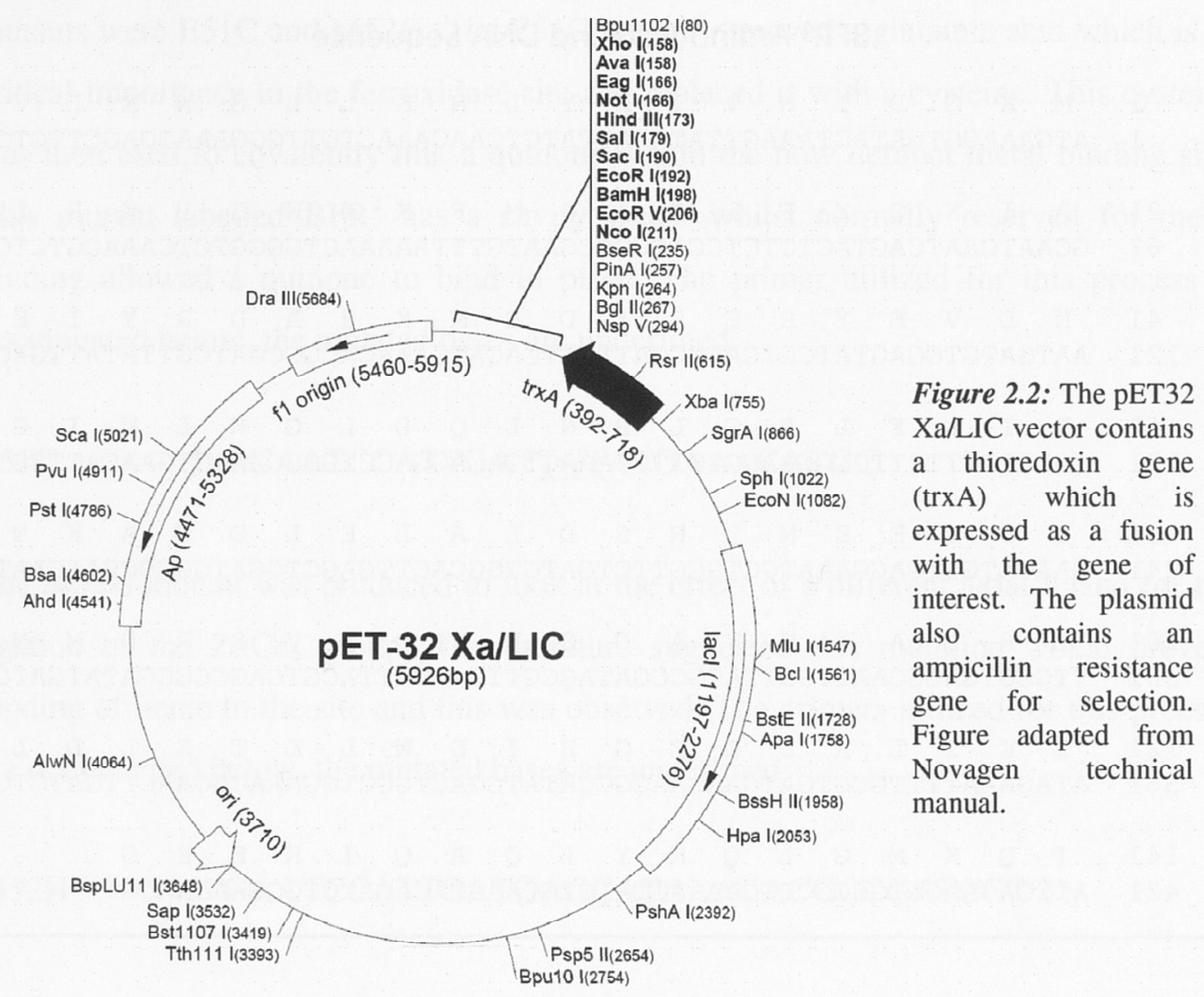

The plasmid was subsequently purified, from liquid cultures of individual colonies of transformed NovaBlue cells, using a QIAprep spin miniprep kit. The purified plasmid was then transformed into BL21 DE3 pLysS cells (Novagen) again using a heat shock protocol. To confirm the DNA sequence of the pET32 Xa/LIC $b f r$ gene, the plasmid was sent to the Australian Genome Research Facility (AGRF) for sequencing. The transformants were then screened for expression of the correct molecular weight protein product using SDS-PAGE. 


\section{BFR Amino Acid and DNA Sequence}

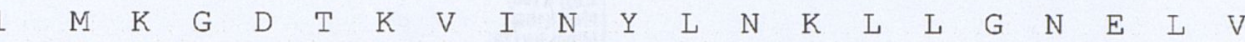

1 ATGAAAGGTGATACTAAAGTtATAAATTATCTCAACAAACTGTTGGGAAATGAGCTTGTC

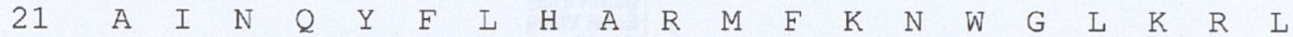

61 GCAATCAATCAGTACTTTCTCCATGCCCGAATGTTTAAAAACTGGGGTCTCAAACGTCTC

$\begin{array}{llllllllllllllllllllllllllllll}41 & N & D & V & E & Y & R & E & S & I & D & E & M & K & H & A & D & R & Y & I & E\end{array}$

121 AATGATGTGGAGTATCGCGAATCCATTGATGAGATGAAACACGCCGATCGTTATATTGAG

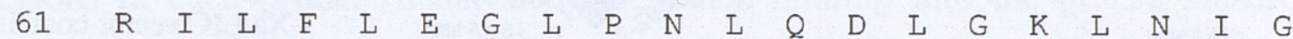

181 CGCATTCTTTTTCTGGAAGGTCTTCCAAACTTACAGGACCTGGGCAAACTGAACATTGGT

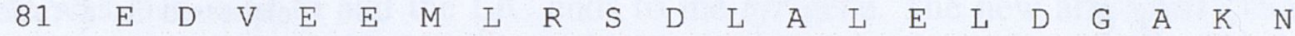

241 GAAgATGTTGAGGAAATGCTGCGTTCTGATCTGGCACTTGAGCTGGATGGCGCGAAGAAT

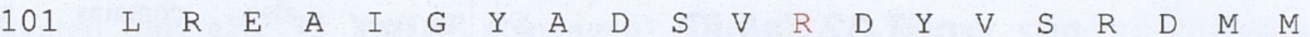

301 TTGCGTGAGGCAATTGGTTATGCCGATAGCGTTCGTGATTACGTCAGCCGCGATATGATG

$\begin{array}{lllllllllllllllllllllllllllllllll} & 121 & I & E & I & L & R & D & E & E & G & H & I & D & W & L & E & T & E & L & D & L\end{array}$

361 ATAGAAATTTGCGTGATGAAGAAGGCCATATCGACTGGCTGGAAACGGAACTTGATCTG

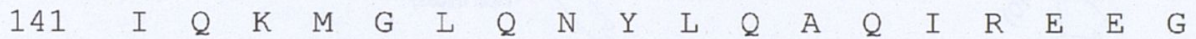

421 ATTCAGAAGATGGGCCTGCAAAATTATCTGCAAGCACAGATCCGCGAAGAAGGT

Figure 2.3: The amino acid and DNA sequence for the double mutant, BFR ${ }^{1}$. The two mutations H46R and H112R are marked in red.

\subsubsection{Site-Directed Mutagenesis of Bacterioferritin}

Two external histidines (H46, H112) were changed to arginines (Figure 2.3) using the Stratagene Qickchange multi site-directed mutagenesis kit. The removal of these histidines was to prevent non-specific binding of porphyrins to the protein. This double mutant $\left(\mathrm{BFR}^{1}\right)$ was utilized for all measurements in Chapter 3. All further mutants originated from the $B F R^{1}$ gene and contain the H46R and H112R mutations. The primers utilized for this process are documented below, the mutated bases are underlined. 
Two other mutants were made which contained the H46R and H112R mutations. These mutants were E51C and M52H. The E51C mutant removed a glutamic acid which is of critical importance in the ferroxidase site and replaced it with a cysteine. This cysteine was then used to covalently link a quinone within the now defunct metal binding site. This mutant labelled $\mathrm{BFR}^{2}$ has a cavity which whilst normally reserved for metal binding allowed a quinone to bind in place. The primer utilized for this process is documented below, the mutated bases are underlined.

E51C 5' CGAATCCATTGATTGTATGAAACACGC

The $\mathrm{M} 52 \mathrm{H}$ mutant was produced to look at the effect of a different axial ligand for the ligation of the $\mathrm{ZnCe}_{6}$ group. The literature suggested this mutation would prevent binding of heme to the site and this was observed. The primers utilized for this process are documented below, the mutated bases are underlined.

$\mathrm{M} 52 \mathrm{H}$ 5' GAATCCATTGATGAGCATAAACACGCCGATCGT 3'

\subsection{Production of the BFR Heterodimer Construct}

A heterodimer of the Bfr protein was engineered to enable directional electron transfer from a Mn centre to a quinone. In order to be able to change one half of the BFR dimer relative to the other half, i.e. form a heterodimer, it was necessary to link two monomers via a glycine rich linker region. This flexible linker was inserted into the gene sequence joining the N-terminus of one molecule to the C-terminus of the other. This utilized a modified form of the linker reported by (Whitney and Sharwood 2006). Two forms of the heterodimer were made, one as a control with no quinone binding site to test for structure and function retention upon adding the linker region, whilst the other contained a metal binding site, a porphyrin binding pocket and quinone binding site.

To produce the different constructs two $b f r$ mutant genes were utilized BFR ${ }^{1}(\mathrm{H} 46 \mathrm{R}$, H112R) and BFR ${ }^{2}$ (H46R, H112R, E51C). To enable the genes to be cut out of and ligated into plasmids it was necessary to add restriction sites at either end of each gene. 
The following primers were used to PCR amplify the $\mathrm{BFR}^{1}$ and $\mathrm{BFR}^{2}$ genes in order to add the required restriction sites:

5 'NdeI

5' TCATATGAAAGGTGATACTAAAGTT 3'

5'SacII

5' TCCGCGGTGGAGATATGAAAGGTGATACTAAAG 3'

3'EcoRV 3' TGATATCGACCTTCTTCGCGGATCTGTGC 5'

3'HindIII 3' AAGCTTAACCTTCTTCGCGGATCT 5'

The PCR rounds produced four different gene constructs (Figure 2.4) with either SacII and EcorRV restriction sites (SE) at either end of the gene or NdeI and HindIII cleavage sites $(\mathrm{NH})$ at either end of the gene. These blunt ended gene products were gel purified then treated with Taq polymerase to A-tail them. This process adds a single deoxyadenosine to the 3'-ends of the DNA which enables it to be readily ligated into a linearised vector containing single $3^{\prime}-\mathrm{T}$ overhangs at the insertion site. Using this method, only one insert will be ligated into the vector as opposed to multiple insertions that can occur with blunt-ended cloning.

\begin{tabular}{|ccc} 
Sacll & ECORV \\
\hline 1 & BFR & \\
\hline
\end{tabular}

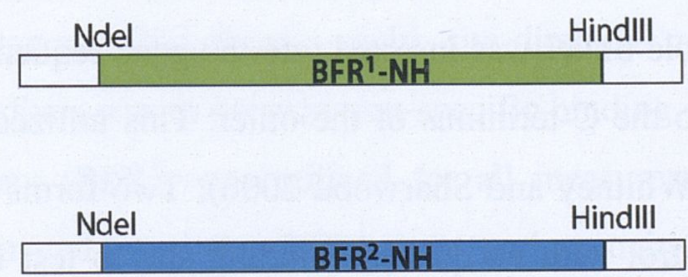

Figure 2.4: Four gene constructs were made with different restriction sites to enable the genes to be cut and ligated in different combinations. SE represents the cleavage sites SacII and EcoRV at either end of the gene. The $\mathrm{NH}$ represents the cleavage sites $\mathrm{NdeI}$ and HindIII at either end of the gene.

$\mathrm{BFR}^{1}-\mathrm{H} 46 \mathrm{R}, \mathrm{H} 112 \mathrm{R}$

$B F R^{2}-H 46 R, H 112 R, E 51 C$ 
The amplified A-tailed gene products $\mathrm{BFR}^{1}$-SE (Figure 2.4: yellow construct), BFR ${ }^{1}$ $\mathrm{NH}$, and BFR ${ }^{2}-\mathrm{NH}$ (Figure 2.4 green and blue constructs) were all ligated into separate pGEM-T Easy vectors (pTE) (Figure 2.5). The high-copy-number pTE vector contains $\mathrm{T} 7$ and SP6 RNA polymerase promoters flanking a multiple cloning region within the $\alpha$-peptide coding region of the enzyme $\beta$-galactosidase. Insertional inactivation of the $\alpha$ peptide allows recombinant clones to be directly identified by colour screening on indicator plates.

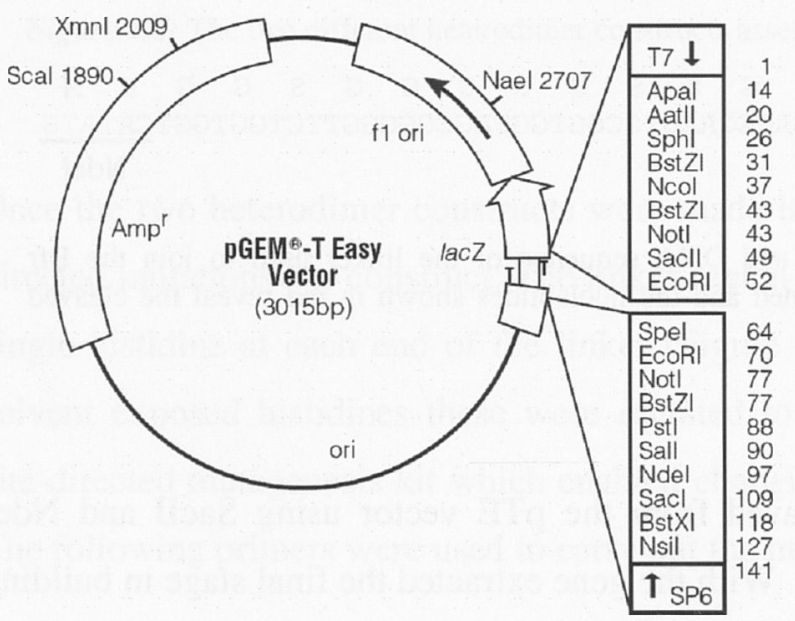

Figure 2.5: pGEM-T easy vector map and sequence reference points displaying the large number of cleavage sites available for gene construct insertion. Figure adapted from Promega technical manual.

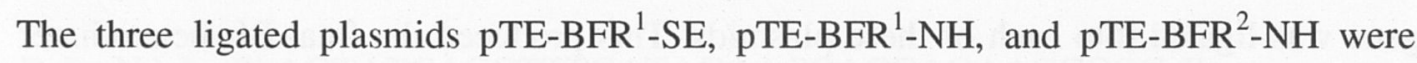
transformed into XL1B E.coli cells. The cells were plated onto LB-agar plates containing ampicillin, X-gal (5-bromo-4-chloro-3-indolyl- $\beta$-D-galactoside) and IPTG. Colonies of self ligated plasmids were blue in colour whilst those containing the gene of interest were white. Single white colonies were selected and grown in overnight cultures before the plasmids were purified using standard plasmid miniprep procedures to isolate the recombinant plasmids.

A DNA cleavage reaction was carried out on the pTE-BFR ${ }^{1}-\mathrm{SE}$ plasmid with EcoRV and SalI to ensure that the gene was inserted in the correct orientation. If it was oriented correctly then a $3.5 \mathrm{~kb}$ fragment was found if not then a $0.5 \mathrm{~kb}$ fragment was produced. Only those clones which had the $3.5 \mathrm{~kb}$ fragment were selected. 
A 20 amino acid linker was used to join the two $b f r$ genes to make the final heterodimer construct. This linker region contained a gly-gly-ser repeat with a single lysine (Figure 2.6). The linker, which was a gift from Spencer Whitney, was supplied in a pHUE plasmid and cleaved out using EcoRV and NdeI restriction enzymes. The 61 base fragment was then gel purified ready for ligation. The pTE-BFR ${ }^{1}$-SE plasmid was then digested with EcoRV and NdeI and the linker gene was ligated into the plasmid producing the pTE-BFR $^{1}$-SE-L construct (Figure 2.7).

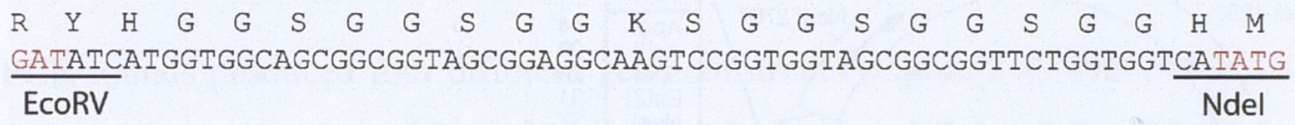

Figure 2.6: The amino acid sequence and DNA sequence of the linker used to join the Bfr subunits. The cleavage sites are underlined and the nucleotides shown in red reveal the cleaved bases.

The pTE-BFR ${ }^{1}$-SE-L gene was cleaved from the pTE vector using SacII and NdeI followed by standard gel purification. With the gene extracted the final stage in building

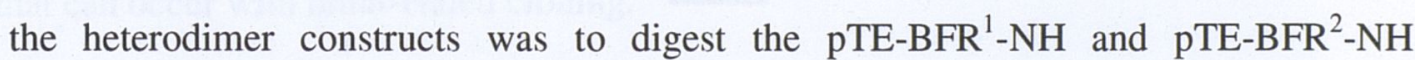
plasmids with SacII and NdeI. The plasmids were gel purified before the BFR ${ }^{1}$-SE-L gene was ligated into each of these plasmids. This produced the final Bfr heterodimer constructs which were then sequenced to verify the result (Figure 2.8).

\section{$\underline{B F R^{1}-S E-L}$}

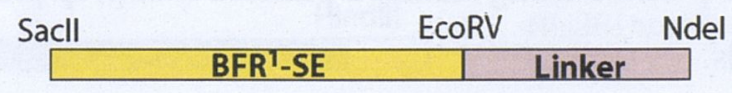

Figure 2.7: The $b f r$ gene construct $\mathrm{BFR}^{1}$-SE-L made with a $b f r$ gene and a linker region. 
Heterodimer Construct 1 (BFR-H1)

\begin{tabular}{|l|l|lll} 
Sacll HindIII \\
\hline BFR $^{1}$-SE & EcoRV & Ninker & BFR $^{1}$-NH \\
\hline
\end{tabular}

\section{Heterodimer Construct 2 (BFR-H2)}

\begin{tabular}{|l|lll} 
Sacll & EcoRV & Ndel & HindIII \\
\hline BFR ${ }^{1}$-SE & Linker & BFR $^{2}$-NH \\
\hline
\end{tabular}

Figure 2.8: The two different heterodimer constructs assembled in the pTE vector.

Once the two heterodimer constructs were made it was necessary to carry out two site directed mutations per construct. The linker region in all of the constructs encodes for a single histidine at each end of the linker (Figure 2.6). Due to the need to remove all solvent exposed histidines these were mutated to serine's using the Stratagene multi site-directed mutagenesis kit which enabled changing both residues in the one reaction. The following primers were used to carry out the mutations:

\section{Delta EcoRV - 3' CCGCCGCTGCCACCAGAATATCGACCTTCTTC 5'}

\section{Delta NdeI - 3' AGTATCACCTTTCATAGAACCACCAGAACCGCC 5'}

The mutation of both histidines to serines in the linker, removed the EcoRV and the NdeI cleavage sites (Figure 2.9) which made for easy verification of the successful mutants.

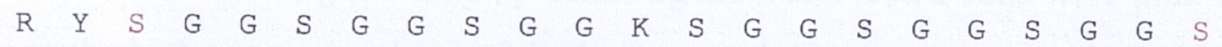
CGATATTCTGGTGGCAGCGGCGGTAGCGGAGGCAAGTCCGGTGGTAGCGGCGGTTCTGGTGGTTCT
}

Figure 2.9: Amino acid sequence and DNA sequence of the linker region after mutation of both histidines to serines. Both the EcoRV and the NdeI cleavage sites have been removed in the process. The mutated residues are shown in red. 
The final constructs contained only SacII and HindIII cleavage sites at the 5' and 3' ends respectively (Figure 2.10). Both constructs were cleaved from the pTE vector using SacII and HindIII, these genes were then gel purified in readiness for insertion into an expression vector.

Heterodimer Construct 1 (BFR-H1)

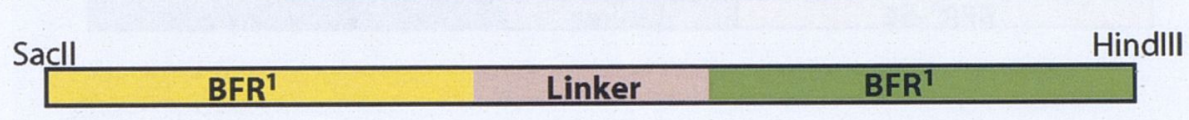

Heterodimer Construct 2 (BFR-H2)

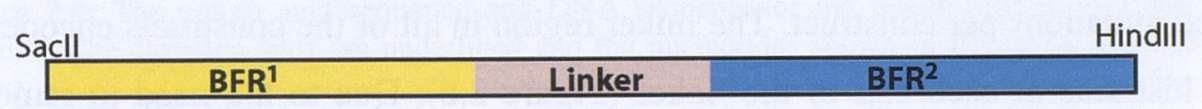

Figure 2.10: The final two heterodimer gene constructs after site-directed mutagenesis to remove the EcoRV and NdeI restriction sites.

The expression vector chosen was pHUE which was supplied as a gift by Spencer Whitney (Figure 2.11). The pHUE vector encodes for a selectable ampicillin resistance gene and has multiple restrictions sites. The construct is designed to express the gene of choice as a fusion protein with ubiquitin and a six histidine tag for ease of purification. The pHUE vector was cleaved with SacII and HindIIII, gel purified and then the two heterodimer gene constructs were ligated into separate vectors. The pHUE vectors were then transformed into E.coli BL21 cells ready for protein expression. 

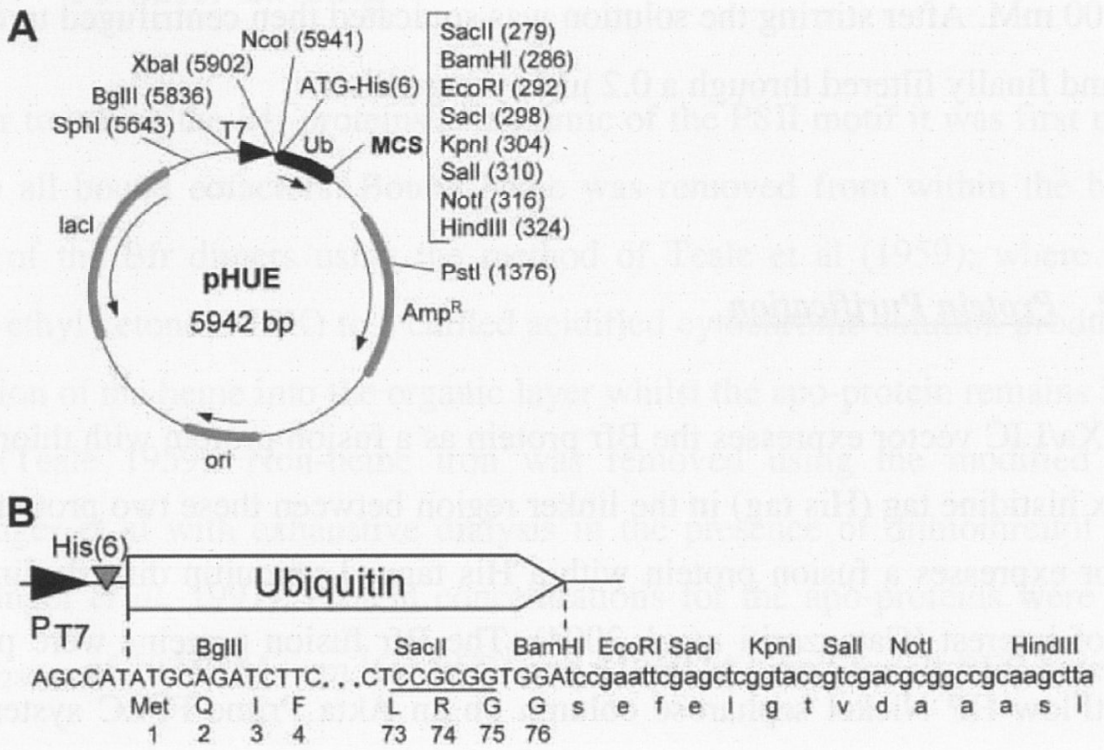

Figure 2.11: The Histidine-tagged Ubiquitin Expression vector, pHUE. (A) Plasmid map of pHUE showing the ubiquitin coding region (black box), restriction enzyme recognition sites within the multiple cloning site (MCS) and the selectable ampicillin resistance gene. Locations are given relative to the start codon upstream of the His-tag. (B) DNA and encoded protein sequence of the ubiquitin coding region showing the engineered SacII site (underlined). Figure adapted from (Catanzariti et al. 2004)

\subsection{Expression and Purification of All Constructs}

\subsubsection{Expression}

E.coli cells containing the pET32 or pHUE plasmid were grown in an $\mathrm{O} / \mathrm{N}$ culture then inoculated into LB media containing $50 \mu \mathrm{g} / \mathrm{ml}$ ampicillin. Cultures were grown at $37^{\circ} \mathrm{C}$ with air sparging to stir the culture and provide oxygen. The cultures were grown to an optical density of $\sim 0.5$ at $600 \mathrm{~nm}$ then induced with a final concentration of $1 \mathrm{mM}$ Isopropyl-thiol-galactose (IPTG) (Sigma). Induced cultures were grown for a further 5 hours before harvesting the cells by centrifugation. Harvested cells were pink in colour due to the high expression level of the heme containing protein (note: the M52H mutant produced normal coloured cells as the protein did not bind heme).

The pelleted cells were resuspended in buffer A $(50 \mathrm{mM}$ Tris- $\mathrm{HCl} \mathrm{pH} 8.0,500 \mathrm{mM}$ sodium chloride) and lysozyme was added to a final concentration of $1 \mathrm{mg} / \mathrm{ml}$. DNase 1 
(Boehringer Mannheim) was then added to a final concentration of $100 \mu \mathrm{g} / \mathrm{ml}$ and $\mathrm{MgSO}_{4}$ to $100 \mathrm{mM}$. After stirring the solution was sonicated then centrifuged to remove precipitate and finally filtered through a $0.2 \mu \mathrm{M}$ syringe filter.

\subsubsection{Protein Purification}

The $\mathrm{pET} 32 \mathrm{Xa} / \mathrm{LIC}$ vector expresses the $\mathrm{Bfr}$ protein as a fusion protein with thioredoxin and has a six histidine tag (His tag) in the linker region between these two proteins. The pHUE vector expresses a fusion protein with a His tagged ubiquitin directly linked to the protein of interest (Catanzariti et al. 2004). The Bfr fusion proteins were purified using a FastFlow HP Nickel sepharose column on an Akta Prime FPLC system (GE Healthcare). The column was equilibrated with buffer $\mathrm{A}$ and the clarified cell supernatant was loaded onto the column. The column was then washed with $95 \%$ buffer A, 5\% Buffer B (50 mM Tris- $\mathrm{HCl} \mathrm{pH} 8.0,500 \mathrm{mM}$ imidazole). Finally the Bfr proteins were eluted using $100 \%$ Buffer B. The purified Bfr fusion proteins eluted as a dark blood red solution due to the bound heme. The purified proteins were then dialysed using $5 \mathrm{kDa}$ cut-off dialysis tubing (Pierce) against tricine buffered saline (TBS) (25mM tricine, $100 \mathrm{mM} \mathrm{KCl}, \mathrm{pH} 7.7$ ) to remove all imidazole.

The purified fusion proteins were cleaved to remove all non-native amino acids using factor $\mathrm{Xa}(\mathrm{FXa})$ for the $\mathrm{pET} 32$ expressed proteins or with ubiquitin specific protease for the pHUE expressed proteins. The cleaved proteins were run on SDS-PAGE gels to determine completion of the cleavage reaction. Cleaved thioredoxin and ubiquitin were removed from the Bfr proteins by again running on a nickel sepharose column where they bound via the His tag and the protein of interest was collected in the flow through. In general the protein was not very concentrated so the volume was reduced by placing the dialysis tubing in high molecular weight polyethylene glycol (>10,000 MW) crystals to draw water from within the dialysis tubing. The proteins were considered to be pure at this stage as they existed as single bands on overloaded SDS-PAGE gels stained with coomassie brilliant blue. 


\subsection{Cofactor Binding}

In order to utilize the Bfr proteins as a mimic of the PSII motif it was first necessary to remove all bound cofactors. Bound heme was removed from within the hydrophobic pocket of the Bfr dimers using the method of Teale et al (1959); where addition of methyl ethyl ketone (MEK) to a chilled acidified cytochrome solution produces a phase separation of the heme into the organic layer whilst the apo-protein remains in the water phase (Teale 1959). Non-heme iron was removed using the modified method of Bauminger et al with exhaustive dialysis in the presence of dithiothreitol and EDTA (Bauminger et al. 1991). Protein concentrations for the apo-proteins were determined using $\varepsilon_{280 \mathrm{~nm}}$ of $20340 \mathrm{M}^{-1} \mathrm{~cm}^{-1}$ for BFR ${ }^{1}$ and $41960 \mathrm{M}^{-1} \mathrm{~cm}^{-1}$ for all BFR heterodimers.

\subsubsection{Spectroscopy}

CD spectroscopy was used to confirm the secondary structure of all proteins after cofactor removal. CD spectra were recorded on a Jobin Yvon type III+ spectrometer (Horiba, Japan). By comparison of the spectra with that of a standard set of proteins with known structures it is possible to deconvolute the spectra and assess secondary structure.

\subsubsection{Isothermal Titration Calorimetry}

Cofactor binding was monitored using isothermal titration calorimetry (ITC) which allows the accurate determination of binding constants $(K)$, reaction stoichiometries $(n)$, enthalpies $\left(\Delta \mathrm{H}^{\circ}\right)$, and entropies $\left(\Delta \mathrm{S}^{\circ}\right)$. Metal binding as well as porphyrin binding were all monitored with this technique. All measurements were carried out on a Microcal calorimeter at $25^{\circ} \mathrm{C}$ and the data was fit to a least squares model with the Microcal Origin fitting software. The heat of dilution was subtracted from the raw data prior to analysis. 
All samples were prepared in $25 \mathrm{mM}$ tricine, $100 \mathrm{mM} \mathrm{KCl} \mathrm{pH} \mathrm{7.7.} \mathrm{Manganese} \mathrm{binding}$ to BFR was measured by injecting $11 \mathrm{ul}$ aliquots of $900 \mu \mathrm{M} \mathrm{MnCl}_{2}$ into a $30 \mu \mathrm{M}$ solution of BFR. BFR binding to $\mathrm{ZnCe}_{6}$ was measured by injecting $11 \mu \mathrm{l}$ aliquots of $300 \mu \mathrm{M}$ BFR into a $15 \mu \mathrm{M}$ solution of $\mathrm{ZnCe}_{6}$.

The light active porphyrin $\mathrm{ZnCe}_{6}$ was prepared as a $2 \mathrm{mM}$ stock by the addition of zinc acetate to free base chlorin $\mathrm{e}_{6}$ dissolved in methanol, added in a 1:1 molar ratio with Zinc binding to the chlorin resulting in a UV-visible red shift in the Soret peak from 400 to $411 \mathrm{~nm}$ and a blue shift in the $\mathrm{Q}_{y}$ band from 661 to $632 \mathrm{~nm}$ (Razeghifard and Wydrzynski 2003). UV-Vis spectroscopy was carried out on a Cary 300 Spectrometer (Varian, USA). Solutions of $\mathrm{MnCl}_{2}$ for binding to $\mathrm{Bfr}$ were prepared fresh in TBS. Solutions of $\mathrm{FeSO}_{4}$ for titrations and iron oxidation assays, were prepared fresh in anaerobic water $\mathrm{pH} 4$ to prevent oxidation by oxygen.

\subsubsection{Covalent Attachment of Quinone's}

Quinones were covalently attached to cysteine residues in the mutant Bfr proteins using a modified method of Hay et al 2007. First the apo-protein was reduced with a 5 fold excess of DTT in $3 \mathrm{M} \mathrm{Gdn:HCl,} \mathrm{50mM} \mathrm{potassium} \mathrm{phosphate} \mathrm{(KPi)} \mathrm{pH} 8.0$ for 3 hours at RT. The Gdn:HCl and DTT were removed by gel filtration with a PD-10 column (GE Healthcare) and exchanged into $50 \mathrm{mM} \mathrm{KPi}, \mathrm{pH}$ 7.0. The protein concentration was then determined using Ellman's assay under denaturing conditions (6 M Gdn: $\mathrm{HCl}$ ) and using an $\varepsilon_{412 \mathrm{~nm}}$ of $13700 \mathrm{M}^{-1} \mathrm{~cm}^{-1}$. A 5-fold excess of quinone was reacted with the reduced protein in $50 \mathrm{mM} \mathrm{KPi}, \mathrm{pH} 7.0$ in the dark at room temperature for 2 hours. The protein-quinone solution was then dialysed in the dark at $4^{\circ} \mathrm{C}$ against a $50 \mathrm{mM} \mathrm{KPi} \mathrm{pH}$ 7.0 buffer containing quinone of interest (DMBQ $\mathrm{E}_{0} 133 \mathrm{mV}$ or naphthoquinone $\mathrm{E}_{0} 137$ $\mathrm{mV})$ and ferricyanide $\left(\mathrm{E}_{0}\right.$ of $436 \mathrm{mV}$ at $\left.\mathrm{pH} 7.0\right)$ at a $1: 1$ and 1:5 protein to oxidant mole ratio, respectively. The dialysis step should maximize the concentration of oxidized quinone-protein. After dialyzing overnight the dialysis buffer was changed to TBS. The quinone bound protein was then concentrated using PEG dehydration before aliquoting and freezing until further use. 


\subsection{Analysis}

\subsubsection{Oxygen Measurements}

All oxygen measurements were carried out at $25^{\circ} \mathrm{C}$ on an oxytherm Clarke-type oxygen electrode (Hansatech, UK) modified to contain a side illumination port. Oxygen measurements were carried out on samples containing $30 \mu \mathrm{M}$ BFR, $15 \mu \mathrm{M} \mathrm{ZnCe} 6,60$

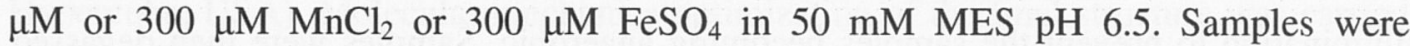
illuminated for long periods of time until oxygen uptake plateaued.

\subsubsection{Fluorescence Measurements}

All fluorescence measurements were made using a Fluoromax-3 (Jobin Yvon HORBIA) spectrofluorimeter. The fluorescence of $\mathrm{ZnCe}_{6}$ when bound to the various Bfr proteins was measured with a slit widths of $1 \mathrm{~nm}, 1$ second sampling time and a concentration of $2.5 \mu \mathrm{M}$ in $50 \mathrm{mM}$ MES buffer $\mathrm{pH}$ 6.5. Samples were excited at $427 \mathrm{~nm}$ after excitation and emission scans revealed that this excitation wavelength produced the maximal fluorescence at $660 \mathrm{~nm}$ ( $\mathrm{Q}_{y}$ band). Fluorescence was recorded from $575 \mathrm{~nm}$ to $775 \mathrm{~nm}$. These concentrations were in the linear range of the detector.

\subsubsection{Redox Measurements}

Cyclic voltammetry of $\mathrm{BFR}^{1}$ with cofactors bound was carried out on pyrolytic edge graphite electrodes at pH 7.75 in $25 \mathrm{mM}$ Tricine, $100 \mathrm{mM} \mathrm{KCl}$. A scan rate of $20 \mathrm{mVs}^{-1}$ was used to prevent hysteresis. After each scan the electrode was cleaned by scouring the surface then reapplying the protein solution and allowing to almost dry before carrying out the measurements. 


\subsubsection{EPR Measurements}

\section{Low Temperature EPR}

To examine light induced changes in oxidation state of the metal centre in BFR ${ }^{1}$ complexes, samples were prepared in the dark at room temperature then either left for one hour in the dark or illuminated for 1 hour. The long illumination time used coincided with the time taken for the oxygen uptake reactions to go to completion. Due to the concentrated nature of the samples they were stirred under pure oxygen during illumination to prevent the samples becoming anaerobic. Samples were then degassed and frozen to liquid nitrogen and stored until use. All samples were measured within 2448 hours. Samples were prepared in 50mM MES pH6.5 or in $25 \mathrm{mM}$ tricine, $100 \mathrm{mM}$ $\mathrm{KCl}$ pH 7.7 with $400 \mathrm{mM}$ sucrose added as cryoprotectant. Low temperature (5K) Xband EPR spectra were acquired on a Bruker ESP 300E spectrometer using either a TM011 cavity or a ER4116 dual mode cavity, perpendicular mode microwave frequency $9.6 \mathrm{GHz}$, parallel mode microwave frequency $9.3 \mathrm{GHz}$, modulation frequency $100 \mathrm{kHz}$. The EPR spectrum of each sample was collected in both parallel and perpendicular mode detection before and after photo-accumulation at room temperature or $200 \mathrm{~K}$.

\section{Room Temperature EPR}

X-band EPR spectra were acquired at room temperature on a Bruker ESP300E spectrometer equipped with a TM011 cavity. Generally the spectra were acquired at varying microwave power with $1-10 \mathrm{G}$ modulation amplitude and $100 \mathrm{KHz}$ modulation frequency. When necessary, the samples were excited with white light at room temperature via a non-magnetic optical fibre which allowed illumination within the sample cavity. The sample was placed in a flat cell which allowed better signal-to-noise and light-saturation. There was negligible UV-excitation in this set up.

\subsubsection{EPR Simulations}

Spectral simulations were solved numerically from a Hamiltonian ( 36 x 36 matrix) using Scilab-4.4.1, an open source vector-based linear algebra package (www.scilab.org). A least squares minimization routine was employed to find the 
optimal solutions for the parameters. A complete description of the EPR simulations can be found in chapter 3 .

\subsection{Molecular Modelling}

Molecular modelling of mutations was carried out with the aid of HyPERCHEM (v7.5 Hypercube, USA). Molecular mechanics optimization of the final structure was carried out using a Polak-Rebiere energy minimisation algorithm (conjugate gradient) in a periodic box. The heterodimer images were produced by including a 22 amino acid linker to the dimer structure and carry out molecular mechanics optimization of the linker sequence whilst bound to the protein structure. The electronic coupling and PATHWAYS calculations in porphyrin-protein-quinone complexes were carried out using HARLEM (HAmiltonians to Research LargE Molecules). Ray-traced images were prepared using PyMOL v0.99 (Delano Scientific, USA). 
Chapter 2. Methods

-40 - 


\section{CHAPTER 3}

\section{Bacterioferritin as a 'Reaction Centre'.}

\subsection{Introduction}

The essential catalytic elements of PSII that enable the oxidation of water to molecular $\mathrm{O}_{2}$ are redox coupled cofactors that include: (i) a strongly oxidizing chlorophyll in the reaction centre termed $\mathrm{P} 680$; (ii) a redox-active tyrosine termed $\mathrm{Y}_{\mathrm{Z}}$; and (iii) the oxygen evolving complex (OEC) consisting of four $\mu$-oxo bridged manganese ions and one calcium $\left(\mathrm{Mn}_{4} \mathrm{O}_{\mathrm{x}} \mathrm{Ca}\right)$ (Wydrzynski and Satoh 2005). The $\mathrm{P} 680$ provides the driving force $(\Delta \mathrm{G})$ for the reaction, the tyrosine is important for proton coupled electron transfer, and the OEC templates the $\mathrm{O}-\mathrm{O}$ bond formation. The one electron photochemistry of charge separation in the photosystem is linked to the four electron chemistry of water oxidation via the sequential oxidation of the $\mathrm{Mn}_{4} \mathrm{O}_{\mathrm{x}} \mathrm{Ca}$ (Wydrzynski and Satoh 2005).

The complexity of the PSII enzyme has thus far limited attempts to reverse engineer a synthetic water oxidase (Wydrzynski et al. 2007). Previous engineering efforts have concentrated on constructing biological motifs that mimic one aspect of the enzyme's mechanism, in particular porphyrin excitation/oxidation (Hay et al. 2004) and metal binding/complex formation (Thielges et al. 2005). Attempts have also been made to design 4-helix bundle proteins through de novo design (Koder and Dutton 2006). These approaches all faced limitations be it an overly complex system which is difficult to work with or limited size to introduce cofactors. Thus, in this work I considered a new approach to meet key design requirements in the production of an artificial photoactive protein with more than one functional element. A naturally occurring protein scaffold was used to bind several introduced redox active cofactors (Conlan 2008). In commencing this task the protein structure database was searched to find naturally occurring proteins which contain existing useful architecture so that cofactors could be placed within appropriate distances of each other. The design of a light activated redox enzyme had to take into consideration the physiological limitations of intra-protein electron transfer and as such all cofactors were placed within $<14 \AA$ of each other (Conlan 2008; Noy et al. 2006; Page et al. 1999; Page et al. 2003). 
In order to more closely mimic the reactions of PSII I have modified the bacterioferritin (BFR) protein to bind several redox active cofactors and initiate light-driven electron transfer. BFR is a soluble 4-helix bundle protein $(\sim 18.5 \mathrm{kDa})$ which naturally contains a di-iron metal site and a heme $b$ binding site (Andrews et al. 1995;Andrews et al. 1993;Davis et al. 1999). Removal of the native cofactors and replacement with manganese in the metal centre and a light active chlorophyll analogue -zinc chlorine within the heme binding site produce a protein with light dependent catalytic properties.

The natural synthesis/expression of the BFR protein results in a self-assembled quaternary structure that is somewhat analogous to a viral particle. The subunits oligomerise to produce a large spherical-shaped shell, made up of 12 homodimeric units, that enclose a hollow cavity with a diameter of $\sim 8 \mathrm{~nm}$ (Figure 3.1) (Moore 1991; Frolow et al. 1994; Harrison and Arosio 1996). The cavity normally stores iron as ferric oxide, hydroxide or phosphate minerals and is connected to the outer protein surface by channels. The natural protein shell thus binds 12 heme groups and 48 iron atoms (Frolow et al. 1994).

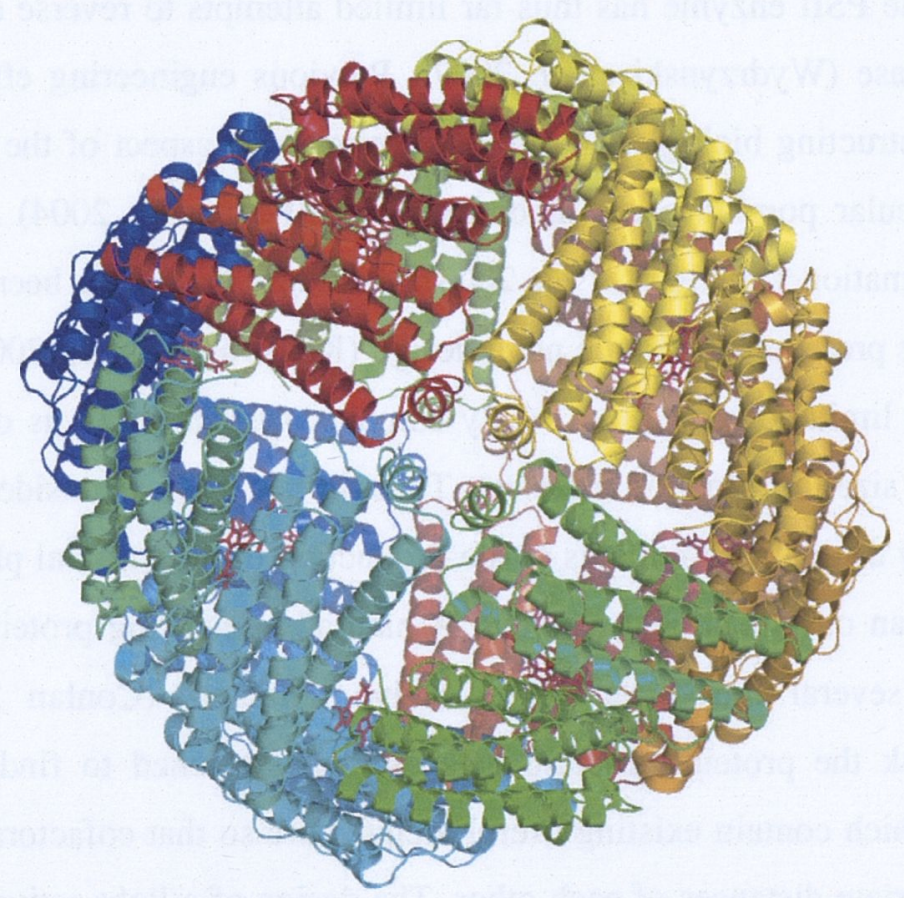

Figure 3.1: A ribbon diagram of the sphere structure formed by E.coli bacterioferritin (PDB 1BFR). The sphere is composed of twelve homodimers. 
The protein forms into a homodimer, binding a single heme group symmetrically at the interface between the two protein monomers (Frolow et al. 1994;LeBrun et al. 1995a). An atypical bis-axial ligation of the heme occurs through the sulphur atoms at equivalent methionyl positions (Met52) in each subunit (Cheesman et al. 1990; Frolow et al. 1994). The function of the heme is unknown but it appears to serve more than a structural role. The heme group can be removed (Teale 1959) and replaced with other similar structured but light active porphyrins (Conlan et al. 2007).

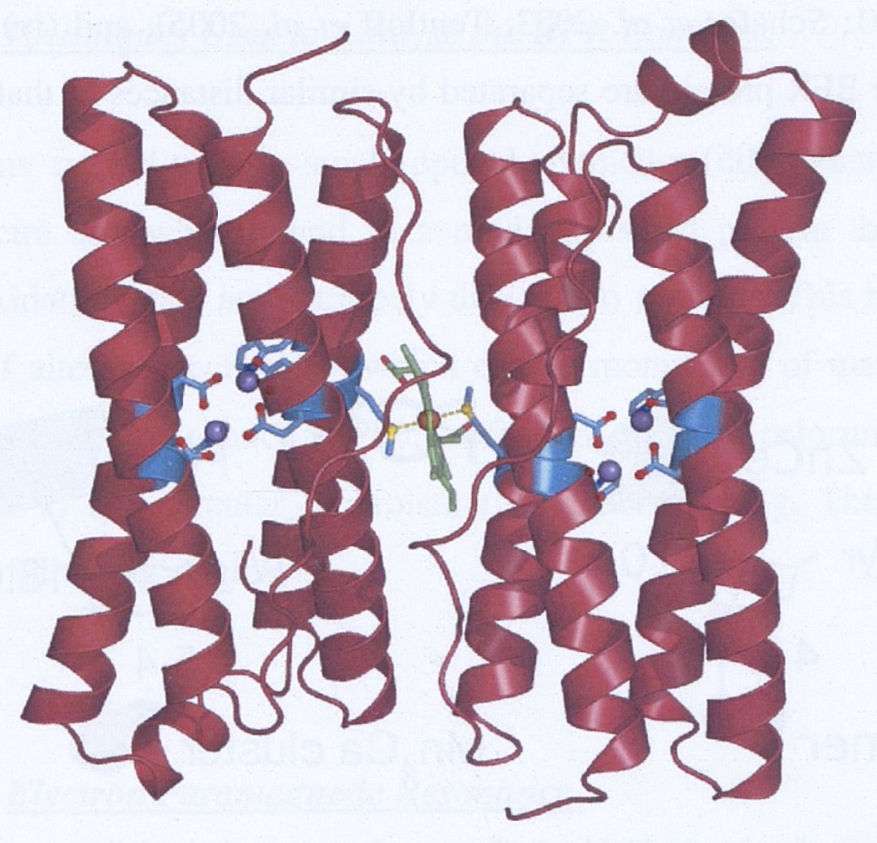

Figure 3.2: The BFR homodimer with two identical subunits each hosting dinuclear metal centres (purple spheres) and a heme (green) which is bound in a hydrophobic pocket at the subunit interface. Two manganese atoms bind per protein subunit. Adapted from the crystal structure (PDB file $1 \mathrm{BCF})$.

Bacterioferritin contains a binuclear metal binding site that links the four helices of the protein together and acts as a ferroxidase site, in which $\mathrm{Fe}^{\mathrm{II}}$ is oxidized to $\mathrm{Fe}^{\mathrm{III}}$ by $\mathrm{O}_{2}$ (LeBrun et al. 1995b). The two Fe ions are ligated to four glutamate residues (Glu18, Glu51, Glu94, Glu127, one from each helix) and two histidine residues (His54, His 130) (Dautant et al. 1998). Residues Glu51 and Glu127 form bridging carboxylate ligands between the two metal sites (di- $\mu-1,3$-caboxylato bridges), while Glu18 and Glu94 form monodentate carboxylate ligands to separate metal sites as do His54 and His139 via $\mathrm{N}^{\delta}$ nitrogen ligation. The organization of the di-iron binding site is very similar to other 
Chapter 3. Bacterioferritin as a 'Reaction Centre'.

class II di-iron proteins. The crystal structure for BFR was initially produced with two $\mathrm{Mn}^{\mathrm{II}}$ ions bound in the metal binding site (Dautant et al. 1998;Frolow et al. 1994) (Figure 3.2).

BFR presents an appealing starting point for engineering a multi-step, light-activated protein as: (i) it is a highly stable and robust protein (ii) the heme can be extracted and reconstituted (Teale 1959)or replaced with a photoactive chlorin (Hay et al. 2004); (iii) the binuclear metal site has similar structural ligation to the manganese catalase where the di-manganese site can reach an oxidation state of $\mathrm{Mn}_{2}{ }^{\mathrm{IIIV}}$ (Yoder et al. 2000; Barynin et al. 2001; Schafer et al. 2003; Teutloff et al. 2005); and (iv) the cofactors when bound to the BFR protein are separated by similar distances to that found in PSII (Figure 3.3) (Loll et al. 2005).
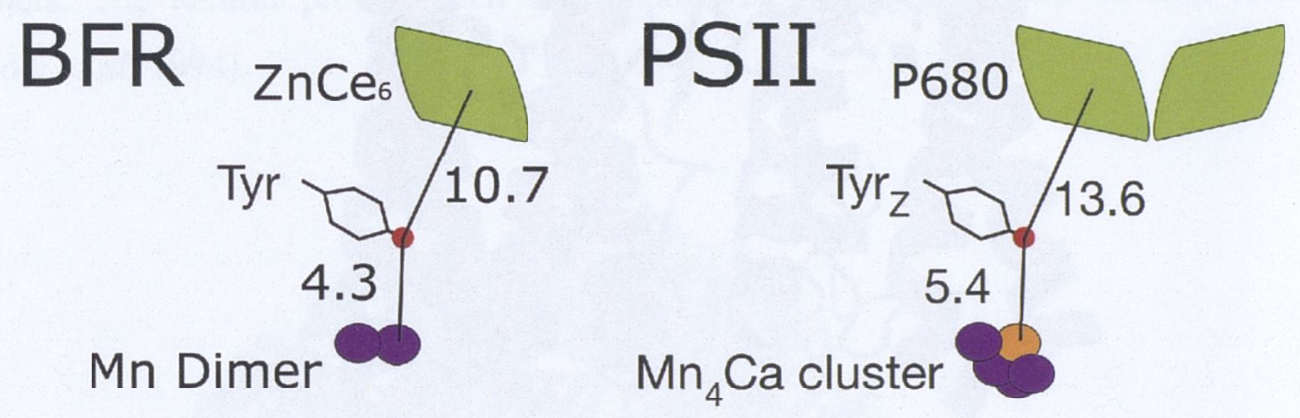

Figure 3.3: Schematic showing the highly similar crystal structure derived distances in $\AA$, between cofactors in the engineered BFR complex as compared to PSII.

Cofactor separation in the BFR protein matrix was an important design constraint as it is necessary for all cofactors to be situated within the protein with an edge-to-edge distance approaching $10 \AA$ (Figure 3.3). The tyrosine/Mn distance is notably shorter than the $\mathrm{ZnCe}_{6} /$ tyrosine distance and this is also found in PSII. In PSII the tyrosine acts as an intermediary for the stepwise oxidation of the Mn centre by P680 (Tommos and Babcock 1998; Haumann and Junge 1999; Ioannidis et al. 2008). This is an important consideration in the design of a photo-catalyst with a metal centre as the donor group. 


\subsubsection{Summary}

Here I report the construction of a light-activated metallo-catalyst, which can oxidize $\mathrm{Mn}^{\text {II }}$ to $\mathrm{Mn}^{\mathrm{III}}$ upon illumination with a tyrosine radical formed during the process. The light induced oxidation state changes were characterized by low temperature perpendicular and parallel mode X-band EPR spectroscopy and oxygen uptake measurements.

\subsubsection{Techniques Used to Analyse the BFR Complex.}

Manganese ions typically have small optical extinction coefficients in the UV-Vis electronic spectra and when bound to a moderate sized protein then changes in its ligation and oxidation state are extremely difficult to monitor. This has lead to the use of a number of alternate techniques which enable monitoring of manganese including electron paramagnetic resonance (EPR), isothermal titration calorimetry (ITC), cyclic voltammetry (CV) and circular dichroism (CD) spectroscopy. These techniques are outlined in the following section.

\subsubsection{Electron Paramagnetic Resonance.}

\section{Manganese CW EPR Properties}

EPR spectroscopy is a magnetic resonance technique which detects the transition between magnetic energy states for unpaired electrons in an applied magnetic field. It is a technique which is particularly useful for the detection of transition metal ions with unpaired d electrons. $\mathrm{Mn}^{\mathrm{II}}$ has 5 unpaired d electrons in the valence shell $\left(\mathrm{d}^{5}\right.$ ion) which give rise to long lived electron spin states and sharp EPR signals. $\mathrm{Mn}^{\mathrm{II}}$ has six possible orientations of electron spin $\left(\mathrm{M}_{\mathrm{s}}= \pm 5 / 2, \pm 3 / 2, \pm 1 / 2\right)$ in an external field yielding five fully allowed $\left(\Delta \mathrm{M}_{\mathrm{s}}= \pm 1\right) \mathrm{EPR}$ fine structure transitions. The $\mathrm{S}=5 / 2$ spin property of $\mathrm{Mn}^{2+}$ is further split by the $\mathrm{I}=5 / 2$ nuclear spin of $\mathrm{Mn}^{55}$. The hyperfine interaction between the electron spin and nuclear spin splits the energy levels into six sublevels corresponding to the six possible orientations of the ${ }^{55} \mathrm{Mn}$ nuclear spin. This sextet splitting is the EPR signature of mononuclear Mn sites. The combination of the electron 
spin of $5 / 2$ and the nuclear spin of $5 / 2$ leads to 36 energy levels and 30 allowed $\left(\Delta \mathrm{M}_{\mathrm{s}}=\right.$ $\pm 1, \Delta m_{\mathrm{I}}=0$ ) transitions. Rarely are all of the allowed transitions realized. In macromolecular complexes in solution the strong orientation dependence of all but the central $\left(M_{s}-1 / 2 \rightarrow 1 / 2\right)$ fine structure transition results in this transition being the dominant signal (Reed and Poyner 2000).

Dinuclear manganese centres are further complicated by the coupling between the unpaired electrons and the manganese nuclei. The presence of exchange interactions in spectra of dimanganese centres gives rise to multiline patterns for the ${ }^{55} \mathrm{Mn}$ hyperfine splitting. In most cases, the electron spin-spin interaction is mediated through bridging ligands and is therefore a form of super-exchange. The exchange is typically antiferromagnetic in such cases (Reed and Poyner 2000).

Conventional perpendicular mode EPR is well suited for the observation of half-integer spin systems (for example $\mathrm{Mn}^{\mathrm{II}}, \mathrm{Mn}^{\mathrm{IV}}$, coupled mixed-valent Mn clusters, and organic radicals), whereas parallel polarization $\mathrm{EPR}^{1}$ has been used for observing EPR signals issued from integer spin systems, in particular $\mathrm{S}=2$ (for example $\mathrm{Mn}^{\mathrm{III}}, \mathrm{Mn}_{2}{ }^{\mathrm{IIIIII}}$ ) (Hendrich and Debrunner 1988, 1989). Improved signals can be obtained for $\mathrm{Mn}^{\text {III }}$ complexes when the microwave magnetic field is applied parallel to the applied magnetic field, in contrast to the conventional perpendicular polarized EPR method (Dexheimer et al. 1989). EPR studies of $\mathrm{Mn}^{\mathrm{III}}$ in manganese superoxide dismutase (Campbell et al. 1999), di-manganese catalase (Whittaker et al. 2003), Photosystem II (Campbell et al. 2000), and in a $\mathrm{Mn}^{\mathrm{III}}$ salen compound (Campbell et al. 2001) have demonstrated that parallel polarization mode EPR can provide useful information on $\mathrm{Mn}^{\mathrm{III}}$ metal centres.

\footnotetext{
${ }^{1}$ In parallel mode the probing microwave magnetic field is rotated from the standard configuration perpendicular to the main magnetic field to a parallel orientation.
} 


\subsubsection{Circular Dichroism Spectroscopy}

Circular dichroism is a measurement of the difference in the absorption of left $\left(\mathrm{A}_{\mathrm{L}}\right)$ and right $\left(A_{R}\right)$ circularly polarised light as a function of wavelength:

$\Delta A=A_{L}-A_{R}$

A chiral molecule will absorb the two oppositely rotating light rays unequally. CD spectroscopy of proteins is an extremely powerful tool for assessing secondary structure. Although several amino acid side chains (notably Tyr, Trp, Phe, His, and Met) absorb light in the far-UV region of the spectrum (below $250 \mathrm{~nm}$ ), the most important contributor here is the peptide bond (amide chromophore), with $n \rightarrow \pi$ and $\pi \rightarrow \pi^{*}$ transitions at $\sim 220$ and $\sim 190 \mathrm{~nm}$, respectively. The far-UV CD bands of proteins reflect the secondary structure of the protein ( $\alpha$-helix, $\beta$-sheet, $\beta$-turn, and unordered content).

The spectrum is converted to the desired units. In the case of proteins, the observed CD signal, $\mathrm{S}$ in millidegrees (Note: 1 millidegree $=32,980 \Delta \mathrm{A}$ ), is generally converted to the molar $\mathrm{CD}$ extinction coefficient $(\Delta \varepsilon)$ :

$$
\Delta \varepsilon=\frac{S}{32980 \times C_{M} \times L}
$$

where $L$ is the path length (in $\mathrm{cm}$ ), $C_{M}$ is the molar concentration, $\mathrm{C}_{\mathrm{mg} / \mathrm{ml}}$ is the concentration in $\mathrm{mg} / \mathrm{ml}$.

All- $\alpha$ proteins show an intense negative bands between $\sim 203-240 \mathrm{~nm}$ with minima at 209-222 $\mathrm{nm}$. The intensities of these bands reflect $\alpha$-helical content. The spectra of regular all- $\beta$ sheet proteins are significantly weaker than those of all- $\alpha$ helix proteins. These spectra usually display minima between 210 and $225 \mathrm{~nm}$ and maxima between 190-200 nm.

Unordered peptides and denatured proteins have a strong negative band (at 195-200 $\mathrm{nm}$ ) and a much weaker band (which can be either positive or negative) between 215 
and $230 \mathrm{~nm} . \alpha+\beta$ and $\alpha / \beta$ proteins almost always have spectra dominated by the $\alpha-$ helical component and therefore often show bands at 222, 208, and 190-195 nm. In some cases, there may be a single broad minimum between 210 and $220 \mathrm{~nm}$ because of overlapping $\alpha$-helical and $\beta$-sheet contributions (Martin and Schilstra 2008).

When a mutant protein is produced using recombinant DNA technology it is important to demonstrate that its has the same overall structure as the wild-type protein. Comparison of the near and far-UV CD spectra is ideal for this purpose. A significant difference in shape between the far-UV CD spectra of the wild-type and mutant proteins can be an indication that the mutation has produced some change in the secondary structure (Martin and Schilstra 2008).

\subsubsection{Isothermal Titration Calorimetry}

ITC provides a complete thermodynamic profile of the molecular interaction between a ligand and a macromolecule. This technique monitors the binding of a ligand to a macromolecule by measuring the heat released or absorbed when the two species interact. The enthalpy of binding is directly measured as the integrated area under the injection peak. By performing a series of injections until the macromolecule is saturated, the binding constant and the entropy of the interaction can be determined (Ladbury and Chowdhry 1996; Pierce et al. 1999; Leavitt and Freire 2001).

The calorimeter outputs a series of injection peaks, proportional to the energy input needed to compensate for the heat evolved or adsorbed upon ligand binding. The area of the peak is directly related to the enthalpy of ligand binding to the macromolecule. The association constant $(\mathrm{Ka})$ determines the amount of bound and unbound ligand after each injection. As the concentration of ligand increases the amount of complex formed decreases until all binding sites are filled. The amount of heat adsorbed or evolved (Q) upon binding is given as:

$Q=\left[\frac{V_{O} \times \Delta H_{a p p} \times[M]_{t o t} \times K_{a} \times[L]}{1+K_{a}[L]}\right]$ 
where $\mathrm{V}_{0}$ is the cell volume, $\Delta \mathrm{H}_{\text {app }}$ is the enthalpy of binding per mol of ligand, $[\mathrm{M}]_{\text {tot }}$ is the total macromolecule concentration including both the bound and free states, and [L] is the concentration of free ligand. The enthalpy of binding is measured along with the enthalpy of dilution. Dilution effects are usually small but are subtracted as a baseline. Binding models which estimate the $\mathrm{K}_{\mathrm{a}}$ and ligand stoichiometry (n) are fitted using a least squares model for ligand-macromolecule complexes assuming either a single set of identical sites, two sets of independent sites, or multiple sequential sites. $\mathrm{K}_{\mathrm{a}}$ for a reversible interaction is given by:

$$
K_{a}=\frac{[M L]}{[M][L]}
$$

where $[\mathrm{M}],[\mathrm{L}]$ and $[\mathrm{ML}]$ are the concentrations of the macromolecule, ligand and complex, respectively. The $\mathrm{K}_{\mathrm{a}}$ is determined by applying a linear regression model to the plot of $\Delta \mathrm{H}_{\text {bind }} \mathrm{vs.}$ molar ratio. The change from a free molecule to a complexed state produces loss of solvent-ligand and solvent-macromolecule interactions and gain of ligand-macromolecule interactions. The free energy of binding $\left(\Delta \mathrm{G}_{\text {bind }}\right)$ is the total thermodynamic effect of these changes. $\Delta \mathrm{G}_{\mathrm{bind}}$ is determined by the $\mathrm{K}_{\mathrm{a}}$ :

$\Delta G_{b i n d}=-R T \ln K_{a}$ Equation 3-3

$\Delta \mathrm{G}_{\text {bind }}$ has contributions from the binding enthalpy $\left(\Delta \mathrm{H}_{\text {bind }}\right)$ and the binding entropy $\left(\Delta \mathrm{S}_{\text {bind }}\right)$ :

$\Delta G=\Delta H-T \Delta S$

\section{Equation 3-4}

Binding is favoured by a negative $\Delta \mathrm{G}_{\text {bind }}$. The $\Delta \mathrm{H}_{\text {bind }}$ reflects the strength of interaction between ligand and macromolecule, relative to their interaction with the solvent. A favourable enthalpy term comes from a gain of interactions through the formation of the complex. The $\Delta \mathrm{S}_{\text {bind }}$ has a favourable contribution to the interaction when solvent molecules, which were restricted by interaction with the macromolecule and ligand, are released. The increase in entropy from freedom of the solvent molecules is offset by the loss of conformational freedom of the ligand and macromolecule. 


\subsubsection{Cyclic Voltammetry}

Cyclic voltammetry (CV) is an electrochemical method for determining redox potentials and uses microelectrodes attached to a potentiostat and carried out in quiescent solution to ensure diffusion control. A three-electrode arrangement is used: working vs. counter vs. reference electrode. This technique is based on varying the applied potential to a working electrode in both forward and reverse directions (at some constant scan rate) while measuring the current. The forward scan produces a current peak for any analytes that can be reduced through the range of the potential scan. The current will increase as the potential reaches the reduction potential of the analyte, but then fall off as the concentration of the analyte is depleted close to the electrode surface. As the applied potential is reversed, it will reach a potential that will reoxidise the product formed in the first reduction reaction, and produce a current of reverse polarity from the forward scan. This data is then plotted as current $(i)$ vs. potential $(E)$.

The important parameters in a cyclic voltammogram are the peak potentials $\left(E_{p c}, E_{p a}\right)$ and peak currents $\left(i_{p c}, i_{p a}\right)$ of the cathodic and anodic peaks, respectively. If the electron transfer process is fast compared with other processes (such as diffusion), the reaction is said to be electrochemically reversible, and the peak separation is:

$$
\Delta E_{p}=\left\lfloor E_{p a}-E_{p c}\right\rfloor=2.303 \cdot R T \cdot n F
$$

Equation 3-5

Thus, for a reversible redox reaction at $25^{\circ} \mathrm{C}$ with $n$ electrons $\Delta E_{p}$ should be $0.0592 / n \mathrm{~V}$ or $59 \mathrm{mV}$ for one electron. In practice this value is difficult to attain because of factors such as cell resistance. Irreversibility due to a slow electron transfer rate results in $\Delta E_{p}>$ $0.0592 / n \mathrm{~V}$, such that the difference is typically $70-100 \mathrm{mV}$ for a one-electron reaction. The formal reduction potential $\left(E^{0}\right)$ for a reversible couple is given by:

$$
E^{0}=\frac{\left(E_{p c}+E_{p a}\right)}{2}
$$




\subsection{Results}

\subsubsection{Cofactor Assembly in Bacterioferritin.}

The BFR proteins were over expressed in E.coli, before purification on a metal affinity column. The purified protein then had the histidine tag cleaved using FXa protease. The cleaved protein was then purified from the tag again using metal affinity chromatography. The expressed proteins were red in colour due to a heme group bound at the interface of the homodimeric subunits in a hydrophobic pocket. UV-visible spectroscopy reveals the characteristic bands found for heme bound via two methionine residues in E.coli bacterioferritin (Figure 3.4) (Yariv et al. 1981). The oxidised and reduced forms of $\mathrm{BFR}^{1}$ and wild-type BFR have identical spectra with the Soret maxima at $418 \mathrm{~nm}$ and red shifting to $425 \mathrm{~nm}$ upon reduction with sodium dithionite. Two characteristic Q bands are found for the bound heme in its oxidized form at 561 and $531 \mathrm{~nm}$ shifting to 558 and $528 \mathrm{~nm}$ when reduced.

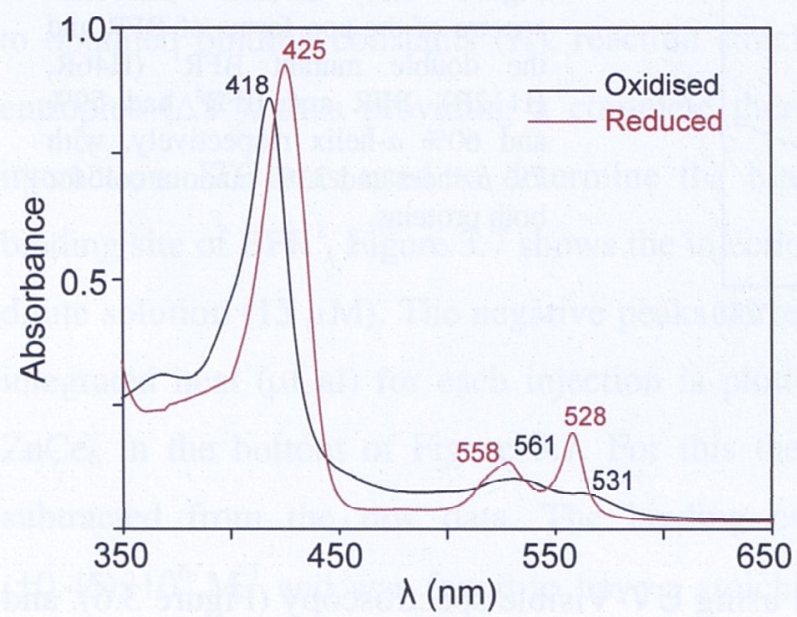

Figure 3.4: UV-visible spectra of $\mathrm{BFR}^{1}$ in its oxidised form (black) and reduced form (red). Wild type BFR produced the same spectra but is not shown for clarity.

\section{$\mathrm{ZnCe}_{6}$ Binding to $\mathrm{BFR}^{I}$}

Previous work has shown that $\mathrm{ZnCe}_{6}$ will bind at the heme site of cytochrome $\mathrm{b}_{562}$ via axial ligation to histidine (Hay et al. 2004). BFR has two surface exposed histidines at positions 46 and 112. To prevent non-specific binding these two residues were replaced 
with arginines. The secondary structure and binding of $\mathrm{ZnCe}_{6}$ to the double mutant $\left(\mathrm{BFR}^{1}\right)$ was identical to the wild type as probed by UV-Vis and Circular Dichroism (CD) spectroscopy (Figure 3.5).

The wild-type BFR and the $\mathrm{BFR}^{1}$ double mutant was analysed with $\mathrm{CD}$ spectroscopy (Figure 3.5) to contain 59\% and $60 \% \alpha$-helix respectively, with $7 \% \beta$-sheet and $33 \%$ random coil for both proteins. BFR ${ }^{1}$ was also found to still form the spherical $\sim 444 \mathrm{kDa}$ dodecamer of dimers as measured by native gel electrophoresis. Thus for all the remaining experiments $\mathrm{BFR}^{1}$ was used. The nomenclature employed throughout this thesis is as follows: $\mathrm{BFR}^{1}$ (BFR ${ }^{1}$ devoid of all cofactors), $\mathrm{BFR}^{1}-\mathrm{M}$ (BFR ${ }^{1}$ with two Mnions bound), $\mathrm{BFR}^{1}-\mathrm{Z}\left(\mathrm{BFR}^{1}\right.$ with $\mathrm{ZnCe}_{6}$ bound) or $\mathrm{BFR}^{1}-\mathrm{ZM}\left(\mathrm{BFR}^{1}\right.$ with $\mathrm{Mn}$ and $\mathrm{ZnCe}_{6}$ bound).

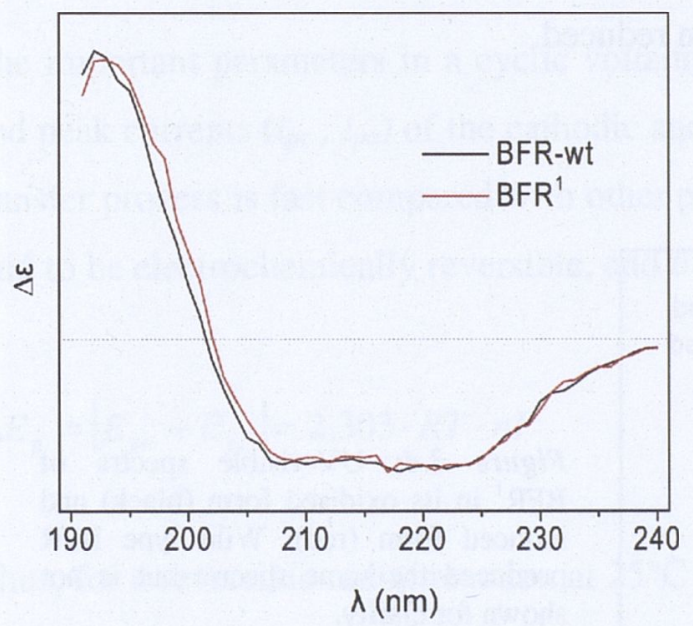

Figure 3.5: Circular dichroism spectra of the apo forms of BFR and the double mutant $\mathrm{BFR}^{1}(\mathrm{H} 46 \mathrm{R}$, H112R). BFR and $\mathrm{BFR}^{1}$ had $59 \%$ and $60 \% \alpha$-helix respectively, with $7 \% \beta$-sheet and $33 \%$ random coil for both proteins.

$\mathrm{BFR}^{1}$ cofactor binding was monitored using UV-Visible spectroscopy (Figure 3.6). and shows the spectra of $\mathrm{ZnCe}_{6}$ titrated into a solution of $\mathrm{BFR}^{1}$. Binding $\mathrm{ZnCe}_{6}$ to $\mathrm{BFR}^{1}$ produces a $\sim 7 \mathrm{~nm}$ shift in the absorbance maxima of the $\mathrm{Q}_{y}$ band of the unbound $\mathrm{ZnCe}_{6}$ from 632 to $639 \mathrm{~nm}$ in the bound protein. Monitoring of this absorption shift upon titration of $\mathrm{ZnCe}_{6}$ into a solution of $\mathrm{BFR}^{1}$ obtained an association constant $\left(\mathrm{K}_{\mathrm{a}}\right)$ of $1.2 \times 10^{6}$. As a control a BFR mutant in which the axial heme ligating M52 was converted to H52 was also measured. This mutant correctly assembled and was capable of oxidizing iron. As expected, no absorbance shift of the chlorin $\mathrm{Q}_{y}$ band was observed, 
suggesting the $\mathrm{ZnCe}_{6}$ can no-longer bind to the BFR. This observation corresponds to the heme binding activity of BFR M52H previously reported by Andrews and coworkers (Andrews et al. 1995).

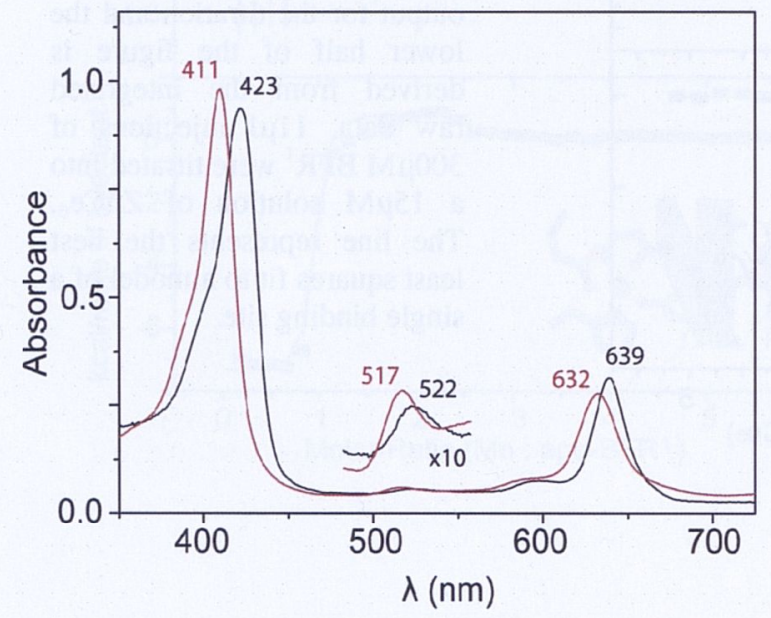

Figure 3.6: UV-visible spectra of $\mathrm{ZnCe}_{6}$ free in solution (red) and bound to $\mathrm{BFR}^{1}$ (black).

$\mathrm{BFR}^{1}$ cofactor binding was also monitored using isothermal titration calorimetry (ITC) to obtained binding constants $(\mathrm{K})$, reaction stoichiometries $(\mathrm{n})$, enthalpies $\left(\Delta \mathrm{H}^{\circ}\right)$, and entropies $\left(\Delta \mathrm{S}^{\circ}\right)$, thus providing a complete thermodynamic profile of the molecular interaction. ITC was used to determine the binding affinity of $\mathrm{ZnCe}_{6}$ to the heme binding site of $\mathrm{BFR}^{1}$. Figure 3.7 shows the injection heat for $\mathrm{BFR}^{1}$ titrated into $\mathrm{ZnCe}_{6}$ in dilute solution $(15 \mu \mathrm{M})$. The negative peaks correspond to an exothermic reaction. The integrated heat $(\mu \mathrm{Cal})$ for each injection is plotted over the molar ratio of protein to $\mathrm{ZnCe}_{6}$ in the bottom of Figure 3.7. For this the heat of dilution of the protein was subtracted from the raw data. The binding constant was determined to be 2.54 $( \pm 0.45) \times 10^{6} \mathrm{M}^{-1}$ and was found to have a stoichiometry of $0.82 \mathrm{ZnCe}_{6}$ molecules per $\mathrm{BFR}^{1}$ dimer. All parameters are reported in Table 3.1. 


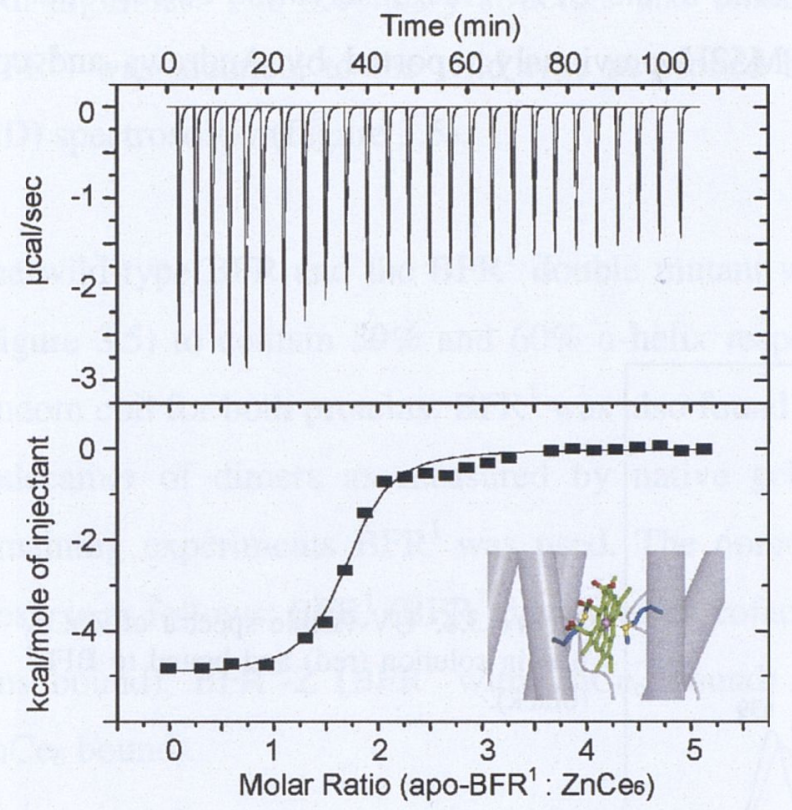

Figure 3.7: Calorimetric titration of $\mathrm{BFR}^{1}$ into a solution of $\mathrm{ZnCe}_{6}$. The top of the figure is the raw ITC output for the titration and the lower half of the figure is derived from the integrated raw data. $11 \mu 1$ injections of $300 \mu \mathrm{M} \mathrm{BFR}^{1}$ were titrated into a $15 \mu \mathrm{M}$ solution of $\mathrm{ZnCe}_{6}$. The line represents the best least squares fit to a model of a single binding site.

\section{Mn Binding to $B F R^{1}$}

$\mathrm{Mn}^{\mathrm{II}}$ binding to $\mathrm{BFR}^{1}$ was measured using ITC. Figure 3.8 shows the injection heat for $\mathrm{Mn}^{\mathrm{II}}$ titrated into a solution of $\mathrm{BFR}^{1}$. Analysis of the integrated heat using the best fit of a least squares model for two independent binding sites (Table 3.1) revealed that BFR ${ }^{1}$ has both a high affinity $\mathrm{Mn}$ site $\left(\mathrm{K}_{\mathrm{a} 1} 1.54( \pm 0.39) \times 10^{9} \mathrm{M}^{-1}\right)$ and a second lower affinity site $\left(\mathrm{K}_{\mathrm{a} 2} 4.31( \pm 1.09) \times 10^{6} \mathrm{M}^{-1}\right)$. Titrations of $\mathrm{Mn}$ into $\mathrm{BFR}^{1}$ showed that binding of the first metal ion to site 1 is an exothermic process, while binding to the lower affinity site 2 is an endothermic process (Figure 3.8). According to the ITC fitting an average of 2.5 $( \pm 0.12)$ moles of $\mathrm{Mn}$ ions bind per mole of $\mathrm{BFR}^{1}$. 


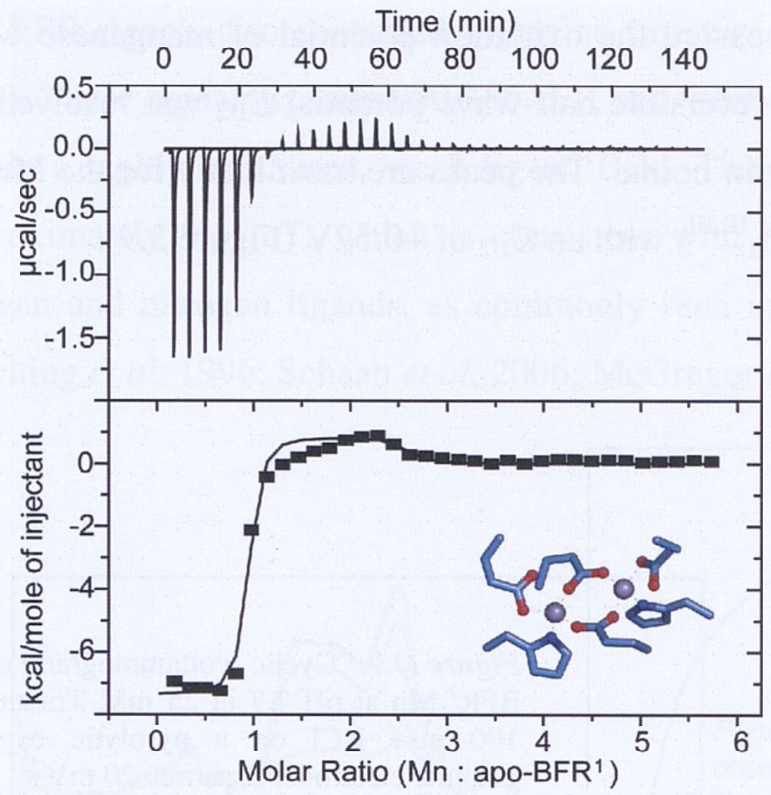

Figure 3.8: Calorimetric titrations of $\mathrm{MnCl}_{2}$ into a solution of $\mathrm{BFR}^{1}$. The top of the figure is the raw ITC output for the titration and the lower half of the figure is derived from the integrated raw data. $11 \mu 1$ injections of $900 \mu \mathrm{M} \mathrm{MnCl}{ }_{2}$ were titrated into a $30 \mu \mathrm{M}$ solution of $\mathrm{BFR}^{1}$. The line represents the best least squares fit to a model of two independent binding sites.

Table 3.1: Best fit parameters for ITC measurements of $\mathrm{BFR}^{1}$ cofactor binding

a. Mn titrated into $\mathrm{BFR}^{1}$

\begin{tabular}{|c|c|c|c|c|}
\hline & $\mathrm{n} / \mathrm{BFR}^{1}$ & $\mathrm{~K}_{\mathrm{a}}\left(\mathrm{M}^{-1}\right)$ & $\begin{array}{c}\Delta \mathrm{H}_{\text {bind }} \\
\left(\mathrm{Kcal} \mathrm{mol}^{-1}\right)\end{array}$ & $\begin{array}{c}\Delta S \\
\left(K_{c a l ~ M}{ }^{-1}\right)\end{array}$ \\
\hline $\mathrm{Mn}_{1}$ & $0.88 \pm 0.01$ & $1.54( \pm 0.39) \times 10^{9}$ & $-7380 \pm 116$ & 17.3 \\
\hline $\mathrm{Mn}_{2}$ & $1.64 \pm 0.11$ & $4.31( \pm 1.09) \times 10^{6}$ & $860 \pm 87$ & 33.2 \\
\hline \multicolumn{5}{|c|}{ b. $\mathrm{BFR}^{1}$ titrated into $\mathrm{ZnCe}_{6}$} \\
\hline & $\mathrm{n} / \mathrm{ZnCe}_{6}$ & $\mathrm{~K}_{\mathrm{a}}\left(\mathrm{M}^{-1}\right)$ & $\begin{array}{c}\Delta \mathrm{H}_{\mathrm{bind}} \\
\left(\mathrm{Kcal} \mathrm{mol}^{-1}\right)\end{array}$ & $\begin{array}{c}\Delta S \\
\left(K_{c a l ~ M^{-1}}\right)\end{array}$ \\
\hline $\mathrm{BFR}^{1}$ & $1.64 \pm 0.02$ & $2.54( \pm 0.45) \times 10^{6}$ & $-4956 \pm 89$ & 12.7 \\
\hline
\end{tabular}

$a$. Fit to best least squares model of two independent binding sites.

$b$. Fit to best least squares model of a single binding site. 


\section{Cyclic Voltammetry of $B F R^{1}-M$}

Cyclic voltammetry was used to measure the oxidation potential of manganese when bound to the $\mathrm{BFR}^{1}$ protein. A semi-reversible half-wave potential $E_{1 / 2}$ was resolved for the $\mathrm{BFR}^{1}-\mathrm{M}$ protein with no porphyrin bound. The peaks are most likely for the $\mathrm{Mn}_{2}{ }^{\text {IIIII }}$ to $\mathrm{Mn}_{2}{ }^{\text {II,III }}$ transition (or possibly $\mathrm{Mn}_{2}{ }^{\text {III,III) }}$ ) with an $E_{1 / 2}$ of $+0.52 \mathrm{~V}$ (Figure 3.9).

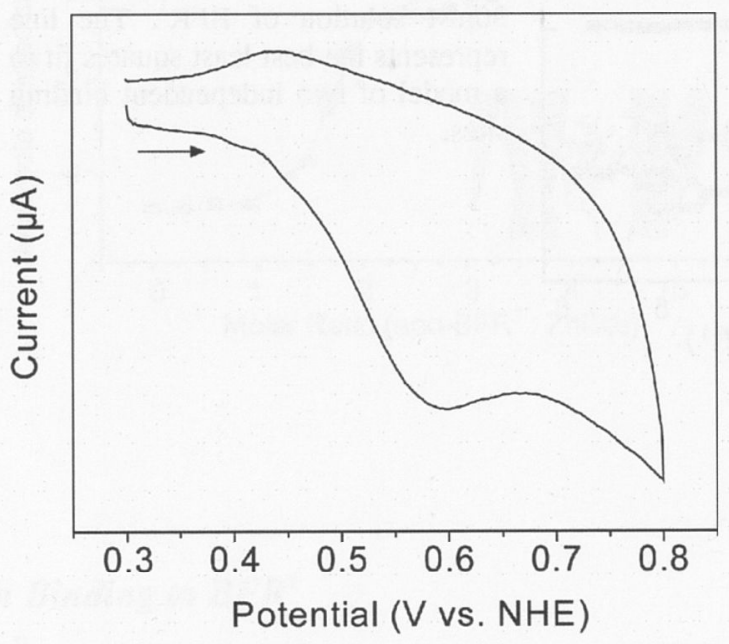

Figure 3.9: Cyclic voltammogram of $\mathrm{BFR}^{1}-\mathrm{Mn}$ at $\mathrm{pH} 7.7$ in $25 \mathrm{mM}$ Tricine, $100 \mathrm{mM} \mathrm{KCl}$ on a pyrolytic edge graphite electrode. Scan rate $20 \mathrm{mV} \mathrm{s}^{-1}$.

\subsection{2. $\quad$ EPR Spectroscopy}

EPR measurements were undertaken to determine the oxidation state of manganese bound to the bacterioferritin protein and their coupling environment.

\subsubsection{Simulated $M n^{I I}$ Dimer Line-Shapes}

\section{$\mathrm{Mn}^{I I}\left(S_{1,2}=5 / 2\right)$ dimer (without $\left.\mathrm{ZnCe}_{6}\right)$}

EPR spectra of $\mathrm{BFR}^{1}$ titrated with two $\mathrm{Mn}$ ions per protein molecule revealed a broad signal ( $400 \mathrm{mT}$ wide), dominated by a large structured $\mathrm{g}=2$ derivative; at least 5 turning points were observed (Figure 3.10). The non-Curie temperature dependence of this signal suggested that it arises from an even spin antiferromagnetically coupled system, most likely a $\mathrm{Mn}_{2}{ }^{\text {IIII }}$ dimer (Figure 3.11 Right) (Khangulov et al. 1990; Pessiki et al. 1994; Howard et al. 2000; Epel et al. 2005). 
The EPR signals also contained hyperfine structure centred at $\mathrm{g}=4.5$ and $\mathrm{g}=9.8$ (Figure 3.10). These signals spanned 50-185 $\mathrm{mT}$, and were assigned to monomeric $\mathrm{Mn}^{\mathrm{II}}$ bound within a highly structured, weak ligand field. The hyperfine splitting of this signal is approximately $9.5 \mathrm{mT}$, which is consistent with $\mathrm{Mn}^{\mathrm{II}}$ coordinated octahedrally with oxygen and nitrogen ligands, as commonly seen in a number of manganese enzymes (Whiting et al. 1996; Schaab et al. 2006; McGregor et al. 2007).

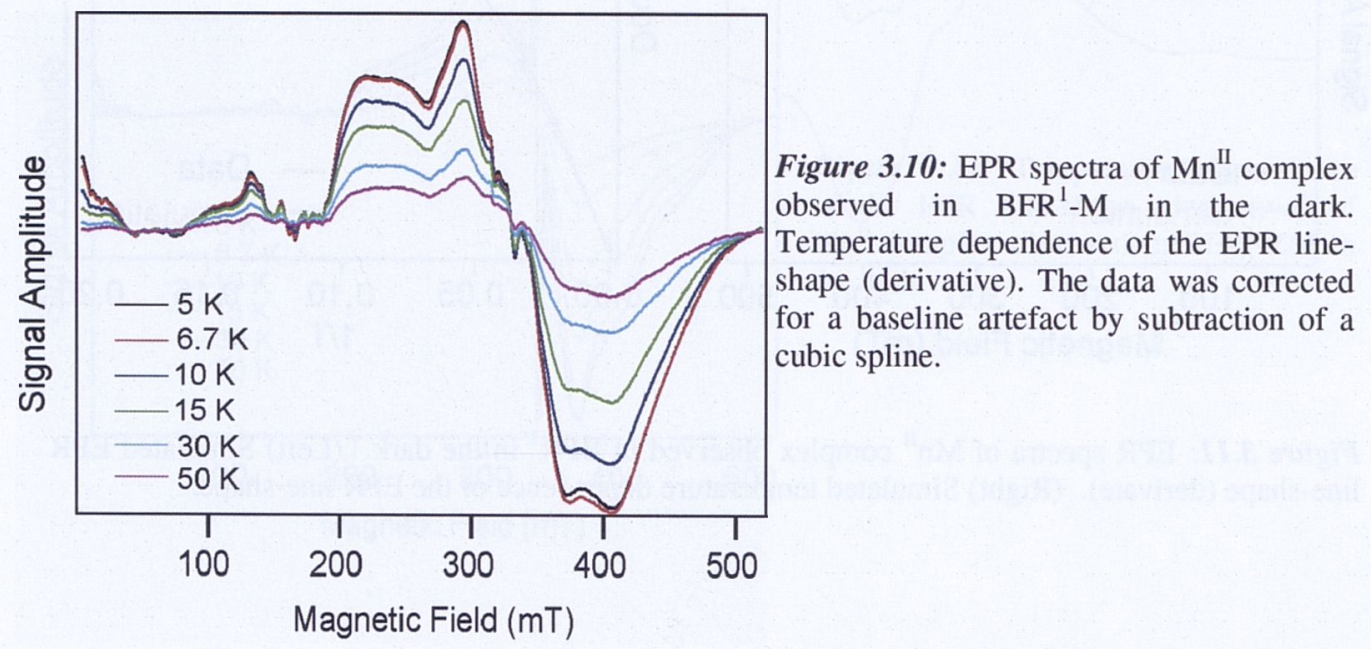

The line-shape of $\mathrm{Mn}^{\mathrm{II}}$ dimer remained constant for temperatures up to $50 \mathrm{~K}$ (Figure 3.10), which suggests the energy-level spacing's within the dimer and by inference the exchange/dipolar coupling between the two metal centres must be small. That is to say, that as the manifold of energy-states are not well separated, all energy-states have the same population over the temperature range $(5-50 \mathrm{~K})$ used in this study; therefore, entropy dominates.

EPR simulations using the Spin Hamiltonian formalism of the line-shape and temperature dependence of the $\mathrm{Mn}_{2}$ IIII signal were undertaken to estimate the exchange/dipole couplings and zero-field parameters for this system. These calculations are described in detail below. The simulated line-shape for the $\mathrm{Mn}^{\mathrm{II}}$ dimer is shown in Figure 3.11 (left). It correctly predicts/models all 5 turning points of the experimental spectrum. The corresponding simulation of the temperature dependence of the $\mathrm{Mn}^{\mathrm{II}}$ 
dimer is quantitatively consistent with the experimental data (Figure 3.11 right). An improvement to the fit can be achieved by allowing the line-width along each of the principle axes to vary (simulation not shown).
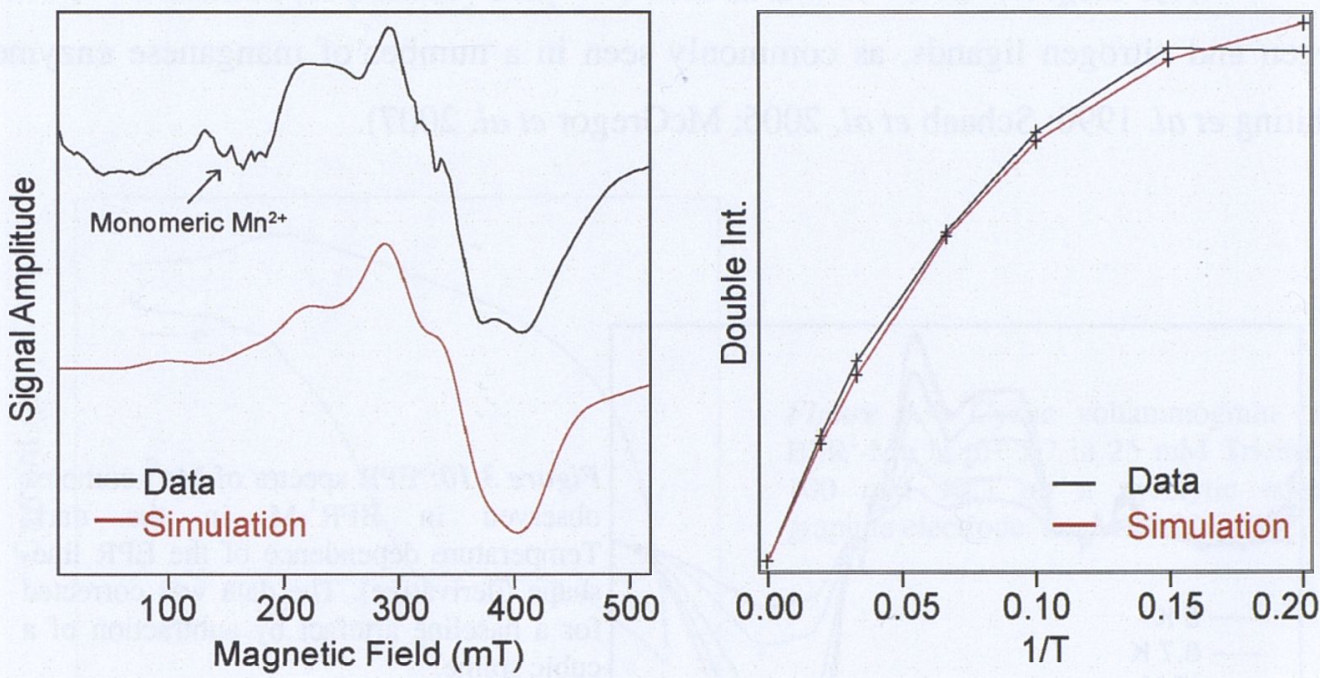

Figure 3.11: $\mathrm{EPR}$ spectra of $\mathrm{Mn}^{\mathrm{II}}$ complex observed in $\mathrm{BFR}^{1}$ in the dark. (Left) Simulated EPR line-shape (derivate). (Right) Simulated temperature dependence of the EPR line-shape.

Optimized parameters for this simulation can be found in Table 3.2. The exchange coupling between the two metal centres was estimated to be $1.3 \mathrm{~K}\left(0.9 \mathrm{~cm}^{-1}\right)$ and is therefore of the order of the microwave quantum $(9 \mathrm{GHz}, 0.43 \mathrm{~K})$. The estimated $\mathrm{Mn}$ Mn distance $(\sim 4 \AA)$ is commensurate with crystallographic evidence ${ }^{2}$. Both $D$ values (for either $\mathrm{Mn}_{1}$ or $\mathrm{Mn}_{2}$ ) are small, typical for a $\mathrm{Mn}^{\mathrm{II}}$ high $\operatorname{spin}(\mathrm{S}=5 / 2)$ centre (Dismukes 1996; Golombek and Hendrich 2003; Epel et al. 2005). The simulation suggests one of the $\mathrm{Mn}$ (here referred to here as $\mathrm{Mn}_{\mathrm{A}}$ ) occupies a more highly structured ligand environment, whereas the second $\mathrm{Mn}$ environment $\left(\mathrm{Mn}_{\mathrm{B}}\right)$ is virtually isotropic.

${ }^{2}$ As we assumed the exchange coupling was isotropic, any exchange anisotropy will be subsumed by the dipolar term. This may account for the small experimental vs. simulation offset. 
$\operatorname{Mn}^{I I}\left(S_{1,2}=5 / 2\right)$ Dimer (with $\mathrm{ZnCe}_{6}$ )

The addition of the pigment to $\mathrm{BFR}^{1}-\mathrm{M}$ led to a dramatic change in the $\mathrm{Mn}^{\mathrm{II}}$ dimer spectrum (Figure 3.12). The main intensity of the spectrum shifted to g 2, and appeared less structured. As before, this new signal demonstrated non-Curie temperature dependence and its line-shape was invariant at all temperatures up to $50 \mathrm{~K}$ (Figure 3.12).

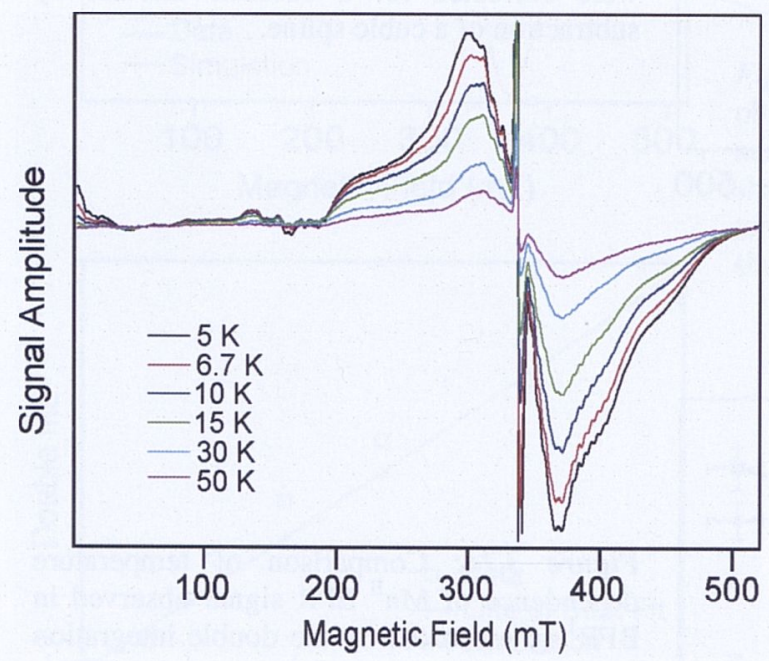

Figure 3.12: Temperature dependence of the EPR line-shape (derivative) of $\mathrm{Mn}^{\text {II }}$ complex observed in $\mathrm{BFR}^{1}-\mathrm{ZM}$ in the dark.

It was noted while the spectrum about g 2 is altered, the wings ( $\mathrm{g} 2.5$ etc., now smaller by approximately a factor of 2) matched the structure seen in the original $\mathrm{Mn}^{\text {II }}$ dimer spectrum, i.e., without $\mathrm{ZnCe}_{6}$. This suggested the spectrum was heterogeneous, made up of both the original $\mathrm{Mn}^{\mathrm{II}}$ dimer spectrum and a new signal. Subtracting the original dimer spectrum yields (Figure 3.13). The estimated the contribution of the original dimer spectrum to the total spectrum observed after the addition of $\mathrm{ZnCe}_{6}$ was $59 \%$. This suggested the chlorin had an effect on $41 \%$ of Mn clusters (i.e. $82 \%$ of reaction centres). This value is approximately the same as the estimate from the number of bound chlorins per Mn cluster as estimated by ITC. The resultant spectrum - the spectrum generated by the subtraction of the original dimer spectrum - appeared as a ‘simple' derivative about g 2. It had near linear temperature dependence (Figure 3.14). 

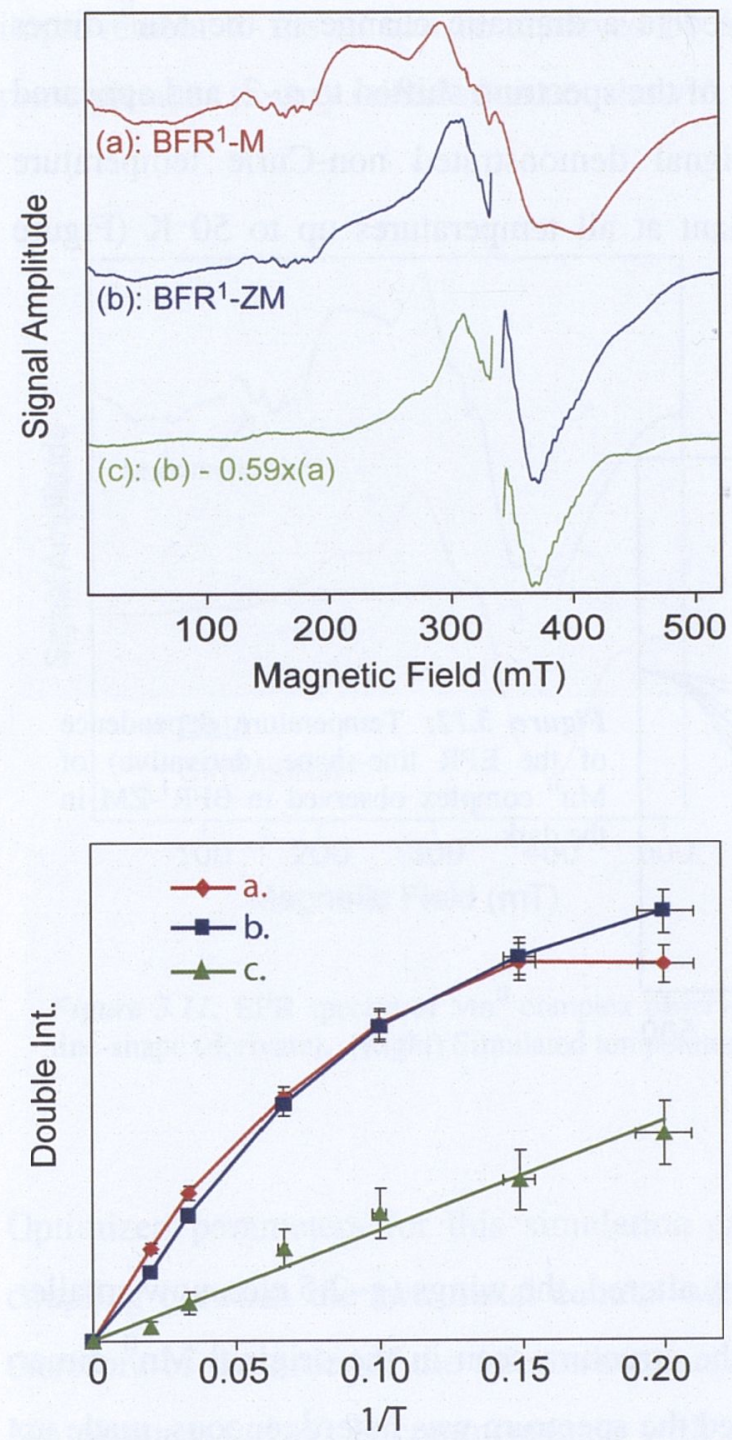

Figure 3.13: Comparison of $\mathrm{Mn}^{\mathrm{II}} \mathrm{EPR}$ signal observed in BFR ${ }^{1}$. Top) The EPR line-shape of (a.) BFR ${ }^{1}-\mathrm{M}$ and (b.) $\mathrm{BFR}^{1}-\mathrm{ZM}$ at $5 \mathrm{~K}$. Trace (c) represents the subtraction of $59 \%$ of trace (a) from trace (b). Data presented were corrected for a baseline artefact by subtraction of a cubic spline.

Figure 3.14: Comparison of temperature dependence of $\mathrm{Mn}^{\mathrm{II}}$ EPR signal observed in $\mathrm{BFR}^{1}$ as estimated by the double integration of the spectra. (a.) $\mathrm{BFR}^{1}-\mathrm{M}$ and (b.) $\mathrm{BFR}^{1}$ $\mathrm{ZM}$ (c) represents the subtraction of 59\% of trace (a) from trace (b).

Subsequent modelling of this signal using the same formalism as before suggested (see Figure 3.15) that the coupling between the two metal centres in this subset of centres decreased, with the exchange component dropping to $\sim 0.01 \mathrm{~K}$ and the Mn-Mn distance lengthening to $\sim 5 \AA$. It is suggested that the $\mathrm{ZnCe}_{6}$ disrupts the coupling environment of the Mn cluster. 

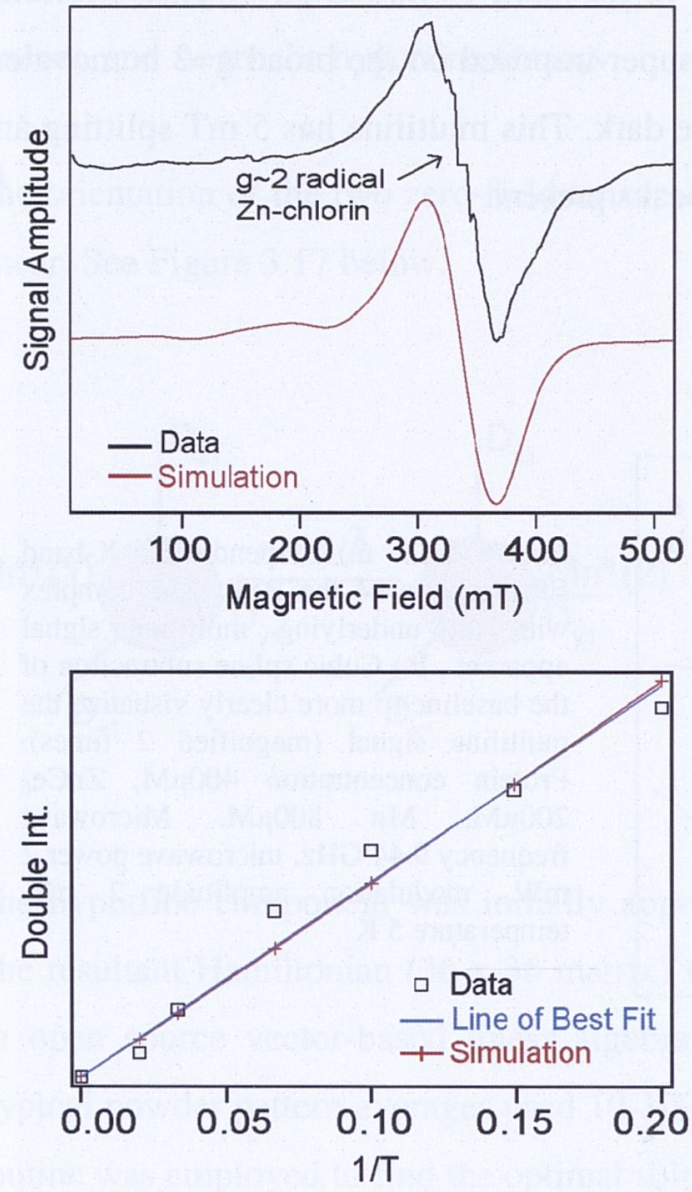

Figure 3.15: EPR spectra of $\mathrm{Mn}^{\mathrm{II}}$ complex observed in $\mathrm{BFR}^{1}-\mathrm{ZM}$ in the dark after the addition of $\mathrm{ZnCe}_{6}$. Top) Simulated EPR lineshape (derivate). Bottom) Simulated temperature dependence of the EPR lineshape

Table 3.2: Simulation parameters for the $\mathrm{Mn}^{\mathrm{II}}$ dimers

\begin{tabular}{ccc}
\hline & $\mathrm{Mn}^{\mathrm{II}}$ (without $\left.\mathrm{ZnCe}_{6}\right)$ & $\mathrm{Mn}^{\mathrm{II}}$ (with $\left.\mathrm{ZnCe}_{6}\right)$ \\
\hline $\mathrm{J}$ & $1.3 \mathrm{~K}$ & 0.001 \\
$\mathrm{r}$ & $3.95 \AA$ & $5.30 \AA$ \\
$\mathrm{D}_{1}$ & $0.15 \mathrm{~K}$ & $0.2 \mathrm{~K}$ \\
$\mathrm{E}_{1} / \mathrm{D}_{1}$ & 0.33 & 0.33 \\
$\mathrm{D}_{2}$ & $0.02 \mathrm{~K}$ & $0.02 \mathrm{~K}$ \\
$\mathrm{E}_{2} / \mathrm{D}_{2}$ & $0.1^{3}$ & 0.1 \\
width & $28 \mathrm{mT}$ & $28 \mathrm{mT}$ \\
\hline
\end{tabular}

${ }^{3}$ Can take any value 0-0.33 (i.e. all allowed values for E/D). The parameter is non-unique. 


\section{Resolved Hyperfine Structure of the Mn ${ }^{I I}\left(S_{1,2}=5 / 2\right)$ Dimer (with $\left.\mathrm{ZnCe}_{6}\right)$.}

Interestingly, $\mathrm{BFR}^{1}-\mathrm{ZM}$ samples prepared in the dark exhibited an unusual multiline EPR signal (Figure 3.16). This signal was super-imposed on the broad $g=2$ homovalent $\mathrm{Mn}_{2}{ }^{\mathrm{II}}$ II spectral components observed in the dark. This multiline has $5 \mathrm{mT}$ splitting and stretches from $290-410 \mathrm{mT}$, with up to 23 peaks present.

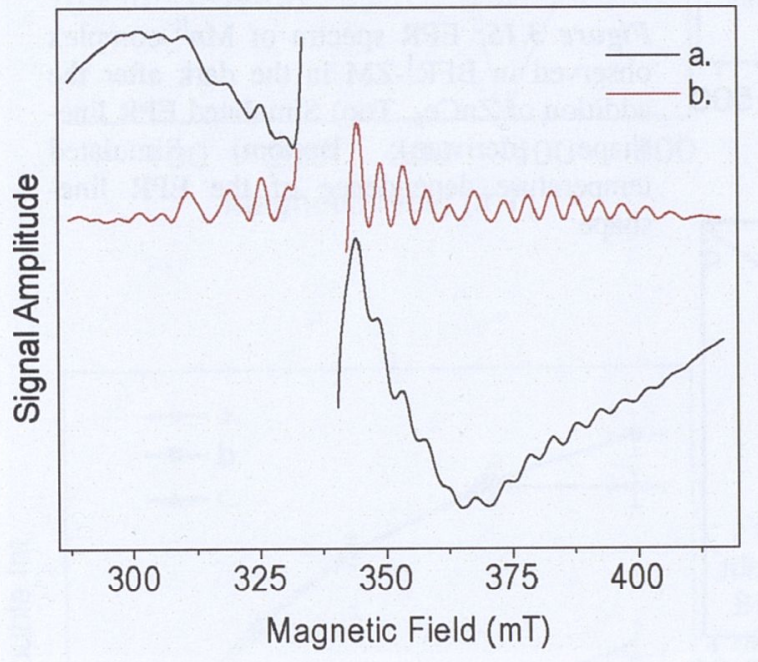

Figure 3.16: a.) Perpendicular X-band EPR spectra of the $\mathrm{BFR}^{1}-\mathrm{ZM}$ complex with an underlying multiline signal apparent . b.) Cubic spline subtraction of the baseline to more clearly visualize the multiline signal (magnified 2 times). Protein concentration $400 \mu \mathrm{M}, \mathrm{ZnCe}_{6}$ $200 \mu \mathrm{M}, \quad \mathrm{Mn} \quad 800 \mu \mathrm{M}$. Microwave frequency $9.44 \mathrm{GHz}$, microwave power 2 $\mathrm{mW}$, modulation amplitude $2 \mathrm{mT}$, temperature $5 \mathrm{~K}$

Within the framework described above the hyperfine structure observed in the $\mathrm{Mn}^{\mathrm{II}}\left(\mathrm{S}_{1}\right.$, ${ }_{2}=5 / 2$ ) dimer (with $\mathrm{ZnCe}_{6}$ ) spectrum most likely arises from the superposition of the hyperfine patterns for each individual $\mathrm{Mn}^{2+}$ centre. $5 \mathrm{mT}$ peak to peak (p-p) hyperfine spacing's are typical for $\mathrm{Mn}^{2+}$ dimer systems. The appearance of multiline signals is a common attribute of $\mathrm{Mn}_{2}{ }^{\mathrm{II}, \mathrm{II}}$ dimer systems (Wu et al. 2004).

\subsubsection{Theoretical Approach: The $M n^{I I} M n^{I I}$ System}

The general Hamiltonian used for the $\mathrm{Mn}^{\mathrm{II}}$ dimer takes the form:

$$
H=-J \cdot S_{1} \cdot S_{2}+S_{1} \cdot D \cdot S_{2}+\sum\left(H \cdot g_{i} \cdot S_{i}+S_{i} \cdot D_{Z F i} \cdot S_{i}+S_{i} \cdot A_{i} \cdot I\right) \quad \text { Equation 3-7 }
$$


Where $\mathrm{J}$ is the exchange tensor (assumed to be isotropic), $\mathrm{D}$ is the dipolar tensor (fixed by the geometry of the system i.e. the $\mathrm{Mn}-\mathrm{Mn}$ inter-distance), $\mathrm{D}_{\mathrm{ZFi}}$ are the zero-field tensors, and $\mathrm{A}_{\mathrm{i}}$ are the hyperfine tensors

The orientation of the two zero-field tensors and dipolar tensor were assumed to be colinear. See Figure 3.17 below.

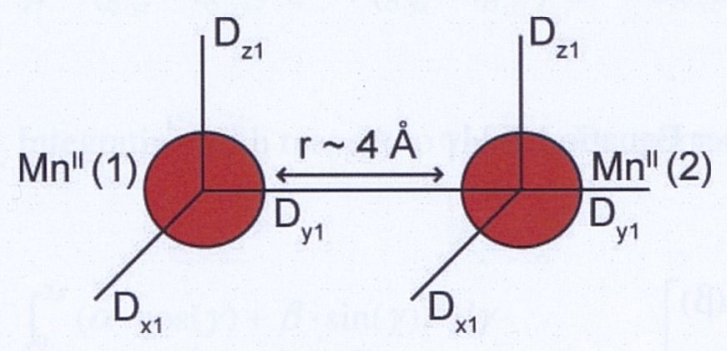

Figure 3.17: Pictorial representation of Mn-

Mn co-ordinate axis system.

The hyperfine component was initially approximated by an isotropic line-broadening. The resultant Hamiltonian (36 x 36 matrix) was solved numerically using Scilab-4.4.1, an open source vector-based linear algebra package available from www.scilab.org. Typical powder pattern averages used 10-100 $\beta$ angles and a least squares minimization routine was employed to find the optimal solutions for the above parameters.

\section{Powder Pattern Averaging}

The paramagnetic centres of a frozen EPR sample take all possible orientations (relative to the field axis), often referred to as a powder pattern. The simulation code allows for this effect by using combination of Euler rotations ( $\alpha$ and $\beta$ ). This system only requires two Euler rotations to define all unique orientations as rotation about the field axis does not alter the Eigen values of the system. A generalized powder pattern code was adopted (shown below). The typical number of $\beta$ angles used ( $n$ ) ranged from 10-100. Dummy variables $\mathrm{x}$ and $\mathrm{y}$ were used to uniformly sample the hemisphere. For a given $\mathrm{x}$ $(\beta)$ angle 1 to $p(x+1)$ y $(\alpha)$ angles were sampled (with the entries of $p(x)$ as defined below). Note: for $\mathrm{x}=0(\beta=0), \alpha$ was also set to zero.

For $\mathrm{x}=0$ to $\mathrm{n}-1$

For $\mathrm{y}=1$ to $\mathrm{p}(\mathrm{x}+1)$ 
$p(x+1)=\left(\frac{360}{90 /(n-1 / 2)}\right) \cdot \sin ((90 /(n-1 / 2)) \cdot x)$

\section{Equation 3-8}

$\beta=x \cdot\left(\frac{90}{n-1 / 2}\right)$

Equation 3-9

$\alpha=(y-1 / 2) \cdot\left(\frac{360}{p(x+1)}\right)$

Equation 3-10

$\alpha$ and $\beta$ angles define the rotation matrix a per Equation 3-11:

$R=\left[\begin{array}{ccc}\cos (\alpha) \cdot \cos (\beta) & \sin (\alpha) \cdot \cos (\beta) & -\cos (\beta) \\ \sin (\alpha) & \cos (\alpha) & 0 \\ \cos (\beta) & \sin (\alpha) \cdot \sin (\beta) & \cos (\beta)\end{array}\right]$

Equation 3-11

The unitary transformation $\mathrm{T}^{*}=\mathrm{R} \cdot \mathrm{T} \cdot \mathrm{R}^{\prime}$ was applied to the tensors:

$\mathrm{D}^{*}=\mathrm{R} \cdot \mathrm{D} \cdot \mathrm{R}^{\prime}$

$\mathrm{g}_{\mathrm{Fe}}{ }^{*}=\mathrm{R} \cdot \mathrm{g}_{\mathrm{Fe}} \cdot \mathrm{R}^{\prime}$

$\mathrm{J}^{*}=\mathrm{R} \cdot \mathrm{J} \cdot \mathrm{R}^{\prime}$

\section{Transition Intensities}

The intensity of transition between the $\mathrm{i}^{\text {th }}$ and $\mathrm{j}^{\text {th }}$ state is given as Equation 3-12

$\mathrm{I} \propto\left|\left\langle\mathrm{i}\left|\beta \mathrm{H}_{1} \cdot \mathrm{g}_{\mathrm{Fe}} \cdot \mathrm{S}_{\mathrm{Fe}}+\mathrm{g}_{\mathrm{Q}} \beta \mathrm{H}_{1} \cdot \mathrm{S}_{\mathrm{Q}}\right| \mathrm{j}\right\rangle\right|^{2}$

Equation 3-12

Where the oscillating $\mathrm{H}_{1}$ field lies in the $x-y$ plane (perpendicular to $H$ ), all of its possible orientations must be included to correctly estimate transition intensities. This is achieved by averaging over the third Euler angle $(\gamma)$. $\mathrm{H}_{1}$ can be expressed as Equation $3-13$

$H_{1}=\left[\begin{array}{c}\cos (\gamma) \\ \sin (\gamma) \\ 0\end{array}\right]$ 
hence

$$
I \propto\left|\left\langle i\left|\frac{H^{2} \beta^{2}}{2}(\cos (\gamma) \cdot \alpha+\sin (\gamma) \cdot \beta)\right| j\right\rangle\right|^{2}
$$

where

$$
\begin{aligned}
& \alpha=\left(g_{x x}-i g_{x y}\right) \cdot S^{+}+\left(g_{x x}+i g_{x y}\right) \cdot S^{-}+2 g_{x z} S_{z} \\
& \beta=\left(g_{y x}-i g_{y y}\right) \cdot S^{+}+\left(g_{y x}+i g_{y y}\right) \cdot S^{-}+2 g_{y z} S_{z}
\end{aligned}
$$

Integrating with respect to $\gamma$ yields Equation 3-16:

$$
\begin{aligned}
& \int_{0}^{2 \pi}(\alpha \cdot \cos (\gamma)+\beta \cdot \sin (\gamma))^{2} d \gamma \\
& =\int_{0}^{2 \pi} \frac{\alpha^{2}}{2} \cdot(1+\cos (2 \gamma))+\frac{\beta^{2}}{2} \cdot(1-\cos (2 \gamma))+\alpha \beta \sin (2 \gamma) d \gamma \\
& =\left|\frac{\alpha^{2}}{2}(\gamma+1 / 2 \sin (2 \gamma))+\frac{\beta^{2}}{2}(\gamma-1 / 2 \sin (2 \gamma))-\frac{\alpha \beta}{2} \cos (2 \gamma)\right|_{0}^{2 \pi} \\
& =\pi\left(\alpha^{2}+\beta^{2}\right)
\end{aligned}
$$

The transition intensity can therefore be expressed as Equation 3-17:

$$
\mathrm{I} \propto\left|\left\langle\mathrm{i}\left|\frac{\pi \mathrm{H}^{2} \beta^{2}\left(\alpha^{2}+\beta^{2}\right)}{2}\right| \mathrm{j}\right\rangle\right|^{2}
$$

\subsubsection{Light Induced Oxidation State Changes}

\section{$\mathrm{O}_{2}$ Consumption of the Di-Metal Site of $B F R^{1}$.}

Bacterioferritins are members of a class of spherical shell-like iron storage proteins that contain a ferroxidase site within the protein and catalyse Fe oxidation and hydrolysis. The Fe oxidation reaction involves the uptake of molecular oxygen from solution and as a consequence the reaction can be monitored using a Clarke type oxygen electrode. Wild type BFR and $\mathrm{BFR}^{1}$ both oxidized $\mathrm{Fe}^{\mathrm{II}}$ to $\mathrm{Fe}^{\mathrm{III}}$ with the concomitant uptake of 0.25 $\mathrm{O}_{2}$ molecules per $\mathrm{Fe}$ atom when a five fold excess of iron was present (see Figure 3.18 
and Table 3.3). Both forms oxidise iron with ratios of oxygen to Fe identical to the literature (Yang et al. 2000) but the rate $\left(\mathrm{k}_{\max }\right)$ of iron oxidation for the mutant form is slightly higher than for the wild type.

The addition of the light active chlorin had potential to induce light dependent oxidation of the metal ions (either $\mathrm{Fe}$ or $\mathrm{Mn}$ ) bound at the ferroxidase site and this too could be monitored by consumption of oxygen. The addition of $\mathrm{ZnCe}_{6}$ to the $\mathrm{BFR}^{1}$ protein did not change the amount of oxygen taken up nor significantly affect the rate of iron oxidation in the dark. Illumination of the $\mathrm{BFR}^{1}-\mathrm{Z}$ protein with iron bound after iron oxidation had gone to completion produced further oxygen uptake at a slower rate. Additional light induced oxygen uptake totalled approximately the same as dark iron oxygen uptake (see Figure 3.18a).

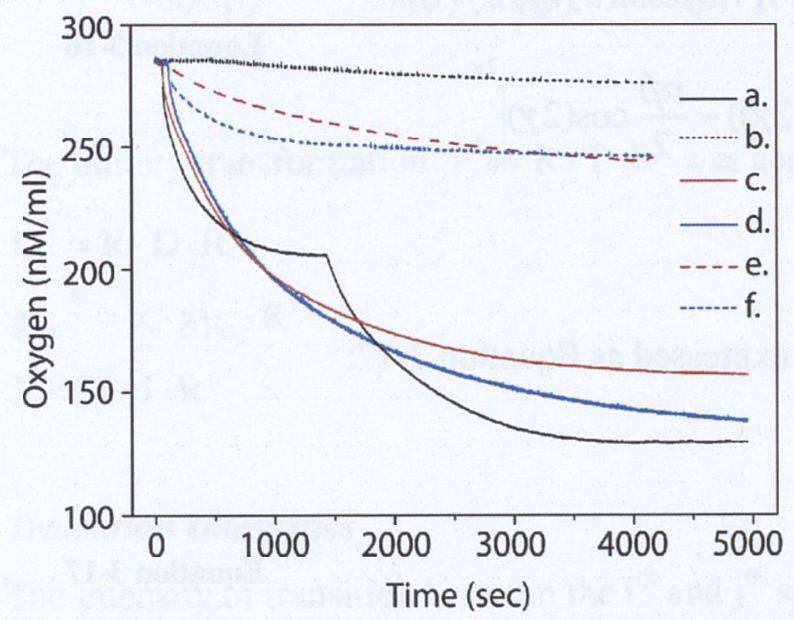

Figure 3.18: Clarke type oxygen electrode measurements depicting oxygen concentrations of samples in the dark and the changes in concentration that occur upon illumination. a.) $\mathrm{BFR}^{1}-\mathrm{Z} \mathrm{Fe} 300$ $\mu \mathrm{M}$, b.) $B F R^{1}-\mathrm{ZM}$ dark, c.) $\mathrm{BFR}^{1}-\mathrm{ZM}$ d.) $\mathrm{BFR}^{1}-\mathrm{ZM} \mathrm{Mn} 300 \mu \mathrm{M}$, e.) $\mathrm{ZnCe}_{6}, \mathrm{Mn}$ (no protein), f.) $\mathrm{BFR}^{1}-\mathrm{Z}$. The light was turned on 60 seconds after stabilisation of the dark signal.

The BFR ${ }^{1}-\mathrm{ZM}$ complex, when measured under the same conditions, did not autooxidise $\mathrm{Mn}$ in the dark. Interestingly though, subsequent illumination of this complex did lead to consumption of oxygen (Figure 3.18b, c, and d). Control measurements demonstrated that only a small amount of oxygen was consumed by the Mn free (BFR ${ }^{1}$ $\mathrm{Z}$ ), and for a protein free solution of $\mathrm{ZnCe}_{6}$ (Figure 3.18e, and f). Similarly, when heme was bound to the protein in place of $\mathrm{ZnCe}_{6}$ and manganese bound at the dimetal site, no oxygen uptake was observed in the dark or upon illumination (Table 3.3). Buffered pH6.5 $\mathrm{Mn}^{2+}$ solutions showed very little oxygen uptake when illuminated (Figure 3.18b). 
Table 3.3: Oxygen uptake data

\begin{tabular}{|c|c|c|c|c|c|}
\hline & & Sample & $\begin{array}{c}\text { Total } \\
\text { oxygen } \\
\text { uptake }(\mu \mathrm{M})\end{array}$ & $\begin{array}{l}\mathrm{O}_{2} \text { uptake / } \\
\text { metal ion }\end{array}$ & $\begin{array}{c}\mathrm{k}_{\max } \\
\left(\mu \mathrm{Mol} \mathrm{s} \mathrm{s}^{-1}\right)\end{array}$ \\
\hline Controls & Dark & $\mathrm{Fe} 300 \mu \mathrm{M}$ (no protein) & 29 & 0.10 & 0.3 \\
\hline & Light & $\mathrm{BFR}^{1}-\mathrm{Z}$ & 39 & - & 0.3 \\
\hline & & $\mathrm{ZnCe}_{6} \mathrm{Mn} 60 \mu \mathrm{M}$ (no protein) & 40 & - & 0.1 \\
\hline $\mathrm{BFR}^{1}-\mathrm{Mn}$ & Dark & $\mathrm{BFR}^{1}-\mathrm{ZM} \quad \mathrm{Mn} 60 \mu \mathrm{M}$ & 9 & 0.14 & 0.1 \\
\hline & Light & BFR $^{1}$ Heme Mn $60 \mu \mathrm{M}$ & 7 & 0.12 & 0.1 \\
\hline & & $\mathrm{BFR}^{1}-\mathrm{ZM} \quad \mathrm{Mn} 60 \mu \mathrm{M}$ & 127 & 2.12 & 0.6 \\
\hline & & $\begin{array}{l}\text { BFR }^{\prime}-\mathrm{ZM} \quad \text { Mn } 60 \mu \mathrm{M} \text { Catalase } \\
\& \text { SOD }\end{array}$ & 133 & 2.22 & 1.3 \\
\hline & & $\mathrm{BFR}^{1}-\mathrm{ZM} \quad \mathrm{Mn} 300 \mu \mathrm{M}$ & 147 & 0.49 & 0.7 \\
\hline $\mathrm{BFR}^{1}-\mathrm{Fe}$ & Dark & $\mathrm{BFR}^{1}-\mathrm{Z}$ Fe $300 \mu \mathrm{M}$ & 81 & 0.27 & 1.4 \\
\hline & & wt-BFR Fe $300 \mu \mathrm{M}$ & 81 & 0.27 & 0.9 \\
\hline & & $\mathrm{BFR}^{1} \quad \mathrm{Fe} 300 \mu \mathrm{M}$ & 71 & 0.24 & 1.3 \\
\hline & Light & $\mathrm{BFR}^{1} \quad \mathrm{Fe} 300 \mu \mathrm{M}$ & $156^{*}(75)^{\#}$ & $0.52^{*}(0.25)^{\#}$ & $-{ }^{*}(0.2)^{\#}$ \\
\hline
\end{tabular}

Note: BFR $30 \mu \mathrm{M}, \mathrm{ZnCe}_{6} 15 \mu \mathrm{M}$, samples with metal contained either stoichiometric amounts $(60 \mu \mathrm{M})$ or a 5 fold excess $(300 \mu \mathrm{M})$. " Total $\mathrm{O}_{2}$ consumption light and dark cumulative. ${ }^{\text {\#Additional } \mathrm{O}_{2}}$ consumption in light (as compared to dark). Maximum uptake rates $\left(\mathrm{k}_{\max }\right)$ are averaged over 10 seconds.

The oxygen uptake rate of the $\mathrm{BFR}^{1}-\mathrm{ZM}$ complex was increased by the addition of superoxide dismutase (SOD) and catalase but the total amount of oxygen consumed was almost the same (Table 3.3). This suggests that SOD and catalase may have a protective function as their addition should slow $\mathrm{ZnCe}_{6}$ breakdown from reaction with superoxide or peroxide. No oxygen was released upon dark adaptation. More oxygen was consumed when a five fold excess of Mn was added suggesting more Mn was oxidised. The same amount of oxygen uptake was found for $B F R^{1}-Z$ with excess iron. Both consumed a total of $\sim 0.5$ moles of oxygen per metal ion.

\section{Light Induced Chlorin Oxidation / Tyrosine Oxidation as Measured by EPR.}

Light induced oxidation of the bound $\mathrm{ZnCe}_{6}$ was readily observed by EPR (Figure 3.19a). Upon illumination of the BFR1-Z complex (i.e. no Mn present) with short actinic light flashes at room temperature a narrow $0.75 \mathrm{mT}$ wide radical centred at $\mathrm{g}=$ 2.0022 was generated. Under the same conditions the $\mathrm{BFR}^{1}-\mathrm{ZM}$ complex generated a broader signal ( $2.5 \mathrm{mT}$ radical) centred at $\mathrm{g}=2.0058$. This broader radical resolved a 4-6 peak hyperfine structure with p-p spacing $\sim 1.5 \mathrm{mT}$ characteristic of an oxidized tyrosine (Figure 3.19b) (Un et al. 1995; Bleifuss et al. 2001; Hofbauer et al. 2001). A corrected spin count for each species revealed that the tyrosine signal area was approximately 6 times more intense than that of the $\mathrm{ZnCe}_{6}$ radical signal. 


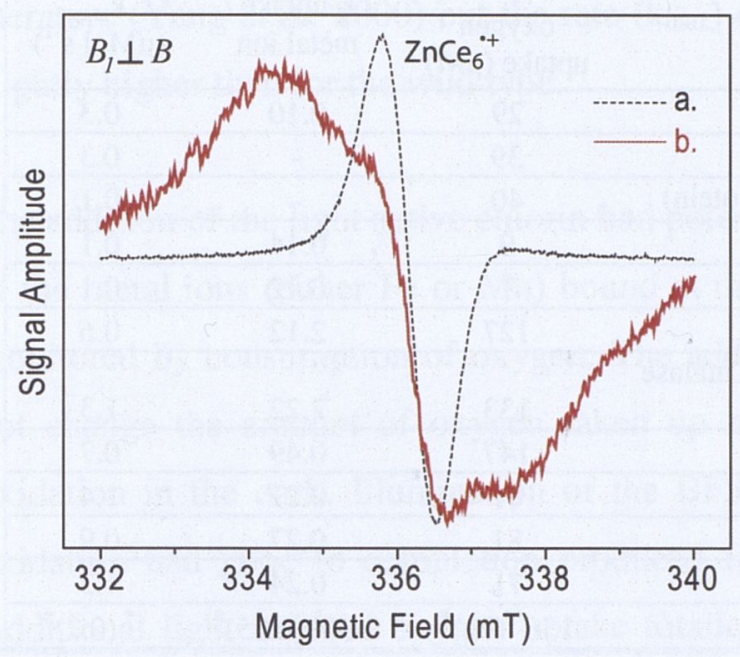

Figure 3.19: Light induced EPR spectra for (a) $B^{1}-Z$ complex, without manganese and (b) with manganese bound. Traces are scaled arbitrarily. Microwave frequency $9.44 \mathrm{GHz}$, microwave power $1 \mu \mathrm{W}$, modulation amplitude $0.3 \mathrm{mT}$, temperature $5 \mathrm{~K}$.

\section{Light Induced $\mathrm{Mn}^{2+}$ Oxidation as Measured by EPR}

$\mathrm{BFR}^{1}$-ZM complexes were prepared containing either stoichiometric $\left(2 \mathrm{Mn}^{2+}\right.$ per BFR unit) or 5-fold excess $\mathrm{Mn}^{2+}\left(10 \mathrm{Mn}^{2+}\right.$ per BFR unit) in the dark. Excess $\mathrm{Mn}^{2+}$ (unbound) appeared as a narrow $100 \mathrm{mT}$ wide 6 line EPR signal centred at $\mathrm{g} \sim 2$ characteristic of $\mathrm{Mn}^{2+}\left(\mathrm{H}_{2} \mathrm{O}\right)_{6}$ (Hoganson et al. 1989). This signal overlayed the structured $\mathrm{Mn}_{2}{ }_{2}^{\mathrm{II}}$ dimer signal discussed above (see $M n$ Binding to $B F R^{l}$ ). The $\mathrm{Mn}_{2}{ }^{\mathrm{IIII}}$ dimer signal was quantitatively the same for both samples.

Upon illumination of the sample containing stoichiometric $\mathrm{Mn}^{2+}$ the structured $\mathrm{Mn}_{2}$ IIII dimer signal decreased by $\sim 1 / 3$. No new Mn signal was observed in perpendicular or parallel mode EPR. Small spectral features observed in parallel mode EPR were attributed to background contaminant $\mathrm{O}_{2}$.

As with stoichiometric samples, illumination of samples that contained excess $\mathrm{Mn}^{2+}$, led to a reduction of the structured $\mathrm{Mn}_{2}{ }^{\text {IIII }}$ dimer by $\sim 1 / 3$. In these samples the additional $\mathrm{Mn}^{2+}$ six-line signal present also partially reduced by $\sim 25 \%$ (see Table 3.4 ). Concomitant with the loss of unbound $\mathrm{Mn}^{2+}$ (six line) was the appearance of broad parallel polarized signal most likely arising from an even spin system (Figure 3.20). This new signal resolves a hyperfine structure with p-p spacing of $\sim 15.6 \mathrm{mT}$. This spacing is larger than previously reported for monomeric $\mathrm{Mn}^{\mathrm{III}}$ (Campbell et al. 1999; Campbell et al. 2000; Whittaker et al. 2003). As a control a parallel mode scan of 
$\mathrm{BFR}^{1}-\mathrm{Z}$ with stoichiometric amounts of iron, revealed a small amount of oxygen contamination but no other features (Figure 3.20b).

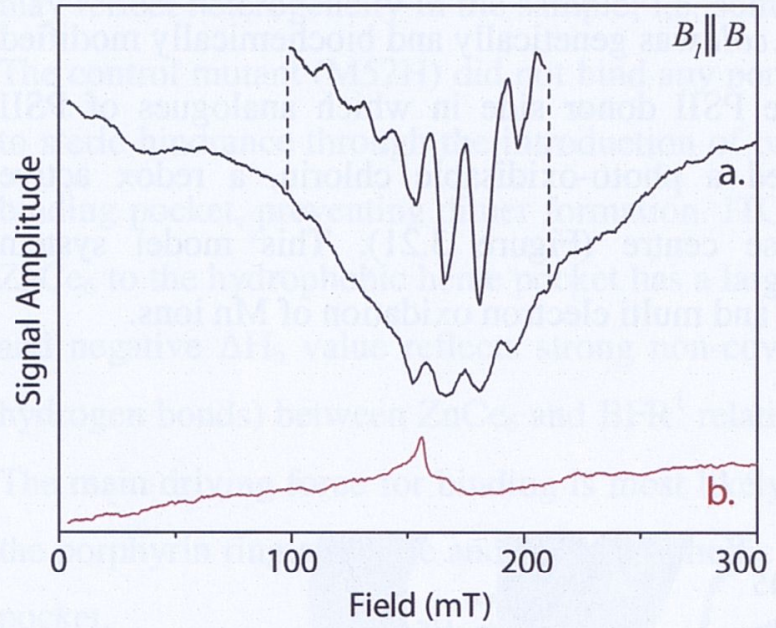

Figure 3.20: Parallel mode EPR spectra of (a.) the light minus dark spectra of BFR $^{1}$-ZM with a five fold excess of Mn. The inset is a higher resolution scan of the multiline signal. (b.) $\mathrm{BFR}^{1}-\mathrm{Z}$ with stoichiometric amounts of iron added. Microwave frequency $9.34 \mathrm{GHz}$, microwave power $10 \mathrm{~mW}$, modulation amplitude $1 \mathrm{mT}$, temperature $5 \mathrm{~K}$. Protein concentration $250 \mu \mathrm{M}, 125 \mu \mathrm{M}$ $\mathrm{ZnCe}_{6}, 2500 \mu \mathrm{M} \mathrm{MnCl}_{2}$ or $500 \mathrm{uM} \mathrm{FeSO}{ }_{4}$ in 50mM MES pH6.5.

Table 3.4: Relative metal ion EPR signal intensities

\begin{tabular}{|c|c|c|c|c|}
\hline & \multicolumn{2}{|c|}{ Dark } & \multicolumn{2}{c|}{ Light } \\
\hline \multicolumn{1}{|c|}{ Sample } & Structured $\mathrm{g}=2$ & Six line & Structured $\mathrm{g}=2$ & Six line \\
\hline BFR $^{1}$-ZM Mn $60 \mu \mathrm{M}$ & $100 \%$ & 0 & $66 \%$ & $0 \%$ \\
BFR $^{1}$-ZM Mn 300 $\mu \mathrm{M}$ & $100 \%$ & $400 \%$ & $65 \%$ & $300 \%$ \\
\hline
\end{tabular}

Note: BFR $30 \mu \mathrm{M}, \mathrm{ZnCe}_{6} 15 \mu \mathrm{M}$, metal concentration either stoichiometric amounts $(60 \mu \mathrm{M})$ or a 5 fold excess $(300 \mu \mathrm{M})$ concentration per BFR ${ }^{1}$ monomer 


\subsection{Discussion}

I have taken a bioengineering approach to develop a totally novel system to study the light-activated electron transport in the water oxidation reactions during oxygenic photosynthesis. Bacterioferritin from E.coli was genetically and biochemically modified to produce a minimalist model of the PSII donor side in which analogues of PSII cofactors were bound. These included a photo-oxidisable chlorin, a redox active tyrosine, and a di-nuclear manganese centre (Figure 3.21). This model system demonstrates both porphyrin excitation and multi electron oxidation of $\mathrm{Mn}$ ions.

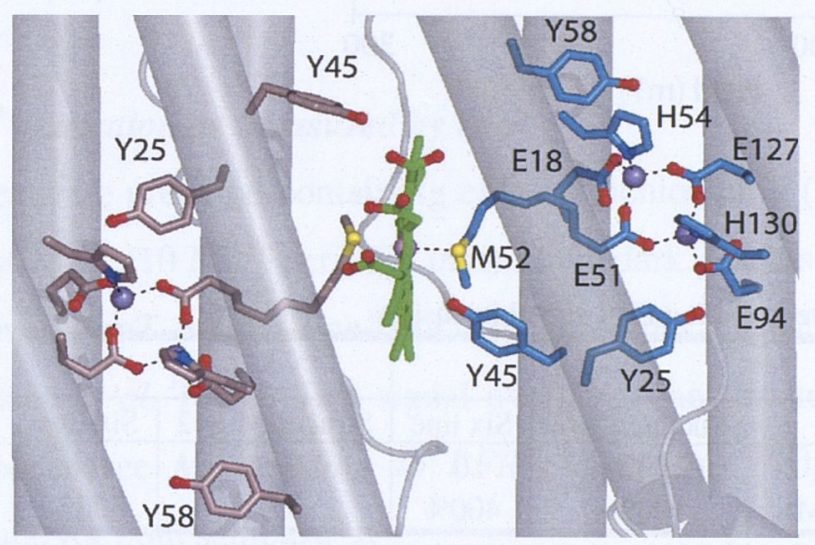

Figure 3.21: Diagram of the amino acid ligands to the dimanganese centre with $\mathrm{ZnCe}_{6}$ bound at the interface of the BFR dimeric complex. Residues from the A subunit are in blue and the B subunit are in salmon. The three tyrosine's have been labelled on either side of the $\mathrm{ZnCe}_{6}$ group to show the orientation of the dimer subunits relative to each other. The alpha helices are pictured as grey rods. The picture is modified from the PDB - 1BFR.

The BFR ${ }^{1}$ mutant was generated by mutating the two histidine residues $-\mathrm{H} 46 \mathrm{R}$ and H112R. These residues are commonly substituted with arginine in other bacterioferritin species and therefore structural changes were considered to be unlikely in the mutant protein. Additionally CD spectroscopy confirmed that the secondary structure remained intact and this was supported by the retained ability of the mutant $\mathrm{BFR}^{1}$ protein to spontaneously bind porphyrins (heme or $\mathrm{ZnCe}_{6}$ ) and metal ions ( $\mathrm{Fe}$ or $\mathrm{Mn}$ ). 


\section{Cofactor-Protein Assembly}

Upon titration of the $\mathrm{BFR}^{1}$ into a solution of $\mathrm{ZnCe}_{6}$, ITC analysis reveals that $82 \%$ of the $\mathrm{BFR}^{1}$ binds $\mathrm{ZnCe}_{6}$ (Table 3.1). The small fraction which doesn't bind may be due to partial aggregation of the chlorin in solution, even at the low concentrations used, or it may reflect heterogeneity in the sample; i.e. some of the binding pockets are perturbed. The control mutant (M52H) did not bind any porphyrins (chlorin or heme) possibly due to steric hindrance through the introduction of two large histidine residues in the heme binding pocket, preventing dimer formation. ITC analysis also revealed that binding of $\mathrm{ZnCe}_{6}$ to the hydrophobic heme pocket has a large enthalpy term (Table 3.1). This large and negative $\Delta \mathrm{H}_{\mathrm{b}}$ value reflects strong non-covalent interactions (van der Waals and hydrogen bonds) between $\mathrm{ZnCe}_{6}$ and $\mathrm{BFR}^{1}$ relative to their interaction with the solvent. The main driving force for binding is most likely the hydrophobic interactions between the porphyrin ring structure and the hydrophobic amino acid residues lining the binding pocket.

As we showed earlier manganese ligates to the di-nuclear metal binding site of bacterioferritin (Conlan 2008) via four glutamate residues (E18, E51, E94, E127) one from each helix and two histidine residues (H54, H130) (Frolow et al. 1994). Residues E51 and E127 form (di- $\mu-1,3$-caboxylato) bridging carboxylates, where each oxygen atom is coordinated to a different metal ion, while residues E18 and E94 form monodentate carboxylate ligands. H54 and H130 coordinate to the metal ions separately through the $\mathrm{N}^{\delta}$ nitrogen (Figure 3.21). ITC analysis of $\mathrm{Mn}$ binding to $\mathrm{BFR}^{1}$ revealed two distinct binding sites in the dark with very different association constants. Site A bound Mn very tightly whilst site B binding was weaker by almost three orders of magnitude. Binding of the first $\mathrm{Mn}$ ion has a large and negative $\Delta \mathrm{H}_{\mathrm{b} 1}$ value, which may reflect structural changes in the protein upon metal ligation (LeBrun et al. 1996). The second Mn binding has a small and positive $\Delta \mathrm{H}_{\mathrm{b}}$ but a larger $\Delta \mathrm{S}_{\mathrm{b}}$ than site 1 indicating that binding Mn to site 2 is entropically driven. The most likely contributions to this positive entropy are changes in the hydration of the protein and of the metal ion upon binding to the protein (Bou-Abdallah et al. 2003). These observations coincide with previous crystal structure findings for BFR with manganese bound, where site B was found to have a lower incidence of occupation than site A (Frolow 2001). 
In comparison, during the photo-assembly of the tetra-nuclear Mn cluster in PSII, the first $\mathrm{Mn}^{\mathrm{II}}$ ion binds tightly at a high affinity site in the apo-complex [ $\mathrm{IM}_{0}$ intermediate]. Light is then needed to start the assembly process in which the bound $\mathrm{Mn}^{\mathrm{II}}$ is oxidised to $\mathrm{Mn}^{\mathrm{III}}$ and a proton is released $\left[\mathrm{IM}_{1}\right]$. The bound $\mathrm{Mn}^{\mathrm{III}}$ is unstable until a conformational change occurs in the dark and allows the formation of the more stable $\mathrm{Mn}^{\mathrm{III}}-\mathrm{O}-\mathrm{Ca}^{\mathrm{II}}\left[\mathrm{IM}_{1} *\right]$. At this point the second $\mathrm{Mn}^{\mathrm{II}}$ binds forming the stable, spincoupled cluster $\mathrm{Mn}^{\mathrm{II}}-\mathrm{Mn}^{\mathrm{III}}-\mathrm{O}-\mathrm{Ca}^{\mathrm{II}}\left[\mathrm{IM}_{2}\right]$. The formation of the $\mu$-oxo bridge thus helps stabilize the intermediates until the full assembly of the tetra-nuclear MnCa cluster (Dasgupta et al. 2008).

The ITC titrations also showed that an average of 2.51 moles of Mn ions bound per mole of $\mathrm{BFR}^{1}$ monomer. This is higher than expected but can be partly explained by the findings from the original crystal structure where an extraneous $\mathrm{Mn}$ ion was shown to be bound at the four-fold axis of the dodecamer of dimers by four Gln151 residues internal to the structure (Dautant et al. 1998). This would account for a further 0.25 binding sites per mole of protein but still leaving 0.25 sites unaccounted for. Nonspecific, low affinity binding sites have also been detected in previous studies of the BFR protein. It is proposed that these sites involve acidic residues located on the inner surface of the protein shell (Baaghil et al. 2002). Under the conditions of these experiments the individual thermodynamic parameters of the weak binding sites cannot be determined. This is due to the limiting form of the equation for two classes of binding sites (Freire et al. 1990).

The oxidation states of the Mn centre were characterised by EPR studies. Simulation of spectra of BFR in the dark strongly suggests that manganese ions bound to the BFR ${ }^{1}$ protein remained in the $2+$ oxidation state and are present as a weakly spin-coupled $\mathrm{Mn}_{2}{ }^{\mathrm{II}}$ II centre. The estimated Mn-Mn distance from EPR simulations was $\sim 4 \AA$, a distance agreeing with that obtained in the crystal structure (Frolow et al. 1994). The addition of $\mathrm{ZnCe}_{6}$ appeared to alter approximately $50 \%$ of the $\mathrm{Mn}_{2}{ }^{\text {IIIII }}$ complexes. This behaviour may be rationalized as follows. Initially the homodimer has two identical Mn-clusters. Upon addition of $\mathrm{ZnCe}_{6}$ this symmetry is lost. The BFR protein was engineered to bind $\mathrm{ZnCe}_{6}$ between the two monomeric $\mathrm{BFR}^{1}$ subunits via a methionine residue. Only one monomer of the dimer subunits provides this ligand (the $5^{\text {th }}$ axial coordinate of the $\mathrm{ZnCe}_{6}$ ) see Figure 3.21. The methionine residue is one amino acid 
from the crucial glutamic acid residue (E51) which ligates to both Mn ions in the metal centre. It is possible that the binding of the $\mathrm{ZnCe}_{6}$ disrupts the coupling through movement of the methionine and thus the glutamic acid residue producing a carboxylate shift (presumably moving the two metal centres further apart).

\section{$\mathrm{O}_{2}$ Consumption}

BFR functions in biology to bind iron and oxidize $\mathrm{Fe}_{2}{ }^{\mathrm{II}}$ to $\mathrm{Fe}_{2}{ }^{\mathrm{III}}$. This process involves the formation of a stabilizing $\mu$-oxo bond between the two metal ions. This reaction consumes dissolved $\mathrm{O}_{2}$ ( $\mathrm{Liu}$ et al. 2004). The three phases to this process involve (Equation 3-18) metal binding and deprotonation of amino acid ligands followed by (Equation 3-19) oxidation of bound metal ions with the formation of a single $\mu$-oxo bond between the metal ions and uptake of one oxygen atom per centre. Once all ferroxidase iron binding sites are filled, and all the 48 iron atoms bound per dodecamer of dimers are oxidized, the complex then begins to oxidize excess $\mathrm{Fe}^{\mathrm{II}}$ within the ball and store it as ferric-oxy-hydroxide (Equation 3-20) (LeBrun et al. 1995a; Yang et al. 2000; Baaghil et al. 2003).

$$
\begin{aligned}
& 2 \mathrm{Fe}^{\mathrm{II}}+\mathrm{BFR} \rightarrow \mathrm{Fe}_{2}{ }^{\mathrm{II}, \mathrm{II}}-\mathrm{BFR}+4 \mathrm{H}^{+} \\
& \mathrm{Fe}_{2}{ }^{\mathrm{II}, \mathrm{II}}-\mathrm{BFR}+1 / 2 \mathrm{O}_{2} \rightarrow \mathrm{Fe}^{\mathrm{III}}-\mathrm{O}-\mathrm{Fe}^{\mathrm{III}}-\mathrm{BFR} \\
& 4 \mathrm{Fe}^{\mathrm{II}}+\mathrm{O}_{2}+6 \mathrm{H}_{2} \mathrm{O} \rightarrow 4 \mathrm{Fe}^{\mathrm{III}} \mathrm{O}(\mathrm{OH})(\text { core })+8 \mathrm{H}^{+}
\end{aligned}
$$

Equation 3-18

Equation 3-19

Equation 3-20

The oxygen assay of the $\mathrm{BFR}^{1}$ protein with iron present revealed that $0.25 \mathrm{O}_{2}$ molecules are taken up per iron oxidised (Table 3.3). This agrees with the literature values for the wild type and the $\mathrm{ZnCe}_{6}$ bound form, supporting the assumption that binding of the $\mathrm{ZnCe}_{6}$ does not change the basic function of the protein. Minimal oxygen consumption is observed for $\mathrm{BFR}^{1}-\mathrm{ZM}$ complex suggesting it cannot auto-oxidize $\mathrm{Mn}^{\mathrm{II}}$ to $\mathrm{Mn}^{\mathrm{III}}$ in the dark. Little or no oxygen consumption is observed for these complexes even under the high $\mathrm{pH}$ conditions at which animal ferritins perform this reaction, which is surprising as animal ferritins are very similar in structure and function (Bou-Abdallah et al. 2002; Meldrum et al. 1991; Zhang et al. 2006). 
Upon illumination the $\mathrm{BFR}^{1}-\mathrm{ZM}$ sample consumes $\sim 2 \mathrm{O}_{2}$ per $\mathrm{Mn}$. This value is 4 times larger than for the BFR with Fe bound and may suggest the di-Mn site constructs multiple $\mu$-oxo bridges. Control samples - samples that lack Mn i.e. BFR ${ }^{1}-Z$ - did not consume a significant amount of oxygen confirming that $\mathrm{O}_{2}$ is reacting with the $\mathrm{Mn}$. In samples with a five fold excess of manganese, a significant increase in $\mathrm{O}_{2}$ consumption was observed $(\sim 20 \mu \mathrm{M})$. This likely indicates that 'free' $\mathrm{Mn}^{2+}$ is oxidised within the ball structure forming $\mathrm{Mn}^{\mathrm{III}}$-oxy-hydroxide. The addition of catalase and SOD was found to increase the rate of oxygen consumption but did not have any significant effect on the total amount consumed. We suggest that it acts to protect the chlorin, removing superoxides and other reactive oxygen species

\section{Tyrosine Oxidation}

In the absence of manganese, illumination of the $\mathrm{BFR}^{1}-\mathrm{Z}$ produces a large $\mathrm{ZnCe}_{6}{ }^{-+}$ radical cation signal at $\mathrm{g}=2.0022$. In contrast, addition of $\mathrm{Mn}$ results in the loss of the $\mathrm{ZnCe}_{6}{ }^{\circ+}$ radical and the appearance of a 'tyrosine like' radical. This new radical signal is unlikely to be the $\mathrm{ZnCe}_{6}{ }^{++}$radical broadened due to through bond / through space interactions with the $\mathrm{Mn}$ site as the distance between the $\mathrm{Mn}$ centre and the $\mathrm{ZnCe}_{6}$ is a relatively large $\sim 14 \AA$. The intensity of the tyrosine signal is significantly in excess of the $\mathrm{ZnCe}_{6}$ ( 6 fold). This is unsurprising as tyrosine radicals are generally much longer lived than chlorin radicals (Tang et al. 1996; Miloslavina et al. 2006).

The most likely mechanisms for tyrosine oxidation is electron hole migration from the oxidized $\mathrm{ZnCe}_{6}{ }^{+}$radical to a nearby tyrosine residue. $\mathrm{ZnCe}_{6}$ has a high estimated oxidation potential of $\sim 1.1 \mathrm{~V}$ (Hay et al. 2004) which is sufficient to oxidize a tyrosine. The $+0.5 \mathrm{~V}$ oxidation potential of the manganese centre should allow it to be oxidised by any tyrosine radical formed. It is unclear why tyrosine oxidation does not occur when no manganese ions are bound. When Mn (or any metal) binds to the BFR metal site deprotonation of the metal ligands occurs along with structural changes to the ligands themselves. These changes may alter the hydrogen bonding network around the tyrosine allowing proton coupled electron transfer.

There are three tyrosine residues in BFR (Y25, Y58, and Y45) that are close enough to the $\mathrm{ZnCe}_{6}(10.6 \AA, 11.0 \AA$, and $4.2 \AA$ respectively) that they could potentially act as 'efficient' electron donors (Figure 3.21). Tyrosine 45 rests within van der Waals 
bonding distance of the $\mathrm{ZnCe}_{6}$ and makes up part of the heme binding pocket. It is unlikely that this tyrosine would be affected by Mn binding and as such is not likely to be the electron donating residue. This leaves only two tyrosines (Y25 and Y58) which are found at the metal binding site and are both involved in the hydrogen bonding network of the site. Tyrosine 58 is not highly conserved and is commonly replaced by a leucine in other bacterioferritins. Tyrosine 25 is hydrogen bonded to glutamate 94 which is one of the metal ligands with the oxygen atom of this tyrosine placed $4.3 \AA$ from the nearest $\mathrm{Mn}$ ion. Ferritins, which have very similar structure and function to bacterioferritin but don't bind heme, have a redox active tyrosine within the hydrogen bonding network of the metal binding site. This residue is highly conserved in ferritins and bacterioferritins (Carrondo 2003). As a consequence, we suggest tyrosine (Y25) is likely to be the redox active residue in our system. This is currently being tested in our lab.

\section{$\mathrm{Mn}^{2+}$ Oxidation}

The loss of $\mathrm{Mn}^{\mathrm{II}}$ signals upon illumination of BFR ${ }^{1}-\mathrm{ZM}$ strongly suggests Mn oxidation occurs in this system. The broad structured $\mathrm{Mn}_{2}{ }^{\mathrm{II}, \mathrm{II}}$ signal centred at $\mathrm{g}=2$ was found to decrease in $\mathrm{BFR}^{1}-\mathrm{ZM}$ samples upon illumination. This structured $\mathrm{Mn}_{2}{ }^{\mathrm{IIII}}$ signal decreased on average by $34 \%$.

No new Mn EPR signals were observed upon loss of the $\mathrm{Mn}^{\mathrm{II}}$ signal in BFR ${ }^{1}-\mathrm{ZM}$. We would expect the one electron oxidation of an $\mathrm{Mn}_{2}{ }^{\text {II,II }}$ to yield a mixed valence $\mathrm{Mn}_{2}{ }^{\text {II,III }}$ dimer. Strongly coupled mixed valance dimers $\left(\mathrm{J} \approx 10 \mathrm{~cm}^{-1}\right)$ display characteristic 'multiline' signals seen in perpendicular mode EPR centred at g 2 with hyperfine splittings of $<90 \mathrm{G}$ (Teutloff et al. 2005). In contrast, the weakly coupled mixed valance dimer should still have broader perpendicular signals and could possibly resolve parallel polarization signals (Teutloff et al. 2005; Groni et al. 2008). As neither of these is seen, it is suggested the Mn cluster undergoes two electron oxidation to a even spin $\mathrm{Mn}_{2}{ }^{\text {IIIIII }}$ system. It is not clear as to whether both proposed $\mathrm{Mn}^{\text {II }}$ oxidation events need to be photo-driven. As no intermediate state $\left(\mathrm{Mn}_{2}{ }^{\text {IIIIII })}\right.$ was observed, the second oxidation state may not require light excitation of the chlorin. Alternatively the mixed valance cluster may be more strongly oxidizing (electron donating) to the oxidized tyrosine/chlorin than the $\mathrm{Mn}_{2}{ }^{\mathrm{II}, \mathrm{II}}$ precursor state. Oxygen bridged $\mathrm{Mn}_{2}{ }^{\text {III,III }}$ dimers with analogous ligand fields have been observed at approximately zero-field $(\mathrm{g}=20$ ) 
(Whittaker et al. 2003). We cannot discount the presence of these signals in our illuminated BFR complex.

The $\mathrm{BFR}^{1}-\mathrm{ZM}$ sample with a five fold excess of $\mathrm{Mn}$ revealed the same decrease in amplitude of the structured $\mathrm{g}=2 \mathrm{Mn}_{2}$ IIII signal upon illumination as seen in samples with stoichiometric Mn. The six-line signal also showed a significant decrease upon illumination. This signal decreased by $25 \%$, equivalent to $4 \mathrm{Mn}$ oxidations per BFR dimer (48 Mn ions per dodecamer of dimers). Parallel polarization EPR on illuminated samples with excess Mn suggested the formation of a manganese species with even spin character, upon illumination of the BFR ${ }^{1}-\mathrm{ZM}$ complex; a broad signal centred at $\mathrm{g}_{\text {eff }} \sim 4$ 5 with clear hyperfine structure (Figure 3.20). As this signal is not observed in illuminated samples with stoichiometric Mn, it is suggested that this signal comes from a new Mn species unlikely to be bound to BFR. Comparing this to the native function of ferritins, it is tempting to assign the species to $\mathrm{Mn}^{\mathrm{III}}$-oxy-hydroxide $\left[\mathrm{Mn}^{\mathrm{III}}(\mathrm{O}) \mathrm{OH}\right]$ which is accumulated in the core of the sphere structure (Zhang et al. 2005).

$\mathrm{Mn}^{\mathrm{III}}$ is a $\mathrm{d}^{4}$ even spin $(\mathrm{S}=2)$ transition ion (Abragam and Bleaney 1970). There are potentially three geometries that $\mathrm{Mn}^{\mathrm{III}}$ complexes in this protein ligand field can take: 6 coordinate octahedral, 5 coordinate square-pyramidal or trigonal-bipyramidal (Campbell et al. 2000). The ground electronic state of the $\mathrm{Mn}^{\mathrm{III}}$ manifold depending on the geometry of the ligand field can have two different $\mathrm{d}^{4}$ configurations corresponding to the electronic hole position. The hole either occupies the $d_{x^{2}-y^{2}}$ orbital (ground state ${ }^{5} \mathrm{~B}_{1}$ ) or the $d_{z^{2}}$ orbital (ground state ${ }^{5} \mathrm{~A}_{1}$ ). The hyperfine splitting for each of these states is different due to the effect of spin-orbit coupling (Gerritsen and Sabisky 1963; Griffith 1971; Al'tshuler and Kozyrev 1974; Campbell et al. 2000). A ground state of ${ }^{5} B_{1}$ yields a hyperfine splitting along $\mathrm{A}_{\mathrm{Z}}$ of $\sim 50 \mathrm{G}$ whereas a ground state of ${ }^{5} \mathrm{~A}_{1}$ yields a hyperfine splitting of $100 \mathrm{G}$ (Gerritsen and Sabisky 1963; Campbell et al. 2000; Tyryshkin et al. 2006). In this instance the sign of the Spin Hamiltonian parameter D indicates the ground state of the manifold. A positive $\mathrm{D}$ value yields a ${ }^{5} \mathrm{~A}_{1}$ ground state (as observed for the $\mathrm{Mn}^{\mathrm{III}}$ centre of the SOD protein) whereas a negative $\mathrm{D}$ values yields a ${ }^{5} \mathrm{~B}_{1}$ ground state (as observed for the $\mathrm{Mn}^{\mathrm{III}}$ photo-assembly intermediate of PS II) (Griffith 1971; Whittaker and Whittaker 1991; Campbell et al. 1999; Campbell et al. 2000). 
Recently parallel polarization EPR signals have been reported for $\mathrm{Mn}^{\mathrm{III}}$ peroxo complexes (i.e. $\left.\mathrm{Mn}^{\mathrm{III}}(\mathrm{O}) \mathrm{OH}\right)(\mathrm{Groni}$ et al. 2008). These signals were generated by the oxidation of (L) $\mathrm{Mn}^{\mathrm{II}}$ (where $\mathrm{L}=\mathrm{N}$-methyl-tris(2-pyridylmethyl)ethan-1,2-diamine) using a 1000 fold excess of $\mathrm{H}_{2} \mathrm{O}_{2}$ as an oxidant. Two parallel polarization signals were observed: a structured signal at $\mathrm{g} \sim 8$ with hyperfine splitting $\sim 50 \mathrm{G}$ (analogous to $\mathrm{Mn}^{\mathrm{III}}$ signals described above (Campbell et al. 2000; Campbell et al. 2001; Tyryshkin et al. 2006) and a less structured signal at g 5 with hyperfine splitting $\sim 95$ G. It was noted that the addition of base (triethyl-amine) led to the loss of the high field signal (g 5). Conversely the addition of acid $\left(\mathrm{HClO}_{4}\right)$ lead to the loss of the low field signal $(\mathrm{g} \sim 8)$. As a consequence the low field signal ( $\mathrm{g}$ 8) was assigned to the monocationic species $\left[\mathrm{LMn}^{\mathrm{III}}(\mathrm{OO})\right]^{+}$. Both UV-Vis and ESI-MS supported this assignment. XSophie EPR simulations estimated the zero-field and hyperfine parameters of this complex to be: $\mathrm{D}$ $=-2.9 \mathrm{~cm}^{-1}, \mathrm{E} / \mathrm{D}=0.075, \mathrm{~A}_{\mathrm{Z}}=6.5 \times 10^{-3} \mathrm{~cm}^{-1}$ (Groni et al. 2008). Curiously, the second signal (g 5) was not assigned to the corresponding protonated species $\left[\mathrm{LMn}^{\mathrm{III}} \mathrm{OOH}\right]^{2+}$. It was noted that though the signal could be modelled as arising from a $\mathrm{Mn}^{\mathrm{III}} \operatorname{signal}(\mathrm{D}=$ $+2.9 \mathrm{~cm}^{-1}, \mathrm{E} / \mathrm{D}=0.111$ ), the resolved hyperfine structure (splittings of $\sim 95 \mathrm{G}$ ) was inconsistent with assignment to a $\mathrm{Mn}^{\mathrm{III}}$ (Groni et al. 2008). From the above discussion this argument does not seem valid; $\mathrm{Mn}^{\mathrm{III}}$ can potentially resolve hyperfine splitting of the order of $\sim 100 \mathrm{G}$. We note the $\mathrm{D}$ value changes sign for these two complexes, which should reflect a re-ordering of electronic state manifold (ground state interchanges from ${ }^{5} \mathrm{~B}_{1}$ to ${ }^{5} \mathrm{~A}_{1}$ ) as seen between $\mathrm{Mn}^{\mathrm{III}}$ photo-assembly intermediate of PS II and Mn-SOD protein, leading to an apparent increase in hyperfine splitting observed (Campbell et al. 1999; Campbell et al. 2000).

Our new Mn EPR signal observed in BFR bears a resemblance to the g 5 signal seen in the above study (Groni et al. 2008) appearing at approximately the same g position (g 4-5). It too has a large hyperfine spacing as seen for the potential $\left[\mathrm{LMn}^{\mathrm{III}} \mathrm{OOH}\right]^{2+}$ species. We do acknowledge though that the hyperfine spacing seen $(\sim 150 \mathrm{G})$ in the 'new Mn EPR signal' is exceedingly large for a monomeric Mn ${ }^{\mathrm{III}}$. The unusually large hyperfine splitting may reflect the unique environment Mn centres occupy in the core of the sphere protein structure (Mn-Mn interactions etc). Alternatively, the new EPR signal may represent a di-Mn species, possibly a weakly coupled mixed valance dimer (i.e. $\mathrm{Mn}^{\mathrm{II}} \mathrm{Mn}^{\mathrm{III}}$ ). 


\subsection{Conclusion}

In this study we have shown that a modified bacterioferritin complex (BFR $\left.{ }^{1}-\mathrm{ZM}\right)$ is capable of using light energy to drive photochemical charge separation and couples this oxidising potential to multiple oxidation events within a protein bound $\mathrm{Mn}_{2}{ }^{\mathrm{II}}$ complex. To my knowledge this work is the first example reported in the literature of a bioengineered protein capable of photo-catalytic, multi-electron oxidation of a dimanganese centre. This represents one of the first steps in developing synthetic photocatalytic, 'green enzymes' that utilize light energy to catalyse oxygen evolution and hydrogen production. 


\section{CHAPTER 4}

\section{Bacterioferritin Heterodimer}

\subsection{Introduction}

The previous chapter outlined the successful implementation of bacterioferritin from E.coli as a scaffold for PSII cofactor binding. This construct was limited in a number of aspects and of particular note was the lack of a bound electron acceptor. Electron acceptors placed in solution provide low yields of electron transfer due to the large reorganization energies associated with transferring an electron through a high dielectric medium such as water. This chapter documents the engineering of a BFR based heterodimeric light activated metallo-protein that contains a quinone electron acceptor built into the protein matrix. Inspiration for this engineering project was again taken from PSII which is made up of a heterodimer that allows for electron transfer along a chain of redox cofactors culminating in the reduction of a quinone.

In order to engineer an electron acceptor within the protein matrix it was necessary to modify the bacterioferritin protein such that a linker chain of amino acids was used to join two monomeric subunits which normally form a homodimer. The linker was a repeated motif joining the $\mathrm{C}$ terminus of one subunit to the $\mathrm{N}$-terminus of the second subunit. A key feature of this linker is that it produced a dimeric form of the protein which allowed one half of the protein to be modified without changing the other half. In joining the proteins it allowed for the amino acids associated with metal (Mn) coordination to be removed in one sub-unit and replaced with a residue that enabled covalent attachment of a quinone. This produced a heterodimeric protein with a redox active metal centre on one side, a light active porphyrin centrally located, and a protein bound electron acceptor on the other side. This linearised electron transfer pathway is shown in Figure 4.1.

To achieve expression of a heterodimeric protein required use of a complex set of molecular biology based techniques. Introducing a combination of three different genes, $\mathrm{BFR}^{1}$ (H46R, H112R), BFR ${ }^{2}$ (H46R, H112R, E51C) and a 22 amino acid linker within 
a plasmid produced two final heterodimer constructs. Both of these constructs were then mutated to remove unwanted histidine residues within the linker region producing the final two different versions of the heterodimeric protein, BFR-H1 and BFR-H2 (see Chapter 2 for details).

BFR-H1 was made of two identical BFR $^{1}$ subunits linked via a 22 amino acid linker. This protein should have similar characteristics to that of the $\mathrm{BFR}^{1}$ protein utilized in the previous chapter. BFR-H2 contained a mutation (E51C) in subunit B as depicted in Figure 4.1, which enabled a quinone to be covalently bound to the cysteine sulphur within the metal binding pocket. This mutation prevents metal binding at the metal centre and produces an asymmetrical heterodimer. The final expressed heterodimeric proteins were 338 amino acids in length and had a molecular weight of $38.8 \mathrm{kDa}$.

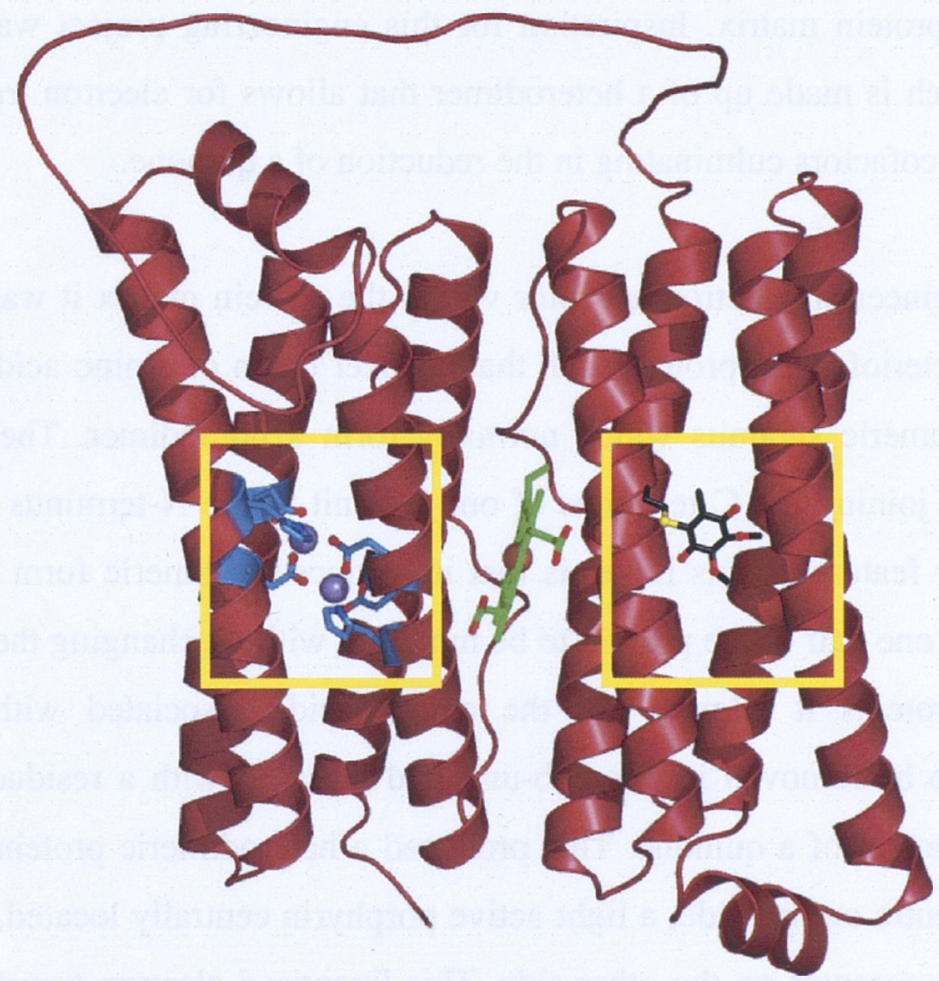

Figure 4.1: Bacterioferritin heterodimer (BFR-H2) with one subunit of the dimer changed relative to the other. This heterodimer contains a complete electron transport chain, with a light active $\mathrm{ZnCe}_{6}$ molecule, a covalently attached quinone electron acceptor, and a di-manganese centre as electron donor. Molecular mechanics optimization of the structure was carried out using a PolakRibiere algorithm (conjugate gradient) on the original dimer structure with the 22 amino acid linker region incorporated (Polak and Ribiere 1969). 
The linker sequence contained a flexible Ser-Gly-Gly repeat with a single basic lysine residue in the middle. This linker is expected to be solvent exposed and free to move in solution. It was necessary to keep the length of this linker region to a minimum to prevent having a large unstructured loop destabilizing the heterodimers. X-ray crystal structure data for the E.coli BFR homodimer sets the spatial separation between the N and $\mathrm{C}$ termini of the adjoining $\mathrm{A}$ and $\mathrm{B}$ subunits as $28.8 \AA$. The linker was modelled to have a length of $79 \AA$ when extended out straight. Modelling of this linker predicted that it should be long enough to prevent steric hindrance of the formation of the dimer but not so long as to destabilise the structure of the protein (Whitney and Sharwood 2006).

The production of the heterodimer enables four cofactors to be placed within close proximity of each other. Overlaying the new cofactors onto the wild type BFR crystal structure and modelling the changes associated with binding the cofactors produces a set of cofactors spaced as per Figure 3.3.

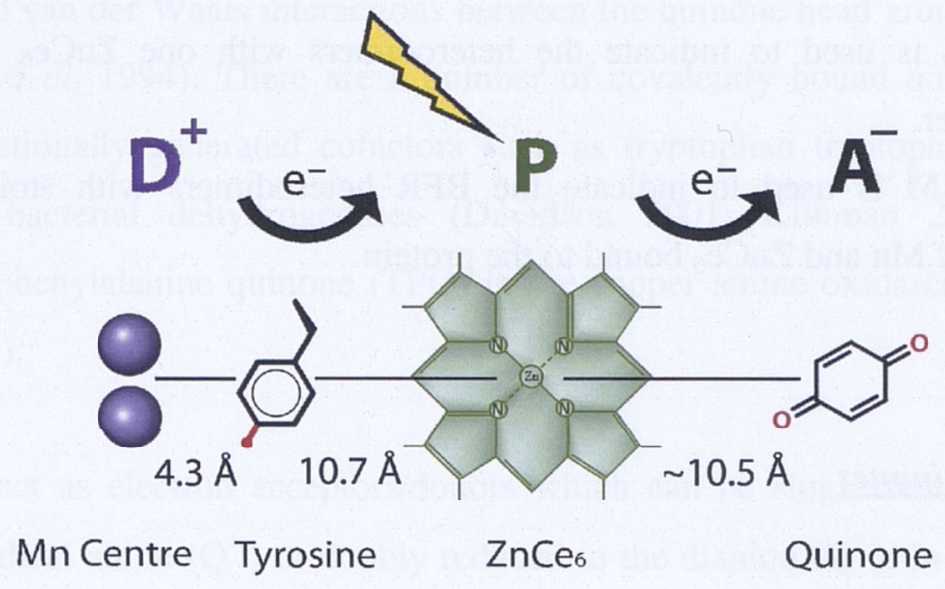

Figure 4.2: Diagram showing the relative distance of separation of all of the cofactors bound to the BFR heterodimer protein. Distances are given as edge to edge for the conjugated systems and metal ions .

The use of an existing protein scaffold (i.e. bacterioferritin), makes the process of constructing and analysing light activated metallo-enzymes much easier. Utilising natural protein folds and tertiary structure removes the need for complete de novo design of a protein and in only making minor modifications the structure is readily maintained. In analysing these complexes there are advantages as each individual 
cofactor can be introduced systematically, allowing the characterization of its interactions with the protein environment. This is much simpler than working with the large membrane bound PSII complex which requires progressively breaking down the complex with detergents in order to study its function. Such treatment can damage the reaction centres before they can be analysed.

The BFR heterodimer constructs were labelled as BFR-H1 and BFR-H2 to refer to the $\mathrm{H} 1$ heterodimer and $\mathrm{H} 2$ heterodimer construct which has the capacity for quinone binding. Further to this the labels $\mathrm{Z}, \mathrm{M}$ or $\mathrm{ZM}$ have been included to indicate the cofactors bound to these proteins.

- BFR-H indicates the apo-form of either of the BFR heterodimer proteins, devoid of all cofactors.

- BFR-H M is used to indicate BFR heterodimer proteins with a stoichiometric number of $\mathrm{Mn}$-ions bound (i.e. $4 \mathrm{Mn}$ ions for BFR-H1 but only $2 \mathrm{Mn}$ ions for BFR-H2).

- BFR-H $\mathbf{Z}$ is used to indicate the heterodimers with one $\mathrm{ZnCe}_{6}$ bound per heterodimer.

- BFR-H ZM is used to indicate the BFR heterodimers with stoichiometric amounts of $\mathrm{Mn}$ and $\mathrm{ZnCe}_{6}$ bound to the protein.

\subsubsection{Quinones}

Quinones are di-ketones and are utilised extensively in nature as electron acceptors in electron transfer chains. Ubiquinone (coenzyme Q, CoQ), is a lipid soluble parabenzoquinone which is ubiquitous in biological systems (Figure 4.3). It is found in the mitochondria and bacterial reaction centres and undergoes cyclic oxidation-reduction during the oxidation of substrates. Ubiquinones are named dependent on the number of isoprene units in the hydrophobic tail e.g. $n=10$ : coenzyme $Q_{10}$. Higher plants use a different quinone as electron acceptor called plastoquinone, which has methyl groups instead of methoxy groups attached to the cyclic carbon ring of the quinone. 
<smiles>COC1=C(OC)C(=O)C(CC=C(C)CCO)=C(C)C1=O</smiles>

Figure 4.3: Ubiquinone Coenzyme Q (2,3dimethoxy-5-methyl-1,4-benzoquinone).

Quinones can be non-covalently bound as is the case of quinones in photosynthetic (Allen and Williams 1998; Heathcote et al. 2002; Wraight 2004) and respiratory (Cecchini et al. 2003; Ohnishi and Salerno 2005; Osyczka et al. 2005) electron-transfer pathways. Non-covalently bound quinones are also found in the pyrroloquinoline quinone (PQQ) containing proteins (Anthony 2004). These non-covalently bound membrane associated quinones tend to bind at specific hydrophobic sites via interaction with the long phytyl tail but are stabilised by hydrogen bonding with the carbonyl oxygen and van der Waals interactions between the quinone head group and the protein (Warncke et al. 1994). There are a number of covalently bound quinones which are post-translationally generated cofactors such as tryptophan tryptophylquinone (TTQ) found in bacterial dehydrogenases (Davidson 2001; Klinman 2001) and 2,4,5trihydroxyphenylalanine quinone (TPQ) in the copper amine oxidases (Klinman 2001; Mure 2004).

Quinones act as electron acceptors/donors which can be singly reduced to the semiquinone radical anion $\left(\mathrm{Q}^{\bullet}\right)$ or doubly reduced to the dianion $\left(\mathrm{Q}^{2-}\right)$. In protic media, the strong affinity of the quinol hydroxyls for protons results in the formation of a stable, neutral quinol at $\mathrm{pH}$ values below their $\mathrm{pK}$ 's that is greatly stabilized in relation to the semi-quinone. This results in the potential of the second reduction step $\left(\mathrm{Q}^{\circ-}\right.$ to $\left.\mathrm{QH}_{2}\right)$ being much higher than that of the first ( $Q$ to $Q^{\bullet}$ ), giving rise to its $n=2$ equilibrium redox chemistry (Rich 2004). The redox potentials of quinones in electron transport chains are ideally suited as electron acceptors with potentials ranging from $-130 \mathrm{mV}$ up to $+250 \mathrm{mV}$ (Krieger et al. 1995; Krieger-Liszkay and Rutherford 1998; Li et al. 2006; Rappaport and Diner 2008). 
General structural motifs for the binding of quinones in natural systems is starting to emerge (Fisher and Rich 2000) though these motifs are not so well understood as to be able to use de novo design to build a pocket for stable quinone binding. The best characterized binding site is the $\mathrm{Q}_{\mathrm{A}}$ site of the photosynthetic reaction centres from purple bacteria (Heathcote et al. 2002; Wraight 2004)). This site is structurally similar to the $\mathrm{Q}_{\mathrm{A}}$ site of photosystem II (Ferreira et al. 2004; Loll et al. 2005) and has similarities to the quinone $\mathrm{Q}_{\mathrm{D}}$ binding site in the $E$. coli fumarate reductase (Iverson $e t$ al. 1999; Cecchini et al. 2003)

Recently, 3,4-dihydroxy-L-phenylalanine was incorporated into proteins by expanded genetic-code technique to generate $o$-quinone bound to proteins (Alfonta et al. 2003). Though this avoids the need to build a quinone binding site but it is a complex process to incorporate a potentially toxic molecule into E.coli and it is easier to simply covalently bind a quinone within the final purified protein matrix. This enables the quinone to be buried away from the high dielectric solvent decreasing the reorganisation energy required for electron transfer.

It has long been known that unsubstituted quinones such as para-benzoquinone (pBQ) form adducts with thiol-containing compounds (Snell and Weissberger 1939) including cysteine (Redfearn 1965). Hay et al (2004) were the first group to make use of this novel addition reaction and by modifying the gene for cytochrome $b_{562}$ were able to place a cysteine residue within the interior of this protein and covalently attach a quinone molecule. When the cysteine site was covalently linked to 2,3-dimethoxy-5methyl-1,4-benzoquinone $\left(\mathrm{CoQ}_{0}\right)$ (ubiquinone lacking the multiprenyl tail), and $\mathrm{ZnCe}_{6}$ was bound in the heme pocket, light-induced electron transfer from the bound pigment to the bound quinone was achieved (Hay et al. 2004).

Other methods for binding quinone's to proteins have been investigated using thiol addition reactions as well as addition-elimination reactions between the cysteine sulphur and thioether quinones ( $\mathrm{Li}$ et al. 2005). The reaction of cysteine and $\mathrm{CoQ}_{0}$ is thought to occur according to Figure 4.4. 


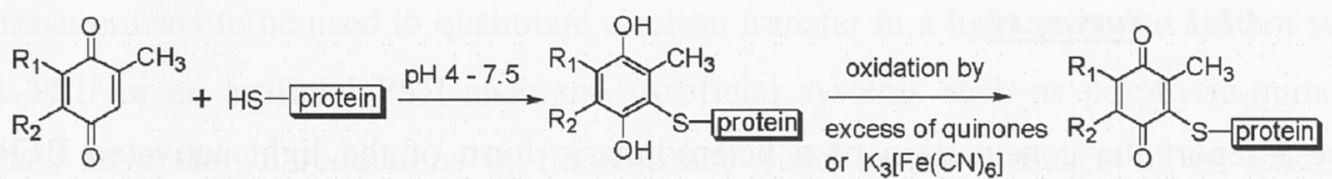

Figure 4.4: The covalent attachment of a quinone to the cysteine sulphur of a protein via a thiol addition reaction Taken from ( $\mathrm{Li}$ et al. 2005).

\subsubsection{Quinone Binding Site Design}

The quinone binding site for BFR was designed such that the quinone could be bound within the protein matrix and shielded from the solvent phase. The site chosen was the metal binding site of BFR ${ }^{1}$. This site allows the binding of a large cofactor due to the cavity that already exists for the incorporation of two iron atoms. The removal of the Glu51 residue and replacement with the much smaller cysteine residue further opens this space for the binding of a quinone. Assuming the structural model of BFR still holds for the heterodimer proteins then it is expected that the quinone will be placed $10.6 \AA$ from the chlorin.

The protein matrix can have a large effect on the redox potential of the quinone when it is conjugated to a cysteine. Reports of shifts between $+110 \mathrm{mV}$ and $+140 \mathrm{mV}$ have been reported for 2,5-dimethyl-1,4-benzoquinone (DMBQ) and $\mathrm{CoQ}_{0}$ respectively, when bound to de novo designed constructs versus acetyl cysteine adducts (Hay et al 2007; Li et al 2006). Although previous work by Hay et al showed only a small shift of $\sim 25 \mathrm{mV}$ when $\mathrm{CoQ}_{0}$ was bound to an engineered Cyt $b_{562}$ (Hay et al. 2004). The protein construct did not contain any potential hydrogen bonding partners with the bound quinone which may be the reason for so little change in the redox potential. The type of quinone covalently bound has been found to have little effect on the rates of electron transfer suggesting that the chemical nature of the quinone itself has little effect on efficiency (Hay et al. 2004). As the quinone binding site in the BFR heterodimer contains two histidine residues which could potentially hydrogen bond with the quinone we could expect an increase in the potential possibly approaching that found by Li et al (2006) i.e. $+229 \mathrm{mV}$. 


\subsubsection{Summary}

Here I report the construction of a heterodimeric form of the light activated BFR ${ }^{1}$ metallo-catalyst from Chapter 3. The previous chapter focused on light induced oxidation state changes in the manganese centre i.e. $\mathrm{Mn}_{2}{ }^{\mathrm{IIII}}$ to $\mathrm{Mn}_{2}{ }^{\mathrm{III}, \mathrm{III}}$. This chapter focuses on the production of the heterodimer and assessment of its biochemical properties. The light induced electron transfer from $\mathrm{ZnCe}_{6}$ to a quinone electron acceptor bound within the protein matrix was followed using steady state fluorescence and EPR.

\subsubsection{Theory of Techniques Used}

\section{Fluorescence Energy Transfer}

When an electron is excited to an orbital with a high electronic energy, the excess energy is stored. In most cases this stored energy is transferred as heat, and is called non radiative energy transfer. Because of the relative configurations of the excited and ground states, the electron can easily make a transition from a vibrational state in the excited system to a nearly degenerate level in the ground state, and it can continue to undergo non radiative energy loss until it reaches the ground state. Radiative energy transfer occurs when the lowest vibrational level of the excited state is too far above any vibrational level in the ground state for energy to be relinquished except with the radiation of a photon. Some energy is given off as heat before radiative processes can occur which is why the wavelength of emitted light is usually of a lower energy than the excitation wavelength, this called the Stokes shift. Other decay processes can occur to enable energy dissipation, these include intersystem crossing to a triplet state followed by phosphorescence, or electron transfer. The levels of phosphorescence are usually small compared to the levels of fluorescence due to the transition from the triplet state to a ground state being forbidden according to quantum mechanical rules and as a result the rate constant is several orders of magnitude smaller than those of fluorescence.

Assuming the major form of energy dissipation is fluorescence for a given light absorbing porphyrin then enabling electron transfer in this system as a form of energy dissipation will markedly decrease the yield of fluorescence. This enables fluorescence 
measurements to be used to quantitate electron transfer in a light activated system such as PSII or an artificial PSII analogue. Artificial systems such as porphyrin-quinone diads have shown reductions in fluorescence yield in the presence of an oxidised quinone. Ho and co-workers used an amide-linked free-base porphyrin and benzoquinone. Quinone-induced quenching of the porphyrin fluorescence was seen. As well as fluorescence quenching a porphyrin cation radical and a semi-quinone radical were generated upon light excitation (Ho et al. 1980). These two observations are consistent with the formation of a charge separated state. There are numerous examples of donor-acceptor molecules that have been designed and several reviews written (Wasielewski 1992; Gust et al. 1993; Kurreck and Huber 1995; Gust et al. 2001).

\section{Electron Paramagnetic Resonance}

Quinones when singly reduced form a semi-quinone radical anion $\left(Q^{\circ}\right)$. EPR acts as a sensitive technique to measure this radical. The semi-quinone radical produces a characteristic signal centred around $g=2$. These radicals like most organic radicals have very long spin lattice relaxation times which results in EPR spectra exhibiting relatively narrow peaks even at room temperature. 


\subsection{Results}

\subsubsection{Cofactor Assembly in BFR Heterodimers}

The BFR heterodimer proteins were over expressed in E.coli, before purification on a metal affinity column. The purified proteins then had the histidine tagged ubiquitin protein cleaved off using a ubiquitin specific protease. The cleaved BFR protein was then purified from the tag again using metal affinity chromatography. The expressed proteins were red in colour due to a heme group bound at the interface of the dimers in a hydrophobic pocket. For the heme to bind between the subunits the protein must be properly folded and structured.

UV-visible spectroscopy reveals the characteristic bands found for heme bound via two methionine residues in E.coli bacterioferritin (Figure 4.5) (Yariv et al. 1981). The oxidised forms of the BFR heterodimers have a Soret band at $418 \mathrm{~nm}$ and this red shifts upon reduction with sodium dithionite out to $425 \mathrm{~nm}$. Two characteristic Q bands are found for the bound heme at 531 and $561 \mathrm{~nm}$ for the oxidised form shifting to 528 and $558 \mathrm{~nm}$ when reduced. All forms of the BFR protein including the wild type and heterodimers $\mathrm{H} 1$ and $\mathrm{H} 2$ retain the same spectral characteristics with no changes in the band positions.

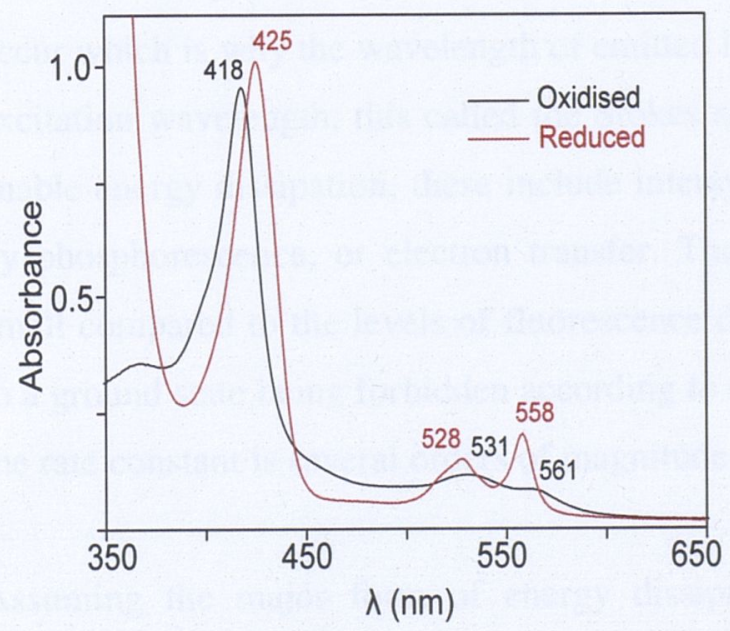

Figure 4.5: The UV-visible spectra of holo BFR-H2 in its oxidised form (black) and reduced form (red). All three BFR heterodimers produced the same spectra but only one is shown for clarity. 
The heme was removed from the BFR heterodimer proteins again using methyl ethyl ketone and any bound metal ions were removed through exhaustive dialysis against EDTA under reducing conditions (Teale 1959; Bauminger et al. 1991) The secondary structure of the BFR-H1 and $\mathrm{H} 2$ proteins was then assessed using $\mathrm{CD}$ spectroscopy (Figure 4.6 and Figure 4.7). A more comprehensive CD analysis program (CD spectra deconvolution v2.1 (C) Dr. Gerald Bohm) was used to fit the spectra which gives a more accurate picture than the previous analysis program $(\mathrm{Kd} 2)$ used in Chapter 3.

Analysis of the CD spectra revealed that the heterodimer proteins were less structured than the $\mathrm{BFR}^{1}$ mutant. Fitting the spectra revealed that the proteins contained less alphahelix than found in $\mathrm{BFR}^{1}$. It was found that the addition of manganese ions to the proteins increased the alpha-helix content marginally and reduced the amount of random coil. This was more evident in BFR-H2 than in BFR-H1.

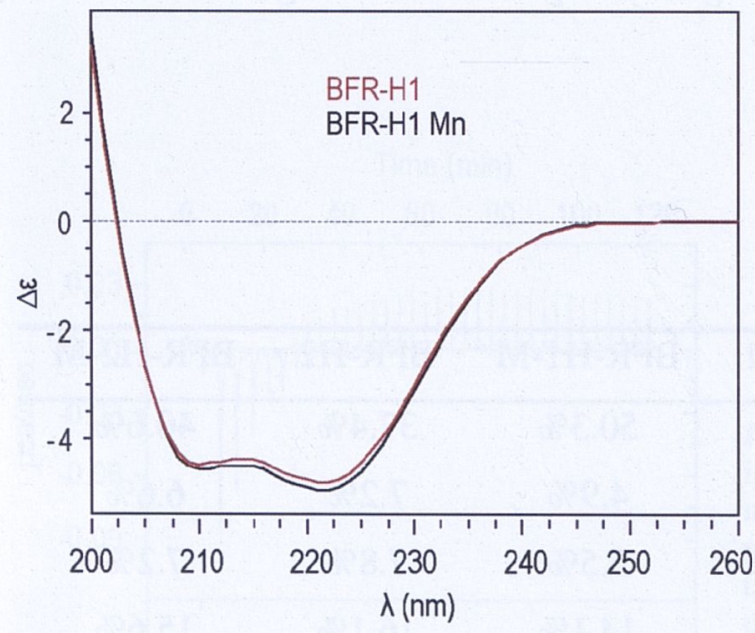

Figure 4.6: The CD spectra of apo BFR-H1 and BFR-H1 in the presence of manganese. The addition of manganese produced a small change in the secondary structure. BFR-H1 $10 \mu \mathrm{M}, \mathrm{Mn} 40 \mu \mathrm{M}$ in TBS buffer $\mathrm{pH} 7.7$

BFR-H2 was less structured than BFR-H1 suggesting that the mutation of Glu51 to a cysteine had an effect on the secondary structure of this protein (Figure 4.7). There was $>10 \%$ reduction in the amount of alpha-helix as compared to BFR-H1 and an increase in the amount of random coil, indicating it is a less structured protein (Table 4.1). 


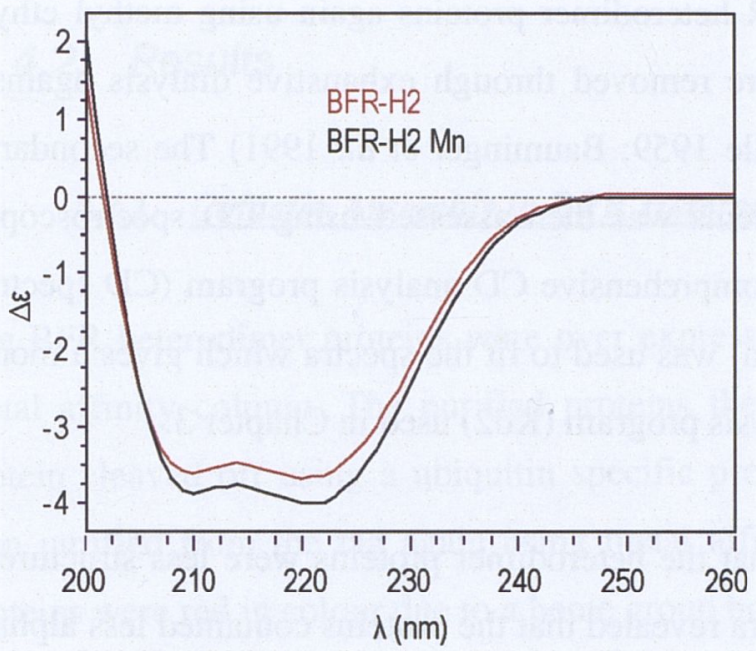

Figure 4.7: The CD spectra of apo BFR-H2 and BFR-H2 plus manganese. The addition of manganese had a significant effect on the secondary structure. BFR-H2 $10 \mu \mathrm{M}, \mathrm{Mn} 40 \mu \mathrm{M}$ in TBS buffer $\mathrm{pH} 7.7$

According to native PAGE electrophoresis the BFR heterodimer proteins do not form the spherical $\sim 444 \mathrm{kDa}$ dodecamer of dimers. It is possible that it does form in solution but under the conditions used to run the gels no high molecule weight multimer bands were found.

Table 4.1: CD Structural Parameters

\begin{tabular}{lccccc}
\hline & BFR & BFR-H1 & BFR-H1-M & BFR-H2 & BFR-H2-M \\
\hline Helix & $75.3 \%$ & $48.6 \%$ & $50.3 \%$ & $37.4 \%$ & $40.6 \%$ \\
Antiparallel & $2.2 \%$ & $5.1 \%$ & $4.9 \%$ & $7.2 \%$ & $6.6 \%$ \\
Parallel & $2.6 \%$ & $5.8 \%$ & $5.5 \%$ & $7.8 \%$ & $7.2 \%$ \\
Beta-Turn & $10.7 \%$ & $14.4 \%$ & $14.1 \%$ & $16.1 \%$ & $15.6 \%$ \\
Random Coil & $12.5 \%$ & $24.2 \%$ & $23.5 \%$ & $30.3 \%$ & $28.5 \%$ \\
Total Sum & $103.3 \%$ & $98.2 \%$ & $98.3 \%$ & $98.8 \%$ & $98.3 \%$ \\
\hline
\end{tabular}

\section{Isothermal Titration Calorimetry}

Cofactor binding was monitored using ITC to determine the binding constants (K), reaction stoichiometries $(\mathrm{n})$, enthalpies $\left(\Delta \mathrm{H}^{\circ}\right)$, and entropies $\left(\Delta \mathrm{S}^{\circ}\right)$ of manganese binding and $\mathrm{ZnCe}_{6}$ interactions. The $\mathrm{BFR}^{1}$ protein from Chapter 3 revealed that $2.5 \mathrm{Mn}$ ions were bound per monomer of protein (Table 4.2a). This construct was only expected 
to bind $2 \mathrm{Mn}$ ions and the extra 0.5 were expected to be either bound within the pores of the dodecamer of dimers sphere structure or non-specifically bound.

The heterodimer construct BFR-H2 has the E51C mutation in one half of the dimer where the crucial glutamic acid residue was mutated to a cysteine such that the metal binding site in one half of the protein should no longer function to bind metal ions. This mutation places a cysteine such that a quinone electron acceptor can be covalently bound within the protein matrix. To look at the effects of this mutation in isolation, the $\mathrm{BFR}^{1}$ homodimer protein was mutated further to produce $\mathrm{BFR}^{2}$ ( $\left.\mathrm{BFR}^{1}-\mathrm{E} 51 \mathrm{C}\right)$. ITC analysis of manganese binding in the $\mathrm{BFR}^{2}$ mutant revealed that it does not bind manganese in any significant amount (Figure 4.8). Fitting the binding isotherm to a single binding site reveals that only $0.31( \pm 0.02)$ manganese ions bind per mole of $\mathrm{BFR}^{2}$ monomer (Table $4.2 \mathrm{~b})$. This binding is quite weak $\left(2.05 \pm 0.28 \times 10^{5}\right)$ and may be at the metal binding site or simply non-specific ligation on the protein surface.

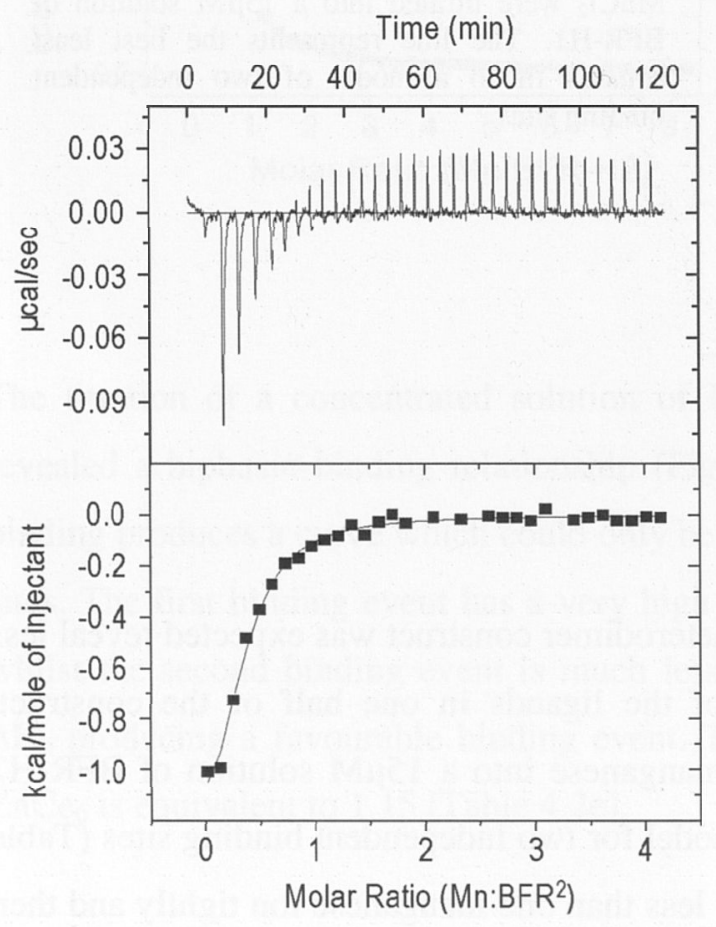

Figure 4.8: Calorimetric titration of $\mathrm{MnCl}_{2}$ into a solution of $\mathrm{BFR}^{2}$ which has the E51C mutation in the metal binding site. The top of the figure is the raw ITC output for the titration and the lower half of the figure is derived from the integrated raw data. $6 \mu \mathrm{l}$ injections of $840 \mu \mathrm{M} \mathrm{MnCl}{ }_{2}$ were titrated into a $30 \mu \mathrm{M}$ solution of $\mathrm{BFR}^{2}$. The line represents the best least squares fit to a model of a single binding site. 
The titration of manganese into the BFR-H1 heterodimer construct was expected to reveal similar metal binding characteristics as that found in the $\mathrm{BFR}^{1}$ homodimer. The metal binding ability of the BFR-H1 heterodimer was significantly reduced with a total of $2.4 \mathrm{Mn}$ ions were bound per heterodimer (Table 4.2c). It was expected that a greater amount of $\mathrm{Mn}$ would bind i.e. $4 \mathrm{Mn}$ ions per dimer. An isotherm representing the average for this titration is shown in Figure 4.9. The decrease in secondary structure and the decrease in the number of $\mathrm{Mn}$ ions bound suggest the heterodimer construct is partially destabilised by the addition of the loop region.

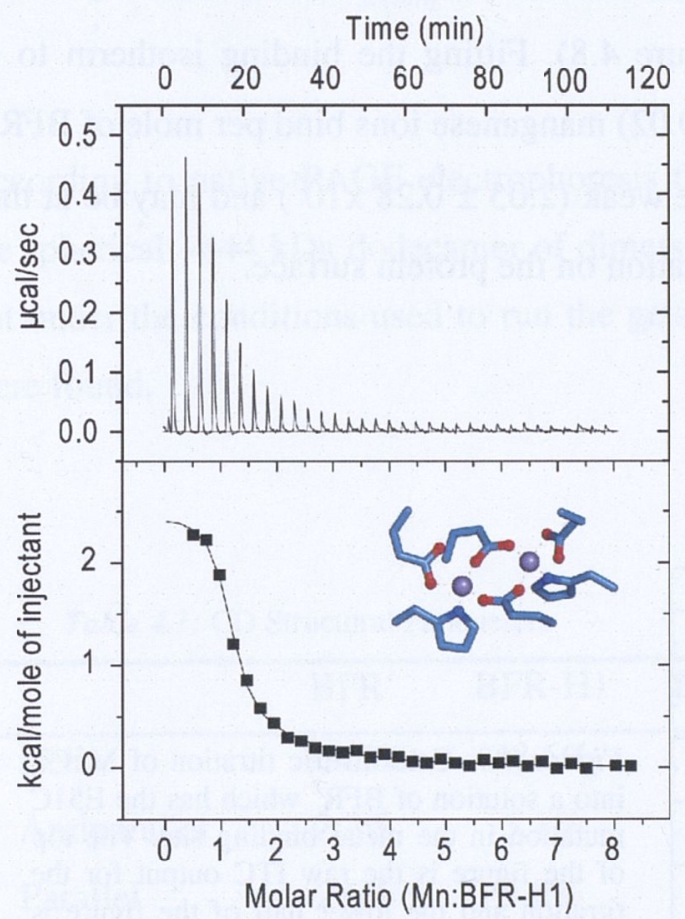

Figure 4.9: Calorimetric titrations of $\mathrm{MnCl}_{2}$ into a solution of BFR-H1. The top of the figure is the raw ITC output for the titration and the lower half of the figure is derived from the integrated raw data. $11 \mu \mathrm{l}$ injections of $900 \mu \mathrm{M}$ $\mathrm{MnCl}_{2}$ were titrated into a $15 \mu \mathrm{M}$ solution of BFR-H1. The line represents the best least squares fit to a model of two independent binding sites.

Titration of manganese into the BFR-H2 heterodimer construct was expected reveal less metal binding due to the modification of the ligands in one half of the construct. Integration of the heat for a titration of manganese into a $15 \mu \mathrm{M}$ solution of BFR-H2 (Figure 4.10) when fit to a least squares model for two independent binding sites (Table 4.2d) revealed that BFR-H2 binds slightly less than one manganese ion tightly and then a second manganese ion more weakly. The main binding event is an endothermic process with $0.76( \pm 0.01) \mathrm{Mn}$ ions binding per heterodimer with a $\mathrm{K}_{\mathrm{a} 1}$ of $3.14( \pm 1.67)$ $\times 10^{6} \mathrm{M}$. The second binding event is much weaker with a $\mathrm{Ka}_{2}$ of $3.24( \pm 1.69) \times 10^{4} \mathrm{M}$. 
The heterodimer complex was expected to bind two manganese ions on one half of the protein complex. This seems to be the case though the second manganese ion binds very weakly. The other half of the heterodimer is not expected to bind any metal ions due to removal of a crucial glutamate ligand to produce a quinone binding pocket.

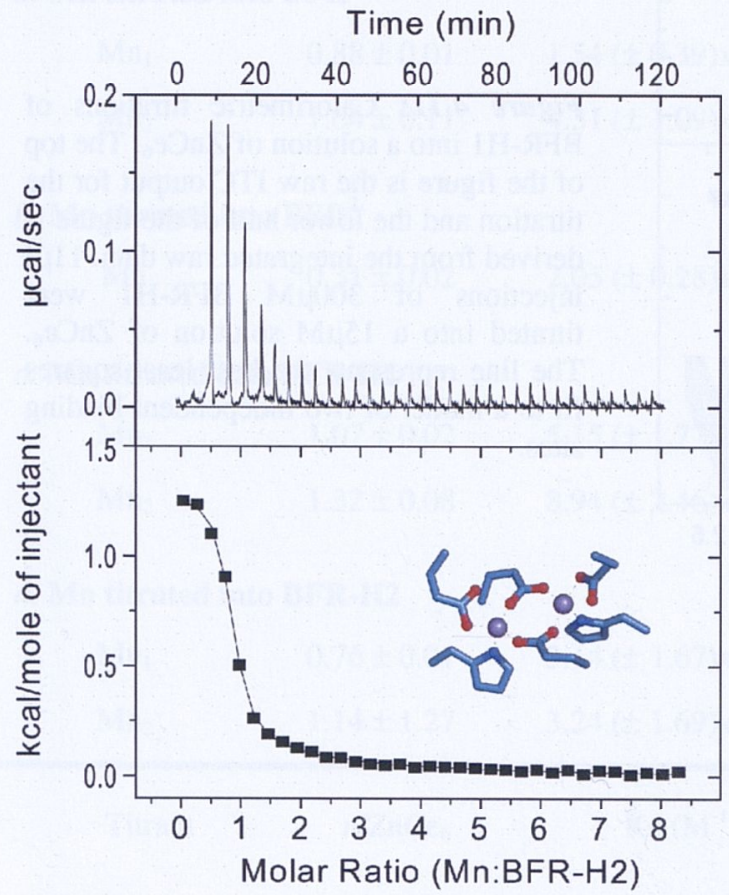

Figure 4.10: Calorimetric titrations of $\mathrm{MnCl}_{2}$ into a solution of BFR-H2. The top of the figure is the raw ITC output for the titration and the lower half of the figure is derived from the integrated raw data. $11 \mu$ injections of $900 \mu \mathrm{M} \mathrm{MnCl}_{2}$ were titrated into a $15 \mu \mathrm{M}$ solution of BFR-H2. The line represents the best least squares fit to a model of two independent binding sites.

The titration of a concentrated solution of BFR-H1 into a $15 \mathrm{uM}$ solution of $\mathrm{ZnCe}_{6}$ revealed a biphasic binding relationship (Figure 4.11). The integration of the heat of binding produces a curve which could only be fit to a model of two independent binding sites. The first binding event has a very high association constant and a moderate $\Delta \mathrm{H}_{\mathrm{b}}$ whilst the second binding event is much less strongly associated but has a very large $\Delta \mathrm{H}_{\mathrm{b}}$ producing a favourable binding event. The total number of BFR-H1 binding per $\mathrm{ZnCe}_{6}$ is equivalent to 1.15 (Table $4.2 \mathrm{e}$ ). 


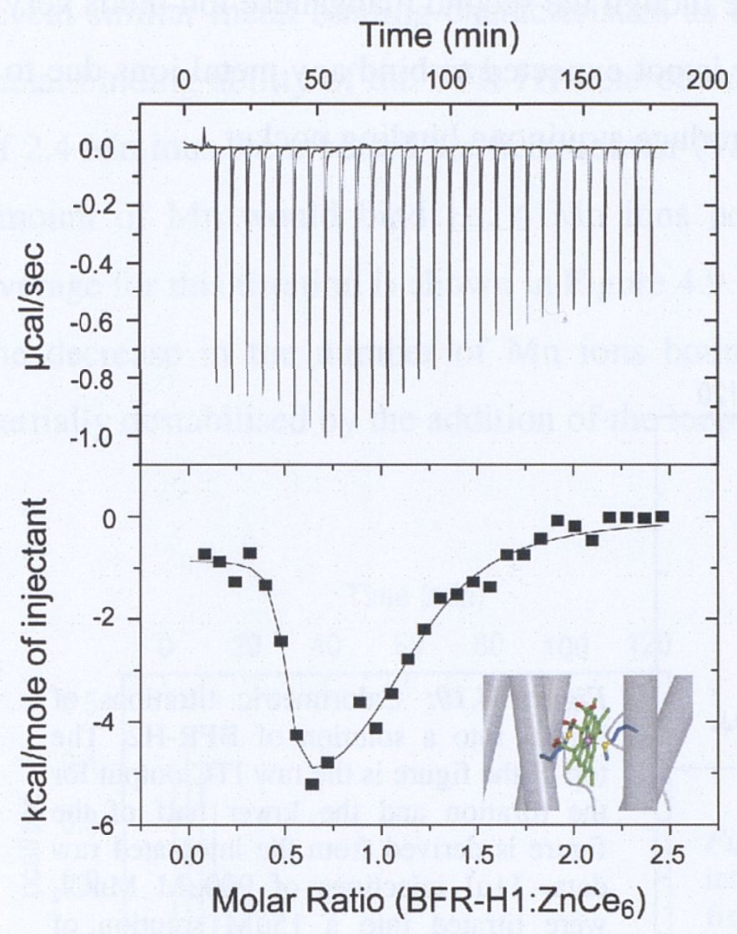

Figure 4.11: Calorimetric titrations of BFR-H1 into a solution of $\mathrm{ZnCe}_{6}$. The top of the figure is the raw ITC output for the titration and the lower half of the figure is derived from the integrated raw data. $11 \mu 1$ injections of $300 \mu \mathrm{M}$ BFR-H1 were titrated into a $15 \mu \mathrm{M}$ solution of $\mathrm{ZnCe}_{6}$. The line represents the best least squares fit to a model of two independent binding sites. 
Table 4.2: Best fit parameters for ITC measurements of $\mathrm{Mn}$ and $\mathrm{ZnCe}_{6}$ binding to BFR constructs

\begin{tabular}{cccc}
\hline Titrant & $\mathrm{n} / \mathrm{BFR}$ & $\mathrm{Ka}\left(\mathrm{M}^{-1}\right)$ & $\Delta \mathrm{H}_{\text {bind }}$ \\
& & $\left(\mathrm{Kcal} \mathrm{mol}^{-1}\right)$ & $\left(\mathrm{Kcal} \mathrm{M}^{-1}\right)$ \\
\hline
\end{tabular}

a. Mn titrated into $\mathbf{B F R}^{1}$

$\begin{array}{lcccc}\mathrm{Mn}_{1} & 0.88 \pm 0.01 & 1.54( \pm 0.39) \times 10^{9} & -7380 \pm 116 & 17.3 \\ \mathrm{Mn}_{2} & 1.64 \pm 0.11 & 4.31( \pm 1.09) \times 10^{6} & 860 \pm 87 & 33.2\end{array}$

\section{b. Mn titrated into $\mathbf{B F R}^{2}$}

$\begin{array}{llll}\text { Mn } & 0.31 \pm 0.02 & 2.05( \pm 0.28) \times 10^{5} & -1630 \pm 123\end{array}$

c. Mn titrated into BFR-H1

\begin{tabular}{|c|c|c|c|}
\hline $\mathrm{Mn}_{1}$ & $1.07 \pm 0.02$ & $5.15( \pm 1.77) \times 10^{6}$ & $2471 \pm 53.8$ \\
\hline [n & $1.32 \pm 0.08$ & $8.94( \pm 2.46) \times 10^{4}$ & $690 \pm 47.7$ \\
\hline
\end{tabular}

d. Mn titrated into BFR-H2

$\begin{array}{lllll}\mathrm{Mn}_{1} & 0.76 \pm 0.01 & 3.14( \pm 1.67) \times 10^{6} & 1294 \pm 12.8 & 34.1 \\ \mathrm{Mn}_{2} & 1.14 \pm 1.27 & 3.24( \pm 1.69) \times 10^{4} & 443.3 \pm 552 & 22.1\end{array}$

Titrant

$\mathrm{n} / \mathrm{ZnCe}_{6}$

$\mathrm{Ka}\left(\mathrm{M}^{-1}\right)$

$\Delta \mathrm{H}_{\mathrm{b}}$

$\Delta \mathrm{S}$

$\left(\mathrm{Kcal} \mathrm{mol}^{-1}\right)$

$\left(\mathrm{Kcal} \mathrm{M}^{-1}\right)$

e. BFR-H1 titrated into $\mathrm{ZnCe}_{6}$

$\begin{array}{llllr}\mathrm{BFR}_{1} & 0.47 \pm 0.01 & 2.42( \pm 1.81) \times 10^{8} & -850 \pm 147 & 35.5 \\ \mathrm{BFR}_{2} & 0.68 \pm 0.05 & 8.17( \pm 2.18) \times 10^{5} & -6135 \pm 536 & 6.47\end{array}$

a, c, $d \& e$ : Fit to best least squares model of two independent binding sites.

$b$ : Fit to best least squares model of a single binding site.

\section{Mn EPR Spectra}

EPR spectra were taken of heterodimer samples with Mn bound to look at the interaction of the $\mathrm{Mn}$ ions within the di-metal sites. The spectra revealed a broad structured signal centred at $\mathrm{g}=2$ and a further structured region at $\mathrm{g}=4$ (Figure $4.12 \mathrm{a}$ and b). These two signals were modelled in the $\mathrm{BFR}^{1}$ protein (Chapter 3 ) showing that the broad signal centred at $\mathrm{g}=2$ was the result of weakly interacting $\mathrm{Mn}_{2}{ }^{\mathrm{II}, \mathrm{II}}$ dimers (Figure $4.12 \mathrm{c}$ ). The spectra of the heterodimers revealed less of the dimeric $\mathrm{Mn}_{2}{ }^{\text {IIII }}$ structure 
than found in the BFR ${ }^{1}-\mathrm{ZM}$ sample. This coincides with the ITC data which shows weaker binding of the second metal ion in the heterodimers versus BFR ${ }^{1}-\mathrm{ZM}$. There is also a larger signal centred at $150 \mathrm{mT}(\mathrm{g}=4)$ associated with the quino-protein which is due to monomeric $\mathrm{Mn}^{\mathrm{II}}$ bound within a highly structured, weak ligand field.

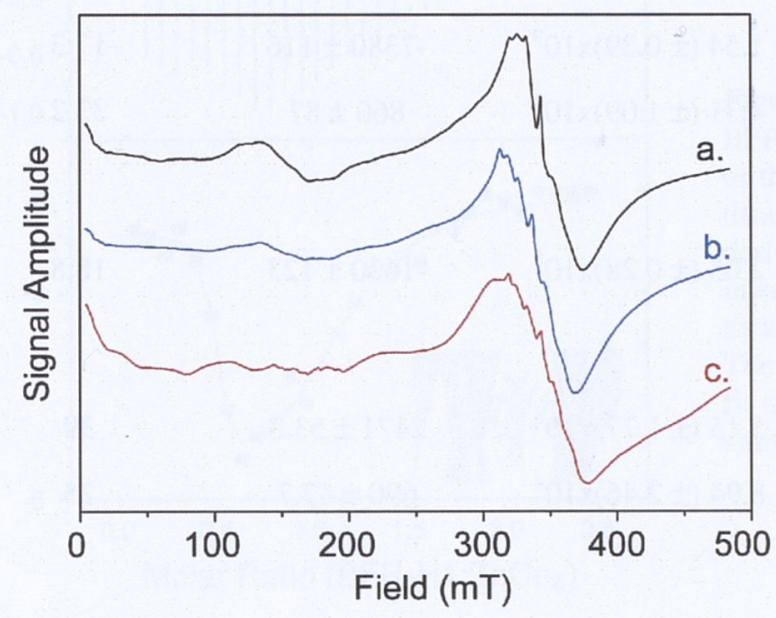

Figure 4.12: EPR spectra of a.) BFR-H2 ZM CoQ ${ }_{0}$, b.) BFR-H1 $\mathrm{ZM}$ and c.) $B \mathrm{BR}^{1}-\mathrm{ZM}$. All samples were in tricine $40 \mathrm{mM} \mathrm{KCl} 100 \mathrm{mM}$ pH7.7 buffer. Microwave frequency $9.4 \mathrm{GHz}$ Microwave power $10 \mathrm{~mW}$, modulation amplitude 10G, temperature $5 \mathrm{~K}$.

\section{Iron Oxidation Rates - $U V$-Vis}

The enzymatic activity of all of the BFR mutants was assessed using a well established iron oxidation assay (Andrews et al. 1995). Bacterioferritin catalyses the oxidation of $\mathrm{Fe}^{\mathrm{II}}$ to $\mathrm{Fe}^{\mathrm{III}}$ with the formation of oxidised iron producing absorbance at $340 \mathrm{~nm}$ which enables the rate of oxidation to be monitored (Figure 4.13). The rate of uncatalysed iron oxidation, without the protein present, was very low for buffers with a $\mathrm{pH}$ less than 6 but above this $\mathrm{pH}$ the rate increased significantly. The assay was therefore carried out at pH5.9. 


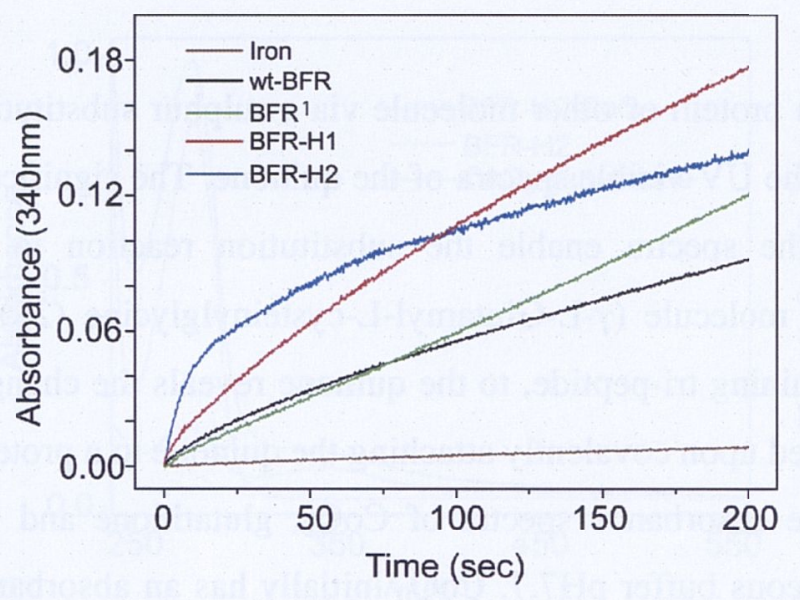

Figure 4.13: Iron oxidation monitored by absorbance at $340 \mathrm{~nm}$. Protein concentrations $5 \mu \mathrm{M}$, iron $2000 \mu \mathrm{M}$, in $40 \mathrm{mM}$ MES buffer $\mathrm{pH}$ 5.9. Iron was injected at time zero with rapid stirring.

The initial rates of iron oxidation, given as the change in absorbance at $340 \mathrm{~nm}$ per minute, are very similar for the wild-type and $\mathrm{BFR}^{1}$ mutant (Table 4.3). The heterodimers on the other hand show much increased initial rates of oxidation. BFR-H1 which from the CD spectra appears to be more structured than BFR-H2 shows slower iron oxidation. BFR-H2 shows very fast iron oxidation but the rate tails off significantly over time. The uncatalysed rate is negligible and is not significant when compared to the catalysed rates.

Table 4.3: Iron oxidation rates as monitored by UVvisible spectroscopy

\begin{tabular}{lc} 
Sample & Rate $\left(\Delta \varepsilon_{340} / \mathrm{min}\right)$ \\
\hline Iron & 0.01 \\
wt-BFR & 0.08 \\
BFR $^{1}$ & 0.07 \\
BFR-H1 & 0.18 \\
BFR-H2 & 0.38 \\
\hline
\end{tabular}




\subsubsection{Quinone Binding}

The covalent binding of $\mathrm{CoQ}_{0}$ to a protein or other molecule via a sulphur substitution reaction has a major influence on the UV-visible spectra of the quinone. The significant changes in the blue region of the spectra enable the substitution reaction to be monitored. Binding a glutathione molecule ( $\gamma$-L-Glutamyl-L-cysteinylglycine (2S)-2Amino-), which is a cysteine containing tri-peptide, to the quinone reveals the changes in absorbance which can be expected upon covalently attaching the quinone to a protein. Figure 4.14 shows the UV-visible absorbance spectra of $\mathrm{CoQ}_{0}$, glutathione and the $\mathrm{CoQ}_{0}$-Glutathione complex in aqueous buffer $\mathrm{pH}$ 7.7. $\mathrm{CoQ}_{0}$ initially has an absorbance band at $268 \mathrm{~nm}$ which red shifts upon sulphur substitution to $276 \mathrm{~nm}$. The new $\mathrm{CoQ}_{0^{-}}$ glutathione adduct produces intense $\pi-\pi^{*}$ transition bands at $276 \mathrm{~nm}$ and $343 \mathrm{~nm}$

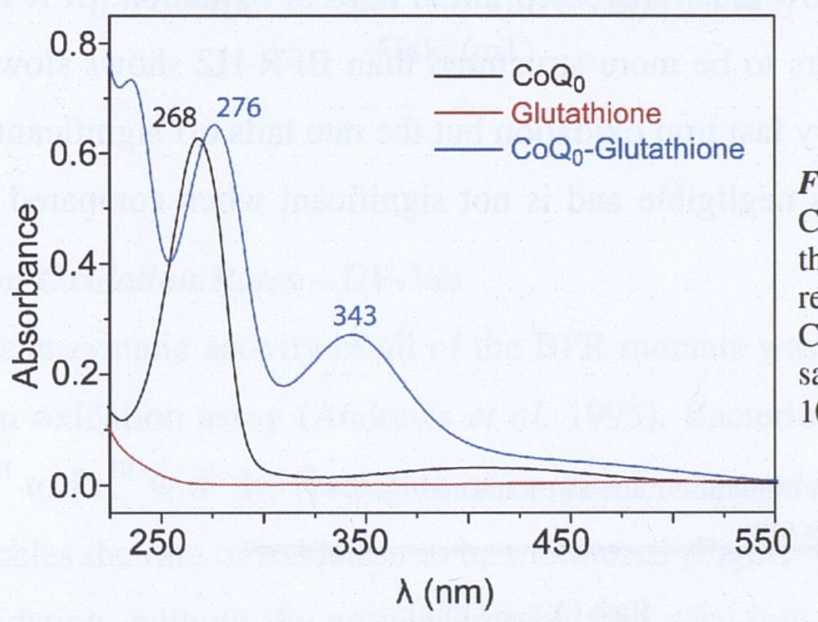

Figure 4.14: Absorbance spectra of $\mathrm{CoQ}_{0}$ (black), glutathione (red) and the product of reacting $\mathrm{CoQ}_{0}$ with reduced glutathione producing the $\mathrm{CoQ}_{0}$-Glutathione complex (blue). All samples were in tricine $40 \mathrm{mM} \mathrm{KCl}$ $100 \mathrm{mM}$ pH7.7 buffer.

Monitoring the absorbance spectra for the binding reaction of $\mathrm{CoQ}_{0}$ with $\mathrm{BFR}-\mathrm{H} 2$ produces a spectrum which is a composite of the protein signal and the substituted quinone (Figure 4.15). The spectra revealed maxima at 276 and $343 \mathrm{~nm}$ characteristic for the quinone with thioether linkage to the protein. The relative amount of $\mathrm{CoQ}_{0}$ bound to BFR-H2 equates to $\sim 1: 1$. 


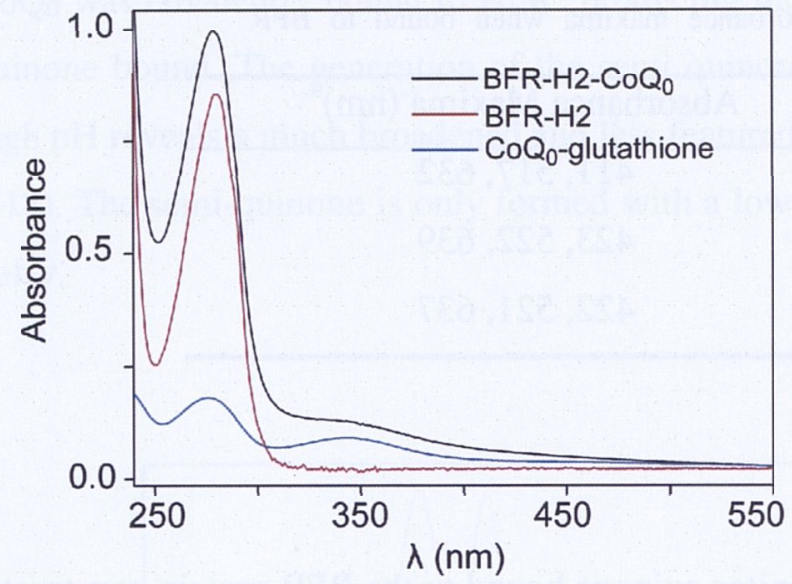

Figure 4.15: UV-visible absorbance spectra of $\mathrm{BFR}-\mathrm{H} 2 \mathrm{CoQ}_{0}$ (black), $\mathrm{BFR}-\mathrm{H} 2$ (red) and $\mathrm{CoQ}_{0}$-Glutathione complex (blue). The concentration of all protein and quino-adducts was $17 \mu \mathrm{M}$ in tricine $40 \mathrm{mM}, \mathrm{KCl} 100 \mathrm{mM}$ pH7.7 buffer.

Binding $\mathrm{ZnCe}_{6}$ to the BFR-H2 $\mathrm{CoQ}_{0}$ protein reveals a spectrum very similar to that of $\mathrm{BFR}^{1}$ with $\mathrm{ZnCe}_{6}$ bound (Table 4.4). Binding produces a red shift in the absorbance maxima of the $\mathrm{ZnCe}_{6}$ Soret band from 411 to $422 \mathrm{~nm}$, whilst the $\mathrm{Q}_{x}$ band shifts from 517 to $521 \mathrm{~nm}$ and the $\mathrm{Q}_{y}$ band from 632 to $637 \mathrm{~nm}$ (Figure 4.16). The absorbance spectra of $\mathrm{ZnCe}_{6}$ bound to BFR-H2 ZM and to BFR-H2 $\mathrm{ZM} \mathrm{CoQ}$ are almost identical, which would suggest that there is no ground-state coupling between the chlorin and quinone.

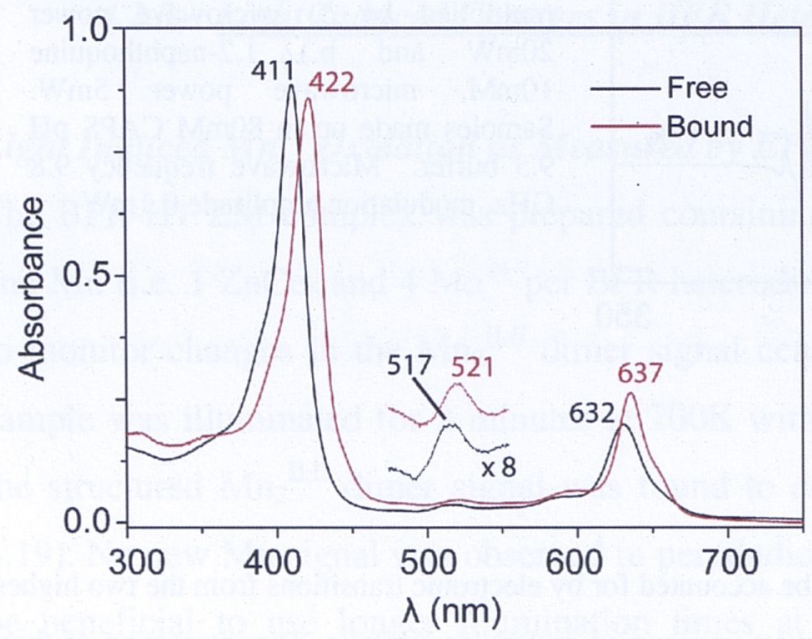

Figure 4.16: Absorbance spectra of $\mathrm{ZnCe}_{6}$ free in solution (black), and bound to BFR-H2 $\mathrm{CoQ}_{0}$ (red). The inset shows the absorbance maxima of the $Q_{x}$ band magnified eight times. Samples were prepared in tricine $40 \mathrm{mM} \mathrm{KCl} 100 \mathrm{mM}$ pH7.7 buffer. 
Table 4.4: $\mathrm{ZnCe}_{6}$ absorbance maxima when bound to BFR proteins

\begin{tabular}{lc}
\hline Binding Partner & Absorbance Maxima $(\mathrm{nm})^{4}$ \\
\hline Free in solution & $411,517,632$ \\
BFR $^{1}$ & $423,522,639$ \\
BFR-H2 CoQ $_{0}$ & $422,521,637$ \\
\hline
\end{tabular}

\section{EPR Dark Spectra of Quinones}

EPR spectroscopy was utilised to monitor quinone bound to the BFR protein constructs. Unbound or bound quinone could be visualised with this technique. The singly reduced quinone radical anion is readily picked up in the region of $\mathrm{g}=2$. By increasing the $\mathrm{pH}$ the semi quinone radical is generated and can be observed at room temperature. Figure 4.17 shows the spectra of the semi quinone form for $\mathrm{CoQ}_{0}$ and also 1,2-naphthoquinone (NQ).

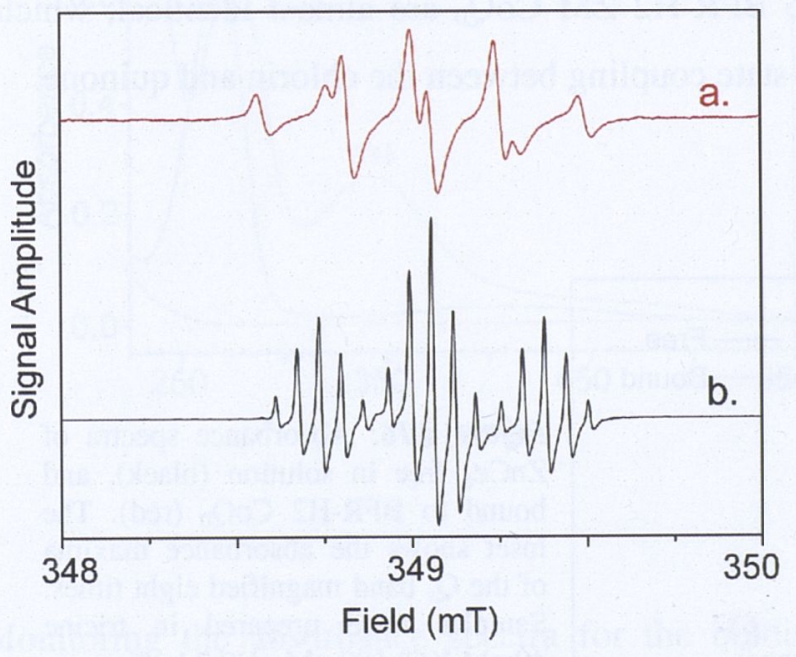

Figure 4.17: Room temperature EPR spectra of a.) $\mathrm{CoQ}_{0} 6.6 \mathrm{mM}$ (spectra multiplied by 5) microwave power $20 \mathrm{~mW}$ and b.) 1,2-naphthoquine $10 \mathrm{mM}$, microwave power $5 \mathrm{~mW}$. Samples made up in $80 \mathrm{mM}$ CAPS $\mathrm{pH}$ 9.5 buffer. Microwave frequency 9.8 $\mathrm{GHz}$, modulation amplitude $0.1 \mathrm{~mW}$.

${ }^{4}$ The optical properties of a porphyrin can be accounted for by electronic transitions from the two highest occupied molecular orbital's to the two lowest unoccupied molecular orbital's. The interaction of these orbital's gives rise to the relatively weak Q band $(\sim 500-650 \mathrm{~nm})$ and the intense Soret band in the UV region. The porphyrin ring system of the chlorin is perturbed, splitting the nominally degenerate $\mathrm{Q}$ band into a lower energy $Q_{y}$ band and a higher energy $Q_{x}$ band Gouterman $M$ (1961) Spectra of porphyrins. Journal of Molecular Spectroscopy 6: 138-163.Ligation of the porphyrins changes the energy levels of these orbital's producing shifts in the absorbance spectra. 
$\mathrm{CoQ}_{0}$ was covalently bound to $\mathrm{BFR}^{2}$ producing the homodimer with two copies of the quinone bound. The generation of the semi quinone radical at room temperature using high $\mathrm{pH}$ reveals a much broadened and less featured signal than the free quinone (Figure 4.18). The semi-quinone is only formed with a low yield and as such the signal is quite noisy.

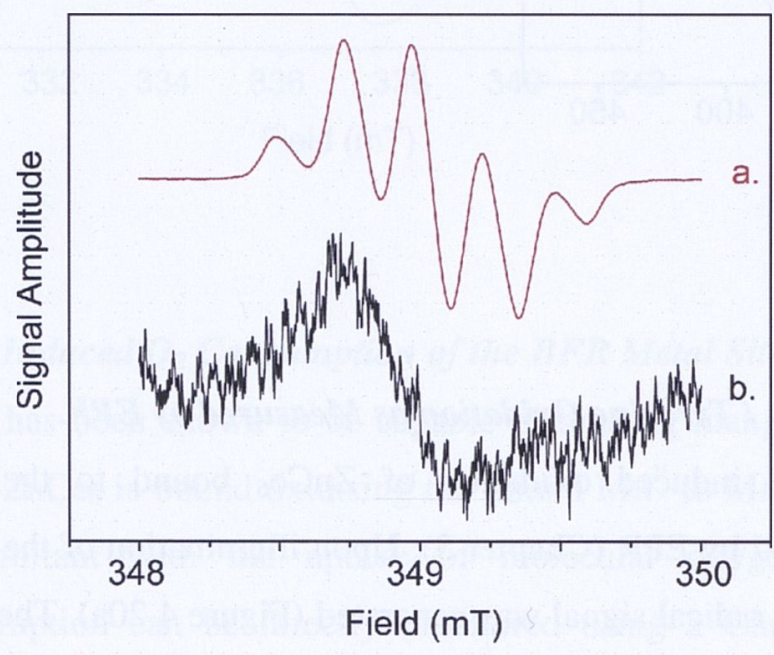

\subsubsection{Light Induced Changes in BFR Heterodimers}

\section{Light Induced $\mathrm{Mn}^{2+}$ Oxidation as Measured by EPR}

The BFR-H1 ZM complex was prepared containing stoichiometric amounts of $\mathrm{ZnCe}_{6}$ and $\mathrm{Mn}$ (i.e. $1 \mathrm{ZnCe}_{6}$ and $4 \mathrm{Mn}^{2+}$ per BFR heterodimer unit) in the dark. EPR was used to monitor changes in the $\mathrm{Mn}_{2}{ }^{\mathrm{II}, \mathrm{II}}$ dimer signal centred at $\mathrm{g}=2$ upon illumination. The sample was illuminated for 2 minutes at $200 \mathrm{~K}$ with white light than quick frozen, and the structured $\mathrm{Mn}_{2}{ }^{I I, I I}$ dimer signal was found to decrease by a small amount (Figure 4.19). No new Mn signal was observed in perpendicular or parallel mode EPR. It would be beneficial to use longer illumination times at room temperature to increase the amount of manganese which is oxidised (see Chapter 3). 


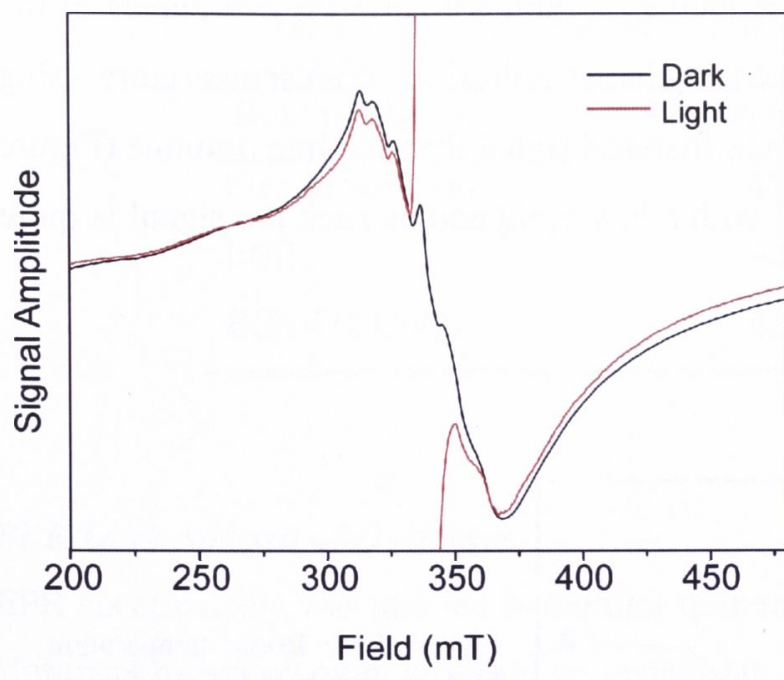

Figure 4.19: EPR spectrum of BFR-H1 $\mathrm{ZM}$ before and after illumination at $200 \mathrm{~K}$ for 2 minutes. Microwave frequency $9.4 \mathrm{GHz}$ Microwave power $10 \mathrm{~mW}$, modulation amplitude 20G, temperature $5 \mathrm{~K}$.

\section{Light Induced Chlorin Oxidation / Tyrosine Oxidation as Measured by EPR.}

As was found for $\mathrm{BFR}^{1}$, light induced oxidation of $\mathrm{ZnCe}_{6}$ bound to the BFR heterodimers was readily observed by EPR (Chapter 3). Upon illumination of the BFRH1 ZM complex at $200 \mathrm{~K}$ a broad radical signal was generated (Figure 4.20a). The same sample with no manganese present (i.e. BFR-H1 Z) produced a much narrower $0.75 \mathrm{mT}$ wide radical centred at $\mathrm{g}=2.0022$ (Figure $4.20 \mathrm{~b}$ ). Subtraction of the spectra of the narrow radical signal from the broad signal reveals a structured underlying signal (2.0 $\mathrm{mT}$ ) centred at $\mathrm{g}=2.0031$, which appears very similar to a tyrosine radical species (Figure 4.20c) (Un et al. 1995; Bleifuss et al. 2001; Hofbauer et al. 2001). This broad structured radical signal appears to be the same signal as that found in the $\mathrm{BFR}^{1}$ protein though the turning points are not as well defined. Again the formation of the tyrosine radical was dependent on $\mathrm{Mn}$ being bound to the metal centre. 


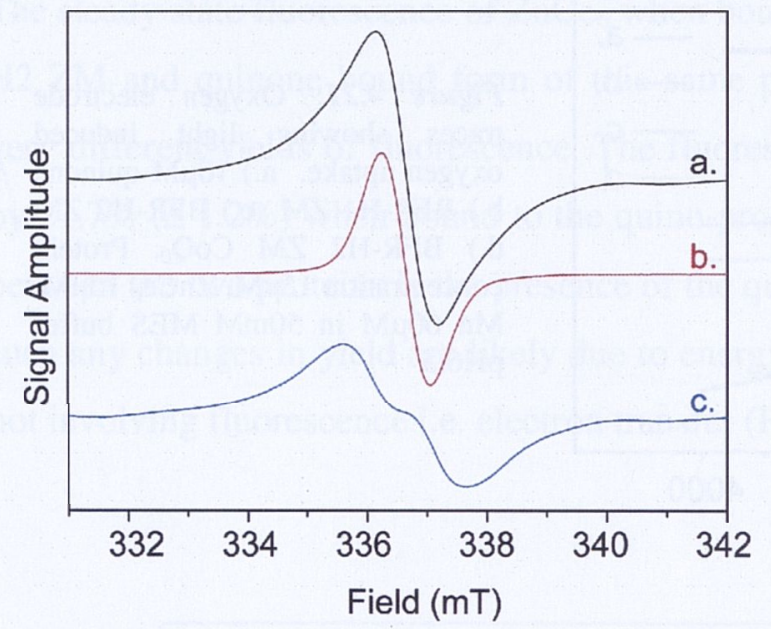

Figure 4.20: EPR spectra of a.) BFR-H1 $\mathrm{ZM}$, b.) BFR-H1 $\mathrm{Z}$ and c.) a. minus $\mathrm{b}$. The samples were illuminated for 2 minutes at $200 \mathrm{~K}$ before measurements were taken. Microwave frequency 9.4 $\mathrm{GHz}$ Microwave power $0.01 \mathrm{~mW}$, modulation amplitude 5G, temperature $5 \mathrm{~K}$

\section{Light Induced $\mathrm{O}_{2}$ Consumption of the BFR Metal Site}

$\mathrm{BFR}^{1}$ has been shown to be capable of binding manganese at the ferroxidase site and when $\mathrm{ZnCe}_{6}$ is bound oxidising the bound $\mathrm{Mn}^{\mathrm{II}}$ to $\mathrm{Mn}^{\mathrm{III}}$ (see Chapter 3). This occurred concomitant with the uptake of molecular oxygen from solution and this $\mathrm{O}_{2}$ consumption can be directly monitored using a Clarke type oxygen electrode. The analysis of BFR ${ }^{1}$, BFR-H1 and BFR-H2 constructs found them to all consume oxygen, but the rate of consumption and amount taken up varied according to the construct. The BFR-H1 ZM, BFR-H2 ZM and BFR-H2 ZM CoQ ${ }_{0}$ complexes did not auto-oxidise Mn in the dark. Though subsequent illumination of these complexes did lead to oxygen uptake (Figure 4.21).

Control measurements demonstrated that minimal $\mathrm{O}_{2}$ was consumed upon illuminating quinone free in solution (Figure 4.21a.). However, illumination of the heterodimer constructs with $\mathrm{ZnCe}_{6}$ and $\mathrm{Mn}$ bound revealed high levels of $\mathrm{O}_{2}$ consumption. The BFR-H1 heterodimer took up the least amount of $\mathrm{O}_{2}$ (Figure 4.21b.) consuming slightly less than that found for BFR ${ }^{1}$ (Table 4.5). BFR-H2 ZM consumed the same amount of $\mathrm{O}_{2}$ as $\mathrm{BFR}^{1}$ but interestingly BFR-H2 ZM CoQ $\mathrm{Q}_{0}$ took up considerably more oxygen than any of the other constructs (Figure 4.21c. and d.). 


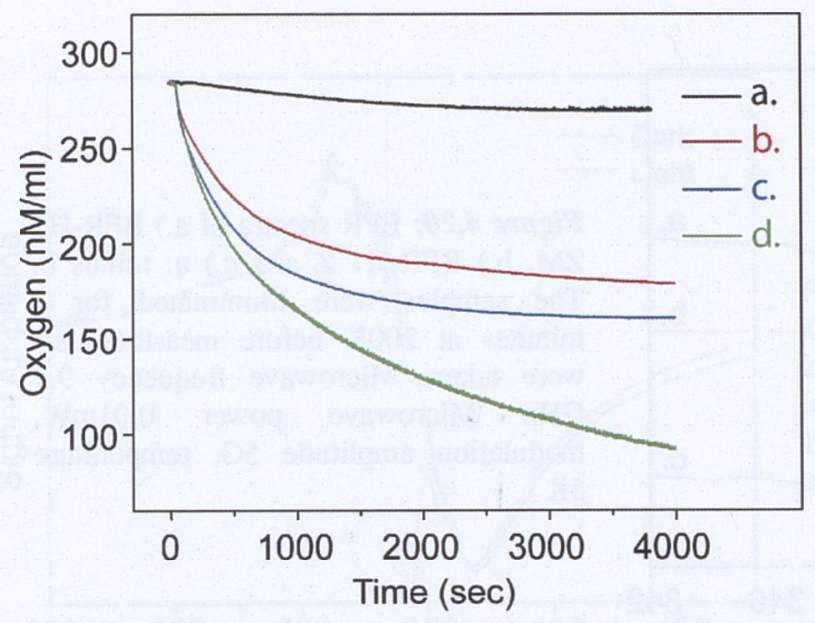

Figure 4.21: Oxygen electrode traces showing light induced oxygen uptake. a.) $10 \mu \mathrm{M}$ quinone b.) BFR-H1 ZM c.) BFR-H2 ZM d.) BFR-H2 ZM CoQ ${ }_{0}$. Protein concentration $15 \mu \mathrm{M}, \mathrm{ZnCe}_{6} 15 \mu \mathrm{M}$, $\mathrm{Mn} 60 \mu \mathrm{M}$ in $50 \mathrm{mM}$ MES buffer pH6.5

$\mathrm{BFR}^{2}-\mathrm{ZM}$ (homodimer with E51C mutation) was shown to bind very little $\mathrm{Mn}$ and then only weakly (see section 4.2.2), yet it still consumes almost as much oxygen as BFR ${ }^{1}$ ZM (Table 4.5). This protein also had the fastest initial rate of oxygen uptake. The BFR-H2 ZM CoQo protein had the next highest rate of oxygen uptake, consuming almost half again the amount of oxygen found for the other constructs, which suggests more $\mathrm{Mn}$ centres were oxidised.

Table 4.5: Oxygen uptake data

\begin{tabular}{lccc}
\hline Sample & $\begin{array}{c}\text { Total } \mathrm{O}_{2} \\
\text { uptake }(\mu \mathrm{M})\end{array}$ & $\begin{array}{c}\mathrm{O}_{2} \text { uptake / } \\
\text { metal ion }\end{array}$ & $\begin{array}{c}\text { Max Rate } \\
(\mu \mathrm{Mol} / \mathrm{s})^{*}\end{array}$ \\
\hline $10 \mu \mathrm{M} \mathrm{CoQ}$ control & 16 & - & 0.16 \\
$\mathrm{BFR}^{1} \mathrm{ZM}$ & 127 & 2.12 & 0.58 \\
$\mathrm{BFR}^{2} \mathrm{ZM}$ & 118 & 1.97 & 1.03 \\
$\mathrm{BFR}-\mathrm{H} 1 \mathrm{ZM}$ & 107 & 1.78 & 0.63 \\
BFR-H2 ZM & 128 & 2.13 & 0.63 \\
BFR-H2 ZM CoQ & 200 & 3.33 & 0.78 \\
\hline
\end{tabular}

Note: BFR 30 $\mu \mathrm{M}, \mathrm{ZnCe}_{6} 15 \mu \mathrm{M}, \mathrm{Mn} 60 \mu \mathrm{M}$.

BFR-H $15 \mu \mathrm{M}, \mathrm{ZnCe}_{6} 15 \mu \mathrm{M}$, Mn $60 \mu \mathrm{M}$

"Maximum rate was determined over an average of the initial 10 seconds. 


\section{Steady State Fluorescence Properties}

The steady state fluorescence of $\mathrm{ZnCe}_{6}$ when bound to oxidised forms of both the BFR$\mathrm{H} 2 \mathrm{ZM}$ and quinone bound form of this same protein (BFR-H2 ZM CoQ $\mathrm{Q}_{0}$ ) produced very different yields of fluorescence. The fluorescence emission of $\mathrm{ZnCe}_{6}$ is decreased by $21.7 \%$ ( $\pm 1.2 \%$ ) when bound to the quino-protein (Figure 4.22 ). The only difference between the two proteins is the presence of the quinone within its binding pocket and as such any changes in yield are likely due to energy dissipation to the quinone via a route not involving fluorescence i.e. electron transfer (Hay et al. 2004).

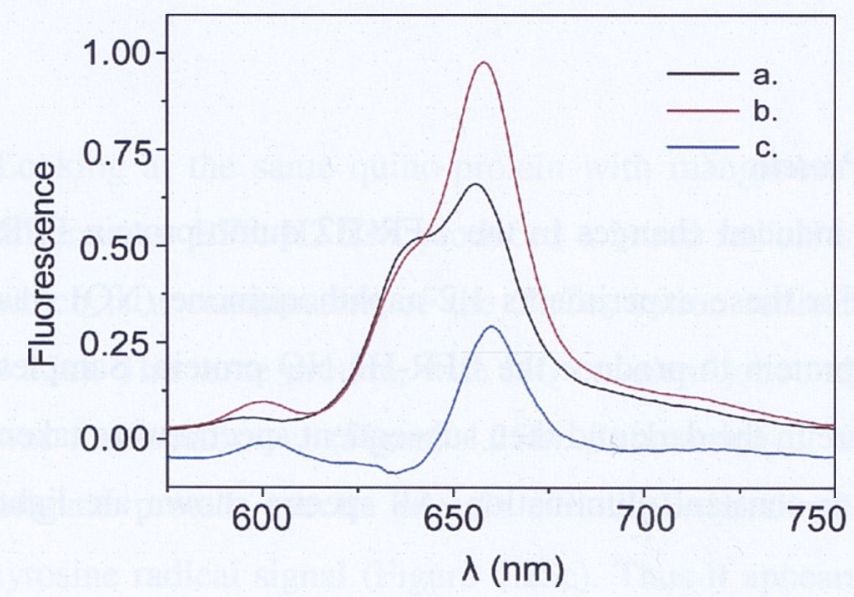

Figure 4.22: Fluorescence spectra of a.) BFR-H2 ZM b.) BFR-H2 $\mathrm{ZM} \mathrm{CoQ} \mathrm{C}_{0}$ c.) spectra a. minus spectra b. BFR-H2 proteins $2.5 \mu \mathrm{M}, \quad \mathrm{ZnCe}_{6} \quad 2.5 \mu \mathrm{M}, \quad \mathrm{MnCl}_{2}$ $66 \mu \mathrm{M}$ in $50 \mathrm{mM}$ MES pH6.5.

When the proteins are reduced with sodium dithionite the overall fluorescence increases significantly for $\mathrm{ZnCe}_{6}$ bound to both the quino-protein and the non-quinone protein (see Figure 4.23). The fluorescence levels of the reduced forms of both proteins are identical $( \pm 1.9 \%)$. The reduced forms show an almost flat difference spectrum as both proteins now have no electron acceptors. The fact that the spectra are so similar when reduced suggests that the binding of the quinone to the protein complex does not change the binding environment of the $\mathrm{ZnCe}_{6}$. 


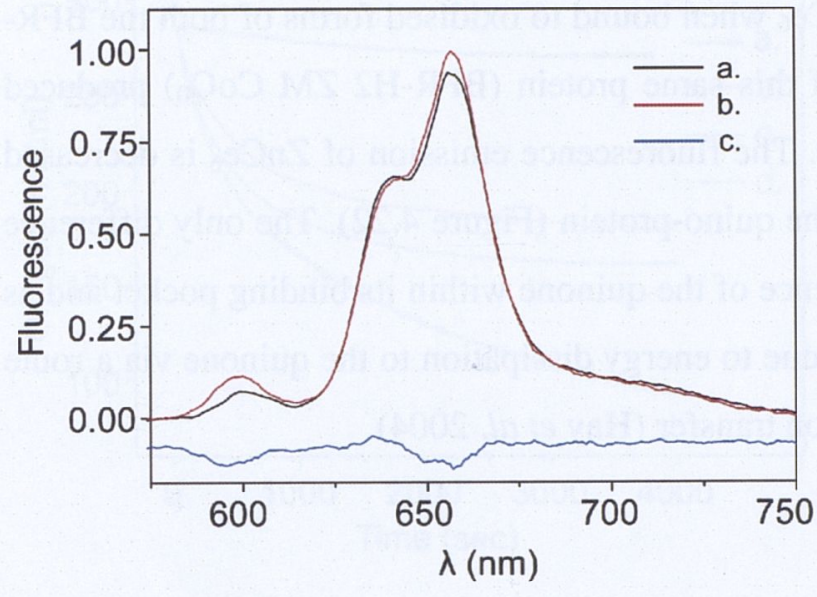

Figure 4.23: Fluorescence spectra of sodium dithionite reduced BFR heterodimer proteins. a.) BFR-H2 $\mathrm{ZM}$ b.) BFR-H2 $\mathrm{ZM} \quad \mathrm{CoQ}_{0} \quad$ c.) resultant spectra of a. minus b. BFR$\mathrm{H} 2$ proteins $2.5 \mu \mathrm{M}, \mathrm{ZnCe}_{6} 2.5 \mu \mathrm{M}$, $\mathrm{MnCl}_{2} 66 \mu \mathrm{M}$ in 50mM MES pH6.5.

\section{EPR Spectra of BFR-H2 Quino-Protein}

In order to try and monitor light induced changes in the BFR-H2 quino-protein EPR spectroscopy was again utilised. For these experiments 1,2-naphthoquinone (NQ) was bound covalently to the BFR-H2 protein to produce the BFR-H2 NQ protein. Samples were monitored at room temperature in the dark and then subsequent spectra were taken under the same conditions but with constant illumination. All spectra shown are light minus dark spectra.

It was found that under constant illumination at room temperature the BFR-H2 $\mathrm{Z}$ quinoprotein (no Mn) produced a radical signal which was broader than a simple $\mathrm{ZnCe}_{6}$ cation radical (Figure 4.24a). The same protein, without NQ bound, produced a signal which was somewhat narrower, centred at $\mathrm{g}=2.0022$, and characteristic of the $\mathrm{ZnCe}_{6}$ radical (Figure 4.24b). The BFR-H2 protein without NQ produced a much larger $\mathrm{ZnCe}_{6}$ signal than the quino-protein. Subtraction of a portion of the $\mathrm{ZnCe}_{6}$ signal from the quino-protein spectra reveals a radical which is broader and with a higher $g$ value centred at $g=2.0032$. This signal appears to be the singly reduced semi-quinone radical (Figure 4.24c). The formation of the semi-quinone radical could only be due to electron transfer from the $\mathrm{ZnCe}_{6}$. 


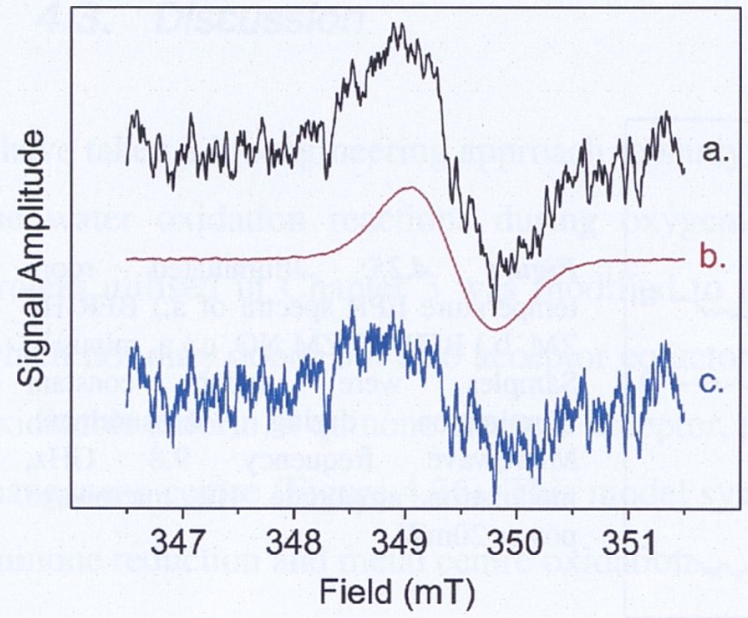

Figure 4.24: Illuminated room temperature EPR spectra of a.) BFR-H2 Z $\mathrm{NQ}$, b.) BFR-H2 Z, and c.) a. minus b. Samples were under constant illumination during measurement. Microwave frequency $9.8 \mathrm{GHz}$, modulation amplitude $4 \mathrm{G}$, microwave power $20 \mathrm{~mW}$

Looking at the same quino-protein with manganese bound revealed some significant differences. BFR-H2 ZM produced a broad radical signal as expected for this sample which is a combination of the $\mathrm{ZnCe}_{6}$ cation radical and the tyrosine radical (Figure 4.25a). The same protein, with NQ covalently bound, produced a radical signal which was much narrower (Figure 4.25b). Subtraction of the quino-protein spectra from the original protein spectra reveals a radical signal which is remarkably similar to the tyrosine radical signal (Figure 4.25c). Thus it appears that the binding of NQ to BFR$\mathrm{H} 2$ results in the loss of a large percentage of the tyrosine radical species. Fifty percent of the tyrosine radical is expected to be lost dye to quinone binding preventing light and manganese dependent tyrosine oxidation in one half of the protein. The binding of NQ which is larger than $\mathrm{CoQ}_{0}$ may also have detrimental effects on the other $\mathrm{Mn}$ centre inhibiting tyrosine oxidation. 


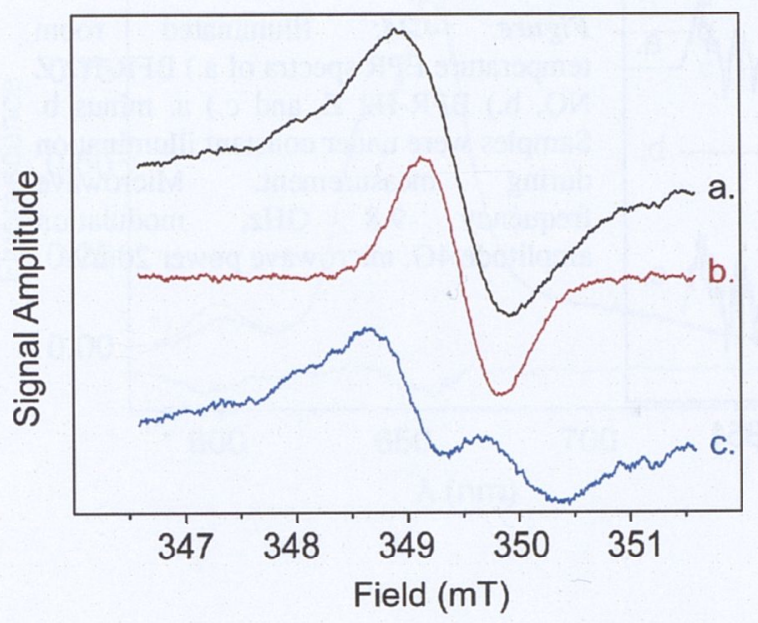

Figure 4.25: Illuminated room temperature EPR spectra of a.) BFR-H2 $\mathrm{ZM}$, b.) BFR-H2 ZM NQ, c.) a. minus b. Samples were under constant illumination during measurement. Microwave frequency $9.8 \mathrm{GHz}$, modulation amplitude $4 \mathrm{G}$, microwave power $20 \mathrm{~mW}$ 


\subsection{Discussion}

I have taken a bioengineering approach to study the light-activated electron transport of the water oxidation reactions during oxygenic photosynthesis. The bacterioferritin protein utilised in Chapter 3 was modified to produce a minimalist model of PSII in which not only donor but also acceptor cofactors were bound. These included a photooxidisable chlorin, a quinone electron acceptor, a redox active tyrosine, and a di-nuclear manganese centre (Figure 4.26). This model system demonstrates porphyrin excitation, quinone reduction and metal centre oxidation.

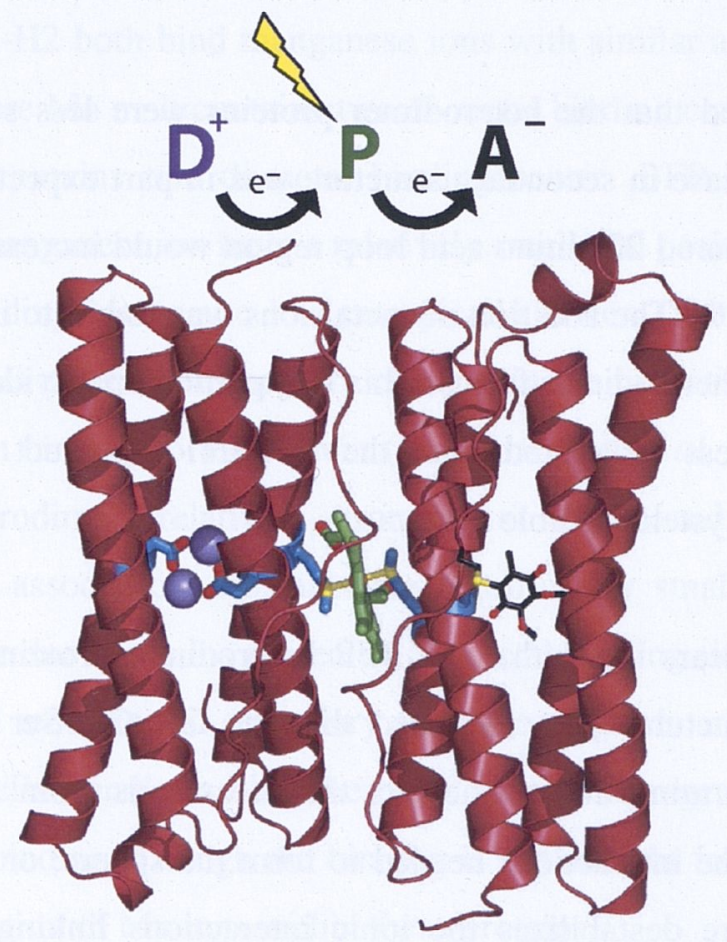

Figure 4.26: A cartoon model of the BFR heterodimer which combines a manganese metal centre as electron donor (D), a redox active tyrosine, a light activated pigment (P), and a covalently bound quinone electron acceptor (A).

\subsubsection{Cofactor-Protein Assembly}

\section{Linker Effects}

The BFR-H1 and BFR-H2 heterodimer constructs were generated by linking the Cterminus of subunit $\mathrm{A}$ to the $\mathrm{N}$ terminus of subunit $\mathrm{B}$ using a 22 amino acid flexible linker. BFR-H2 incorporated a mutation to allow a quinone to be bound within the 
metal binding site of subunit B. Upon expression of these constructs they were found to bind heme as per the wild-type and there were no shifts in the absorbance spectrum of the bound heme for any of the mutant forms.

In order to bind the heme it is expected that the dimer must form properly and the structure of the proteins remain intact. Even upon removal of the heme and any bound metal ions the BFR heterodimer proteins still retained the majority of secondary structure as determined by CD spectroscopy. This was supported by the retained ability of the mutant BFR proteins to spontaneously bind porphyrins (heme or $\mathrm{ZnCe}_{6}$ ) and metal ions ( $\mathrm{Fe}$ or $\mathrm{Mn})$.

The CD spectra revealed that the heterodimer proteins were less structured than the BFR $^{1}$ mutant. The decrease in secondary structure was in part expected as the addition of a completely unstructured 22 amino acid loop region would increase the random coil component by at least $7 \%$. The addition of metal ions was found to increase the alphahelical constant of both heterodimer forms. This was particularly evident in the BFR-H2 construct which was less structured than the BFR-H1 construct due to the extra mutation of Glu51 to a cysteine (Table 4.1).

It is not certain but appears likely that the BFR heterodimer proteins do not form the large $24 \mathrm{mer}$ sphere structure. This indicated that the Gly-Gly-Ser linker was either inhibiting the $24 \mathrm{mer}$ forming due to the fact that it extends from a region which is inherently involved in the interactions needed to form the sphere; or that the reduction in alpha-helical structure destabilizes the ionic interactions linking the components. Addition of the linker region is estimated to increase the iso-electric point (pI) of the protein from the literature value of 4.72 up to 4.79 , due to the basic nature of the linker. This is a small amount but the BFR complex relies on negative interactions to form the dodecamer of dimers.

\section{Isothermal Titration Calorimetry}

Manganese ligates to the di-nuclear metal binding site of bacterioferritin (Conlan et al. 2007) via four glutamate residues (E18, E51, E94, E127) one from each helix and two histidine residues (H54, H130) (Frolow et al. 1994). E51 and E127 form di- $\mu-1,3-$ 
caboxylato bridges, where each oxygen atom is coordinated to a different metal ion, removal of E51 was expected to cancel metal binding within the site.

ITC analysis of $\mathrm{Mn}$ binding to $\mathrm{BFR}^{2}$ revealed that there was no longer a distinct binding site within the protein and the small amount of manganese which did bind was not ligated very strongly (Table 4.2). The large and negative $\Delta \mathrm{H}_{\mathrm{b} 1}$ value found for $\mathrm{Mn}$ binding to $\mathrm{BFR}^{1}$ was significantly less in $\mathrm{BFR}^{2}$ which reflects the lack of structural changes normally associated with metal binding at the ferroxidase site (LeBrun et al. 1996).

BFR-H1 and BFR-H2 both bind manganese ions with similar association constants but BFR-H1 binds more Mn as it contains two di-metal binding centres where as the BFR$\mathrm{H} 2$ mutant only contains one di-metal binding centre. BFR-H1 and BFR-H2 when binding the first manganese ion have a relatively small and positive $\Delta \mathrm{H}_{\mathrm{b}}$ but a large $\Delta \mathrm{S}_{\mathrm{b}}$ indicating that binding Mn to site 1 is entropically driven (Table 4.2). The most likely contributions to this positive entropy are changes in the hydration of the protein and of the metal ion upon binding to the protein (Bou-Abdallah et al. 2003). The first Mn ion binds to the heterodimers relatively strongly but the second ion binds much more weakly. Both the association constants are significantly smaller than that found for $\mathrm{BFR}^{1}$. This may be due to strains placed on the metal binding site due to the large linker and the associated reduction in secondary structure. Ligands are required from all four helices of the 4-helix bundle to bind the metal ions so changes in just one helix could destabilise metal binding. Though the binding is not as tight for the heterodimers there is still definite ligation of $\mathrm{Mn}$ ions within these proteins.

The BFR-H1 heterodimer appeared to bind $\mathrm{ZnCe}_{6}$ quite differently to that found for $\mathrm{BFR}^{1}$. The heterodimer appeared to have two binding events taking place. The initial binding event which was quite strong and proceeded until 0.47 BFR-H1 molecules were titrated in per $\mathrm{ZnCe}_{6}$ molecule. The next binding event was not as strong and may have to do with multimerisation of the dimer subunits as they become more structured upon binding to $\mathrm{ZnCe}_{6}$. This second binding event may also reflect heterogeneity in the sample; i.e. some of the protein aggregating at high concentration. ITC analysis revealed that the second binding event of $\mathrm{ZnCe}_{6}$ to the hydrophobic heme pocket has a large enthalpy term (Table 4.2). This large and negative $\Delta \mathrm{H}_{\mathrm{b}}$ value probably reflects 
strong non-covalent interactions (van der Waals and hydrogen bonds) between $\mathrm{ZnCe}_{6}$ and $\mathrm{BFR}^{1}$ relative to their interaction with the solvent. The driving force for binding is likely the hydrophobic interactions between the porphyrin and the hydrophobic amino acid residues lining the binding pocket (Zhang et al. 2007).

\section{Iron Oxidation Rates}

Analysis of iron oxidation rates is a good method to determine if the native activity of the BFR protein is retained upon production of different mutants. All forms of the BFR protein tested retained iron oxidation activity (Figure 4.13). The wild-type and BFR ${ }^{1}$ forms had very similar rates of oxidation, though the heterodimers appear to oxidise iron at a much faster rate (Table 4.3). The initial rate of oxidation for BFR-H2 is very fast but this rate tails off significantly over time. This change in apparent rate may be due to precipitation of the oxidised iron which is no longer being stored within the sphere structure of the BFR protein shell.

The rate of oxidation seems to increase as the number of mutations and changes in secondary structure increase. The slight unwinding the BFR protein when expressed as the heterodimeric form appears to speed up iron oxidation in solution. It is suggested here that loosening of the structure opens the ferroxidase site slightly which allows faster access and exit of reactants and products to this site.

\section{Quinone Binding}

The covalent binding of quinones to proteins or other molecules produces distinctive shifts in the absorbance spectrum (Figure 4.14) (Hay et al. 2004; Li et al. 2005; Li et al. 2006). Binding $\mathrm{CoQ}_{0}$ to the reduced forms of $\mathrm{BFR}^{2}$ and $\mathrm{BFR}-\mathrm{H} 2$, produced absorbance bands at $276 \mathrm{~nm}$ and $343 \mathrm{~nm}$ due to the covalent linkage to the cysteine sulphur. This binding was further validated by EPR analysis of the singly reduced semi-quinone form of the quino-proteins. The semi-quinone radical can be detected by EPR at high $\mathrm{pH}$ $(\sim 9)$.

For para-benzoquinone in water at $\mathrm{pH} 7.0, \mathrm{E}\left(\mathrm{Q} / \mathrm{Q}^{\circ}\right)=99 \mathrm{mV}$, and $\mathrm{E}\left(\mathrm{Q} / \mathrm{Q}^{2-}\right)=286 \mathrm{mV}$ (Depew and Wan 1988) and no semi-quinone is observed. As the $\mathrm{pH}$ is increased above $\mathrm{pH} 7, \mathrm{E}\left(\mathrm{Q} / \mathrm{Q}^{\bullet}\right)$ doesn't change but $\mathrm{E}\left(\mathrm{Q} / \mathrm{Q}^{2-}\right)$ decreases by $120 \mathrm{mV}$ per $\mathrm{pH}$ unit above $\mathrm{pH}$ 
7 up until the $\mathrm{pK}\left(\mathrm{QH}^{-} / \mathrm{QH}_{2}\right)$ which is approximately 10 (Chambers 1988). This decreases $\left[E\left(Q / Q^{\circ-}\right)-E\left(Q / Q^{2-}\right)\right]$ and stabilises the semi-quinone form. The yield of semi-quinone upon increasing the $\mathrm{pH}$ is predicted to be very low (Hay 2005).

The solution EPR spectra of $\mathrm{CoQ}_{0}$ and NQ reveal complex hyperfine splitting centred around $\mathrm{g}=2$. $\mathrm{CoQ}_{0}$ did not resolve as many peaks as NQ and the yield of semi-quinone when placed into high $\mathrm{pH}$ buffer was much lower for $\mathrm{CoQ}_{0}$ than NQ. The level of semiquinone formed is greater for the NQ under the conditions used (i.e $\mathrm{pH} 9.5$ ) due to the $\mathrm{pK}$ of $\mathrm{NQ}$ being higher than $\mathrm{CoQ}_{0} . \mathrm{CoQ}_{0}$ is either forming the dianion $\left(\mathrm{QH}_{2}\right)$ or degrading at the high $\mathrm{pH}$ used.

\subsubsection{Light Induced Effects}

\section{$\mathrm{Mn}^{2+}$ Oxidation State as Measured by EPR}

The EPR spectra of the heterodimer with Mn bound showed less of the dimeric $\mathrm{Mn}_{2}{ }^{\text {IIII }}$ structure than did the $\mathrm{BFR}^{1}$ homodimer. When compared to the homodimer the spectra was narrower suggesting less interaction of the $\mathrm{Mn}$ ions due to an increase in the distance separating them. This same phenomenon was found in $\sim 50 \%$ of the homodimer metal centres when $\mathrm{ZnCe}_{6}$ was bound but appears to occur in a greater number of centres in the heterodimer construct. The amount of bound monomeric $\mathrm{Mn}^{\mathrm{II}}$ signal centred at $\mathrm{g}=4$ is increased in the heterodimer again pointing to a decoupling of the manganese ions in the metal centre.

The BFR-H1 ZM complex showed some changes in the amount of $\mathrm{Mn}_{2}{ }^{\mathrm{II}, \mathrm{II}}$ dimer signal centred at $\mathrm{g}=2$ upon illumination. Illumination produced a small decrease in the structured $\mathrm{Mn}_{2}$ II,II dimer signal, though no new signals were observed. It would be beneficial to use longer illumination times at room temperature to increase the amount of manganese oxidised (see Chapter 3). Longer illumination times should also produce new EPR signals as a result of $\mathrm{Mn}^{\mathrm{III}}$ species forming. 


\section{Light Induced Chlorin Oxidation / Tyrosine Oxidation as Measured by EPR.}

Illumination of the BFR-H1 heterodimer with no metal bound produced a large pronounced $\mathrm{ZnCe}_{6}$ radical signal. When manganese was bound to the same protein then a broader signal was produced. Subtraction of the narrow $\mathrm{ZnCe}_{6}$ radical from the broader signal reveals a structured radical signal $(2.0 \mathrm{mT})$ centred at $\mathrm{g}=2.0031$ (Figure 4.20). This broad radical signal appears to be the same signal as that found in the BFR ${ }^{1}$ protein though the $\mathrm{g}$ value is slightly shifted and the turning points are not quite as well defined.

The protein environment is known to affect the g-value of tyrosine radicals (Un et al. 1995; Bleifuss et al. 2001; Hofbauer et al. 2001).There are some slight structural changes in the heterodimer protein as compared to $\mathrm{BFR}^{1}$ so it is not surprising that the g-value of the tyrosine signal is slightly shifted. The presence of the tyrosine radical does confirm that the system is still intact and capable of carrying out light induced electron transfer.

\section{Light Induced Oxygen Consumption of the BFR Metal Site}

BFR functions in biology to bind iron and oxidize $\mathrm{Fe}_{2}{ }^{\mathrm{II}}$ to $\mathrm{Fe}_{2}{ }_{2}{ }^{\text {III }}$ forming a stabilizing $\mu$ oxo bond between the two metal ions. This reaction consumes dissolved $\mathrm{O}_{2}$ (see Chapter 3) (Liu et al. 2004). BFR ${ }^{1}$ has been shown to be capable of binding manganese at the ferroxidase site and when $\mathrm{ZnCe}_{6}$ is bound oxidising the bound $\mathrm{Mn}$ from $2+$ to $3+$. BFR $^{1}$, BFR-H1 and BFR-H2 all consume significant amounts of oxygen upon illumination (Figure 4.21).

BFR-H1 and BFR-H2 consumed similar amounts of oxygen as found for the BFR ${ }^{1}$ homodimer (Table 4.5). The addition of a quinone electron acceptor was found to significantly increase both the rate of uptake and the total oxygen consumed. A control of quinone in solution proved that the increase was not due to light effects on the quinone itself. The total amount of oxygen consumed far exceeded the other constructs indicating that more manganese centres were oxidised than in the other constructs. The increased oxygen uptake is likely through improvements in the efficiency of transferring the electron away from the $\mathrm{ZnCe}_{6}$ pigment resulting in a longer lived charge-separated state. As suggested in Chapter 3 it is possible that coinciding with the extra oxygen 
consumption more than one $\mu$-oxo bond is formed. This hypothesis could in future be tested using EXAF measurements to look at bond lengths of the metal complex.

\section{Steady State Fluorescence Properties}

Comparison of the steady-state fluorescence spectra of BFR-H2 ZM CoQ $\mathrm{Z}_{0}$ with the reference protein BFR-H2 ZM indicates significant fluorescence quenching due to the presence of the $\mathrm{CoQ}_{0}$ moiety (Figure 4.22). The $22 \%$ quenching of the chlorin fluorescence by the quinone in its oxidized state is either due to non-radiative Forster energy transfer (the absence of ground-state coupling rules-out a Dexter mechanism) or electron transfer. Forster energy transfer is a mechanism of excitation transfer which can occur between molecular entities separated by distances considerably exceeding the sum of their van der Waals radii. It involves a dipole-dipole coupling mechanism between donor and acceptor. This form of energy transfer requires spectral overlap of the donor emission spectrum and the acceptor absorption spectrum. There is no detectable spectral overlap between the $\mathrm{ZnCe}_{6}$ emission and quinone absorbance and as the quenching is only observed in the presence of the oxidised quinone, which is a renowned electron acceptor, the later explanation of electron transfer is favoured.

It follows from this that $\sim 78 \%$ of the excited-state population decays through channels other than photo-induced electron transfer, such as internal conversion to the ground state and intersystem crossing to the triplet state whose lower energy compared to that of the singlet excited state may not provide sufficient driving force for the photoinduced electron transfer reaction.

The quenching of fluorescence as a result of electron transfer to an oxidised quinone was reported by Hay et al (2004). The Cyt $b_{562}$ quino-protein with a $\mathrm{ZnCe}_{6}$ bound at the heme binding site showed a similar reduction in steady state fluorescence yield. Measurements of the fluorescence lifetimes quenching gave very similar efficiency values to that found by steady state fluorescence quenching (i.e. $\approx 20 \%$ ).

Having manganese bound to the BFR-H2 quino-protein was found to have very little effect on fluorescence yield. There was a very slight quenching when Mn was bound but this was hardly significant. This lack of effect was expected due to the fast back 
reaction of the electron from the quinone to the $\mathrm{ZnCe}_{6}$ and the slow movement of the electron hole to the metal centre (Rappaport et al. 1994).

\section{EPR Spectra of BFR-H2 Quinone}

Illumination of the BFR-H2 Z naphthoquinone protein produced a radical signal which was broader than a simple $\mathrm{ZnCe}_{6}$ cation radical. Subtraction of some of the simple $\mathrm{ZnCe}_{6}$ signal revealed a radical which was broader and with a higher $\mathrm{g}$ value centred at $\mathrm{g}=2.0032$. This signal appeared to be the singly reduced semi-quinone radical (Figure 4.24).

This protein has no metal ions bound and as such we do not expect to see any tyrosine radical. This simplifies analysis of the EPR spectra as the only two possible radical signals are the $\mathrm{ZnCe}_{6}$ cation radical and the semi-quinone anion radical signal. Subtraction of the $\mathrm{ZnCe}_{6}$ portion of the spectra reveals a signal which could only be due to the singly reduced semi-quinone.

Looking at the solution EPR spectra of the same quino-protein but with manganese bound revealed some significant differences. The BFR-H2 ZM sample produces the expected mix of $\mathrm{ZnCe}_{6}$ radical signal and an oxidised tyrosine radical. (Figure 4.25). When the NQ was bound the protein a much narrower $\mathrm{g}=2 \mathrm{EPR}$ signal, remarkably similar to the BFR-H2 Z spectra, was produced with little tyrosine species detectable. Thus it appears that the binding of NQ to BFR-H2 results in the loss of a large percentage of the tyrosine radical species. It is expected that at least $50 \%$ of the tyrosine radical signal would be removed due to no metal ions binding in one half of the protein. There may also be changes in the metal binding site which could prevent the formation of the tyrosine radical which is dependent on Mn being bound and the subsequent deprotonation of the metal amino acid ligands (Conlan et al. 2007).

The complexity of the sample makes it very difficult to assign the radicals to one particular species. There are three potential radical signals all overlaid within these spectra. There is the $\mathrm{ZnCe}_{6}$ cation radical, the tyrosine radical and the semi-quinone radical. All of these are centred around $g=2$ with only slight shifts due to the nature of the radicals. Further studies of the Mn containing heterodimer need to be carried out to visualise electron transfer to the quinone by EPR. 


\subsubsection{Electron Pathways Modelling}

The optimal electron tunnelling pathway (Beratan et al. 1992) from $\mathrm{ZnCe}_{6}$ to the bound quinone was calculated using the HARLEM program (Kurnikov and Beratan 1996). This program uses a modified superexchange coupling model developed by Beratan, Onuchic, and co-workers which accommodates the structural complexity of a protein matrix in electron transfer reactions (Onuchic and Beratan 1990; Beratan et al. 1991, 1992a; Onuchic et al. 1992)

In this tunnelling-pathway model, the medium between donor and acceptor is broken down into small subunits linked by covalent bonds $\left(\varepsilon_{C}\right)$, hydrogen bonds $\left(\varepsilon_{H}\right)$, or through-space jumps $\left(\varepsilon_{\mathrm{S}}\right)$. A coupling decay is assigned to each link, and a structuredependent search algorithm is used to identify the optimum coupling pathway between the two redox sites. The electronic coupling matrix element $\left(H_{\mathrm{AB}}\right)$ reflects the strength of the interaction between reactants and products. The total coupling is given as a product of the couplings for the individual links (Equation 4-1):

$$
H_{A B} \propto \Pi \varepsilon_{C} \Pi \varepsilon_{H} \Pi \varepsilon_{S}
$$

\section{Equation 4-1}

The tunnelling-pathway model has proved to be a useful method for estimating distant electronic coupling and as such was used to compare the bacterioferritin system and the Cyt $b_{562}$ system of Hay and co-workers (Beratan et al. 1987; Onuchic and Beratan 1990; Onuchic et al. 1992; Hay et al. 2004; Hay 2005). The optimal electron tunnelling pathway from $\mathrm{ZnCe}_{6}$ to the bound quinone was predicted to proceed via the axial ligand sulphur of Met51 and transfer along the protein backbone through Cys51 which is covalently attached to the quinone (Figure 4.27). Altogether the path includes 9 covalent bonds. This corresponds to an effective tunnelling length $\sigma_{t}=15.8 \AA$ and an electronic coupling decay factor, $H_{\mathrm{AB}}=6.05 \times 10^{-3}$. The direct $\mathrm{ZnCe}_{6}$ to quinone distance $r=10.6 \AA$. 


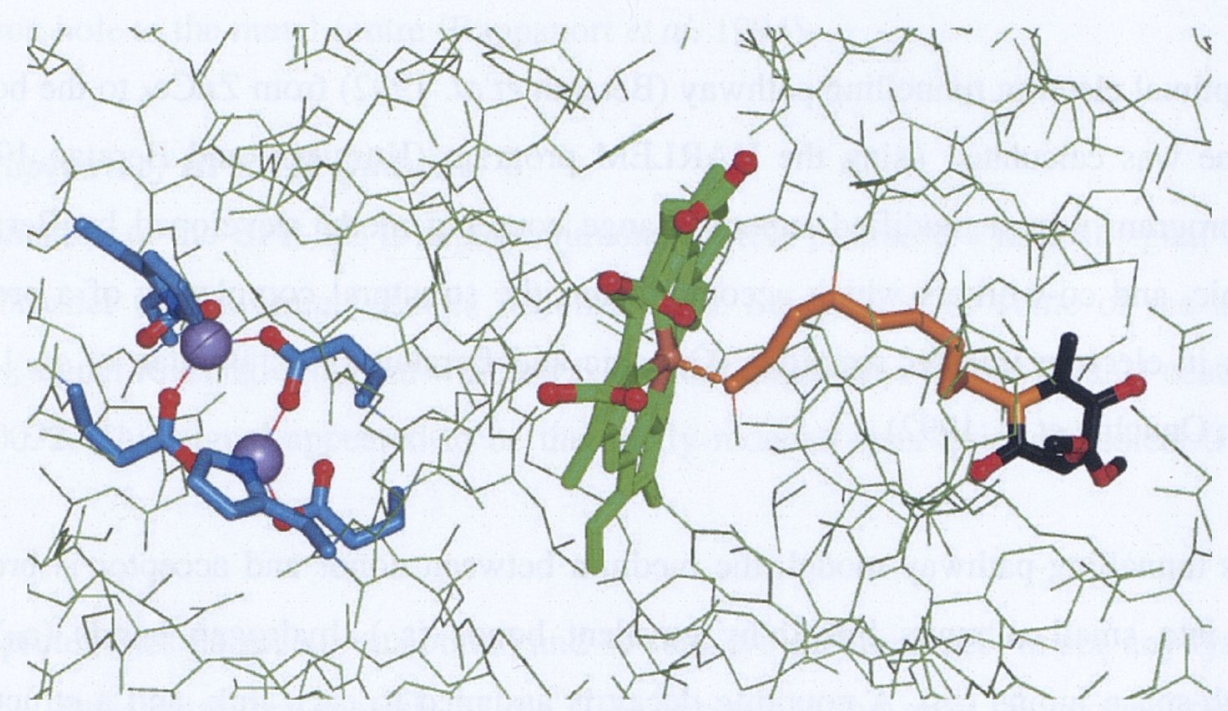

Figure 4.27: The calculated best pathway for electron transfer from the $\mathrm{ZnCe}_{6}$ to the quinone in BFR-H2 ZM CoQ ${ }_{0}$. The electron likely travels along the axial ligand Met51 and then along Cys52 which is covalently linked to $\mathrm{CoQ}_{0}$.

When the previously characterised quino-protein of Hay et al (2004) was modelled (a protein proven to have high electron transfer efficiency), the coupling is theoretically less favourable than that of the BFR quino-protein. The best pathway coupling between donor and acceptor $H_{\mathrm{AB}}=7.84 \times 10^{-5}$ is much smaller than that of the BFR heterodimer system. In the Cyt $b_{562}$ model the electron has an effective tunnelling length $\sigma_{t}=11.3 \AA$ and the straight $\mathrm{ZnCe}_{6}$ to quinone distance $r=9.5 \AA$. Even though this quinone is placed $\sim 1.1 \AA$ closer the smaller coupling is due to the electron having to transfer through space as opposed to along covalently bonded atoms (Figure 4.28). Tunnelling is much more efficient (decays more slowly) through bonded orbitals than through space because the effective potential barrier is lower. 


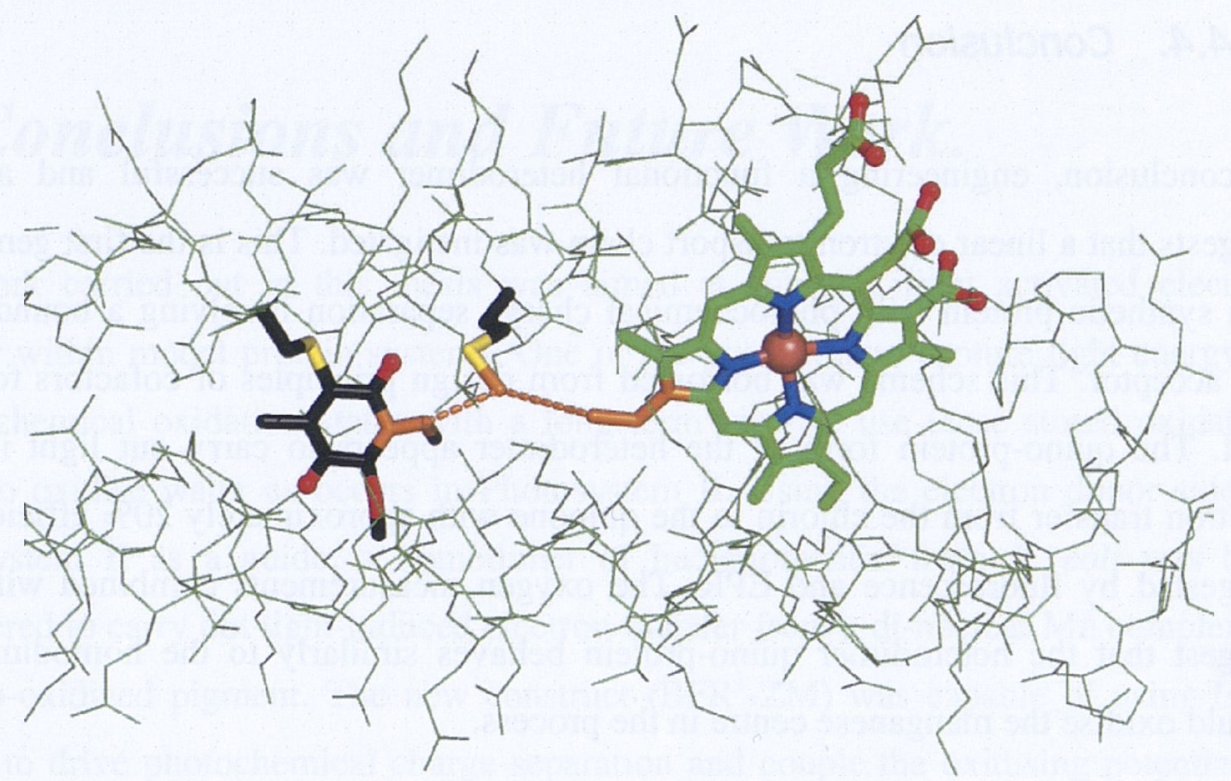

Figure 4.28: The calculated best pathway for electron transfer from the $\mathrm{ZnCe}_{6}$ to the quinone in the Cyt $b_{562}$ quino-protein of Hay et al (2004). The electron likely travels from the $\mathrm{ZnCe}_{6}$ outer carbon atoms through space to Met34 and then again through space to the oxygen of the methoxy group of the covalently linked to $\mathrm{CoQ}_{0}$.

Assuming that $\mathrm{CoQ}_{0}$ is buried equally within the protein framework for both Cyt $b_{562}$ and BFR-H2 then we could expect similar reorganisation energies for the system. The same porphyrin is utilised and the driving force of the system is likely to be similar. Under such conditions, we would expect better yields of electron transfer in the BFR quino-protein than that found in the Cyt $b_{562}$ protein due to the electronic coupling being higher in the BFR system. Then again the BFR system may be limited to a single dominant pathway of electron transfer via the axial ligand which could generate a single-pathway limit and slower rates. (Prytkova et al. 2007). There remain many further measurements to be carried out on this system to determine the efficiency of electron transfer. 


\subsection{Conclusion}

In conclusion, engineering a functional heterodimer was successful and analysis suggests that a linear electron transport chain was instigated. This is the first generation of a synthetic protein with photochemical charge separation involving a bound donor and acceptor. This scheme was borrowed from design principles of cofactors found in PSII. The quino-protein form of the heterodimer appears to carry out light induced electron transfer from the chlorin to the quinone with approximately $20 \%$ efficiency as suggested by fluorescence and EPR. The oxygen measurements combined with EPR suggest that the heterodimer quino-protein behaves similarly to the homodimer and should oxidise the manganese centre in the process.

Further work is needed on these constructs in order to fully characterise them. This will include spectroscopy of donor and acceptor function and will be continued in the future in the Photobioenergetics lab. It is hoped that these studies will be able to answer some of the many questions that have been raised in the study of these engineered proteins and refine the heterodimer reaction centre mimic of PSII. 


\section{CHAPTER 5}

\section{Conclusions and Future Work.}

The work carried out in this thesis was aimed at studying light activated electron transfer within model protein systems. One of the goals was to capture light energy as stored chemical oxidation states with a long term view to use these stored oxidation states to oxidise water as occurs in Photosystem II. Using the electron donor side of Photosystem II as a guide, a homodimer of bacterioferritin from E. coli was bioengineered to carry out light-induced electron transfer from a di-nuclear Mn complex to a photo-oxidized pigment. The new construct (BFR ${ }^{1} \mathrm{ZM}$ ) was capable of using light energy to drive photochemical charge separation and couple the oxidising potential to multiple oxidation events at the bound $\mathrm{Mn}_{2}{ }^{\mathrm{II}}$ complex. This work is the first bioengineered protein capable of photo-catalytic, multi-electron oxidation of a dimanganese centre that has been reported in the literature.

Having shown that a protein can be modified to undergo a photochemical reaction, the next step was to design and construct a bacterioferritin heterodimer to mimic the PSII reaction centre. PSII is made up of a heterodimeric protein core which binds multiple cofactors necessary to create a light dependent charge separated state. The modified bacterioferritin is also a heterodimer with multiple cofactors capable of forming such a state. Both heterodimers bind light active pigments which transfer an electron to a quinone electron acceptor bound to the protein complex. Also both proteins have multiple symmetrically positioned tyrosine residues which are selectively oxidised during light activation. These tyrosines likely mediate transfer of electrons from the manganese centre.

The heterodimer proteins are a successful attempt at engineering a linear electron transport chain, which contains a number of the cofactors found in PSII. The quinoprotein form of the heterodimer appears to carry out light induced electron transfer from the chlorin to the quinone with approximately $20 \%$ efficiency as suggested by fluorescence and EPR. The oxygen measurements combined with EPR suggest that the heterodimer quino-protein behaves similarly to the homodimer and should oxidise the manganese centre in the process. 
More work needs to be completed on these constructs to fully characterise them. Nevertheless, the modified heterodimer of BFR promises to be a good model system for testing out the properties of PSII reactions, e.g.

(1) If there are two nearby tyrosine donors to the oxidised pigment, is electron transfer purely distance dependent or controlled by intervening chemical bonds?

(2) If a H-bond can be engineered to the tyrosine, how does this affect the redox potentials of the oxidation? Can a $\mathrm{H}$-acceptor histidine be engineered.

(3) If the di-metal site can be modified to bind more than two Mn ions within the complex, how does this affect the oxidation sequence?

(4) What is the affect if two quinone electron acceptors are incorporated into the heterodimer.

The most immediate question to be answered is the nature of the tyrosine radical found in illuminated samples of the bacterioferritin complex with chlorin and manganese bound. Mutation of the three potentially redox active tyrosine's, found within close proximity of the chlorin and metal centre, should reveal which is oxidised during illumination. This is currently being studied in the Photobioenergetics lab with some interesting observations on the tyrosine story already emerging.

Limited attempts have been made in the generation of a protein-bound manganese centre that acts as an electron donor species. However numerous synthetic dimanganese compounds have been produced as models of the OEC, of which several are able to catalyse the oxidation of water to molecular oxygen (Limburg et al. 1999; Limburg et al. 2001; Poulsen et al. 2005; Tagore et al. 2008). The use of a dimanganese centre in our protein based system could therefore potentially facilitate the oxidation of water. Theoretically introduction of mutations to the BFR system that increases the number of hydrogen bonds to the $\mathrm{ZnCe}_{6}$ could substantially increase the oxidation potential (Kalman et al. 2005). This could promote oxidation of the dimanganese centre to the higher oxidation states that are necessary for water splitting (Kurz et al. 2007). 
The unique spherical dodecamer of dimers of the BFR model system has a large internal cavity of $\sim 8 \AA$, which could potentially be used to compartmentalize reactions within the same molecular assembly. This could allow separation of oxidative and reductive processes across a protein interface. It is proposed that the internal cavity of the BFR sphere structure is anaerobic (Baaghil et al. 2003) in which case the addition of a hydrogenase site within the sphere would limit $\mathrm{O}_{2}$ poisoning the hydrogenase catalyst. If for instance the Mn centre was capable of photo-catalytic oxidation of water this oxidative reaction could be coupled to reduction of protons to hydrogen gas on the inside of the complex.

The ultimate aim of this ongoing research is to produce an artificial catalyst whereby water is efficiently split into molecular oxygen, protons and electrons. To my knowledge this work is novel and the first example of a bioengineered protein capable of photo-catalytic, multi-electron oxidation of a dimanganese centre. This system should enable theoretical PSII problems to be tested on a much simpler protein complex with fewer cofactors to confuse analysis. This work represents one of the first steps in developing synthetic photo-catalytic, 'green enzymes' that utilize light energy to catalyse oxygen evolution and hydrogen production. 
Chapter 5. Conclusions and Future Work. 


\section{References}

Abragam A and Bleaney BI (1970) Electron Paramagnetic Resonance of Transition Ions. Oxford University Press, Oxford

Ahmad I, Cusanovich MA and Tollin G (1981) Laser Flash-Photolysis Studies of Electron-Transfer between Semi-Quinone and Fully Reduced Free Flavins and Horse Heart Cytochrome-C. Proc Natl Acad Sci USA 78: 6724-6728

Al'tshuler SA and Kozyrev BM (1974) Electron Paramagnetic Resonance in Compounds of Transition Elements. Halsted-Wiley, New York, NY, USA

Alfonta L, Zhang ZW, Uryu S, Loo JA and Schultz PG (2003) Site-specific incorporation of a redox-active amino acid into proteins. J Am Chem Soc 125: $14662-14663$

Allen JP and Williams JC (1995) Relationship between the Oxidation Potential of the Bacteriochlorophyll Dimer and Electron-Transfer in Photosynthetic Reaction Centers. J Bioenerg Biomembr 27: 275-283

Allen JP and Williams JC (1998) Photosynthetic reaction centers. Febs Letters 438: 5-9

Andrews SC, Harrison PM and Guest JR (1989) Cloning, Sequencing, and Mapping of the Bacterioferritin Gene (bfr) of Escherichia coli K-12. Journal of Bacteriology 171: $3940-3947$

Andrews SC, Lebrun NE, Barynin V, Thomson AJ, Moore GR, Guest JR and Harrison PM (1995) Site-Directed Replacement of the Coaxial Heme Ligands of . Bacterioferritin Generates Heme-Free Variants. J Biol Chem 270: 23268-23274

Anthony C (2004) The quinoprotein dehydrogenases for methanol and glucose. Arch Biochem Biophys 428: 2-9

Armstrong FA (2008) Why did nature choose manganese to make oxygen? Philos Trans R Soc Lond B Biol Sci 363: 1263-1270

Arnesano F, Banci L, Bertini I, Faraone-Mennella J, Rosato A, Barker PD and Fersht AR (1999) The solution structure of oxidized Escherichia coli cytochrome b(562). Biochemistry 38: 8657-8670

Baaghil S, Lewin A, Moore GR and Le Brun NE (2003) Core formation in Escherichia coli bacterioferritin requires a functional. Biochemistry 42: 14047-14056

Baaghil S, Thomson AJ, Moore GR and Le Brun NE (2002) Studies of copper(II)binding to bacterioferritin and its effect on iron(II) oxidation. J Chem Soc Dalton: $811-818$

Barker PD, Nerou EP, Cheesman MR, Thomson AJ, deOliveira P and Hill HAO (1996) Bis-methionine ligation to heme iron in mutants of cytochrome $b(562)$.1. 
Spectroscopic and electrochemical characterization of the electronic properties'. Biochemistry 35 : 13618-13626

Barynin VV, Whittaker MM, Antonyuk SV, Lamzin VS, Harrison PM, Artymiuk PJ and Whittaker JW (2001) Crystal structure of manganese catalase from Lactobacillus plantarum. Structure 9: 725-738

Bauminger ER, Harrison PM, Hechel D, Nowik I and Treffry A (1991) Mossbauer Spectroscopic Investigation of Structure-Function Relations in Ferritins. Biochim Biophys Acta 1118: 48-58

Bellelli A, Brzezinski P, Arese M, Cutruzzola F, Silvestrini MC and Brunori M (1996) Electron transfer in zinc-reconstituted nitrite reductase from Pseudomonas aeruginosa. Biochem J 319: 407-410

Beratan DN, Onuchic JN, Winkler JR and Gray HB (1992) Electron-Tunneling Pathways in Proteins. Science 258: 1740-1741

Blankenship RE (2002) Molecular Mechanisms of Photosynthesis. Blackwell Science Ltd

Bleifuss G, Kolberg M, Potsch S, Hofbauer W, Bittl R, Lubitz W, Graslund A, Lassmann $G$ and Lendzian $F$ (2001) Tryptophan and tyrosine radicals in ribonucleotide reductase: A comparative high-field EPR study at $94 \mathrm{GHz}$. Biochemistry 40: 15362-15368

Bou-Abdallah F, Arosio P, Levi S, Janus-Chandler C and Chasteen ND (2003) Defining metal ion inhibitor interactions with recombinant human $\mathrm{H}$ - and $\mathrm{L}$-chain ferritins and site-directed variants: an isothermal titration calorimetry study. J Biol Inorg Chem 8: 489-497

Boussac A, Rappaport F, Carrier P, Verbavatz JM, Gobin R, Kirilovsky D, Rutherford AW and Sugiura M (2004) Biosynthetic Ca2+/Sr2+ exchange in the photosystem II oxygen-evolving enzyme of Thermosynechococcus elongatus. J Biol Chem 279: 22809-22819

Campbell KA, Force DA, Nixon PJ, Dole F, Diner BA and Britt RD (2000) Dual-mode EPR detects the initial intermediate in photoassembly of the photosystem II mn cluster: The influence of amino acid residue 170 of the D1 polypeptide on $\mathrm{Mn}$ coordination. J Am Chem Soc 122: 3754-3761

Campbell KA, Lashley MR, Wyatt JK, Nantz MH and Britt RD (2001) Dual-mode EPR study of $\mathrm{Mn}$ (III) salen and the $\mathrm{Mn}$ (III) salen-catalyzed epoxidation of cis-betamethylstyrene. J Am Chem Soc 123: 5710-5719

Campbell KA, Yikilmaz E, Grant CV, Gregor W, Miller AF and Britt RD (1999) Parallel polarization EPR characterization of the Mn(III) center of oxidized manganese superoxide dismutase. J Am Chem Soc 121: 4714-4715

Carrondo MA (2003) Ferritins, iron uptake and storage from the bacterioferritin viewpoint. The EMBO Journal 22: 1959-1968 
Catanzariti A-M, Soboleva TA, Jans DA, Board PG and Baker RT (2004) An efficient system for high-level expression and easy purification of authentic recombinant proteins. Protein Sci 13: 1331-1339

Cecchini G, Maklashina E, Yankovskaya V, Iverson TM and Iwata S (2003) Variation in proton donor/acceptor pathways in succinate : quinone oxidoreductases. Febs Letters 545: 31-38

Chambers J (1988) The Chemistry of The Quinoid Compounds. In: Patai S and Rappaport Z (eds), pp 719-759. John Wiley and Sons

Chang IJ, Gray HB and Winkler JR (1991) High-Driving-Force Electron-Transfer in Metalloproteins - Intramolecular Oxidation of Ferrocytochrome-C by $\mathrm{Ru}\left(2,2^{\prime}-\right.$ Bpy)2(Im)(His-33)3+. J Am Chem Soc 113: 7056-7057

Chen M, Eggink LL, Hoober JK and Larkum AWD (2005) Influence of structure on binding of chlorophylls to peptide ligands. J Am Chem Soc 127: 2052-2053

Cheung E, Taylor K, Kornblatt JA, English AM, McLendon G and Miller JR (1986) Direct Measurements of Intramolecular Electron-Transfer Rates between Cytochrome-C and Cytochrome-C Peroxidase - Effects of Exothermicity and Primary Sequence on Rate. Proc Natl Acad Sci USA 83: 1330-1333

Clausen J, Debus RJ and Junge W (2004) Time-resolved oxygen production by PSII: chasing chemical intermediates. Biochim Biophys Acta 1655: 184-194

Conlan B (2008) Designing photosystem II: molecular engineering of photo-catalytic proteins. Photosyn Res 98: 687-700

Conlan B, Wydrzynski T and Hillier W (2007) Designing artificial photosynthesis: Engineering bacterioferritin for light-activated electron transfer. Photosyn Res 91: $281-281$

Connick WB, DiBilio AJ, Hill MG, Winkler JR and Gray HB (1995) Tricarbonyl(1,1Ophenanthroline)(imidazole)rhenium(I): A powerful photooxidant for investigations of electron tunneling in proteins. Inorg Chim Acta 240: 169-173

Cowan JA (1996) Inorganic Biochemistry - an introduction. Wiley-VCH

Cowan JA and Gray HB (1989) Synthesis and Properties of Metal-Substituted Myoglobins. Inorg Chem 28: 2074-2078

Dasgupta J, Ananyev GM and Dismukes GC (2008) Photoassembly of the wateroxidizing complex in photosystem II. Coord Chem Rev 252: 347-360

Dau H and Haumann M (2008) The manganese complex of photosystem II in its reaction cycle - Basic framework and possible realization at the atomic level. Coord Chem Rev 252: 273-295 
Dautant A, Meyer JB, Yariv J, Precigoux G, Sweet RM, Kalb AJ and Frolow F (1998) Structure of a monoclinic crystal form of cytochrome b1 (bacterioferritin) from E-coli. Acta Crystallogr D 54: 16-24

Depew M and Wan J (1988) The Chemistry of the Quinoid Compounds. In: Patai S and Rappaport Z (eds), pp 899-962. John Wiley and Sons

Dexheimer SL, Gohdes JW, Chan MK, Hagen KS, Armstrong WH and Klein MP (1989) Detection of Epr-Spectra in $S=2$ States of Trivalent Manganese Complexes. J Am Chem Soc 111: 8923-8925

Di Bilio AJ, Crane BR, Wehbi WA, Kiser CN, Abu-Omar MM, Carlos RM, Richards JH, Winkler JR and Gray HB (2001) Properties of photogenerated tryptophan and tyrosyl radicals in structurally characterized proteins containing rhenium(I) tricarbonyl diimines. J Am Chem Soc 123: 3181-3182

Di Bilio AJ, Dennison C, Gray HB, Ramirez BE, Sykes AG and Winkler JR (1998) Electron transfer in ruthenium-modified plastocyanin. J Am Chem Soc 120: 7551-7556

Diner BA and Britt RD (2005) The Redox-Active Tyrosines $\mathrm{Y}_{\mathrm{Z}}$ and $\mathrm{Y}_{\mathrm{D}}$. In: Wydrzynski $\mathrm{T}$ and Satoh K (eds) Photosystem II - The Light Driven Water:Plastoquinone Oxidoreductase, pp 207-233. Springer, Dordrecht

Dismukes GC (1996) Manganese enzymes with binuclear active sites. Chem Rev 96: 2909-2926

Eggink LL and Hoober JK (2000) Chlorophyll binding to peptide maquettes containing a retention motif. J Biol Chem 275: 9087-9090

Epel B, Schafer KO, Quentmeier A, Friedrich C and Lubitz W (2005) Multifrequency EPR analysis of the dimanganese cluster of the putative sulfate thiohydrolase SoxB of Paracoccus pantotrophus. J Biol Inorg Chem 10: 636-642

Ferreira KN, Iverson TM, Maghlaoui K, Barber J and Iwata S (2004) Architecture of the photosynthetic oxygen-evolving center. Science 303: 1831-1838

Fisher N and Rich PR (2000) A motif for quinone binding sites in respiratory and photosynthetic systems. J Mol Biol 296: 1153-1162

Freire E, Mayorga OL and Straume M (1990) Isothermal Titration Calorimetry. Analytical Chemistry 62: A950-A959

Frolow F, Kalb AJ and Yariv J (1994) Structure of a Unique Twofold Symmetrical Heme-Binding Site. Nature Structural Biology 1: 453-460

Frolow FK, A.J. (2001) Handbook of metalloproteins. In: A. M (ed) Handbook of metalloproteins, pp 782-790. Wiley, New York

Furukawa Y, Ishimori K and Morishima I (2000) Electron transfer reactions in Znsubstituted cytochrome P450cam. Biochemistry 39: 10996-11004 
Gerritsen HJ and Sabisky ES (1963) Paramagnetic Resonance of Trivalent Manganese in Rutile $\left(\mathrm{TiO}_{2}\right)$. Physical Review 132: 1507-\&

Golombek AP and Hendrich MP (2003) Quantitative analysis of dinuclear manganese(II) EPR spectra. J Magn Reson 165: 33-48

Gouterman M (1961) Spectra of porphyrins. Journal of Molecular Spectroscopy 6: 138163

Grabolle M and Dau H (2005) Energetics of primary and secondary electron transfer in Photosystem II membrane particles of spinach revisited on basis of recombination-fluorescence measurements. Biochim Biophys Acta 1708: 209218

Gray HB and Winkler JR (1996) Electron transfer in proteins. Annu Rev Biochem 65: 537-561

Gray HB and Winkler JR (2003) Electron tunneling through proteins. Q Rev Biophys 36: $341-372$

Griffith JS (1971) Theory of Transition: Metal Ions. Cambridge University Press

Groni S, Dorlet P, Blain G, Bourcier S, Guillot R and Anxolabehere-Mallart E (2008) Reactivity of an aminopyridine [LMnII] $(2+)$ complex with $\mathrm{H} 2 \mathrm{O} 2$. Detection of intermediates at low temperature. Inorg Chem 47: 3166-3172

Gunner MR (1991) The Reaction Center Protein from Purple Bacteria - Structure and FunctionCurr Top Bioenerg, pp 319-367.

Hamada K, Bethge PH and Mathews FS (1995) Refined Structure of Cytochrome B(562) from Escherichia-Coli at 1.4 Angstrom Resolution. J Mol Biol 247: $947-$ 962

Harrison PM and Arosio P (1996) Ferritins: Molecular properties, iron storage function and cellular regulation. Biochim Biophys Acta 1275: 161-203

Haumann M, Liebisch P, Muller C, Barra M, Grabolle M and Dau H (2005) Photosynthetic O-2 formation tracked by time-resolved X-ray experiments. Science 310: 1019-1021

Hay S (2005) Thesis - Protein Engineering of Novel Porphyrin/Quinone-Binding Proteins for Light-Induced Electron Transfer, Australian National University, Canberra

Hay S, Wallace BB, Smith TA, Ghiggino KP and Wydrzynski T (2004) Protein engineering of cytochrome $b_{562}$ for quinone binding and light-induced electrons transfer. Proc Natl Acad Sci USA 101: 17675-17680

Heathcote P, Fyfe PK and Jones MR (2002) Reaction centres: the structure and evolution of biological solar power. Trends in Biochemical Sciences 27: 79-87 
Hendrich MP and Debrunner PG (1988) Electron-Paramagnetic-Res Spectra of Quintet Ferrous Myoglobin and a Model Heme Compound. J Magn Reson 78: 133-141

Hendrich MP and Debrunner PG (1989) Integer-Spin Electron-Paramagnetic Resonance of Iron Proteins. Biophys J 56: 489-506

Hendry $\mathrm{G}$ and Wydrzynski T (2003) O-18 isotope exchange measurements reveal that calcium is involved in the binding of one substrate-water molecule to the oxygen-evolving complex in photosystem II. Biochemistry 42: 6209-6217

Hersleth HP, Ryde U, Rydberg P, Gorbitz CH and Andersson KK (2006) Structures of the high-valent metal-ion haem-oxygen intermediates in peroxidases, oxygenases and catalases. J Inorg Biochem 100: 460-476

Hillier W and Messinger J (2005) Mechanism of Photosynthetic Oxygen Production. In: Wydrzynski $\mathrm{T}$ and Satoh $\mathrm{K}$ (eds) Photosystem II: The light-driven water:plastoquinone oxidoreductase. , pp 567-608. Springer, Dordrecht

Ho FM and Styring S (2008) Access channels and methanol binding site to the CaMn4 cluster in Photosystem II based on solvent accessibility simulations, with implications for substrate water access. Biochim Biophys Acta 1777: 140-153

Ho TF, McIntosh AR and Bolton JR (1980) Intramolecular Photochemical ElectronTransfer in a Linked Porphyrin-Quinone Molecule as a Model for the Primary Step of Photosynthesis. Nature 286: 254-256

Hofbauer W, Zouni A, Bittl R, Kern J, Orth P, Lendzian F, Fromme P, Witt HT and Lubitz W (2001) Photosystem II single crystals studied by EPR spectroscopy at $94 \mathrm{GHz}$ : The tyrosine radical Y-D(center dot). Proc Natl Acad Sci USA 98: 6623-6628

Hoganson CW, Ghanotakis DF, Babcock GT and Yocum CF (1989) Mn-2+ Reduces $\mathrm{Y}_{\mathrm{Z}}^{+}$in Manganese-Depleted Photosystem-II Preparations. Photosyn Res 22: 285-293

Hughes JL, Razeghifard R, Logue M, Oakley A, Wydrzynski T and Krausz E (2006) Magneto-optic spectroscopy of a protein tetramer binding two exciton-coupled chlorophylls. J Am Chem Soc 128: 3649-3658

Iverson TM, Luna-Chavez C, Cecchini G and Rees DC (1999) Structure of the Escherichia coli fumarate reductase respiratory complex. Science 284: 19611966

Jiang W, Yun D, Saleh L, Barr EW, Xing G, Hoffart LM, Maslak M-A, Krebs C and Bollinger JM, Jr. (2007) A Manganese(IV)/Iron(III) Cofactor in Chlamydia trachomatis Ribonucleotide Reductase. Science 316: 1188-1191

Johnson ET and Parson WW (2002) Electrostatic interactions in an integral membrane protein. Biochemistry 41: 6483-6494 
Kalman L, LoBrutto R, Allen JP and Williams JC (1999) Modified reaction centres oxidize tyrosine in reactions that mirror photosystem II. Nature 402: 696-699

Kalman L, LoBrutto R, Williams JC and Allen JP (2006) Iron as a bound secondary electron donor in modified bacterial reaction centers. Biochemistry 45: 1386913874

Kalman L, Williams J and Allen J (2005) Mimicking the properties of photosystem II in bacterial reaction centers. In: Wydrzynski T and Satoh K (eds) Photosystem II: The light-driven water:plastoquinone oxidoreductase. , pp 715-727. Springer, Dordrecht

Kaneko Y, Tamura M and Yamazaki I (1980) Formation of Porphyrin-Pi Cation Radical in Zinc-Substituted Horseradish-Peroxidase. Biochemistry 19: 57955799

Kehoe JW, Meadows KA, Parkes-Loach PS and Loach PA (1998) Reconstitution of core light-harvesting complexes of photosynthetic bacteria using chemically synthesized polypeptides. 2. Determination of structural features that stabilize complex formation and their implications for the structure of the subunit complex. Biochemistry 37: 3418-3428

Klinman JP (2001) Commentary - How many ways to craft a cofactor? Proc Natl Acad Sci USA 98: 14766-14768

Koder RL and Dutton PL (2006) Intelligent design: the de novo engineering of proteins with specified functions. Dalton Trans: 3045-3051

Krieger-Liszkay A and Rutherford AW (1998) Influence of Herbicide Binding on the Redox Potential of the Quinone Acceptor in Photosystem II:\&nbsp; Relevance to Photodamage and Phytotoxicity\&\#x2020. Biochemistry 37: 17339-17344

Krieger A, Rutherford AW and Johnson GN (1995) On the determination of redox midpoint potential of the primary quinone electron acceptor, QA, in Photosystem II. Biochim Biophys Acta 1229: 193-201

Krishtalik LI (1986) Energetics of Multielectron Reactions - Photosynthetic Oxygen Evolution. Biochim Biophys Acta 849: 162-171

Kruse O, Rupprecht J, Mussgnug JR, Dismukes GC and Hankamer B (2005) Photosynthesis: a blueprint for solar energy capture and biohydrogen production technologies. Photoch Photobio Sci 4: 957-970

Kulik LV, Epel B, Lubitz W and Messinger J (2007) Electronic Structure of the Mn4OxCa Cluster in the S0 and S2 States of the Oxygen-Evolving Complex of Photosystem II Based on Pulse 55Mn-ENDOR and EPR Spectroscopy. J. Am. Chem. Soc. 129: 13421-13435

Kurnikov IV and Beratan DN (1996) Ab initio based effective Hamiltonians for longrange electron transfer: Hartree-Fock analysis. Journal of Chemical Physics 105: 9561-9573 
Kurz P, Berggren G, Anderlund MF and Styring S (2007) Oxygen evolving reactions catalysed by synthetic manganese complexes: A systematic screening. Dalton Trans: 4258-4261

Ladbury JE and Chowdhry BZ (1996) Sensing the heat: The application of isothermal titration calorimetry to thermodynamic studies of biomolecular interactions. Chem Biol 3: 791-801

Leavitt S and Freire E (2001) Direct measurement of protein binding energetics by isothermal titration calorimetry. Curr Opin Struct Biol 11: 560-566

LeBrun NE, Andrews SC, Guest JR, Harrison PM, Moore GR and Thomson AJ (1995a) Identification of the Ferroxidase Center of Escherichia-Coli Bacterioferritin. Biochem J 312: 385-392

LeBrun NE, Keech AM, Mauk MR, Mauk AG, Andrews SC, Thomson AJ and Moore GR (1996) Charge compensated binding of divalent metals to bacterioferritin: $\mathrm{H}+$ release associated with cobalt(II) and zinc(II) binding at dinuclear metal sites. Febs Letters 397: 159-163

LeBrun NE, Moore GR and Thomson AJ (1995b) Magnetic Circular-Dichroism Spectroscopy of the Iron Cores of Ferritin and Bacterioferritin. Molecular Physics 85: 1061-1068

Lewis NS and Nocera DG (2006) Powering the planet: Chemical challenges in solar energy utilization. Proc Natl Acad Sci USA 103: 15729-15735

Li WW, Heinze J and Haehnel W (2005) Site-specific binding of quinones to proteins through thiol addition and addition-elimination reactions. J Am Chem Soc 127: 6140-6141

Li WW, Hellwig P, Ritter M and Haehnel W (2006) De novo design, synthesis, and characterization of quinoproteins. Chem-Eur J 12: 7236-7245

Limburg J, Vrettos JS, Chen HY, de Paula JC, Crabtree RH and Brudvig GW (2001) Characterization of the O-2-evolving reaction catalyzed by [(terpy)(H2O)Mn$\mathrm{III}(\mathrm{O})(2) \mathrm{Mn}-\mathrm{IV}(\mathrm{OH} 2)($ terpy)](NO3) (terpy=2,2 ': 6,2 "-terpyridine). J Am Chem Soc 123: 423-430

Limburg J, Vrettos JS, Liable-Sands LM, Rheingold AL, Crabtree RH and Brudvig GW (1999) A functional model for O-O bond formation by the O-2-evolving complex in photosystem II. Science 283: 1524-1527

Lin RJ, Lin KS and Chang IJ (1996) Photophysical properties of tricarbonyl(histidine)(diimine)rhenium(I) complexes in aqueous solution. Inorg Chim Acta 242: 179-183

Lin X, Murchison HA, Nagarajan V, Parson WW, Allen JP and Williams JC (1994) Specific Alteration of the Oxidation Potential of the Electron-Donor in Reaction 
Centers from Rhodobacter-Sphaeroides. Proc Natl Acad Sci USA 91: 1026510269

Liu HL, Zhou HN, Xing WM, Zhao HF, Li SX, Huang JF and Bi RC (2004) 2.6 angstrom resolution crystal structure of the bacterioferritin from Azotobacter vinelandii. Febs Letters 573: 93-98

Loll B, Kern J, Saenger W, Zouni A and Biesiadka J (2005) Towards complete cofactor arrangement in the 3.0 angstrom resolution structure of photosystem II. Nature 438: $1040-1044$

Magner E and McLendon G (1989) Ground-State and Excited-State Electron-Transfer Reactions of Zinc Cytochrome-C. J Phys Chem 93: 7130-7134

Marcus RA (1956) On the Theory of Oxidation-Reduction Reactions Involving Electron Transfer. I. J Chem Phys 24: 966-978

Marcus RA and Sutin N (1985) Electron transfers in chemistry and biology. Biochim Biophys Acta, Rev Bioenerg 811: 265-322

Martin SR and Schilstra MJ (2008) Circular dichroism and its application to the study of biomolecules. Biophysical Tools for Biologists: Vol 1 In Vitro Techniques, pp 263-293. Elsevier Academic Press Inc, San Diego

McEvoy JP and Brudvig GW (2006) Water-splitting chemistry of photosystem II. Chem Rev 106: 4455-4483

McEvoy JP, Gascon JA, Batista VS and Brudvig GW (2005) The mechanism of photosynthetic water splitting. Photoch Photobio Sci 4: 940-949

McGourty JL, Petersonkennedy SE, Ruo WY and Hoffman BM (1987) Characterization of Long-Range Electron-Transfer in Mixed-Metal [Zinc,Iron] Hybrid Hemoglobins. Biochemistry 26: 8302-8312

McGregor WC, Swierczek SI, Bennett B and Holz RC (2007) Characterization of the catalytically active $\mathrm{Mn}$ (II)-loaded argE-encoded $\mathrm{N}$-acetyl-L-ornithine deacetylase from Escherichia coli. J Biol Inorg Chem 12: 603-613

McLendon GL, Winkler JR, Nocera DG, Mauk MR, Mauk AG and Gray HB (1985) Quenching of Zinc-Substituted Cytochrome-C Excited-States by CytochromeB5. J Am Chem Soc 107: 739-740

Meadows KA, Parkes-Loach PS, Kehoe JW and Loach PA (1998) Reconstitution of core light-harvesting complexes of photosynthetic bacteria using chemically synthesized polypeptides. 1. Minimal requirements for subunit formation. Biochemistry 37: 3411-3417

Mennenga A, Gartner W, Lubitz W and Gorner H (2006) Effects of noncovalently bound quinones on the ground and triplet states of zinc chlorins in solution and bound to de novo synthesized peptides. Phys Chem Chem Phys 8: 5444-5453 
Messinger J, Badger M and Wydrzynski T (1995) Detection of One Slowly Exchanging Substrate Water Molecule in the S-3 State of Photosystem-II. Proc Natl Acad Sci USA 92: 3209-3213

Messinger J, Robblee JH, Bergmann U, Fernandez C, Glatzel P, Visser H, Cinco RM, McFarlane KL, Bellacchio E, Pizarro SA, Cramer SP, Sauer K, Klein MP and Yachandra VK (2001) Absence of Mn-centered oxidation in the S-2 -> S-3 Transition: Implications for the mechanism of photosynthetic water oxidation. J Am Chem Soc 123: 7804-7820

Miller JE, Di Bilio AJ, Wehbi WA, Green MT, Museth AK, Richards JR, Winkler JR and Gray HB (2004) Electron tunneling in rhenium-modified Pseudomonas aeruginosa azurins. Biochim Biophys Acta 1655: 59-63

Miloslavina Y, Szczepaniak M, Muller MG, Sander J, Nowaczyk M, Rogner M and Holzwarth AR (2006) Charge separation kinetics in intact photosystem II core particles is trap-limited. A picosecond fluorescence study. Biochemistry 45: 2436-2442

Moore GR (1991) Bacterial 4-Alpha-Helical Bundle Cytochromes. Biochim Biophys Acta 1058: 38-41

Moore GR, Williams RJP, Peterson J, Thomson AJ and Mathews FS (1985) A Spectroscopic Investigation of the Structure and Redox Properties of Escherichia-Coli Cytochrome B-562. Biochim Biophys Acta 829: 83-96

Moser C and Dutton L (1996) Outline of theory of protein electron transfer. In: Bendall DS (ed) Protein Electron Transfer, pp 300. Bios Scientific Publishers, Oxford, UK

Moser C and Dutton PL (1992) Engineering protein structure for electron transfer function in photosynthetic reaction centers. Biochim Biophys Acta 1101: 171176

Mure M (2004) Tyrosine-derived quinone cofactors. Acc Chem Res 37: 131-139

Murray JW and Barber J (2007) Structural characteristics of channels and pathways in photosystem II including the identification of an oxygen channel. J Struct Biol 159: $228-237$

Narvaez AJ, Kalman L, LoBrutto R, Allen JP and Williams JC (2002) Influence of the protein environment on the properties of a tyrosyl radical in reaction centers from Rhodobacter sphaeroides. Biochemistry 41: 15253-15258

Noy D, Discher BM, Rubtsov IV, Hochstrasser RA and Dutton PL (2005) Design of amphiphilic protein maquettes: Enhancing maquette functionality through binding of extremely hydrophobic cofactors to lipophilic domains. Biochemistry 44: $12344-12354$ 
Noy D and Dutton PL (2006) Design of a minimal polypeptide unit for bacteriochlorophyll binding and self-assembly based on photosynthetic bacterial light-harvesting proteins. Biochemistry 45: 2103-2113

Petersonkennedy SE, McGourty JL and Hoffman BM (1984) Temperature-Dependence of Long-Range Electron-Transfer in [Zn,Fe-III] Hybrid Hemoglobin. J Am Chem Soc 106: 5010-5012

Pierce MM, Raman CS and Nall BT (1999) Isothermal titration calorimetry of proteinprotein interactions. Methods 19: 213-221

Polak E and Ribiere G (1969) Note on Convergence of Conjugate Direction Methods. Revue Francaise D Informatique De Recherche Operationnelle 3: 35-\&

Poulsen AK, Rompel A and McKenzie CJ (2005) Water oxidation catalyzed by a dinuclear Mn complex: A functional model for the oxygen-evolving center of photosystem II. Angew Chem Int Edit 44: 6916-6920

Prytkova TR, Beratan DN and Skourtis SS (2007) Photoselected electron transfer pathways in DNA photolyase. Proc Natl Acad Sci USA 104: 802-807

Qin L and Kostic NM (1994) Photoinduced Electron-Transfer from the Triplet-State of Zinc Cytochrome-C to Ferricytochrome B5 Is Gated by Configurational Fluctuations of the Diprotein Complex. Biochemistry 33: 12592-12599

Rappaport F, Blancharddesce M and Lavergne J (1994) Kinetics of Electron-Transfer and Electrochromic Change During the Redox Transitions of the Photosynthetic Oxygen-Evolving Complex. Biochim Biophys Acta 1184: 178-192

Rappaport F and Diner BA (2008) Primary photochemistry and energetics leading to the oxidation of the $(\mathrm{Mn}) 4 \mathrm{Ca}$ cluster and to the evolution of molecular oxygen in Photosystem II. Coord Chem Rev 252: 259-272

Rau HK, Snigula H, Struck A, Robert B, Scheer H and Haehnel W (2001) Design, synthesis and properties of synthetic chlorophyll proteins. Eur J Biochem 268: 3284-3295

Razeghifard AR and Wydrzynski T (2003) Binding of Zn-chlorin to a synthetic fourhelix bundle peptide through histidine ligation. Biochemistry 42: 1024-1030

Redfearn E (1965) Biochemistry of Quinones. Academic Press, New York

Reed G and Poyner R (2000) Chapter 7: $\mathrm{Mn}^{2+}$ as a Probe of Divalent Metal Ion Binding and Function in Enzymes and Other Proteins. In: Sigel HS, A. (ed) Manganese and its role in biological processes, pp 183-207. Marcel Dekker, Inc., New York

Rehm D and Weller A (1970) Kinetics of Fluorescence Quenching by Electron and HAtom Transfer. Isr J Chem 8: 259

Rex JH (2000) Purification of genomic DNA from Gram-Negative bacteria. Focus 22: 26-27 
Rich PR (2004) The quinone chemistry of bc complexes 13th European Bioenergetics Conference (EBEC 2004). Elsevier Science Bv, Pisa, ITALY

Robinson CR, Liu YF, Thomson JA, Sturtevant JM and Sligar SG (1997) Energetics of heme binding to native and denatured states of cytochrome $b(562)$. Biochemistry 36: $16141-16146$

Satoh H, Uchida A, Nakayama K and Okada M (2001) Water-soluble chlorophyll protein in Brassicaceae plants is a stress-induced chlorophyll-binding protein. Plant Cell Physiol 42: 906-911

Sauer K, Yano J and Yachandra VK (2005) X-ray spectroscopy of the Mn4Ca cluster in the water-oxidation complex of Photosystem II. Photosyn Res 85: 73-86

Schaab MR, Barney BM and Francisco WA (2006) Kinetic and spectroscopic studies on the quercetin 2,3-dioxygenase from Bacillus subtilis. Biochemistry 45: 10091016

Schafer KO, Bittl R, Lendzian F, Barynin V, Weyhermuller T, Wieghardt K and Lubitz W (2003) Multifrequency EPR investigation of dimanganese catalase and related Mn(III)Mn(IV) complexes. J Phys Chem B 107: 1242-1250

Sharp RE, Moser CC, Rabanal F and Dutton PL (1998) Design, synthesis, and characterization of a photoactivatable flavocytochrome molecular maquette. Proc Natl Acad Sci USA 95: 10465-10470

Siegbahn PEM (2006) O-O bond formation in the S-4 state of the oxygen-evolving complex in photosystem II. Chem-Eur J 12: 9217-9227

Siegbahn PEM (2008) Mechanism and energy diagram for O-O bond formation in the oxygen-evolving complex in photosystem II. Philos Trans R Soc Lond B Biol Sci 363: $1221-1228$

Simolo KP, McLendon GL, Mauk MR and Mauk AG (1984) Photoinduced ElectronTransfer within a Protein Protein Complex Formed between Physiological Redox Partners - Reduction of Ferricytochrome-B5 by the Hemoglobin Derivative Alpha-2zn-Beta-2fe-Iiicn. J Am Chem Soc 106: 5012-5013

Snell J and Weissberger A (1939) The reaction of thiol compounds with quinones. J Am Chem Soc: $450-453$

Springs SL, Bass SE, Bowman G, Nodelman I, Schutt CE and McLendon GL (2002) A multigeneration analysis of cytochrome $\mathrm{b}(562)$ redox variants: Evolutionary strategies for modulating redox potential revealed using a library approach. Biochemistry 41: 4321-4328

Su JH, Lubitz W and Messinger J (2008) Probing mode and site of substrate water binding to the oxygen-evolving complex in the S-2 state of photosystem II by O17-HYSCORE Spectroscopy. J Am Chem Soc 130: 786-787 
Tagore R, Crabtree RH and Brudvig GW (2008) Oxygen Evolution Catalysis by a Dimanganese Complex and Its Relation to Photosynthetic Water Oxidation. Inorg. Chem. 47: 1815-1823

Tang XS, Zheng M, Chisholm DA, Dismukes GC and Diner BA (1996) Investigation of the differences in the local protein environments surrounding tyrosine radicals Y-Z(center dot) and Y-D(center dot) in photosystem II using wild-type and the D2-Tyr160Phe mutant of Synechocystis 6803. Biochemistry 35: 1475-1484

Teale FWJ (1959) Cleavage of the Haem-Protein Link by Acid Methylethylketone. Biochim Biophys Acta 35: 543-543

Teutloff C, Schafer KO, Sinnecker S, Barynin V, Bittl R, Wieghardt K, Lendzian F and Lubitz W (2005) High-field EPR investigations of $\mathrm{Mn}(\mathrm{III}) \mathrm{Mn}(\mathrm{IV})$ and $\mathrm{Mn}(\mathrm{II}) \mathrm{Mn}(\mathrm{III})$ states of dimanganese catalase and related model systems. Magn Reson Chem 43 Spec no.: S51-64

Thielges M, Uyeda G, Camara-Artigas A, Kalman L, Williams JC and Allen JP (2005) Design of a redox-linked active metal site: Manganese bound to bacterial reaction centers at a site resembling that of photosystem II. Biochemistry 44: 7389-7394

Tommos C, Skalicky JJ, Pilloud DL, Wand AJ and Dutton PL (1999) De novo proteins as models of radical enzymes. Biochemistry 38: 9495-9507

Twitchett MB, Ferrer JC, Siddarth P and Mauk AG (1997) Intramolecular Electron Transfer Kinetics of a Synthetic Flavocytochrome c. J. Am. Chem. Soc. 119: 435-436

Tyryshkin AM, Watt RK, Baranov SV, Dasgupta J, Hendrich MP and Dismukes GC (2006) Spectroscopic evidence for $\mathrm{Ca} 2+$ involvement in the assembly of the $\mathrm{Mn} 4 \mathrm{Ca}$ cluster in the photosynthetic water-oxidizing complex. Biochemistry 45: 12876-12889

Un S, Atta M, Fontecave M and Rutherford AW (1995) G-Values as a Probe of the Local Protein Environment - High-Field Epr of Tyrosyl Radicals in Ribonucleotide Reductase and Photosystem-Ii. J Am Chem Soc 117: 1071310719

Vanderkooi JM, Adar F and Erecinska M (1976) Metallocytochromes c : Characterization of Electronic Absorption and Emission Spectra of Sn4+ and Zn2+ Cytochromes c. Eur J Biochem 64: 381-387

Warncke K, Gunner MR, Braun BS, Gu LQ, Yu CA, Bruce JM and Dutton PL (1994) Influence of Hyrdocarbon Tail Structure on Quinone Binding and ElectronTransfer Performance at the $\mathrm{Q}_{\mathrm{A}}$ and $\mathrm{Q}_{\mathrm{B}}$ Sites of the Photosynthetic ReactionCenter Protein. Biochemistry 33: 7830-7841

Weng TC, Hsieh WY, Uffelman ES, Gordon-Wylie SW, Collins TJ, Pecoraro VL and Penner-Hahn JE (2004) XANES evidence against a manganyl species in the S-3 state of the oxygen-evolving complex. J Am Chem Soc 126: 8070-8071 
Whiting AK, Boldt YR, Hendrich MP, Wackett LP and Que L (1996) Manganese(II)dependent extradiol-cleaving catechol dioxygenase from Archrobacter globiformis CM-2. Biochemistry 35: 160-170

Whitney SM and Sharwood RE (2006) Linked rubisco subunits can assemble into functional oligomers without impeding catalytic performance. J. Biol. Chem.: M610479200

Whittaker JW and Whittaker MM (1991) Active-Site Spectral Studies on Manganese Superoxide-Dismutase. J Am Chem Soc 113: 5528-5540

Whittaker MM, Barynin VV, Igarashi T and Whittaker JW (2003) Outer sphere mutagenesis of Lactobacillus plantarum manganese catalase disrupts the cluster core - Mechanistic implications. Eur J Biochem 270: 1102-1116

Williams JC, Haffa ALM, McCulley JL, Woodbury NW and Allen JP (2001) Electrostatic interactions between charged amino acid residues and the bacteriochlorophyll dimer in reaction centers from Rhodobacter sphaeroides. Biochemistry 40: 15403-15407

Winkler JR, Di Bilio AJ, Farrow NA, Richards JH and Gray HB (1999) Electron tunneling in biological molecules. Pure Appl Chem 71: 1753-1764

Winkler JR and Gray HB (1997) Electron tunneling in proteins: Role of the intervening medium. J Biol Inorg Chem 2: 399-404

Wraight CA (2004) Proton and electron transfer in the acceptor quinone complex of photosynthetic reaction centers from Rhodobacter sphaeroides. Front. Biosci. 9: 309-337

Wu AJ, Penner-Hahn JE and Pecoraro VL (2004) Structural, spectroscopic, and reactivity models for the manganese catalases. Chem Rev 104: 903-938

Wydrzynski T, Hillier W and Conlan B (2007) Engineering model proteins for Photosystem II function. Photosyn Res 94: 225-233

Wydrzynski T, Hillier W and Messinger J (1996) On the functional significance of substrate accessibility in the photosynthetic water oxidation mechanism. Physiol Plant 96: 342-350

Wydrzynski T and Satoh K (2005) Photosystem II : the light-driven water:plastoquinone oxidoreductase. Springer, Dordrecht

Yachandra VK (2005) The Catalytic Manganese Cluster: Organization of the Metal Ions. In: Satoh K and Wydrzynski T (eds) Photosystem II - The light driven water:plastoquinone oxidoreductase, pp 235-260. Springer, Dordrecht

Yang X, Le Brun NE, Thomson AJ, Moore GR and Chasteen ND (2000) The Iron Oxidation and Hydrolysis Chemistry of Escherichia coli Bacterioferritin. Biochemistry 39: 4915-4923 
Yariv J, Kalb AJ, Sperling R, Bauminger ER, Cohen SG and Ofer S (1981) The Composition and the Structure of Bacterioferritin of Escherichia-Coli. Biochem J 197: 171-175

Yoder DW, Hwang J and Penner-Hahn JE (2000) Chapter 16: Manganese Catalases. In: Sigel HS, A. (ed) Manganese and Its Role in Biological Processes pp 527-557. Marcell Dekker, Inc., New York

Zhang B, Harb JN, Davis RC, Kim JW, Chu SH, Choi S, Miller T and Watt GD (2005) Kinetic and thermodynamic characterization of the cobalt and manganese oxyhydroxide cores formed in horse spleen ferritin. Inorg Chem 44: 3738-3745

Zhang LY, Wang LJ, Kao YT, Qiu WH, Yang Y, Okobiah O and Zhong DP (2007) Mapping hydration dynamics around a protein surface. Proc Natl Acad Sci USA 104: $18461-18466$ 